\title{
He rawe tona kakahu/She Wore A Becoming Dress: Performing the Hyphen
}

\author{
by
}

\section{Miki Seifert}

\author{
A thesis \\ submitted to Victoria University of Wellington \\ in fulfilment of the requirements for the degree of \\ Doctor of Philosophy
}

Victoria University of Wellington

2011 
2| P a ge 


\section{TABLE OF CONTENTS}

ABSTRACT

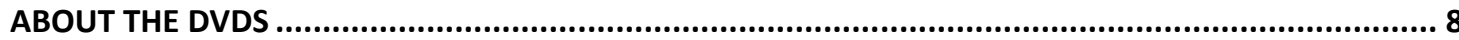

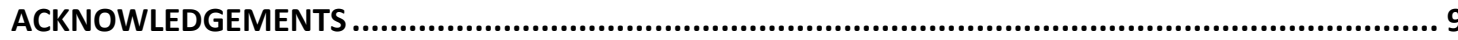

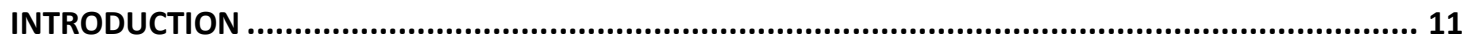

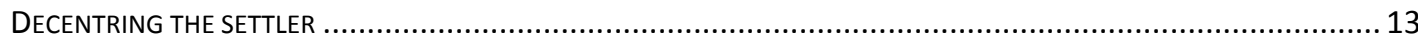

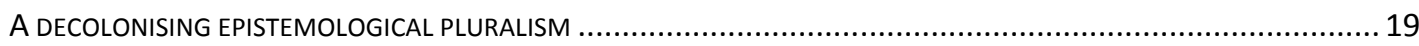

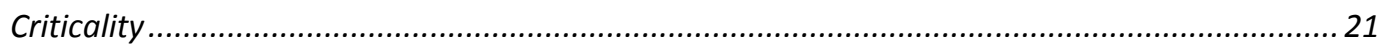

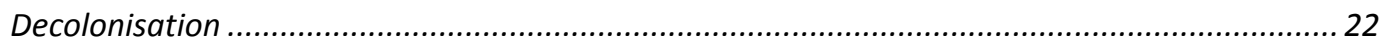

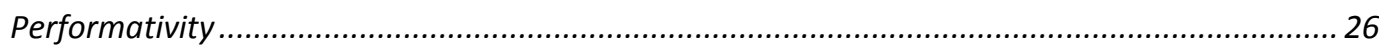

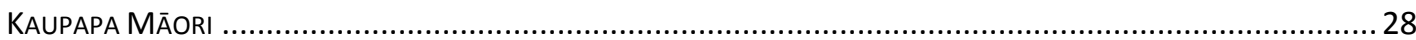

CONCLUSION

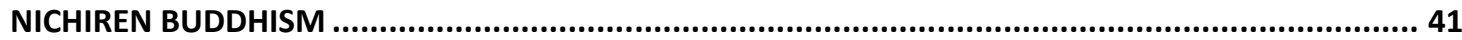

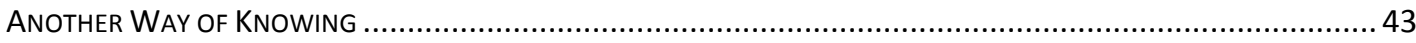

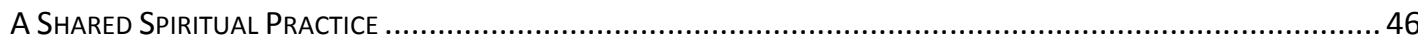

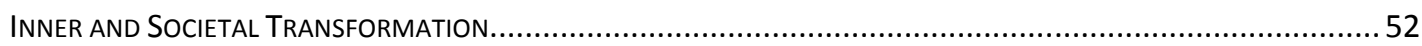

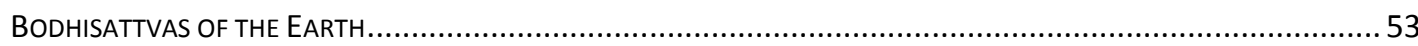

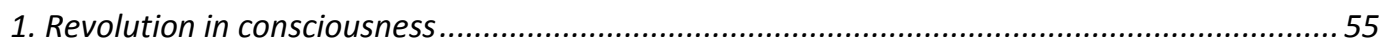

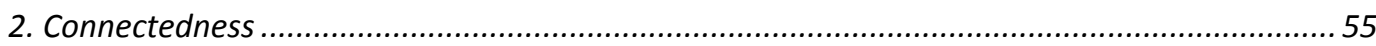

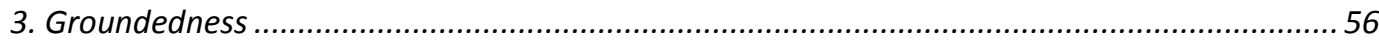

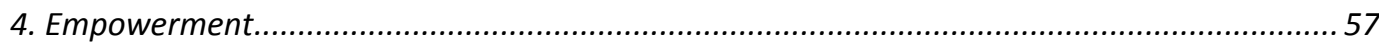

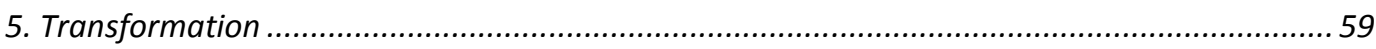

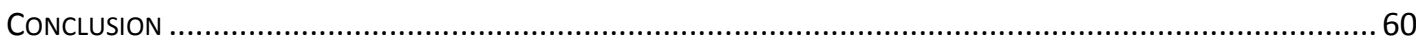

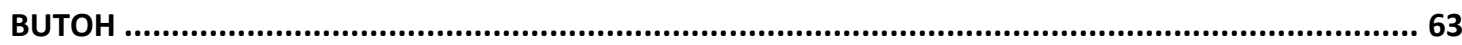

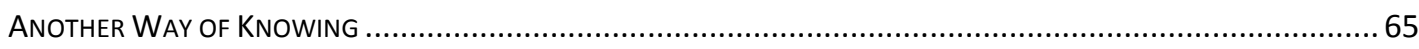

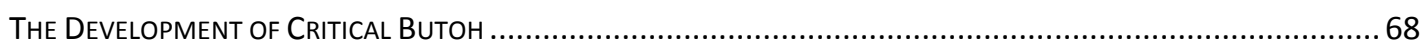

WHAT IS CRITICAL BUTOH? .................................................................................................. 75

1. Critical Butoh is a body-based practice that is critical, decolonising and performative. .......... 76

2. Critical Butoh is a body-based exploration of the Cultural Interface. ..................................... 76

3. In Critical Butoh, process and product are inseparable. ..................................................... 79

4. Critical Butoh is strategic about what is created and where it is performed...........................80

5. Critical Butoh is a collaborative, consensus-based practice .................................................. 81

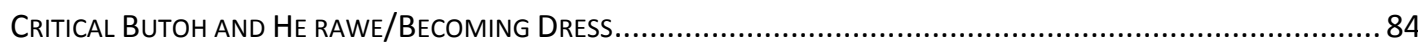

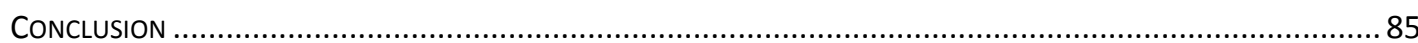

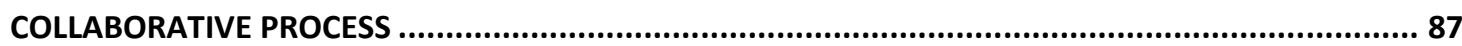

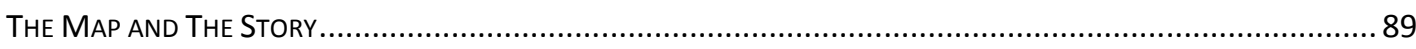

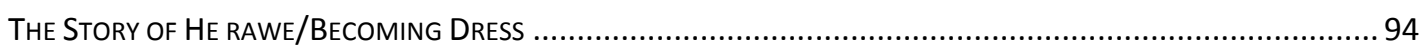

Meeting - 26 January 2009 ............................................................................................. 94

Excerpts from Anahera's journal - 26 January 2009 ......................................................... 100

Excerpts from my journal - 26 January 2009 ................................................................ 103 


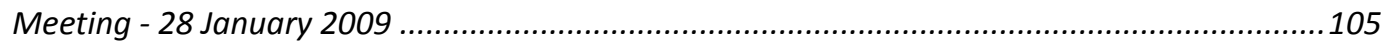

Excerpts from Anahera's journal - 28 January 2009 ........................................................... 109

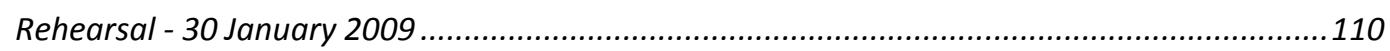

Excerpt from Anahera's journal - 30 January 2009...........................................................111

Excerpts from my journal - 30 January 2009................................................................... 111

Excerpts from my journal - 3 February 2009.................................................................. 112

Meeting - 11 February 2009....................................................................................... 113

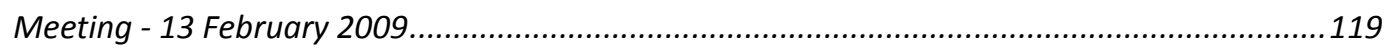

Excerpt from my journal - 2 March 2009 .............................................................................. 122

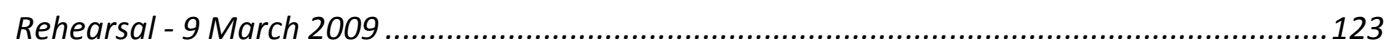

Excerpts from Anahera's journal - 14 March 2009....................................................................127

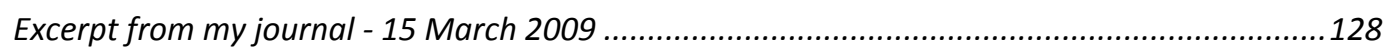

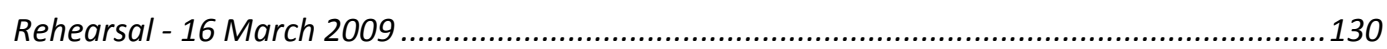

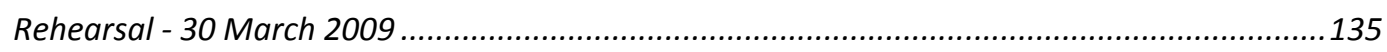

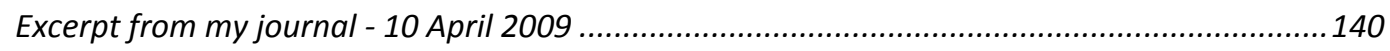

Excerpt from Anahera's journal - 13 April 2009............................................................... 140

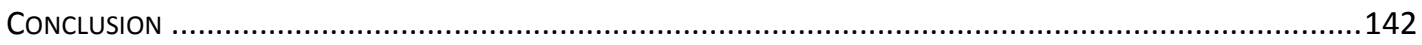

HE RAWE TONA KAKAHU/SHE WORE A BECOMING DRESS ............................................. 145

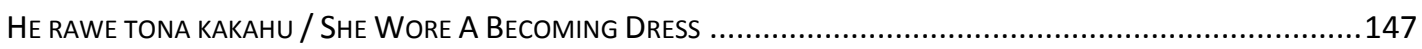

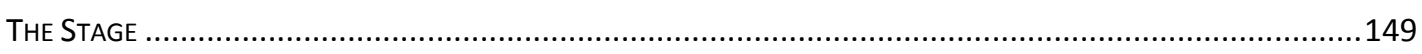

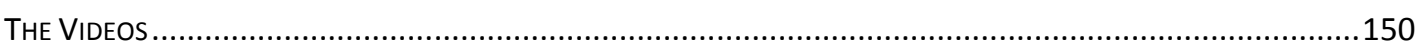

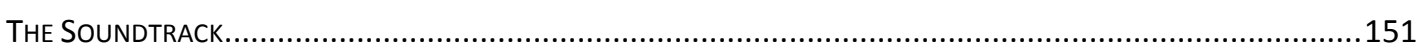

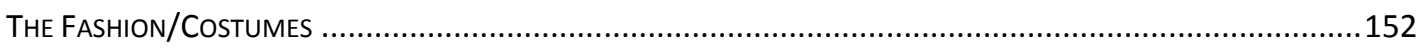

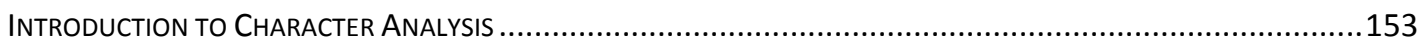

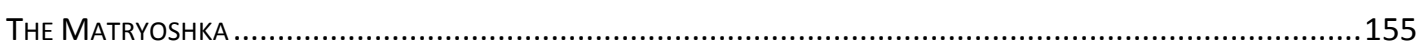

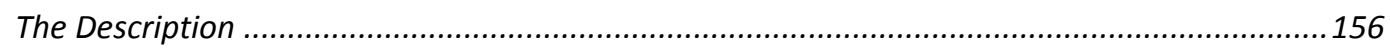

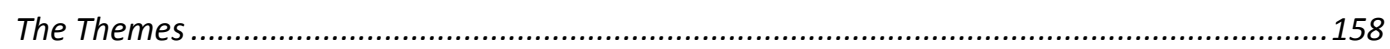

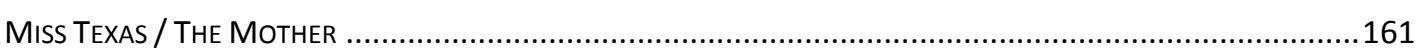

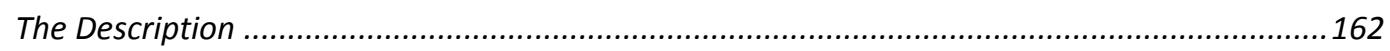

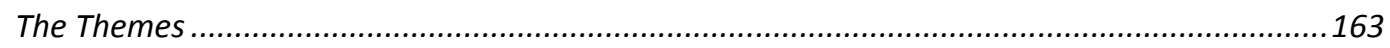

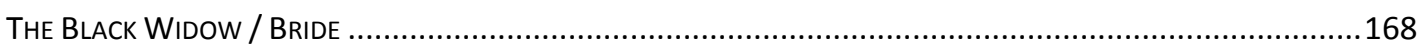

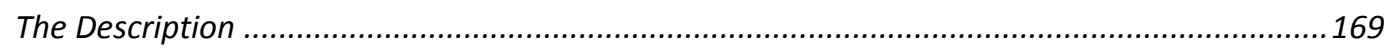

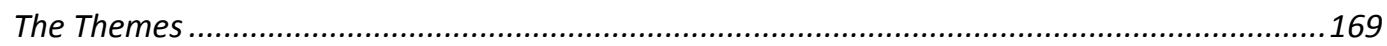

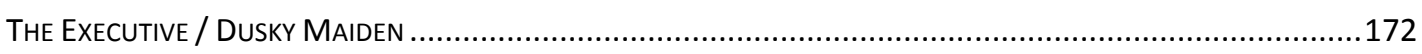

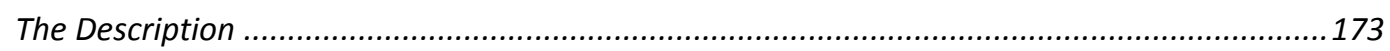

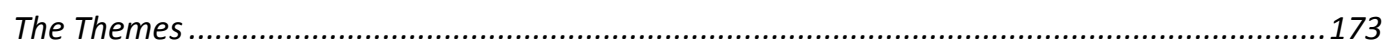

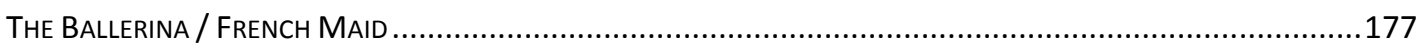

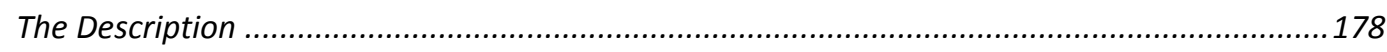

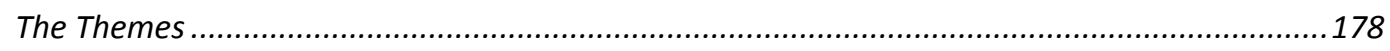

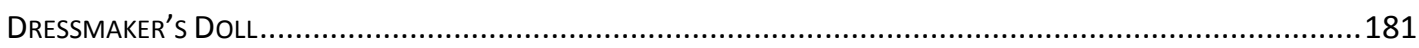

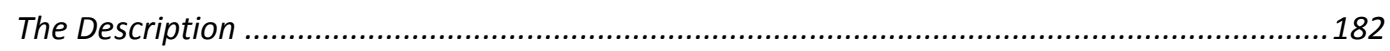

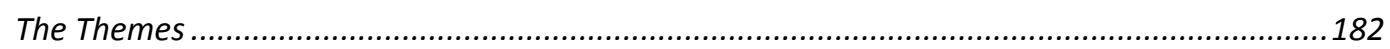

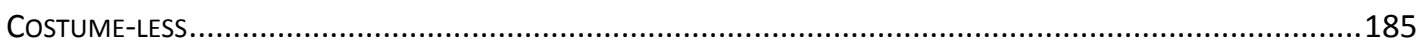

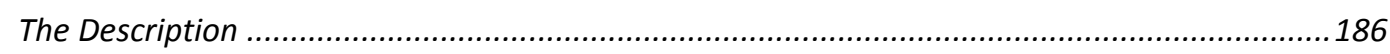

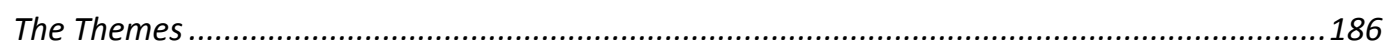

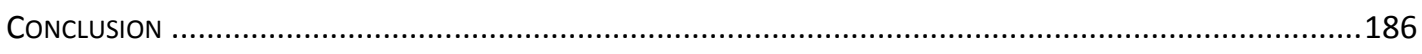

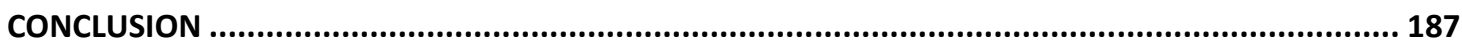

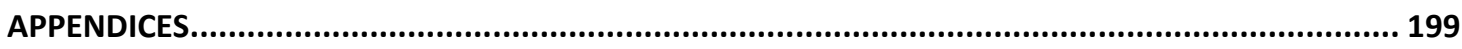


APPENDIX 1 - HE RAWE/BECOMINg DRESS BUTOH-FU ................................................................ 201

ApPendix 2 - He RAWe/Becoming Dress Project Timeline .......................................................... 202

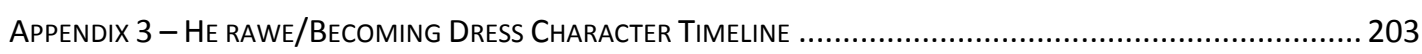

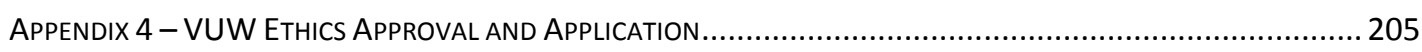

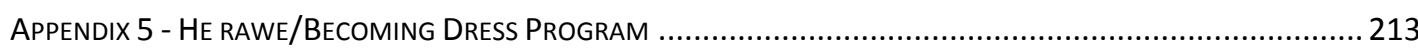

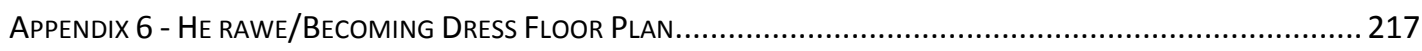

APPENDIX 7 -SALIENT ReVIEW Of He RAWE/BeCOMIng DreSS ........................................................ 218

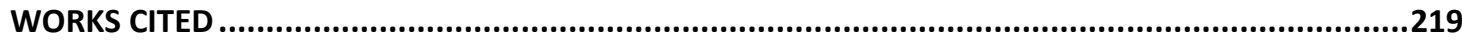

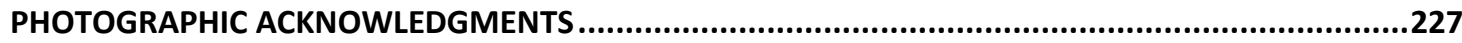


$6 \mid$ P a g e 


\section{Abstract \\ He rawe tona kakahu/ She Wore A Becoming Dress: Performing the Hyphen}

In the British settler nations of the United States, New Zealand, Australia and Canada, there continues to be debate about how to conduct research across the coloniserindigene hyphen. Various indigenous scholars have discussed, at length, how western scholarship has been and continues to be implicated in the colonisation of indigenous peoples. While some progress has been made, it continues to be an unresolved issue.

As a white American woman, I have responded to this situation by conducting my doctoral research using a decolonising epistemological pluralism that I developed through my practice as an artist and performer. This methodology, which is critical and performative, seeks to dismantle the colonial matrix of power and the dualisms that underpin the hegemony of western knowledge and casts a critical eye on power relations as they manifest out in the world and as they reproduce themselves inside individuals. It is my belief that such an approach will decentre the settler and facilitate working across the hyphen. As an example of how such a methodology could function, I undertook a collaborative and performative research project ${ }^{1}$ with Anahera Gildea, a Māori writer and performer from the iwi (tribe) of Ngāti Raukawa ki te Tonga.

Our research examined the intersection of gender and colonisation. The knowledge systems that we chose to use arose naturally out of who we are and what we know. We are both Butoh performers. We both practice Nichiren Buddhism and use it to guide our daily lives. The outcome of our research was He rawe tona kakahu/She Wore A Becoming Dress, a multimedia Butoh performance, which was performed for two nights at the Film Archive in Wellington, New Zealand in 2009. As a collaboration that worked across the hyphen, we both engaged with critical and decolonising theory from our respective positions on the hyphen, as well as brought our respective world views—I, white American and Anahera, Te Ao Mãori. This thesis is an attempt to provide a practicebased understanding of what it was like to undertake research using such a decolonising epistemological pluralism.

\footnotetext{
${ }^{1} \mathrm{It}$ is this thesis, not the performance, that is being assessed.
} 


\section{About the DVDs}

On the inside of the back cover of this thesis are two DVDs of the performance of $\mathrm{He}$ rawe tona kakahu/She Wore $A$ Becoming Dress. Disc One contains a split screen version of the performance where the video of the performers and the video projections are composited together. It attempts to give the viewer a sense of the 'whole' experience. On Disc Two are the individual videos of the performance and the projections.

These DVDs are supplementary materials. The thesis was written as a stand alone document. For this reason, it is up to the reader when and if to watch the DVDs. 


\section{Acknowledgements}

Even lowly creatures know enough to repay a debt of gratitude. Thus the bird known as the wild goose will invariably carry out its filial duty to the mother bird when she is about to die. And the fox never forgets its old hillock. If even animals will do such things, then how much more so should this be true of human beings? ('On Prayer’ by Nichiren Daishonin)

I would like to thank the following people and organisations: my supervisors, Maria Bargh and Megan Evans, for their unstinting efforts and warm encouragement throughout this endeavour; the entire staff at Te Kawa a Māui/School of Māori Studies and School of English, Film, Theatre \& Media Studies, Victoria University of Wellington; New Zealand International Doctoral Research Scholarship and The Research Trust of Victoria University for their financial support of my research; David Avalos and Gary Olson for their life-long inspiration and support; Anahera Gildea for being my collaborator and co-creator of He rawe/Becoming Dress; William Franco, Janet Dunn, Bex Weatherhead, Fern Karun, Aimee Lyn, Danielle Caldow, Daniel Weatherhead, Darrell Haddon, Jeremy Desmond and The New Zealand Film Archive for their contributions to He rawe/Becoming Dress.

I am indebted to my parents, Jeanette and Conrad Seifert, for their gifts of life and love. I offer my love and gratitude to my sisters, Joanne, Connie Sue and Barbara.

I do not have the words to express my gratitude and appreciation to my husband and life-long collaborator, William Franco. Tu es mi otro yo. 
$10 \mid \mathrm{Page}$ 


\section{CHAPTER ONE}

Introduction

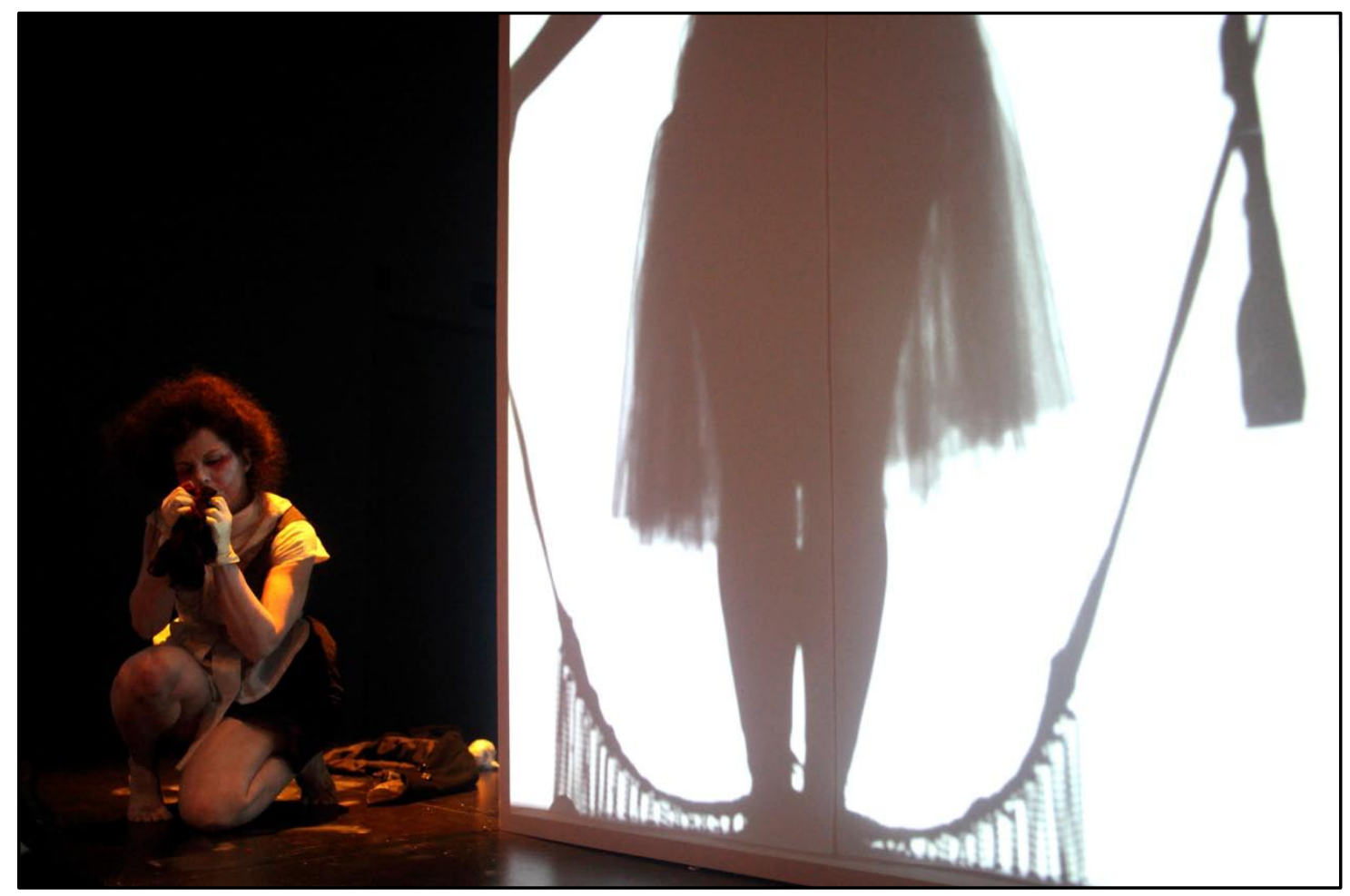


12| P a g e 


\section{DECENTRING THE SETTLER}

Māori and indigenous education scholar Linda Tuhiwai Smith states that it was through the western construction of the concepts of line, centre and outside, which were used to define the spatial relationships of colonisation, that indigenous space was colonised (L. T. Smith 1999: 51-53). The centre, the place of power, was claimed by the coloniser. Therefore, as sociologist Avril Bell has found, writings about how to re-structure these colonising relationships have coalesced around the ideas of recentring and decentring (Bell 2008: 852). As a white woman who is a United States citizen descended from settlers from Germany, the first believed to arrive in 1751, I have chosen to respond to this call and work on what Bell describes as 'decentring the settler' (Bell 2008: 853). In 2008, I facilitated the development of a performance project that examined the intersection of gender and colonisation, employing a decolonising epistemological pluralism that I had developed through my practice as an artist and performer. This performative research project was undertaken with Anahera Gildea, a Māori writer and performer from the iwi (tribe) of Ngāti Raukawa ki te Tonga. The outcome of our research was He rawe tona kakahu/She Wore A Becoming Dress, which was performed for 17 and 18 April 2009 at the Film Archive in Wellington, New Zealand. The performance, which for simplicity will be referred to as He rawe/Becoming Dress, will be discussed in more detail later in this and subsequent chapters.

Because I chose to locate my research in Aotearoa New Zealand, I adopted a transnational lens to examine my position in regards to the relationship between coloniser and colonised, settler and indigenous peoples, in former British settler nations of the United States, Canada, Australia and New Zealand. It is useful to look across a transnational perspective, as cultural geographer Kay Anderson framed it, in order to 'identify channels of dialogue across axes of difference structuring foundational stories of nationhood' (K. Anderson 2000: 389). Responding to the many U.S. historians who frame U.S. history as unique and outside of a global narrative, U.S. historian Michael Adas used a cross-cultural and comparative history analysis between the U.S. and settler societies in Canada and Oceania to 'contest persisting notions of American exceptionalism' (Adas 2001: 1698).

A common feature of transnational literature is to place the relationship of settler and indigenous peoples within the frame of nation-building and the nation-state. Bell finds that it is through nationalism that settler societies 'consolidated their rights to belong, and 
to rule' (Bell 2006: 253) and that their nationalism is based on 'assertions of attachment to place... while the history of how that attachment was secured is "forgotten"” (Bell 2006: 256). This 'forgotten' history was generally filled with the appropriation of indigenous land and resources, and the genocide, displacement, assimilation and institutionalisation of indigenous peoples. Postcolonial theorist Alan Lawson (2004: 158) also points out that the settlers in the United States, Canada, Australia and New Zealand were caught between two authorities and two authenticities, the British Crown and the First Nations. The settlers were no longer part of the centre, as they now laid claim to the land in the New World. Yet, their claim to the New World was fraught when faced with the authority and authenticity of the 'prior' inhabitants, the First Nations peoples. The settlers' lack of authority and authenticity continues to cause what Bell calls the settlers' 'ontological unease', the knowledge that their presence in the land they call home and the nations to which they claim belonging is based on 'their dubious moral origins as colonizers' (Bell 2006: 254).

Further, various strategies were used to construct the national identity of the colonisers as settlers rather than invaders. American Indian legal scholar Robert A. Williams argues that all the various methods that were utilised throughout the world, from the outright declaration of the land as terra nullius to the claim of the necessity to open up unused or under-used land and resources, can trace their genealogy back to the Crusades: 'Longheld notions of the rightness of subjugating non-Christian peoples for the purposes of their remediation provided a firm roadbed upon which European colonial theory might claim its right-of-way in lands occupied by the "heathen" and "infidel" savages of the New World' (Cited in Grande 2004: 36). It is important to note here the connection between using the justification of Christianity for the subjugation of non-Christians and colonisation in the New World. The connection between Christianity and colonisation will be further developed later in this chapter.

One way was to empty the land of prior significance and occupation; that is, to conceptualise emptiness in relation to Christianity and European cilvilisation. The land was empty if not occupied by Christian, civilised people. Thus, as Lawson wrote, 'Empty land can be settled, but occupied land can only be invaded. So the land must be emptied so that it can be filled, in turn, with both discourse and cattle' (Lawson 2004: 155). Another way, in contradiction to these dubious means to claim possession and sovereignty over the indigenous lands, was to negotiate treaties with the various First 
Nations. It is these treaties and their attendant recognition of indigenous peoples' sovereignty that, as indigenous and postcolonial literature scholar Chadwick Allen states, 'continue to offer strong legal and moral bases from which indigenous minority people can argue for land and resource rights as well as articulate cultural and identity politics' (Allen 2002: 17).

Therefore, it is important to place the relationship between settlers and indigenous peoples in settler nation-states within the nation-building frame and acknowledge that the status of indigenous peoples is different than that of other racial and cultural Others because, at the heart of their status, is the issue of sovereignty rather than differential belonging. However, it is also just as important to state the obvious: 'the nation-state itself was an export of Europe' (K. Anderson 2000: 383). Thus, there is an inherent tension between the nation-state and indigenous peoples. During an interview, Bonita Lawrence, Mi'kmaw indigenous studies scholar, expressed it this way:

Never is the issue of what are we going to do about the existence of the United States, the existence of Peru, Bolivia, Columbia, you name it, the existence of Guatemala, of these settler states. The cases are different because of different experiences of colonization. But, in practical ways, what do you do when the existence of Canada means that our identities are always on the verge of extinction? (Thorpe 2005: 6-7)

Given such sentiments, it is not unreasonable to assume that the settlers' reluctance to engage with the question of indigenous sovereignty arises out of their fear that to do so would threaten their conception of their nation-state as they know it. In his book Imagined Communities, international studies theorist Benedict Anderson, in his analysis of the rise of nations and nationalism, discusses how the nation-state arose out of specific historical and cultural circumstances and, that prior to the rise of the nation-state in Europe, people had other ways of defining themselves and their communities (B. Anderson 1983, 1991: 11-12). Therefore, is it not conceivable that there will be other ways of defining ourselves in the future?

A re-definition of the settler nation-state does not necessarily have to be viewed as a negative event, but could be envisioned as an opening up of a new way of being in the world, an opening up of the potential to build peaceful and just societies. Such a perspective is more likely to be adopted when the rise of the nation-state and modernity 
is not viewed as a decisive step in the march of human progress. Sociologist Edgardo Lander asks the thought-provoking question what if 'colonialism, imperialism, racism, and sexism were thought of not as regretful by-products of modern Europe, but as part of the conditions that made the modern West possible' (Cited in Walsh 2007: 228).

Such questions are part of the Modernity/Coloniality Research Program. ${ }^{2}$ Participant and anthropologist Arturo Escobar explains that their purpose is to seek 'to make a decisive intervention into the very discursivity of the modern sciences in order to craft another space for the production of knowledge — an other way of thinking, un paradigma otro, the very possibility of talking about "worlds and knowledges otherwise"" (Escobar 2007: 179).

Like many of these researchers, semiotician Walter D. Mignolo draws upon the writings of Peruvian sociologist Anibal Quijano and argues that the rise of modern Europe-and, by extension, the rise of the nation-state—are inextricably linked to colonialism, which began with the 'discovery' of the Americas. Prior to this 'discovery', 'Western Christendom was, in the fifteenth century... relatively, marginal in the world-trade economy...The emergence of a "New World" coupled with the protestant reformation facilitated the translation of Western Christendom into Europe' (Mignolo 2007: 482). This feat was accomplished by the enormous transfer of wealth from the Americas to Europe and gave rise to the modern/colonial world and the expansion of the Christian, western, capitalist empire (Mignolo and Tlostanova 2008: 110). Philosopher Santiago Castro-Gómez summarises Mignolo's position as 'the modern and the colonial are simultaneous in time and space' (Castro-Gomez 2007: 433). Like Mignolo, CastroGómez argues that 'coloniality is not modernity's "past" but its other face' (CastroGomez 2006: 218).

Further, the rise of modern Europe brought into being what Quijano calls the colonial matrix of power (also called coloniality). Castro-Gómez states that coloniality references, not a historical period, but 'a technology of power' (Castro-Gomez 2006: 218). This colonial matrix of power functions in four different domains: the appropriation of land and exploitation of labour; control of authority; control of sexuality and gender; and

\footnotetext{
${ }^{2}$ Modernity/Coloniality Research Program is 'a series of researches, meetings, publications, and so forth around a shared - even of course contested - set of concepts' which 'can be said to have roots in the Latin American experience, [but] finds sustenance globally.' Arturo Escobar, 'Worlds and Knowledges Otherwise', Cultural Studies, 21/2 (2007), 179-210 at 179.
} 
control of knowledge and subjectivity (Mignolo 2007: 478). These domains 'are interrelated through knowledge, and racism and capitaP [italics in original text] (Mignolo 2007: 478). Sociologist Ramón Grosfugel conceives of the colonial matrix of power as 'entangled global hierarchies' (Grosfugel 2009: 18). Drawing on the work of Mignolo, Quijano, Wallerstein, Spivak and Enloe, Grosfugel lists these global hierarchies as:

1. A particular global class formation where a diversity of labor... are going to coexist and be organized by capital as a source of production of surplus value through selling of commodities for a profit in the world market;

2. An international division of labor at the core and periphery (Wallerstein 1974);

3. An inter-state system of politico-military organizations controlled by European males and institutionalized in colonial administration (Wallerstein 1979);

4. A global racial/ethnic hierarchy that privileges European people over nonEuropean people (Quijano 1993, 2000);

5. A global gender hierarchy that privileges males over females and European patriarchy over other forms of gender relations (Spivak 1988; Enloe 1990);

6. A sexual hierarchy that privileges heterosexuals over homosexuals and lesbians...;

7. A spiritual hierarchy that privileges Christians over non-Christian/nonspiritualities...;

8. An epistemic hierarchy that privileges western knowledge and cosmology over non-western knowledge and cosmologies, and institutionalized in the global university system (Mignolo 1995, 2000; Quijano 1991);

9. A linguistic hierarchy between European languages and non-European languages that privileges communication and knowledge/theoretical production in the former and subalternises the latter as sole producers of folklore or culture but not of knowledge/theory (Mignolo 2000). (Grosfugel 2009: 18-19)

While it is beyond the scope of this thesis to go into detail regarding these hierarchies and their impact on indigenous people, it is worth considering, for a moment, how 
foreign these hierarchies were — and are—to indigenous cultures and societies. For example, Māori education researcher Leonie Pihama writes, 'The concept of race is a colonial importation. Prior to contact between Māori and Pākehāả race did not exist for Māori...[S]ocial organisation was mediated through whakapapa (genealogy) and the complex ways in which relationships were determined amongst whänau [family], hapū [sub-tribe] and iwi [tribe]' (Pihama 2001: 144-5). This social organisation gave rise to an 'economy of affection' rather than an 'economy of exploitation' (Henare cited in Henry and Pene 2001: 235).

The purpose of this discussion of the colonial matrix of power is to show the interconnectedness of modernity, colonisation, capitalism and Christianity; to show how Lander can assert that colonisation, imperialism, racism, and sexism are constitutive of western modernity, not merely unfortunate by-products that need to be mediated while retaining the framework of western modernity.

From this standpoint, returning to the dilemma of settlers in the former British settler nation-states, it is now possible to imagine that an engagement with indigenous peoples and their call for recognition of their sovereignty could pave the way for a reconstruction of settler societies that is not based on modes of domination and oppression. I argue that such a path begins with the individual, and the transformation of the individual will ripple out to his/her family, friends and communities. Such a path recognises the responsibility and empowerment of each individual, while simultaneously affirming the interconnectedness of our lives and our environment.

Yet having an understanding of the positive potential of redefining of the nation-state in former British settler societies and transforming the relationship between indigenous peoples and settlers only fosters the desire to move in such a direction. The question of how still remains. As stated above, the colonial matrix of power rests on knowledge, capital and racism. While acknowledging their interconnectedness, I have chosen to focus on responding to the hegemony of western knowledge and how it might be decentred to become part of what physicist and eco-feminist Vandana Shiva calls 'a plurality of knowledges' and through my analysis of He rawe/Becoming Dress offer a preliminary model of a decolonising epistemological pluralism that is critical and performative.

${ }^{3}$ Pākehā is the Māori word for non-Māori people. 


\section{A DECOLONISING EPISTEMOLOGICAL PLURALISM}

My research methodology has developed through my practice as an artist and performer. This methodology seeks to overcome the dualisms that are the foundation of western knowledge. In her article, 'The Politics of Reason: Towards a Feminist Logic', ecofeminist Val Plumwood finds that 'Western thought and society has been characterised by a set of interrelated and mutually reinforcing dualisms which... should be seen as forming a system, an interlocking structure' (Plumwood 1993: 443). She goes on to state that in dualisms 'the qualities, (actual or supposed), the culture, the values and the areas of life associated with the dualised other are systematically and pervasively construed and depicted as inferior' and are constructed in such a way as to make 'equality and mutuality literally unthinkable' (Plumwood 1993: 447). While the list of dualisms is potentially endless, the pairings that are relevant to this thesis are: civilised/primitive, male/female, mind/body, spirit/body, spirit/intellect, subject/object, self/other, fact/value, and universal/local. These dualisms 'are conceptual responses to and foundations for social domination' (Plumwood 1993: 444) and intertwine with Quijano's colonial matrix of power. In order to explain this intersection of Plumwood and the colonial matrix of power, it is necessary to note the origin of western dualisms and its implications on knowledge production.

In his discussion about René Descartes' role in the development of 'the foundation of knowledge in European modernity' (Grosfugel 2009: 15), Grosfugel finds that by 'producing dualisms between mind and body and between mind and nature, Descartes was able to claim non-situated, universal, God-eyed view knowledge' and that 'it is this god-eye view that always hides its local and particular perspective under abstract universalism' [ italics in original text] (Grosfugel 2009: 15). In this way, Grosfugel concludes, that ' $\mathrm{h}]$ istorically, this has allowed western man to represent his knowledge as the only one capable of achieving a universal consciousness, and to dismiss non-western knowledge as particularistic and, so unable to achieve universality' (Grosfugel 2009: 15). Descartes' dualisms and abstract universalism provide a theoretical underpinning of the colonial matrix of power, remembering that control of knowledge and subjectivity was one of the four domains of the colonial matrix of power and that a global racial hierarchy was one of Grosfugel's hierarchies. It is in this way, as Castro-Gómez explains, that 'Europe appears as a privileged place of enunciation and generation of knowledge' and 
that 'European particularity [is identified] with universality tout-court' (Castro-Gomez 2007: 433). This privileging of one knowledge over others transformed the relationship between different knowledge systems, as Castro-Gómez explains:

The coexistence of diverse ways of producing and transmitting knowledge is eliminated because now all forms of human knowledge are ordered on an epistemological scale...By way of this strategy, scientific thought positions itself as the only valid form of producing knowledge, and Europe acquires an epistemological hegemony over all other cultures of the world [italics in original text]. (Castro-Gomez 2007: 433)

To summarise, the dualistic thinking that forms the foundation of western knowledge allows it to claim universality and to rank all other knowledges on its own epistemological scale, which places the knowledge produced by white Europeans at the top. As the basis of all modern western thought, this concept of universality permeates the sciences, social sciences and humanities (Castro-Gomez 2006). Because of this, Mignolo, Castro-Gómez and Grosfugel call for ‘epistemic decolonisation’ (Mignolo 2007: 485), that is, the decolonisation of western knowledge.

Through the use of epistemological pluralism, my research is my attempt to work towards this goal of epistemic decolonisation, which, in turn, I believe will work towards de-centring the settler. While I have been analysing this knowledge dynamic through the lens of the colonial matrix of power, it has also been examined by various philosophers of science. Joseph Rouse describes how the sciences deny legitimacy to other knowledge production systems as 'epistemic sovereignty' (Rouse 1996: 30-33) and Stephen Healy finds that there is an interdependence between 'epistemic sovereignty' and the political culture that supports it: "political hegemony" and "epistemic sovereignty" turn out to be two sides of the same coin with the pre-eminence of vision assumed granted by the latter a key to the legitimation assumed by the former' (Healy 2003: 699). Similarly, in the social sciences, Castro-Gomez finds that ' $[\mathrm{t}]$ he taxonomies elaborated by social sciences were... not limited to the development of an abstract system of rules called "science", but these taxonomies constructed 'mechanisms of power/knowledge' that functioned both representationally and materially' (Castro-Gomez 2006: 213-4). Healy offers 'epistemological pluralism... as a step in the direction of reconceptualising knowledge and, consequently, reconfiguring the relations of power of which it is part' (Healy 2003: 693-4). Epistemological pluralism, which promotes 'the deployment of all relevant 
knowledge, perspectives and viewpoints' (Healy 2003: 697), doesn't deny the value of scientific knowledge, but merely understands that there are many ways of knowing the world (Healy 2003: 694).

Thaddeus R. Miller et al., a group of researchers from the disciplines of anthropology, ecology, environmental philosophy, geography, mathematics and policy science, find that epistemological pluralism produces 'a more complete understanding of complex issues', but 'may require continual negotiations' between differing knowledge systems and that, therefore, 'requires both an attention to collaborative processes and a certain set of skills to enable group introspection' (Miller et al. 2008: para. 12). The collaborative process is something in which I have had a reasonable amount of experience, having spent much of my life as an artist working on collaborative projects; the specifics of my collaborative process will be more fully explored in subsequent chapters. The collaborations in which I have participated have involved participants from different disciplines; different cultures, races, classes and nationalities; and different genders and sexual orientations. What I have found to be essential for the success of such collaborations is that the process is critical, decolonising and performative. While there is crossover in these terms, as discussed below, each does not necessarily imply the other and each privileges something different.

\section{Criticality}

As critical pedagogy theorists Joe L. Kincheloe and Peter McLaren point out critical theory is not a single unified theory, but a pluralistic approach that makes space for disagreement and contestation, that is continually changing and evolving, that is held together by the search for 'new and interconnected ways of understanding power and oppression and the ways they shape everyday life and human experience' (Kincheloe and McLaren 2005: 303, 06); and that seeks to create change and to transform society (Kincheloe and McLaren 2005: 305). I have chosen to use the term 'critical', simultaneously embracing this lineage while inscribing my own meanings. There are four dimensions that I ascribe to the term 'critical'.

The first is a concern with an analysis of issues of power and justice. In their discussion of critical methodologies, communications scholar Norman K. Denzin and higher education professor Yvonna S. Lincoln define critical research as consisting of 'a set of interpretative, material practices that make the world visible' (Denzin and Lincoln 2008: 5). Further, it seeks to create a space 'where the work of resistance, critique, and 
empowerment can occur' and that this space is collaborative and dialogical (Denzin and Lincoln 2008: 5).

The second is the recognition of how I as an individual am part of those larger power relations - a microcosmic expression of the macrocosm—and that I not only reflect upon my imperatives and assumptions (Kincheloe and McLaren 2005: 305) but also strive towards a self-criticality to unseat the ways in which these larger relations are inscribed on my being and being-in-the-world.

The third draws from the meaning of critical as essential or crucial. It is important for me to assume responsibility for how my being and existence interacts with the currently constructed power relations, and the acceptance of that responsibility demands that I act in ways to transform that construction. What I choose to think, say and do matters and, therefore, become acts that are critical.

The fourth is critical as in 'critical mass,' the ability to sustain a chain reaction. While what I do as an individual is critical, it is also necessary to work towards building communities that can support and sustain on-going efforts. To do so requires those of us coming from hyper-individualistic western backgrounds which privilege the individual to learn how to think as a 'we' and 'us', not just 'I' and 'me.'

\section{Decolonisation}

As with critical theory, educators Beth Blue Swadener and Kagendo Mutua find that decolonising research does not adhere to 'a single agreed-upon set of guidelines or methods' (Swadener and Mutua 2008: 33). In fact, it cannot do so and remain decolonising. Decolonisation must be localised and 'grounded in the specific meanings, traditions, customs, and community relations that operate in each indigenous setting' (Denzin 2005: 935-6). Anthropologist Anna Tsing frames local as 'acts of positioning within particular contexts' (Cited in Conquergood 1995: 138). While there is not a common method, there is a common purpose, which Linda Tuhiwai Smith states as:

The decolonization project in research engages in multiple layers of struggle across multiple sites. It involves the unmasking and deconstruction of imperialism, and its aspects of colonialism, in its old and new formations alongside a search for sovereignty; for reclamation of knowledge, language, and 
culture; and for the social transformation of the colonial relations between the native and settler (L. T. Smith 2005: 88).

How one approaches and conducts oneself in regards to decolonisation depends on which side of the hyphen one sits. That is, my relationship to decolonisation as a white, American woman is different than that of my Māori collaborator, Anahera Gildea. Decolonising research practices must be 'culturally responsive' (Denzin and Lincoln 2008: 6). While later in this chapter, I will discuss my research in relation to Kaupapa Māori, here I would like to discuss decolonisation from the perspective of the settler: how can we decolonise ourselves? As writer, educator, and sociologist Albert Memmi writes, 'Colonization can only disfigure the colonizer' (Memmi 1965: 147).

One approach that decolonising researchers have adapted is to 'work the hyphen' (Fine 1994: 72). Educators Alison Jones and Kuni Jenkins talk about their work around the Pākehā-Māori hyphen:

...this hyphen, mapped onto the indigene-colonizer relationship, straddles a space of intense interest. The colonizer-indigene hyphen always reaches back into a shared past. Each of our names-indigene and colonizer-discursively produces the other...The shared indigene-colonizer/Māori-Pākehā hyphen not only holds ethnic and historical difference and interchange; it also marks a relationship of power and inequality that continues to shape differential patterns of cultural dominance and social privilege. (Jones and Jenkins 2008: 473)

The strength of working across the hyphen is that there is the recognition that there are two distinct positions; one doesn't collapse into the other, but together they define a relationship. Working across the hyphen not only works against the Enlightenmentdriven concept of universality, but is a step towards de-centring the western. The coloniser is no longer defined alone, but in relation to the indigene. Looking across the hyphen is also implicit in this relationship. Traditionally, it is the coloniser looking at and defining the indigene, and the indigene responding to that gaze, but what if it is the coloniser who is gazed upon by the indigene and who has to respond to this indigenous gaze? 
While working on the Nō Näianei/From This Moment project, which was a cross-cultural comparison of colonisation from the perspective of Māori and Chicano ${ }^{4}$ and which will be discussed more fully later in this chapter, our group of collaborators found that it was impossible to talk about Māori and Chicano without also talking about Pākehā and Anglos. Yet we also noted that white people could talk about themselves without ever referencing Māori, Chicano, Black, etc. It was at this moment that it occurred to me that this is the essence of white privilege-remembering Mignolo's intersection of colonisation and racism. White people can define themselves as they choose and without ever having to reference the values and judgment of their Others. As Memmi writes, the coloniser is part of the group whose 'values are sovereign' (Memmi 1965: 12), and because of this, they don't have to develop double-consciousness.

In her essay, 'Signifying Self: Re-presentations of the Double-Consciousness in the Work of Maxine Greene', educator Denise M. Taliaferro offers a new way of understanding W.E.B DuBois' use of double-consciousness in which he describes the situation of the African-American as:

...gifted with second sight in this American world—a world which yields him no true self-consciousness, but only lets him see himself through the revelation of the other world. It is a peculiar sensation, this double-consciousness, this sense of always looking at one's self through the eyes of others, of measuring one's soul by the tape of a world that looks on in amused contempt and pity. (DuBois cited in Taliaferro 1998: 90)

Taliaferro notes that double-consciousness emerges '[ $\mathrm{f}$ ]rom an oppressed positionality' that 'is founded on the ability of the person to see Self through the eyes of the Other' and 'has been characterized as an unfortunate, tragic burden' (Taliaferro 1998: 92). While still recognising the negative impact that double-consciousness has had on African Americans, she also, through drawing on the work of arts educator Maxine Greene, has come to recognise that:

\footnotetext{
${ }^{4}$ The term 'Chicano' 'came into widespread usage in the 1960's as part of the Chicana/o civil rights movement. Unlike the ethnic description "Mexican American," these terms signaled a decolonizing political ideology critical of anti-Mexican sentiment and melting-pot ideals of assimilation into Eurocentric culture.' Laura Elisa Pérez, Chicana Art : The Politics of Spiritual and Aesthetic Altarities (Durham: Duke University Press, 2007) at 12.
} 
...double-consciousness need not only be a burden, but might be a virtue as well. And, it need not be only a situation of blackness, it can also describe, albeit differently, the experiences of ... any of America's oppressed. Not only that, but we should all seek to understand it and those who have escaped the pain of splitting soul should surrender to the possibility. (Taliaferro 1998: 90-91)

Taliaferro's 'virtuous' double-consciousness is an apt tool to dismantle our inner colonisation, our individual colonial matrix of power-double-consciousness as a personal tool of decolonisation. 'Those who have escaped the pain of splitting soul should surrender to the possibility' is a call to white people to look 'at one's self through the eyes of the others', to measure one's self by the tape of the Other's world. Taliaferro's later discussion of bell hooks' essay, 'Representations of Whiteness in the Black Imagination', clarifies how white people generally don't see the terror that whiteness causes in the minds of black people nor do they see how they, white people, exist in the imagination of blacks (Taliaferro 1998: 95). Taliaferro extends this discussion beyond the American black-white racial discourse when she states that her call for the development of double-consciousness is the same as postcolonial theorist Gayatri Spivak's call to 'holders of hegemonic discourse' to 'learn how to occupy the subject position of the other' (Taliaferro 1998: 95).

It needs to be noted that few are exclusively privileged or oppressed. For most, one's positionality with regards to the hyphen depends on which relationship is under scrutiny. For example, as a woman I am the oppressed in the male-female hyphenate, but as a white settler woman, I am on the privileged side of the coloniser-indigene hyphenate. Further, my oppression as a white woman is distinctly different than the oppression of a Māori woman. This difference, caused by the intersection of gender and colonisation, became the central issue of investigation in the performative research that culminated in He Rawe/Becoming Dress, which will be discussed later in this chapter. What is perplexing is that, for whatever reason, while I as a woman am forced to 'occupy the subject position of the other' with regards to patriarchy, I don't automatically 'occupy the subject position of the other' with regards to my Others. My whiteness and how it exists in the imagination of my Others remains untouched unless I actively seek to understand it from the positionality of my Others. The question then is how do I as a white woman develop double-consciousness with regards to my whiteness? Taliaferro points back to Maxine Greene: 
Maxine identifies her situatedness as white and woman, and it is from these positionalities that she uses her imagination to get in touch with alternative realities...Maxine, instead, uses her imagination in such a way that does not victimize the Other, or assume to be the Other. Rather, she extracts from the other's experience that which leads to some broader understanding of self. This is her cultivation of a positive and powerful double-consciousness, one that gives credence to the dialectical rather than the oppositional nature of Self and Other. (Taliaferro 1998: 95-96)

For Greene and Taliaferro, it is the imagination and the arts that can facilitate the development of double-consciousness. Art historian and critic Grant Kester, drawing on Kant, Schiller, Hutcheson and Shaftesbury, sees 'the aesthetic as a unique form of knowledge' (Kester 1998: 8) that 'can overcome the boundaries of conventional thought' (Kester 1998: 12) and explains that 'the aesthetic is linked to the social and the political through its function as a mediating discourse between subject and object, between somatic and the rational, and between the individual and the social' (Kester 1998: 8). The aesthetic is able to visualise and embody both what is and what could be: ' $[\mathrm{t}$ ] combine to provide the aesthetic with a unique ability to identify and describe the operations of political, social, cultural, and economic power, while at the same time allowing it to think beyond the horizons established by these forms of power' (Kester 1998: 8).

\section{Performativity}

Drawing on this power of the aesthetic, beginning in the 1970's, there arose an activist model of art that used their art practice to interrogate these power relations (Kester 1998: 12). Simultaneously in the realm of qualitative research, there arose questions about representation and reflexivity that made space for new and innovative ways of conducting research (Denzin and Lincoln 2003: 4). Arts-based research was one of the methodologies that developed as a result of, as activist, artist, and author Susan Finley describes, the activist turn in social sciences and the search to make research participatory and relevant to the researched and their community (Finley 2005: 682). Kester finds that this 'activist aesthetic [is] based on performativity and localism' and describes performativity as 'a practice that is adaptive and improvisational rather than originary and fixed', concluding that 'the work of art is less a discrete object than it is a process of dialogue, exchange, and even collaboration that responds to the changing conditions and 
needs of both the viewer and maker' (Kester 1998: 15). Likewise, in his discussion of performance ethnography, ${ }^{5}$ Denzin states that there is no division between doing and done, performativity and performance and that:

Performance is an act of intervention, a method of resistance, a form of criticism, a way of revealing agency. Performance becomes public pedagogy when it uses the aesthetic, the performative, to foreground the intersection of politics, institutional sites, and embodied experiences. In this way performance is a form of agency, a way of bringing culture and the person into play. (Denzin 2003a: 9)

Similarly, though coming from a performance studies perspective, Dwight Conquergood sees performance '(1) as a work of imagination, as an object of study; (2) as a pragmatics of inquiry... as an optic and operator of research; (3) as a tactics of intervention, an alternative space of struggle' (Conquergood 2002: 152). Further, the strength of performance as a research tool is that it utilises three kinds of knowledges: (1) 'knowledge that comes from doing' or accomplishment; (2) 'knowledge that comes from contemplation and comparison' or analysis; and (3) 'knowledge that is tested by practice within a community' or articulation (Conquergood 2002: 152).

My performative approach, therefore, is a weaving together of these threads and defines an epistemological pluralism that is performative as one that uses the aesthetic and imagination to create spaces of resistance and intervention; is adaptive and improvisational in order to be grounded in and responsive to the local; and does not separate knowing from its context, knowing from doing and doing from done. Moreover, performative research challenges what Conquergood calls 'the hegemony of the text' (Conquergood 2002: 151) which 'underpins the supremacy of western knowledge systems by erasing the vast realm of human knowledge and meaningful action that is unlettered' (Conquergood 2002: 147). Conquergood finds that 'by embracing both written scholarship and creative work' [italics in original text] a re-alignment of 'texts and performances in horizontal, metonymic tension' (Conquergood 2002: 151) can be achieved. The combination of my performative research project and written thesis is an example of such an endeavour. The recognition of the validity of non-textual modes of

\footnotetext{
${ }^{5}$ Performance ethnography uses standard ethnographic practices, but presents its findings through theatrical representations rather than in print, whereas the ethnography of performance is an investigation of cultural performances. Ronald J. Pelias, 'Performance Ethnography', in George Ritzer (ed.), Blackwell Encyclopedia of Sociology (Malden, MA: Blackwell Publishing Ltd., 2007).
} 
expressing knowledge is required to fully embrace epistemological pluralism where different knowledge systems have different ways of expressing knowledge; this is particularly true of indigenous knowledges which have traditionally been embodied in oral traditions and customary arts.

In summary, my research is guided by an epistemological pluralism that seeks to dismantle the colonial matrix of power and its dualisms that underpin the hegemony of western knowledge. Through a performative research process, it casts a critical eye on power relations as they manifest out in the world and reproduce themselves inside me in order to work across the hyphen and decentre the settler. As a result of my decolonising work in the Chicano community in Southern California and learning on a personal level the importance of being 'culturally responsive' (Denzin and Lincoln 2008: 6), I have been deeply committed to grounding this research in the specific meanings, traditions, customs, and community relations' (Denzin 2005: 935-6) of Māori. For this reason, my research is responsive to the research principles of Kaupapa Māori.

\section{KAUPAPA MĀORI}

Māori and indigenous education scholar Graham Hingangaroa Smith states that Kaupapa Māori, which is Māori-directed research, seeks 'to create the moral and ethical conditions and outcomes which allow Māori to assert greater cultural, political, social, emotional and spiritual control over their own lives' (G. H. Smith 1997: 456). Kaupapa Māori places Māori at the centre (G. H. Smith 1997: 476). Its imperatives are the survival and revival of te reo Māori (Māori language) and tikanga (Māori culture) in conjunction with the struggle for tino rangatiratanga (Māori autonomy) (G. H. Smith 1997: 466).

There were three factors that contributed to the development of Kaupapa Māori: (1) te reo Māori revitalisation, (2) Māori cultural renaissance and (3) the establishment of the Waitangi Tribunal. Kaupapa Māori grew out of the Māori community response to the dissolution and loss of Māori language, culture and knowledge due to the impact of colonisation (G. H. Smith 2003: 8), exacerbated by the urban migration in the 1950s and New Zealand's English-only education system (Benton 1986: 57). In 1971, Dr. Richard Benton observed that te reo Māori was in the last throes of language 'death' (G. H. Smith 2003: 8). At that time, less than $20 \%$ of Māori were fluent speakers of te reo Māori, and 
the use of te reo Māori was primarily limited to whaikōrero (formal speeches) on the marae (Benton 1991: 187). Thus, in 1981, out of a meeting of Māori leaders, sponsored by the Department of Māori Affairs, began Te Kobanga Reo (Language Nest Movement) (Benton 1986: 67). However, Te Kohanga Reo were 'developed as resistance initiatives outside of the "mainstream' system"” (G. H. Smith 2003: 8). As such, it was more than the establishment of Māori educational institutions from Te Kohanga Reo (pre-school) to Wanaga (tertiary); this 'Māori educational resistance...correlated with an emerging political consciousness among Māori communities' that 'developed around understandings of the politics of the control of knowledge, understandings of the debilitating effects of hegemony, and understanding of the general politics of existing in a societal context of unequal power relations' (G. H. Smith 1992: 2). Concurrently, there was a revitalisation of Māori culture (Bishop 1996) (Pipi et al. 2004: 143) and a 'renewed sense of commitment to indigenous values and knowledge' that was 'accompanied by a demand for increased autonomy and a parallel rejection of policies of assimilation and dependency' (Durie 2004: 1140).

It was also during this time that there was, what Māori educator and historian Ranginui Walker calls, 'a remarkable elevation in the status of the Treaty [of Waitangi] from a "simple nullity" to the level of a constitutional instrument in the renegotiation of the relationship between Māori and Pākehā in modern times' (Walker 1990: 265-6). The Treaty, signed in 1840, formalised a partnership between Māori and the British Crown and is now interpreted as 'a charter for power sharing in the decision-making process' of Aotearoa New Zealand and for Māori determination of their own destiny' as the tangata whenua (the indigenous people of the land) of Aotearoa New Zealand (Bishop 2005: 133). The Treaty of Waitangi Act 1975 established the Waitangi Tribunal as 'a permanent commission of inquiry charged with making recommendations on claims brought by Māori relating to actions or omissions of the Crown, which breach the promises made in the 'Treaty of Waitangi' (Tribunal 2011). Writing in 2001, Māori social psychologist Fiona Cram explains how the Tribunal process positively impacted the growth of Māoricentred research:

Over the past 25 years, a great deal of Māori energy has gone into researching and assembling tribal knowledge for the purpose of putting a case before the

${ }^{6}$ Marae is the open area in front of the wharenui (meeting house), where formal greetings and discussions take place. It can also be used to include the complex of buildings around the marae. 
Waitangi Tribunal. The Tribunal process has therefore achieved multiple aims, including acknowledging past grievances, the collection of $i w i$ [tribal], hapū [subtribal] and whänau [family] knowledge, and a growing awareness of the role of research. (Cram 2001a: 40)

Kaupapa Māori is neither monolithic nor static. It has great breadth, being used in a variety of contexts and disciplines, articulating and clarifying itself with each new application. Linda Tuhiwai Smith, Graham Hingangaroa Smith, Russell Bishop and Leonie Pihama have written extensively on Kaupapa Māori, education and research; Fiona Cram on psychology; Mason Durie on health care; Moana Jackson on law and politics, to name a few examples. These varied articulations aren't necessarily at odds with each other; they merely reflect the diversity of Māori and their contexts (Bishop 1998: 114).

As a white, American woman conducting research with a Māori woman in Aotearoa New Zealand, I took a two-prong approach to guide my interactions with Kaupapa Māori and Mãtauranga Māori. First, I educated myself about Māori, focusing on their culture, history and political thought. (I had intended to learn te reo Māori and took one te reo Mãori paper in the first year of my Ph.D. but due to the time constraints, I was not able to continue.) I did this not only through written texts but through lived experiences, which meant I had to be willing to assume the unfamiliar-for a white person-position of being in a situation where my knowledge and points of reference were not necessarily valid. I engaged in Māori settings where, for a time, I was uncertain about what I should be doing and uncomfortable with that uncertainty. I did not seek to become an expert on anything Māori-I did not feel that this was my place. Instead I sought to gain a respectful understanding; that is, I sought to have enough cultural understanding that I could interact comfortably in a Māori context and that I could, when working with Māori in Pākehā contexts, (hopefully) create a measure of Māori-friendly space.

Second, I used the knowledge and understanding I had gained to align my research with Māori values, ethics and aspirations. I used the insights of Kaupapa Māori as they pertain to keeping power relations in the forefront of my mind, specifically, how Kaupapa Māori seeks to deconstruct the hegemony of western knowledge and the academy which 'have disempowered Māori from controlling their own knowledge' (G. H. Smith 1992: 2). It is with this imperative in my heart that I developed the decolonising epistemological pluralism that Anahera and I used for our performative research project. I developed this 
methodology — and its theoretical foundation — as a way to positively respond to and begin to address Māori concerns about western knowledge production and academic research. To ensure that Māori values, ethics and aspirations were an integral part of my research, I conducted my research under the auspices of Te Kawa a Māui/School of Māori Studies.

How I chose to represent—or not represent—Mätauranga Māori was a carefully reasoned political strategy based on my response to Kaupapa Māori and was informed by the following considerations.

First, I did not feel that I had 'speaking rights' to write extensively on Mätauranga Māori. This understanding arose out of the debate in the literature about who can do Kaupapa Māori research. Reflecting on the complexity involved in answering this question, Linda Tuhiwai Smith says, on one hand, that there are those who hold that 'Kaupapa Māori is Maori research exclusively' (L. T. Smith 1999: 184) and that Kaupapa Māori is 'research by Mãori, for Māori and with Mäori (cited in Henry and Pene 2001: 236) . On the other hand, she says that there are those who believe that perhaps a non-Māori could be involved in Kaupapa Māori research but not on their own (L. T. Smith 1999: 184). I chose to align my research with the position that, as a non-Māori, I cannot conduct Kaupapa Māori research, though I can use its insights regarding the construction and impact of colonising power relations. In addition to conducting my research under the auspices of Te Kawa a Māui, I sat a paper on Māori methodology. It was during this paper that I wrote a brief piece that reflected on being a non-indigenous researcher. This became the foundation of how I conducted myself and my research. I found being a non-indigenous researcher in indigenous communities required:

- Engaging in constant self-reflection, questioning and examining one's privilege and an on-going effort to decolonise/dehegemonise oneself. It is your responsibility to do this, not the indigenous people you're working with.

- Having a willingness to assume unfamiliar 'positions', i.e. your context isn't the one being engaged. This also means a willingness to be uncomfortable and uncertain.

- Risking being vulnerable. 
- Taking care to make sure that the exchange is consensual and beneficial to everyone, but especially to the indigenous community in which you're working.

- Understanding and appreciating the risk that the indigenous person or community is taking by working with you. Treasure and look after their gift — their trust— that they are giving you.

Returning to Smith's comments on non-Māori and Kaupapa Māori, 'but not on their own' is a key phrase for me when considering not only doing Kaupapa Māori research but also what non-indigenous researchers can and should say and write about Māori. From the perspective of western knowledge, as long as one can justify and make cogent arguments for the credibility of one's understanding, point of view and conclusions, one has the right to speak and write about any subject. What I learned, especially from working with Anahera, is that this is not how it is for Māori. Working within a Māori context, knowing and speaking do not always only belong to the realm of the individual, but also arise out of the intricate web of relationships between people and the land. Mason Durie writes, '...the basis for knowledge creation is the dynamic relationships that arise from the interaction of people with the environment, generations with each other, and social and physical relationships' (Durie 2005: 303). Who can speak about what in what setting arises from these same dynamic relationships.

Fiona Cram writes, 'For Māori, the purpose of knowledge is to uphold the interests and mana of the group; it serves the community' (Cram 1997: 46). For this reason, knowledge traditionally was not something that was universally available, but was entrusted to certain individuals who could ensure that 'it was transmitted accurately and used appropriately' (Cram 1997: 46).

Although I have read work on Kaupapa Māori, I still see that it is inappropriate for me, a white, American woman who has spent less than five years in Aotearoa New Zealand, to claim to be able to write with any authority on matters regarding Mātauranga Māori. In her essay 'Lost in Indophile Translation: A Validation of My Experience', Bhavana Mody writes of her discomfort at listening to 'Indophiles' - the term she has given to white males who are obsessed with India—talk with authority about India, after only spending a short time there. She also raises the point that their interest in India is not necessarily an indication of wanting to understand Indians: 'Sure, the India-obsessed dudes...that go 
to India understand more about the 'third world', Hinduism, yoga and what not, but do they really understand actual Indians (including me)? How do they treat actual Indians in this country?' (Mody 2002: 271). Which brings me to my second consideration.

I find that there is a delicate balancing act that is required of white people who wish to decolonise themselves with regards to their interaction with indigenous knowledge such as Mätauranga Māori. On one hand, it is important to learn and understand the culture and values of Māori in order to engage with Māori on their terms, but on the other hand, how much is this desire for knowledge of Mātauranga Māori a desire for consumption of the Other, of which Leslie Roman and Megan Boler speak (Jones 1999: 313)? Spokane/Coeur d'Alene writer Sherman Alexie adeptly illustrates this interaction in his short story, 'Dear John Wayne'. It is a fictious interview between Spencer Cox, a cultural anthropologist who is an expert on the Interior Salish tribes of Washington State and Etta Joseph, an 118 year old Spokane woman. After an exchange where Mr. Cox asserts that he is an expert in his field and Miss Joseph responds that she knows so much more about him than he will ever know about her, the dialogue continues:

Miss Joseph:... For the last one hundred and eighteen years, I have lived in your world, your white world. In order to survive, to thrive, I have to be white for fifty-seven minutes of every hour.

Mr Cox: How about the other three minutes?

Miss Joseph: That, sir, is when I get to be Indian, and you have no idea, no concept, no possible way of knowing what happens in those three minutes.

Mr Cox: Then tell me. That's what I'm here for.

Miss Joseph: Oh, no, no, no. Those three minutes belong to us. They are very secret. You've colonized Indian land but I am not about to let you colonize my heart and mind. (Alexie 2000: 194)

Out of these understandings came my decision not to write a chapter on Mätauranga Māori, as I did on the other knowledges, Nichiren Buddhism and Butoh, that Anahera and I used in our performative project. However, I hope that I have put forward here the ways in which I have been influenced and have taken note of Mätauranga Mãori and Kaupapa Māori research. 
In light of the role that research has played in the colonisation of indigenous people, Linda Tuhiwai Smith states that research that involves Māori needs 'to make a positive difference for the researched' (L. T. Smith 1999: 191). She puts forth a set of questions that need to be asked by non-Māori when researching Māori:

Who defined the research problem?

For whom is this study worthy and relevant? Who says so?

What knowledge will the community gain from this study?

What knowledge will the researcher gain from this study?

What are some likely positive outcomes from this study?

What are some possible negative outcomes?

How can the negative outcomes be eliminated?

To whom is the researcher accountable?

What processes are in place to support the research, the researched and the researcher?

(L. T. Smith 1999: 173)

While most of these questions have been answered implicitly in the preceding discussion of epistemological pluralism, there are several to which I would like to respond explicitly. As to accountability and support for the research, the researched and the researcher, having located my research within Te Kawa a Māui, the School of Māori Studies at Victoria University, I am accountable to this community and my research is guided by their protocols and standards. With regards to the knowledge gained and by whom, because our performative research project is a collaboration, the knowledge it produces belongs to both Anahera and I. It is for this reason that I chose not to pursue a practicebased doctorate. It was important to me that I not claim sole ownership of our performance; it belongs to both of us. Given the history of white researchers in indigenous communities, I was determined not to claim what did not rightfully belong to me. I also feared that if the performance was to be assessed, that the requirements of assessment would skew our collaborative process and our way of making art. Such an 
assessment would most likely require me to show how I contributed to this performance. It could potentially move our consensus-based collaborative process in the direction of a directorial one; that is, the process of collaboration that I prefer to use is one where all participants are the creators rather than one where collaborators work in service to the director's vision. As to who defined the research problem for the performative research project, it was Anahera Gildea and I. As it grew out of our experience of working together on Nō Näianei/From This Moment, the following discussion of how we arrived at our research problem is a personal narrative.

Anahera and I met at a Soka Gokkai International (SGI) meeting in 2007. SGI is an international lay Buddhist organisation that practices Nichiren Buddhism as a practical philosophy of inner transformation and whose activities aim to promote peace, culture and education (Soka Gakkai 2006: 1). At the time, my husband, William Franco, a Chicano, and I had recently arrived in Aotearoa New Zealand on his Fulbright Fellowship, and we were looking for collaborators for our project on colonisation from the perspectives of Māori and Chicano. In the end, Anahera became one of the collaborators on Nò Näianei, in addition to VJ (video deejay) and time-based installation artist Eugene Hansen from the iwi (tribes) Ngāti Mahuta, Ngāti Maniapoto. Nō Näianei was a ten-month cross-cultural collaboration that, within the context of colonisation, explored the question: How can the artist be a catalyst for change in a society by fostering dialogue and discussion? The outcome was a three-part project that consisted of a Butoh bikoi (march/procession), Butoh/VJ performance and multimedia installation. Butoh is not easy to define and will be discussed fully in a subsequent chapter, but it will suffice to say that 'it is both theatre and dance, yet it has no choreographic conventions' (Hoffman and Holborn 1987: 9).

To explain Anahera's interest in Nō Näianei, I draw upon what she wrote on our applications for funding for the project:

Approaching the question of how an artist might be a catalyst for social change provides a rare opportunity for me to realise the driving forces that underpin my practice. The motivating aspects, not only of my artistic practices, but also my whole life direction, have been to find ways in which to answer this question. The first artwork I ever sold was a six foot oil pastel painting on watercolour paper. The entire background was filled with the words of all versions of Te Tiriti o Waitangi [Treaty of Waitangi]. Layered on top of that was a foetus nestled inside 
a fish hook and, underneath, the words: when I grow up I want to be a princess and live in a castle. Though this work was very raw and young, it still underpins the urges that compel me to create.

I began predominantly as a dancer and performer and evolved into a multi-media artist and writer. It is my continual engagement with and reaction to my highly politicised status as a Māori that urges and drives me forward. I have been involved in a huge range of work beginning with performance and choreography in 1990 in "NZ Made" right through to film work in 2003/2004. I have had the good fortune to have been trained by outstanding people such as Mark Lipman, Ellie Smith, Michael Robinson and KC Kelly and to have completed my BA at Canterbury University studying Drama with Peter Falkenburg and Sharon Maizer and Art Theory with Dennis Dutton.

Working on this project will enable me to merge so many of my previous skills (performance, video, writing, visual art and publicity) into a unified whole. I have long desired to learn the skills involved with video installation and could not have found better teachers and a more purposeful and fulfilling project.

I have twice been a finalist in the Huia Short Story Competition and also in the Montana Poetry Slam. I have published in several books and magazines and am currently working on the completion of a novel, the co-direction of a play with playwright Nathan Matthews, and an exhibition with Kiriana O'Connell, an emerging Māori fibre artist.

Besides being my first collaboration with Anahera, $N \bar{o}$ Näianei is significant for two additional reasons. One, this was my first interaction with Māori over an extended period of time, and it was in a context where being Māori and being Chicano were seen as being 'normal' rather than Other. In order to understand colonisation from both a Māori and Chicano perspective, for eight months we four collaborators met once a week for four to six hours at one of our homes, shared food and had wide-ranging conversations about Māori and Chicano culture, politics and history. Further, there arose, at different times, the need to find our way through conflicting cultural ways of doing things. For example, one of the ideas for the installation was for William to make eels out of sugar, using the 
traditional Mexican process of making sugar skulls. ${ }^{7}$ For Eugene and Anahera, as Māori, it was not appropriate to use food for anything other than eating, whereas for William and I, food was often used in an art setting, an outgrowth of the Mexican tradition of building altars for the dead which included offering their favorite foods.

Two, we four collaborators formed With Lime, an international, intercultural, interdisciplinary arts company in order to produce innovative arts projects with the longterm goal of creating social and cultural change. While Eugene chose not to continue as part of With Lime after the completion of Nò Näianei, Anahera, William and I remained as its artistic directors and produced other projects, including He rawe/Becoming Dress. William's and With Lime's role in He rawe/Becoming Dress will be discussed later in this chapter.

It was while working on Nò Näianei that the seeds for He rawe/Becoming Dress were planted. It was on this project that Anahera was introduced to Butoh. Over the course of eight months, William and I trained Anahera in how we do Butoh. Butoh was an art form that resonated with Anahera, and she desired to learn more and do more Butoh. Additionally, it quickly became clear, as the collaboration progressed, that there were aspects of colonisation that we-Anahera and I-as women wanted to discuss that were not appropriate for the $N \bar{o}$ Näianei project. As they came up, we tucked them away and said that they were for our next project, not knowing exactly what that meant, but it was an indication that we planned to find a way to explore these issues sometime in the future. When I decided to do my Ph.D. in Aotearoa New Zealand, we both knew that this would be our opportunity to do this investigation. It is in this way that Anahera and I came to define the research problem for our performative research project.

Similarly, the way that we chose to conduct our performative research project arose naturally out of who we are and what we know. We both wanted to do a Butoh performance. We both practice Nichiren Buddhism and use it to guide our daily lives, as a way of understanding the world, as a way of resolving problems and conflicts. As a collaboration that worked across the hyphen, we both engaged with decolonisation from our respective positions on the hyphen, as well as having brought our respective world views-I, white American and Anahera, Te Ao Mãori. He rawe/Becoming Dress was the outcome of this epistemological pluralistic approach.

${ }^{7}$ Sugar skulls are skulls made of sugar that are placed as offerings to the deceased on altars that are built to celebrate the Mexican holiday of Dia de los Muertos/Day of the Dead. 
He rawe/Becoming Dress, an hour-long Butoh performance created and performed by Anahera Gildea and me, was built around the concept of a fashion show where we, as models, begin the show wearing all our fashions, one layered upon the other, and shed them one at a time through the course of the performance. It also included five video projections and a live DJ mix.

As I mentioned earlier in this chapter, He rawe/Becoming Dress was produced by With Lime. As its artistic directors, Anhera, William and I make our decisions and run our projects using consensus decision-making. When we three decided that we would pursue the development of what came to be He rawe/Becoming Dress, William recognised that, because it was about gender and being a woman, the project would have to be created by Anahera and I, and saw his role as supporting us in whatever way was necessary to bring it to fruition. As a result, he is not considered a primary collaborator on He rawe/Becoming within this thesis, though he was the Production Designer and DJ.

While Janet Dunn also made a significant contribution to He rawe/Becoming Dress through her costumes, she, too, is not considered a collaborator within this thesis. Originally, Anahera and I had planned that Anahera, with my assistance, would design and create the costumes. However, by the time we realised that this would not be feasible from a time management standpoint, Anahera and I had already developed the concept and structure of He rawe/Becoming Dress, so Janet joined the project once its vision had already been conceived, and her contribution was to support this vision.

Finally, as with any theatrical production, there are technical people who come in to perform specific skilled tasks. In addition to the stage hands who assisted with set up and tear down, Bex Weatherhead was the Lighting Designer and Fern Karun was the Video Technician.

\section{CONCLUSION}

Anahera's and my performative research project was He rawe/Becoming Dress, which was developed using the aesthetic of Butoh as our primary research tool. Our efforts to create an artistic outcome, a performance, were what allowed us to uncover the hidden dynamics of our lives as a Māori woman and an American woman and how those dynamics both reflected and confronted the larger societal forces of which our lives are a part. As Denzin writes, '[P]erformances make sites of oppression visible' (Denzin 2003b: 
192). Remembering Kester's power of the aesthetic, the aesthetic also allowed us to find new ways to reconfigure these dynamics, to challenge and transform what we experienced and perceived as their negative aspects; our Buddhist practice also guided us in this process. However, the performativity of our performative research project is not limited to the actual artistic performance, but applies equally to how we conducted our research. As the chapter on our collaborative process explains, we did, we experienced, we performed our research process. Denzin finds 'performed experience as a way of knowing, as a method of critical inquiry, and as a mode of understanding' (Denzin 2003b: 192). Butoh is a body-based practice where knowledge and knowing emerge from an excavation of the performer's body; Denzin defines knowing as 'those embodied, sensuous experiences that create conditions for understanding' (Denzin 2003b: 192).

While our performative research project focuses on our lives as women, the focus of our investigation was gender as one of the hierarchies of the colonial matrix of power. (Grosfugel 2009: 18). The colonial matrix of power sought to control gender relations and thereby had, as Smith states, 'a destructive effect on indigenous gender relations which reached out across all spheres of indigenous society' (L. T. Smith 1999: 151). As many indigenous women have argued, education researcher Sandy Grande writes that the oppression for indigenous women comes from colonisation (Grande 2004: 149). Lorelei DeCora Means, co-founder of Women of All Red Nations (WARN), said, 'We are American Indian women, in that order. We are oppressed first and foremost as American Indians, as peoples colonized by the United States of America, not as women... Decolonization is the agenda, the whole agenda' (Cited in Grande 2004: 149).

Further, Pihama and Cram find that colonisation distorted and denigrated the gender roles within Māori society (Pihama 2001: 256) (Cram 2001b: 402). Regarding the fact that only a few Māori women signed the Treaty of Waitangi, Cram finds that ' $t$ ] his was not so much an indication of the differential status of men and women in Māori society as a denial of Māori women's access by the British controlling the signing process. This denigration of Māori women began during the very first contacts between the British and the Māori' (Cram 2001b: 402) and continued into the $20^{\text {th }}$ century through the Native School system where the school curriculum was 'designed to make them [Māori girls] into good wives and/or servants' (Cram 2001b: 403).

Additionally, Pihama points out that 'the representation and definitions of Māori women have been, in many instances, historically constituted through the voices of the coloniser. 
We have been defined, painted, filmed, researched, imaged within dominant Pākehā frameworks and assumptions. The voices of Māori women have been marginalised or made invisible within the power relations that exist in our colonial experience' (Pihama 2001: 244).

As a result, it is white women, along with white men, who are sources of indigenous women's oppression. Grosfugel, in his discussion of 'the global gender hierarchy' of the colonial matrix of power, finds that the colonial matrix of power accorded white women 'a higher status and access to resources than the majority of men in the world (who are of non-European origin)' (Grosfugel 2009: 20). While white women are oppressed by western patriarchal society, they also are the carriers of white privilege. For these reasons, while He rawe/Becoming Dress is concerned with gender, it is an interrogation of the relationship between a white woman and an indigenous woman; it is a body-based exploration of the hyphenate of coloniser woman-indigenous woman, white American woman-Māori woman.

This thesis is an examination of He rawe/Becoming Dress, a practice-based example of the decolonising epistemological pluralism I have theorised in this Introduction. This methodology is not dependent upon using Butoh or Buddhism. What it does require is a selection of knowledges that provides space for the research to be decolonising, critical and performative. This methodology also requires a commitment to transforming the relationship between settler and indigene. This commitment will open the way to finding the appropriate tools — that is, the right mix of knowledges — that will provide space for the research to be decolonising, critical and performative. The structure of this thesis is this: Chapters Two and Three are on Nichiren Buddhism and Butoh respectively and serve as informational chapters on these two ways of knowing. They will provide the necessary background to allow for full engagement with the material presented in Chapter Four which discusses the collaborative process of creating He rawe/Becoming Dress. Chapter Five describes and analyses He rawe/Becoming Dress. 


\section{CHAPTER TWO}

Nichiren Buddhism

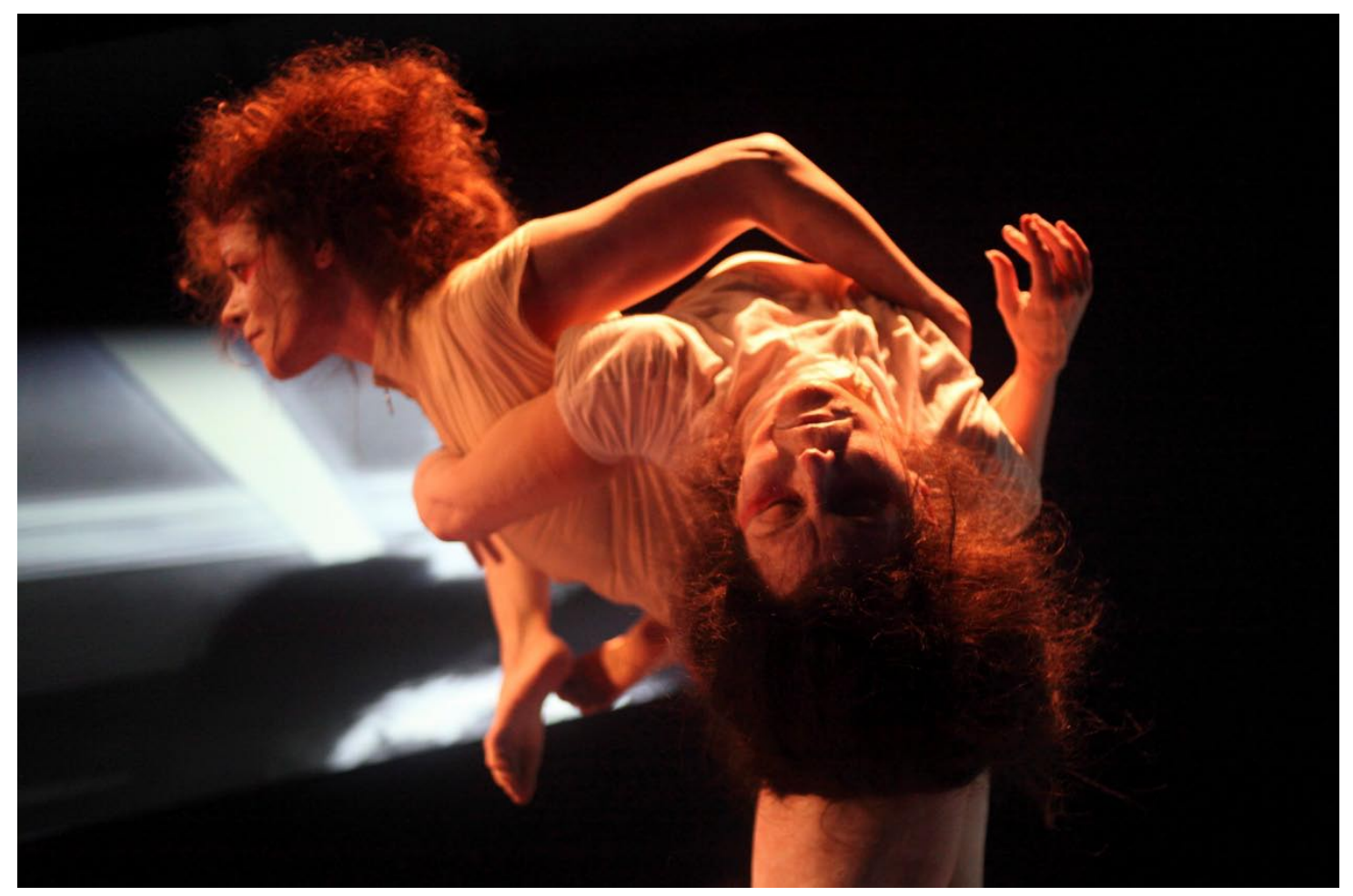


42 P a g e 


\section{ANOTHER WAY OF KNOWING}

In the Introduction, I stated that my research is my attempt to work towards the goal of epistemic decolonisation. To this end, I embarked on a collaboration with Māori artist and performer Anahera Gildea to create a performative research project, $\mathrm{He}$ rawe/Becoming Dress, that investigated gender as part of the colonial matrix of power. Our methodology for this project was a decolonising epistemological pluralism that is critical and performative. In order to avoid the domination of one knowledge system over the others, Miller et. al. finds that it is necessary for all knowledges to be engaged when formulating the problem (Miller et al. 2008: para. 9). For He rawe/Becoming Dress, Anahera's and my multiple ways of knowing, shared and unshared, gave rise to the conception of this project, and the project utilised these ways of knowing in order to be realised. Further, '[c]ollaborators may accept an epistemological perspective unique to the effort' (Miller et al. 2008: para. 10) in order to be 'responsive to the context and the nature of the problem under investigation' (Miller et al. 2008: para. 14). Miller's assertion supports my claim that my methodology can use a variety of knowledge systems, not just Butoh and Nichiren Buddhism, for example.

The focus of Anahera's and my project was gender and the colonial matrix of power. As discussed in the Introduction, Grosfugel's hierarchies of the colonial matrix of power show how the colonial matrix of power permeates every aspect of being human. Through the hierarchies of knowledge and language, it colonises the mind. Through the hierarchies of race, sexuality and gender, it colonises the body. Through the hierarchy of spirituality, it colonises the spirit. Therefore, our research project used a mix of knowledges that addressed all three levels of mind, body and spirit. Our shared knowledges included western decolonising and critical theory that focused on transformation of the mind; Butoh, the body and Nichiren Buddhism, the spirit. Additionally, Anahera used Mãtauranga Mãori as a tool in her work on He rawe/Becoming Dress, as well as it informing both our understanding of the nature of knowledge and of how knowledge emerges. This, as discussed in the previous chapter, was supported by my choice to locate this project under the supervision of Te Kawa a Māui/School of Māori Studies.

In this chapter, which covers Nichiren Buddhism - and in the next chapter on Butoh-I discuss these knowledge systems which are not widely used in academic discourse, even in their respective disciplines of religious and performance studies. Further, in Anahera's 
and my performative research project and in this thesis, they are used as investigative tools as part of an inquiry into the colonial matrix of power, which has generally been analysed using the tools of the social sciences. As epistemological pluralism seeks to redraw the boundaries of academic disciplines (Miller et al. 2008: para. 10), one of the purposes of my explanations of Nichiren Buddhism and Butoh is to provide an understanding of these knowledges that points to the breadth and depth of these knowledge systems and how they can be applicable to a variety of contexts and problems.

Additionally, in regards to the use of Nichiren Buddhism, I am responding to education theorist Riyad Ahmed Shahjahan's request to 'address the question of spirituality in research' (Shahjahan 2005b: 703). Shahjahan 'problematize[s] the permanence and dominance of...secular and materialist 'western' worldviews and ideas in the western academy', finding that he, as a Muslim, is 'surrounded by secular ideas that do not affirm my way of life and instead they negate my history, spiritual worldviews and ways of living' (Shahjahan 2005b: 686). He also finds that the '[d]ominant discourses prevalent within the western academy do not reflect the diverse bodies, religions, languages, ethnicities, histories and values of people that make up...the world (Shahjahan 2005b: 686). Elsewhere, he clarifies that he is not arguing 'for religious fundamentalism' but 'rather to understand the interconnections we have with each other and other beings that surround us' (Shahjahan 2005a: 233), drawing on Burman's definition of spirituality as being 'about connection and making these connections' (Burman cited in Shahjahan 2005b: 689). Similarly, Linda Tuhiwai Smith finds that the 'arguments of different indigenous peoples based on spiritual relationships to the universe, to the landscape and to stones, rocks, insects and other things, seen and unseen, have been difficult arguments for western systems of knowledge to deal with or accept' (L. T. Smith 1999: 74). Māori tohunga ${ }^{8}$ Rev. Māori Marsden writes:

It is also obvious that the Māori does not, and never has, accepted the mechanistic view of the universe which regards it as a closed system into which nothing can impinge from without. The Māori conceives of it as at least a twoworld system in which the material proceeds from the spiritual, and the spiritual

\footnotetext{
8 The tohunga was a person chosen or appointed by the gods to be their representative and the agent by which they manifested their operations in the natural world by signs of power (tohu mana)'. Maori Marsden, The Woven Universe: Selected Writing of Rev. Maori Marsden, ed. Te Ahukaramu Charles Royal (Otaki, New Zealand: The Estate of Rev. Maori Marsden, 2003) at 14.
} 
(which is the higher order) interpenetrates the material physical world of Te Ao Mãrama [the world of light and illumination]. (Marsden 2003: 20)

The inclusion of Nichiren Buddhism as one of Anahera's and my ways of knowing was a clear statement that spirituality had a legitimate place within our performative research project. Anahera, for whom 'spirituality in general is fundamental to who I am', states that 'though I practice Buddhism and recognise it to be a useful lens through which to see my world and make sense of it, I find that is only possible because it is closely aligned with Māori spirituality...It would be impossible to annex me from spirituality and thankfully, my Buddhist practice and Māoritanga [Māori culture, practices and beliefs], in my mind, are allies' (personal communication, 25 February 2011).

Because Anahera and I have a shared spiritual practice, it was easy to bring spirituality into our research. However, if Anahera and I had not shared the common spiritual practice of Nichiren Buddhism, we would have had to re-configure our epistemological mix to ensure that both our spiritual ways of knowing were acknowledged and able to be accessed. While the shared practice of Nichiren Buddhism facilitated our ability to communicate about our project in spiritual terms, in reflecting back, I can see how it also prevented us from further exploring how to bring Mätauranga Māori into our epistemological mix. The following discussion on tapu and noa illustrates this point.

Through both lived experience and academic research, I knew that there were certain things that needed to be considered in order for Anahera to feel culturally safe. For example, my very basic understanding about tapu (sacred) and noa (common) made me mindful of what I put on the top of a table. A table is associated with noa because it is where food is eaten and food is noa. Thus, one does not sit on a table nor put a hat, hair tie, anything related to the head on a table because the head is tapu. However, I did not fully grasp how these concepts of tapu and noa permeated how Anahera understood the world and how that understanding related to He rawe/Becoming Dress. Anahera explains:

Another concept that became increasingly important as Miki and I developed our piece was the concept of noa. This perhaps did not influence Miki in the same way but, for me, it was something I was, and am, constantly aware of. Tapu and noa $\ldots$ were spiritual constructs of ritual. They are equal in power...(personal communication, 25 February 2011). 
Similarly, she saw Costume-less, the moment when we were both naked on stage, as being noa (personal communication, 21 February 2011). In hindsight, I can see that we could have more fully explored how Mätauranga Mãori could have been used, perhaps through adopting the concepts of tapu and noa as another way of seeing gender and the colonial matrix of power.

Returning to the earlier discussion of Shahjahan, he finds that the inclusion of spirituality in academic inquiry, in addition to providing a framework of connectedness and interconnectedness between all life and the universe, brings four additional concepts that can positively transform research. The first is that spirituality 'acknowledges and integrates different levels of consciousness' (Shahjahan 2005b: 698-9). Second, it maintains a balance between 'oppressive consciousness' and 'victorious consciousness' that is, a balance between analysis of 'the "outsides of people" (social structure, history, political realm and so on)" and 'the agency that lies within the "insides" of people" (Shahjahan 2005b: 700). Third, it has rituals and ceremonies to "reconnect", "reclaim", "respect" and "rename" our world' (Shahjahan 2005b: 702). Fourth, 'a spiritual way of knowing' can bring with it the imperative that knowing should produce healing, not just knowledge (Shahjahan 2005b: 702).

Correspondingly, I found that Nichiren Buddhism contributed to the creation of $\mathrm{He}$ rawe/Becoming Dress in three ways. First, it was a shared spiritual practice that Anahera and I used to connect, support and sustain us through our creative process. Second, it was a practice which facilitated our inner transformation and provided us with a framework in which to view how our individual lives and actions could have a positive effect on the transformation of society. Third, through adopting the positionality of Bodhisattvas of the Earth, who appear in the Buddhist scripture, the Lotus Sutra, Anahera and I applied this philosophy to our performative research project. I will now discuss each aspect in turn.

\section{A SHARED SPIRITUAL PRACTICE}

While there are numerous sects of Nichiren Buddhism, Anahera Gildea and I both practice as members of Soka Gakkai International (SGI), which is a lay Buddhist movement in which members integrate their Buddhist practice into their daily lives, following the Lotus Sutra based teachings of Nichiren Daishonin, a 13th-century Japanese Buddhist priest (Soka Gakkai International 2011). The Lotus Sutra is a sacred 
Buddhist text said to be originally preached by Shakyamuni Buddha, the founder of Buddhism and is believed to have lived in India sometime in the fourth century B.C.E (Soka Gakkai 2002: 581-2). When and where it was originally composed is unknown. However, it is 'not so much an integral work as a collection of religious texts, an anthology of sermons, stories and devotional manuals' (Watson 1993: pp. ix, xxii)

Within the SGI, the Lotus Sutra is seen as describing a cosmology in which all life is connected by a fundamental law of the universe that is the essence of life, and that enlightenment, the ability to perceive and live in rhythm with this law, is 'an imminent, inherent possibility possessed by all' (Ikeda 2001: 15). Nichiren Buddhism scholar and president of the SGI, Daisaku Ikeda explains that 'the fundamental law, which may be called the cosmic force of life, manifests itself in all individual life forms-humanity, nonhuman nature, and the stars of the firmament. Not mere isolated parts, individual life forms are integrated with the cosmic life force. In other words, the part is the whole, and the whole is the part' (Ikeda and Unger 2005: 6). In this way, 'enlightenment can...be understood in terms of a fusion between the human being, representing the individual's own power, and the cosmic life, representing external power' (Matsuoka 2005: 55). While it is beyond the scope of this thesis to conduct a comparison between Buddhism and Māori cosmology, it is worth mentioning at this juncture, as an illustration of why Anahera finds them to be allies, that Mätauranga Mãori is based on the worldview in which everything is interrelated and is imbued with a mauri (life force) and tapu (a spirituality) (Durie 2005: 18).

Sharon Elizabeth Smith explains that '...the core practices of the SGI centre on the Lotus Sutra and involve:

a) Faith: believing in the Gohonzon, a sacred scroll to which Nichiren Buddhists chant that is believed to embody the law of life...

b) Practice: chanting Nam-myoho-renge-kyo (daimoku)...the title of the Lotus Sutra and performing gongyo (a twice-daily ritual in which one recites portions of the Lotus Sutra and prayers). Also, sharing Buddhist teachings with others;

c) Study of the teachings of Nichiren and application of these in daily life. (S. E. Smith 2008: 165) 
Before discussing how Anahera and I used this practice in our performative research project, I will briefly review the development of the SGI because its unique history has influenced its practice of Nichiren Buddhism (Hickey 2010: 13). In 1928, Tsunesaburo Makiguchi was 57 when he, along with Josei Toda, embraced the teachings of Nichiren Buddhism (Gebert and Joffee 2007: 70). Makiguchi and Toda were elementary school teachers and had met in 1920. Makiguchi had begun to mentor the younger man, and they had formed a lifelong bond and collaborated to promote Makiguchi's educational theories (Gebert and Joffee 2007: 71). In 1930, Makiguchi and Toda started the Soka Kyoiku Gakkai (Value Creation Educational Society) to promote educational reform based on Makiguchi's theory of value-creation and Nichiren Buddhism in 1930. In developing their lay organisation, ${ }^{9}$ Makiguchi and Toda sought to create a modern religious movement that, from the standpoint of doctrine, adhered to the tenets of Nichiren Buddhism, while making them accessible to the people of the twentieth century and beyond. Soka Kyoiku Gakkai was not temple-based nor dependent on priests for instructions. Following Shakyamuni's and Nichiren's admonition to 'rely on the Law and not upon persons' (Daishonin 1999: 102) led Makiguchi and Toda to reading and studying Nichiren's writings themselves.

To promote their ideas, they established small discussion meetings 'offering experimental proof of the validity of the life of major good' (Ikeda 1999: 131). These meetings were small, friendly gatherings of members, their friends and neighbors, coming together to share their experiences in faith. Additionally, there were study meetings where Makiguchi, Toda and other lay leaders did presentations on various Buddhist concepts and principles for members and guests and gave guidance on religious faith (Miyata 2000: 66) (Gebert and Joffee 2007: 71) (Hurst 2000: 70). Their purpose was to strengthen the members' own understanding of Buddhism and strengthen their practice.

In July 1943 because of their refusal to participate in the cult of emperor worship and the rites of State Shinto that supported the military aggression of Japan, Makiguchi and Toda were imprisoned under the Peace Preservation law, which was used to suppress dissent (Gebert and Joffee 2007: 72). Makiguchi died in prison, but Toda was released on 3 July

\footnotetext{
${ }^{9}$ The relationship between the Soka Gakkai and the priesthood is too complex to delve into here. For a well-rounded discussion of this, see Jane Hurst, 'A Buddhist Reformation in the Twentieth Century: Causes and Implications of the Conflict between the Soka Gakkai and the Nichiren Shoshu Priesthood' in Global Citizens: The Soka Gakkai Buddhist Movement in the World (Oxford: Oxford University Press, 2000).
} 
1945. While imprisoned, Toda had what Kawada calls 'a momentous religious experience' (Kawada 2009: 105) and came to two important understandings through studying of the Lotus Sutra and chanting Nam-myoho-renge-kyo. The first was that the Buddha was life itself. In his essay 'Seimei ron' ('An Essay Concerning Life'), Toda explained his realisation; Miyata summarises it as follows: ${ }^{10}$

Life is eternal; it has existed in the past, exists now, and will exist always in the future, and continues in conformity with the law of cause and effect. Life exists not only in living beings, but also in the whole universe, which contains inanimate beings. In short the whole universe is life itself and is filled with life force. (Miyata 2000: 68)

Through equating Buddha with the concrete word 'life', Toda demystified the concept of Buddhahood, giving it a practical, concrete meaning (Ikeda et al. 2000: 23). A few months after this realisation, while chanting he recognised for the first time that he was a Bodhisattva of the Earth, who appear in the Lotus Sutra and will be discussed in detail later in this chapter.

After his release, he began rebuilding the organisation under the name of Soka Gakkai, seeking to broaden its membership and purpose (Josei Toda Website Committee 2011b). Based on his realisations in prison, Toda continued to develop his philosophy of life, working to apply religious faith and practice to the real problems of daily life. At the core of his philosophy was the concept of 'human revolution', which is the process of inner transformation that maximises meaning and value creation and builds an unfaltering view of life based on an understanding of the eternity of life (Josei Toda Website Committee 2011a).

After the death of Toda, his long-time disciple, Daisaku Ikeda, became the third president of the Soka Gakkai in 1960 (Ikeda 2000: viii). In 1975, Ikeda established Soka Gakkai International (SGI) and became its first president (Kawada 2009: 106). Ikeda, building on the legacy of Makiguchi and Toda, made the teachings of Nichiren Daishonin relevant to people in modern times and accessible worldwide through the establishment of organisations to promote these teachings. SGI is one of the most diverse international lay Buddhist associations in the world today (Strand 2008). While it is global, the SGI follows the Buddhist precept of rule of adapting to local customs,

10 This essay has not yet been translated into English. 
which means that consideration needs to be 'given to the times, the society, the culture and customs of the region in which Buddhism was being practiced' (Soka Gakkai International - USA 2011). On this point, Nichiren Daishonin writes, 'The meaning of this precept is that, so long as no seriously offensive act is involved, then even if one were to depart to some slight degree from the teachings of Buddhism, it would be better to avoid going against the manners and customs of the country' (Daishonin 1999: 72). It is in this way, while all members follow the teachings of Nichiren Daishonin, there is a space within the organisation for diversity of cultures and customs. Additionally, Ikeda promotes the concept of 'global citizenship' and states that its three essential elements are:

1. The wisdom to perceive the interconnectedness of all life and living.

2. The courage not to fear or deny difference; but to respect and strive to understand people of different cultures, and to grow from encounters with them.

3. The compassion to maintain an imaginative empathy that reaches beyond one's immediate surroundings and extends to those suffering in distant places. (Ikeda 1996: 26)

In her comparative thesis on diversity and race of two Buddhist sects in London, Smith finds that the SGI's promotion of this 'cosmopolitan identity (the "global citizen")...decentres whiteness' and challenges racism (S. E. Smith 2008: 228).

As noted above, Nichiren Buddhism is practice-based. While adherents argue that Buddhahood is inherent in all life, it needs to be awakened, activated and manifested; to do this requires continuous effort. Nichiren said, '[D]iligently polish your mirror day and night' (Daishonin 1999: 4). Thus, Nichiren Buddhists do morning and evening prayers in front of the Gohonzon; every member has a Gohonzon enshrined in his/her home. These prayers consist of chanting daimoku, or Nam-myobo-renge-kyo, and reciting gongyo, excerpts from the Lotus Sutra. These daily practices are not seen as separate from everyday life, but are used to transform life's problems and sufferings into causes for happiness. As Ikeda writes, 'Each aspect of an individual's life- the challenges of work, family, study, health, finances, relationships, etc.-provides a venue for the creation of value by manifesting one's Buddha nature and the chance to experience actual proof of the practice in the form of material and spiritual improvement and growth' (Ikeda 1999: 
132). In this way, chanting Nam-myoho-renge-kyo is a tool to transform the very foundation of one's life.

However, Nichiren Buddhism is a practice not only for oneself, but for others. Taking Toda's realisation that he is a Bodhisattva of the Earth as a prime point, the SGI is a gathering of Bodhisattvas of the Earth (Ikeda et al. 2001: 250). In modern terms, Ikeda describes a bodhisattva:

The bodhisattva, as a world citizen, is someone who is constantly challenging egotism and is engaged in the race to transform what Buddhism refers to as deluded impulses (represented by the three poisons of greed, anger and stupidity) into enlightenment. Bodhisattvas, refusing to be engulfed in the consumerism and materialism of contemporary society, embrace a noble spirit of serving others, and pledge to make this their mission in life. This process sets in motion a fundamental change in life orientation-from egotism to the desire to create happiness for oneself and others. (Ikeda 1999: 136)

To support the development of this bodhisattva spirit, SGI members participate in various SGI group activities; the primary one being the discussion meeting as started by Makiguchi and Toda. A discussion meeting consists of chanting daimoku and reciting gongyo, one member giving an experience in faith and another member presenting a short study on a Buddhist concept or principle, concluding with an open discussion. The discussion meeting 'provides a link between the inner-motivated and the shared' (Ikeda 1999: 132) and is 'an embodiment of cooperation between individual human beings on an equal basis' (Ikeda 1999: 132). The sharing of an experience is 'not describing knowledge imparted by others, but an actualized experience that comes from within, the outcome of an inner-motivated effort of self-transformation' (Ikeda 1999: 132). In this way, members learn how to practice for both themselves and for others.

In addition to our own personal ${ }^{11}$ practice of chanting daimoku and gongyo and attending regular SGI activities, Anahera and I met once a week at the Wellington centre to chant for the success of the project and to overcome whatever challenges we were facing in that regard. While our rehearsals were held at Victoria University, our meetings were at

\footnotetext{
${ }^{11}$ By personal, I do not mean solitary. It is personal in so far as I am personally responsible for deciding if, when and how much I chant. In additional to chanting with one's own family if they practice, SGI members frequently gather together in each other's homes to chant and support each other in their daily lives.
} 
my flat, where my Gohonzon is enshrined. Whenever leaving or arriving at a place where there is a Gohonzon, it is a common practice to do sansho, that is, to recite Nam-myoho-rengekyo three times slowly as a salutation to the Gohonzon which represents one's own life. So, all of our meetings started and ended with sansho. Additionally, if we felt the need, we would chant together for a while before getting to the business at hand.

\section{INNER AND SOCIETAL TRANSFORMATION}

Anahera and I approached our performative research project with the understanding that, for us, the success of He rawe/Becoming Dress hinged on our own inner transformations. Our belief in the necessity of inner transformation arose from our practice of both Buddhism and of Butoh; inner transformation and Butoh will be discussed in the next chapter. Further, as Buddhists, we also understood that our inner transformation and transformation on a societal level were interconnected.

Shahjahan writes of the necessity to problematise how the western view separates one's personal spiritual transformation from social transformation 'because it unconsciously assumes that there are two different domains of transformation' (Shahjahan 2005a: 233). The SGI and its practice of Nichiren Buddhism is based on the idea of societal transformation through individual spiritual transformation: 'The core philosophy of the SGI can be summed up by the concept of "human revolution." This is the idea that the self-motivated inner change of even a single individual positively affects the larger web of life' (Soka Gakkai 2006). As Nichiren Daishonin writes, "It [the Vimlalakirti Sutra] also states that, if the minds of living beings are impure, their land is impure, but if their minds are pure, so is their land. There are not two lands, pure or impure in themselves. The difference lies solely in the good or evil of our minds' (Daishonin 1999: 4). About this, Ikeda writes,

To extrapolate, if human life is sullied with greed, antagonism, and egoism, these evils will disturb the social environment and destroy the ecology. If, on the other hand, the human mind is filled with love, nonviolence, and reverence for nature, these good traits will harmonize human actions with the natural world and create a symbiotic social environment. Faith supplies the power enabling the good mind to triumph. (Ikeda and Unger 2006: 6) 
Elsewhere, Ikeda explains that this interaction between the individual, society and the environment is possible because of the Buddhist concept of dependent origination: 'Buddhism teaches that all forms of existence in both the natural and human realms are connected with one another through an interrelatedness of mutual dependence and assistance' (Ikeda 2005: 45). A related concept is the oneness, or non-duality, of life and its environment which sees life and its environment as 'two distinct phenomena but one in their fundamental essence' (Nichiren Shoshu International Center 1993: 70).

Based on these concepts, Nichiren writes in his treatise, 'On Establishing the Correct Teaching for the Peace of the Land', how individual happiness requires a peaceful society and how a peaceful society could only come about through the wise actions of people. For the word 'land', Nichiren uses the Chinese character that represents people rather than more widely used character that represents king, indicating that he believes that people rather than kings, governments or nations, are of the utmost importance (Kawada 2009: 114). Similarly, Ikeda argues for the transition from national to human sovereignty, finding that 'the question comes down to the question of how to develop the resources of character that can bravely challenge and wisely temper the seemingly overwhelming powers of official authority' (Ikeda 1995: 14).

While this discussion highlights the need for inner reformation, this is not to argue that there is no place for political consciousness and action. Nichiren had a life-long interest in politics and kept 'a vigilant eye' on the political currents of his time, 'so that he would know what kind of circumstances the people would be facing as a result of decisions made by the government' (Kobayashi 2008: 152). Kobayashi puts forth a balanced perspective on the relationship between spirituality - he uses the term 'religion'-and politics when he says that 'politics function to remove the external barriers to people's happiness, whereas it is the mission of religion to provide the means to remove the internal barriers' (Kobayashi 2008: 152). Anahera's and my performative research project achieved such a balance by utilising the spiritual practices of Nichiren Buddhism and Mätauranga Mäori in conjunction with decolonising and critical theories.

\section{BODHISATTVAS OF THE EARTH}

To bring the idea that spirituality — and its understanding of the world through a lens of interconnectedness - can positively influence individual and social change into the performance of He rawe/Becoming Dress, Anahera and I used the story of the Bodhisattvas 
of the Earth from the Lotus Sutra. In Chapter Fifteen, 'Emerging from the Earth', of the Lotus Sutra, Bodhisattvas of the Earth emerge from the empty space beneath the world: '...out of it emerged at the same instant immeasurable thousands, ten thousands, millions of bodhisattvas and mahasattvas ${ }^{12}$ (Watson 1993: 213). It is their appearance that prompts Maitreya, one of Shakyamuni's most learned and senior disciples, to ask, '[W] here have they come from, what causes and conditions bring them together' (Watson 1993: 216); the answer to which overturns their previous held beliefs about Shakyamuni. Up until this point, the hearers of Shakyamuni's preaching believe that he had attained enlightenment in this lifetime. However, when he reveals who the Bodhisattvas of the Earth are, he reveals that this, in fact, is not true:

These great bodhisattvas

for countless kalpas

have practiced the Buddha wisdom.

All have been converted by me;

I caused them to set their minds on the great way. (Watson 1993: 219)

Here then, Shakyamuni raises the question of when did he actually attain enlightenment by stating that he has been instructing these bodhisattvas for 'countless kalpas' and creates great uncertainty in the minds of Shakyamuni's disciples about the beliefs to which they are attached; that is, they believe that Shakyamuni had attained enlightenment in his present lifetime under the bodhi tree. In this way, the Bodhisattvas of the Earth can be seen as a catalyst and symbol of spiritual revolution (Ikeda et al. 2001: 196).

While volumes can be written on the multi-layered meanings of the Bodhisattvas of the Earth, for the purposes of this discussion, I will focus on five aspects:

1. Revolution in consciousness

2. Connectedness

3. Groundedness

4. Empowerment

5. Transformation

${ }^{12}$ Mahasattva is an honorific title for bodhisattvas, meaning a great being. 


\section{Revolution in consciousness}

The Lotus Sutra portrays the emergence of the Bodhisattvas of the Earth from the Earth as a momentous, ground-breaking, ground-shaking event. It describes their appearance as impressive and awe-inspiring: 'The bodies of these bodhisattvas were all golden in hue, with the thirty-two features and an immeasurable brightness' (Watson 1993: 213). Their mere existence shattered all the previously held beliefs about Shakyamuni, dealing 'a decisive blow to the foundation of an existing worldview' (Ikeda et al. 2001: 196).

Ikeda et. al. suggest that the Bodhisattvas of the Earth both symbolise and are the catalyst for a revolution in consciousness (Ikeda et al. 2001: 195). To affect a change in consciousness, they assert that it is first necessary to upset attachments and arouse doubts, by 'causing uncertainty in people's minds about the ideas to which they have been attached' and '[h]aving doubt cast on the correctness of their current beliefs allows them to open their eyes to a higher plane of awareness' (Ikeda et al. 2001: 195). It was our intention through the creation and performance of He rawe/Becoming Dress to upset attachments and arouse doubts to generally held beliefs about gender and colonisation. Have women really come that far? What is the difference in impact and repercussions of the mainstream narrative about women, their bodies and their sexuality when refracted through the lenses of indigeneity and white privilege? What alternative narratives can women construct for themselves around gender and colonisation?

\section{Connectedness}

As their name indicates, Bodhisattvas of the Earth are beings of the Earth and as such, they attest to the deep connection between life and its environment. As Toda writes in his essay 'On Compassion', the universe from which life arises is 'an entity of compassion' (Toda cited in Ikeda et al. 2001: 267). Ikeda finds that this compassion is the hallmark of the Bodhisattva of the Earth:

The compassion of the universe is the function of the Buddha. It is also the function of the inherent world of Bodhisattva, the power of the Bodhisattva of the Earth. Therefore, in a general sense, all living things in the universe are sacred Bodhisattvas of the Earth; whereas in a specific sense, Bodhisattvas of the Earth refers to those awakened to this law of life. (Ikeda et al. 2001: 267) 
Whereas western thought is based on dualisms (Plumwood 1993: 443) that are hierarchal relationships that are unequal and mutually exclusive, Bodhisattvas of the Earth express a worldview of interconnectedness and interdependency. Through adapting the positionality of a Bodhisattva of the Earth ourselves, Anahera and I had hoped to be able to find our way through the dualistic relationship of indigene and coloniser.

\section{Groundedness}

Bodhisattvas of the Earth are grounded in the realities of daily life, while infusing it with the wisdom and compassion of the Mystic Law. ${ }^{13}$ In fact, as discussed above, they are the catalyst for Shakyamuni to reveal his true identity as the Eternal Buddha. As Kanno points out, this revelation also redefines the meaning of the saha ${ }^{-14}$ world (Kanno 2007: 193). In the Lotus Sutra, when Shakyamuni discloses that he attained enlightenment in the distant past and is continuously present in the sahā world-'I am always here,/but through my transcendental powers/I make it so that living beings in their befuddlement/do not see me even when close by'(Watson 1993: 229)—-he is clarifying that the pure land of the Buddha and the saha world are one and the same. Bodhisattvas of the Earth have taken a vow to be reborn into the $s a b \bar{a}$ world with the purpose of transforming it from a place of suffering into a place 'where living beings enjoy themselves at ease' (Watson 1993: 230). The various descriptions of them in the Lotus Sutra emphasise the qualities that are needed to undertake such work:

Firm in the power of will and concentration,

With constant diligence seeking wisdom,

They expound various wonderful doctrines

And their minds are without fear. (Watson 1993: 222)

And:

They are clever at difficult questions and answers,

Their minds know no fear.

They have cultivated a persevering mind,

Upright in dignity and virtue. (Watson 1993: 223)

\footnotetext{
${ }^{13}$ Mystic Law is another way of referring to the fundamental law of the universe that is seen by adherents as the essence of life.

${ }^{14}$ Sahā world refers to the world in which we live. Sahā means 'earth'.
} 
In addition to diligence, perseverance, courage and wisdom, by virtue of their vow, they also possess compassion, a deep sense of responsibility and a respect for life. As they emerge dancing forth from the Earth, they are clearly filled with vitality and joy. It was these qualities that Anahera and I strove to bring to both our process and performance. Just as the Bodhisattvas of the Earth are grounded in the saba world, our research was grounded in our daily lives; that is to say, that our approach arose from our own personal standpoints; that how we treated each other in the process of creation was not seen as divorced from the outcome; and that theorising about the project came from and fed back into our praxis.

\section{Empowerment}

Awakened to the true aspect of all phenomena, Bodhisattvas of the Earth are argued to be empowered, living lives based on the great power that lies at the depth of all life (Ikeda et al. 2001: 267). Their vow to spread the Mystic Law and lead all people to enlightenment is fundamentally a vow to cause all people to see the immenseness of their own lives for the foundation of all life is the eternal life of the universe.

As a result of Toda's realisation that he is a Bodhisattvas of the Earth, the Bodhisattvas of the Earth are not seen as super-human beings, but ordinary people who, by dedicating their lives to the Mystic Law, by basing their lives on compassion and respect, are able to establish a towering state of life that not only weathers all storms and challenges, but is able to transform them into causes for happiness. Theirs is not a mere intellectual understanding of the Mystic Law and the eternity of life; it is an embodied, lived experience. Ikeda explains:

By struggling against difficulties, we polish our clouded hearts and fuse with eternal life. We might think of it as gaining self-mastery. It's a matter of harmonizing one's life, as though tuning a musical instrument, with the eternal rhythm of the Mystic Law. It is a matter of fusing one's entire being with the eternal life of the cosmos. This is what it means to be a Bodhisattva of the Earth. (Ikeda et al. 2001: 259)

Through chanting Nam-myoho-renge-kyo and reciting gongyo every day, Anahera and I participate in the Ceremony in the Air and renew our vows as Bodhisattvas of the Earth. It is during the Ceremony in the Air that the Bodhisattvas of the Earth emerge. The 
Lotus Sutra begins in the historical reality of Shakyamuni conducting a dialogue with his followers on Eagle Peak near the city of Rajagriha in India, but in Chapter Ten, 'Emergence of the Treasure Tower', it moves into a 'cosmic world of vast dimensions' (Watson 1993: xiii, xvi) that is called the Ceremony in the Air. Then, in Chapter TwentyThree, 'Former Affairs of the Bodhisattva Medicine King', it returns to Eagle Peak. This progression from Eagle Peak to the Ceremony in the Air back to Eagle Peak is described as 'three assemblies in two places' (Ikeda et al. 2000: 92). According to Ikeda, the significance of this progression is that it represents the movement 'from reality prior to enlightenment to the state of enlightenment and then to reality after enlightenment' (Ikeda et al. 2000: 96); it is an 'interaction between the microcosm and the macrocosm' (Ikeda et al. 2000: 105). Further, in the Ceremony in the Air, Shakyamuni lifts the entire assembly into the air with him, teaching that he seeks to lift all living beings up to the same level as himself rather than looking down on them from above (Ikeda et al. 2000: 94).

It is in this way that twice a day Anahera and I participate in the 'three assemblies in two places', which represents our transition from reality to enlightenment and returning to reality, filled with wisdom and compassion, as this exchange between Ikeda and Saito clarifies:

Ikeda:... To 'rise in the air' means to elevate our state of life through our determined and unwavering faith. This is the significance of the sutra's progression from the first assembly on Eagle Peak to the Ceremony in the Air.

Saito: Then the subsequent progression from the Ceremony in the Air back to Eagle Peak represents returning to the reality of daily life and society and facing its challenges based on the life force of Buddhahood we have tapped through reciting the sutra and chanting Nam-myoho-renge-kyo. (Ikeda et al. 2000: 96-97)

To understand our daily recitation of gongyo as participating in the 'three assemblies in two places' is to 'provide us with the actual experience-not just a conceptual understanding — of the life of the universe' (Ikeda et al. 2000: 105). Our positionality as Bodhisattvas of the Earth is deeply embedded in our lives and provides us with tools to develop our wisdom, respect and compassion upon which we drew in the course of our performative research project. 


\section{Transformation}

Bodhisattvas of the Earth are seen as transformers. They seek to transform society through helping people see the greatness inherent in all life (Ikeda 2009: 97). They view all the circumstances of their lives as the appropriate conditions for accomplishing their task and therefore, take full responsibility for their lives, seeing obstacles and challenges as opportunities to bring forth the compassion and wisdom that lies at the depths of their lives and transform negative situations into ones that create value, promote personal and communal growth and become causes for happiness (Ikeda et al. 2001: 257-60). Not only do they hope that their transformative experiences serve to inspire others, but through the oneness of self and environment, they have a ripple effect out into their family, friends and wider community. As Ikeda has affirmed, 'A great inner revolution in just a single individual will help achieve a change in the destiny of a nation and, further, will enable a change in the destiny of all humankind' (Ikeda 2004: viii). It is this belief of inner and outer transformation that both inspired and underpinned the creation and development of He rawe/Becoming Dress.

To look at the colonial matrix of power from the perspective of a Bodhisattva of the Earth then would be to understand the colonial matrix of power as a manifestation of the fundamental darkness of life. While much can be written about the meaning of the concept of fundamental darkness, briefly it is ignorance of the inherent dignity of all human life and the inability, therefore, to have respect for all peoples (Yatomi 2006: 166). It is this fundamental darkness that gives rise to the 'base, self-centred human inclinations, such as greed, anger and foolishness' (Yatomi 2006: 2), which are known as the three poisons. Remembering that Mignolo finds that the domains of the colonial matrix of power are connected through capital, racism and knowledge (Mignolo 2007: 478), viewed through the lens of Nichiren Buddhism, the colonial matrix of power can be seen to arise out of greed, anger and foolishness and is the denial of the dignity of all human life. Anger in Buddhism is more akin to arrogance than to rage, though arrogance can give rise to violence; foolishness is holding a mistaken view of life.

However, Buddhism sees both fundamental darkness, or evil, and inherent Buddhahood, or good, as 'innate, inseparable aspects of life' (Yatomi 2006: 138). This is the oneness of good and evil. Yatomi explains, 'This teaching [oneness of good and evil], however, does not mean that evil is good, nor does it imply that the distinction between good and evil is irrelevant. Instead, it teaches us to perceive and triumph over evil inside-thereby 
conquering evil on the outside- through confidence in the universal goodness of life'(Yatomi 2006: 138). When viewed in this way, the decolonisation and the dismantling of the colonial matrix of power becomes as much about inner transformation as outer transformation. Yatomi writes, 'Buddhas accept their innate goodness without arrogance because they know all people share the same Buddha nature. Buddhas also recognize their innate evil without despair because they know they have the strength to overcome and control their negativity' (Yatomi 2006: 139). Decolonisation then requires not only the capacity to look inside one's heart and accept both the good and evil that resides there but the ability to overcome one's fundamental darkness. As stated above, the way to overcome fundamental darkness is 'through confidence in the universal goodness of life', or as Ikeda states, to 'rediscover the eternal sanctity and dignity' within one's own life (Ikeda 2008: 12). Awakening others to the greatness of life is the message of the Bodhisattvas of the Earth.

\section{CONCLUSION}

Nichiren Buddhism was one of the knowledge systems that underpinned the epistemological perspective that informed the development and performance of $\mathrm{He}$ rawe/Becoming Dress. Our inclusion of this spiritual practice functioned to counter the secular nature of western knowledge that is foreign to Māori and other indigenous people. Our use of Nichiren Buddhism also illustrated how a spiritual knowledge system can be used to enhance the academic research process. For He rawe/Becoming Dress, Anahera and I adopted the Bodhisattvas of the Earth as a multi-layered icon representing the ideas of revolution in consciousness, connectedness, groundedness, empowerment and transformation. Connecting the Bodhisattvas of the Earth to her Mãoritanga, Anahera writes,

When I think of the concept of the Bodhisattvas of the Earth, I automatically am transported to think of Papatüanuku [the land]. We are all born of the Earth and come through the Earth. As far as the character traits of a Bodhisattva of the Earth go, manaakitanga is central as it means to protect, respect and treasure all life and all people. This is exactly the mandate of the Bodhisattvas of the Earth...The emphasis is on the interconnectedness of people and land and so the lesson is about cherishing and preserving. (personal communication, 25 February 2011) 
While Nichiren Buddhism was an underpinning of He rawe/Becoming Dress, Butoh was the aesthetic that we used to create and perform it. The next chapter will discuss the bodybased knowledge system of Butoh. 
62 $\mid \mathrm{P}$ a g e 


\section{CHAPTER THREE}

Butoh

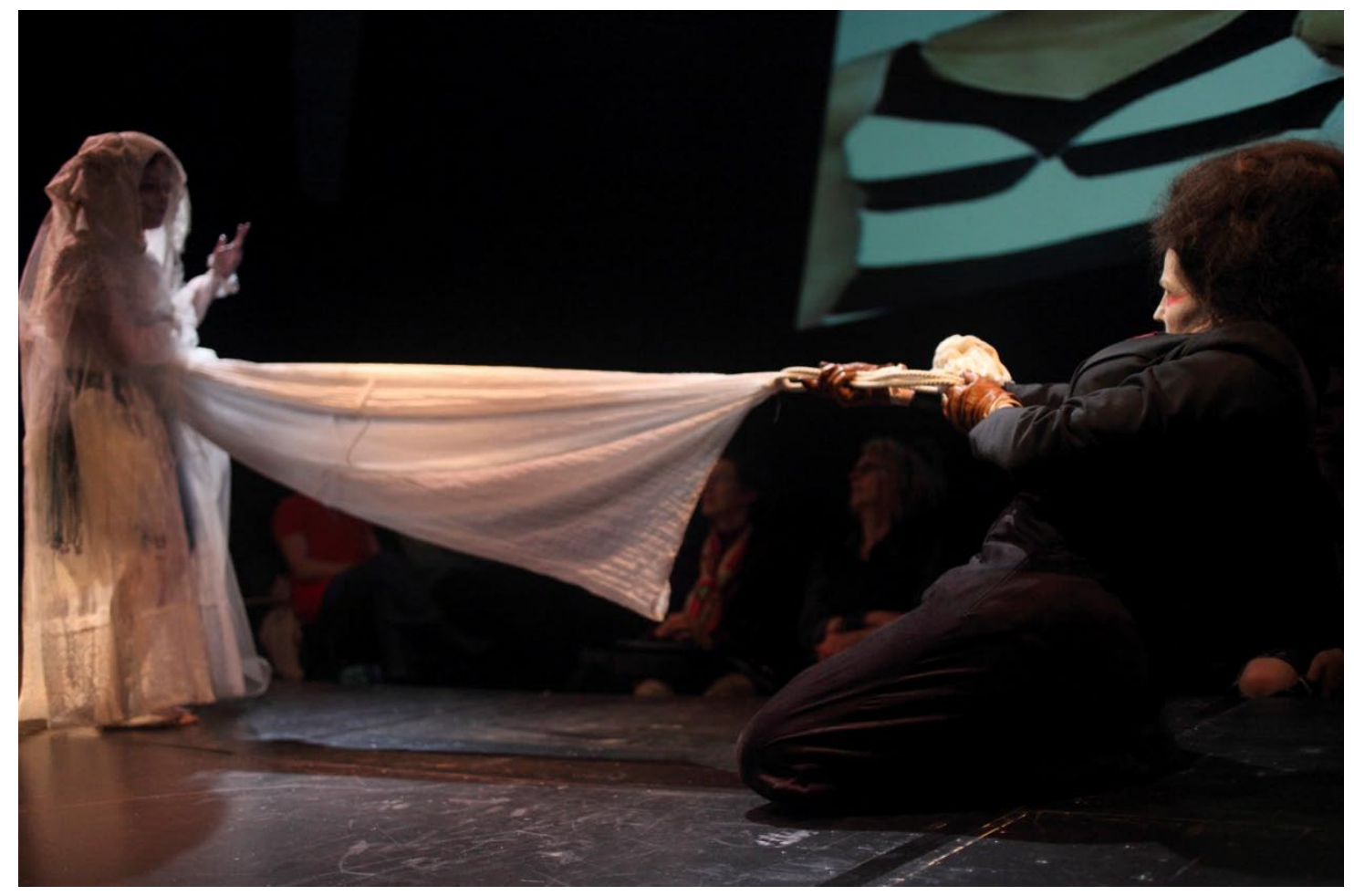


$64 \mid \mathrm{P}$ a g e 


\section{ANOTHER WAY OF KNOWING}

What Tatsumi Hijikata and Kazuo Ohno uncovered in their movement investigations called Butoh was local and global at the same time. They were responding to local conditions: the westernisation of Japan, World War II and the dropping of the atomic bombs, the renewal of the security treaty between U.S. and Japan, rural poverty, societal conformity and suppression of self, ethnic self-loathing, and the rise of a materialistic, consumer-oriented culture. ${ }^{15}$ These local conditions were an expression of larger, global issues: war and militarism, dominance and defeat, occupation and assimilation, materialism and technology, individuality and conformity, orientalism and exoticism, catastrophic loss and reclamation.

Hijikata and Ohno were searching for a way to illuminate the unseen, the hidden in Japanese society. What is remarkable about what Hijikata and Ohno did is not in the external outcomes or the specific content of their dances, it is the development of a process that allowed the performer to find the hidden levels in her/himself and her/his society. Toshiharu Kasai, a Professor of Clinical Psychology who has developed a Butoh dance method for psychosomatic exploration and integration, calls this 'body archaeology' and sees it as something that is unique to Butoh in relation to other dance styles (Kasai 1999: 310). As theatre and dance scholar Judith Hamera reflects, ‘...in doing so, they ultimately created a revisionist view of technical competence, one based not on faithful reproduction of traditional forms, but instead on fidelity to the essence of their psycho-social experience of their culture at this time' (Hamera 1990: 55).

This reflection points out that Butoh is not a technique to be learned; Hijikata wrote that he doesn't believe in 'a dance teaching method nor in controlling movement' (Hijikata 2002: 225). Thus, the skill required of a Butoh dancer is to find the essence of one's own 'psycho-social' experience within the context of one's own culture. In this way, Butoh is not a Japanese dance form. It is grounded in the experience of the dancer and his/her historical, material, social, political, cultural time and place. However, as Kasai emphasises the Butoh dancer does not seek to portray his/her 'internal experience into its visible manifestations' but rather seeks 'simply to experience it and allow this to arouse motion' (Kasai and Parsons 2003: 259). This arousal of motion is facilitated

${ }^{15}$ To examine the specific influences that led Butoh founders Tatsumi Hijikata and Kazuo Ohno is beyond the scope of this paper. Further, others-Sondra Fraleigh and Tamah Nakamura, in particular — have written extensively about these issues. 
through the finding of what I call Butoh Space. Butoh Space is not truly able to be defined through words and rational discourse, which is why it needs to be experienced through the body. Still, a definition, however incomplete, is needed. Therefore, I offer this working definition of Butoh Space: it is the lived experience where the boundaries between mind/body, self/others and self/environment are erased and from which it is possible to create authentic movement, where the quotidian experience of self, time and space is altered. Kasai uses the term 'body time' to describe what I have called Butoh Space: 'When the dancer transitions from 'social time' to the slower 'body time', s/he allows passive perception to direct movement, allowing stimuli to 'call' him or her in ways that most of us fail to hear and then respond to' (Kasai and Parsons 2003: 261). Kasai confirms my experience as a Butoh teacher that 'the well-trained expert' can discern when a dancer has found Butoh Space (Kasai and Parsons 2003: 259). To come into rhythm with 'body time' requires a slowing down, a quieting of the mind, a shift in consciousness. One way to achieve this is to literally move slowly (Kasai and Parsons 2003: 262). In this way, the performance of Butoh becomes about time-shifting; hence, Butoh performances are usually a juxtaposition of extremely slowly movements punctuated from time to time with extremely fast movements.

Butoh is an excavation of the dancer's body that seeks to free the body from its bondage. Ohno said that ' $[a]$ s long as the body maintains an existence marked by social experience, it cannot express the purity of the soul' (Viala and Sekine cited in Fraleigh and Nakamura 2006: 17). Ohno's reference to the soul points out that there is also a spiritual dimension to Butoh. This is clear from both Ohno's and Hijikata's writings. Hijikata wrote that his dance experience 'has been for me a marvelous spiritual journey' (Hijikata 2000a: 41).

Whether this spirituality is connected to a specific religion is a decision that each Butoh dancer makes. However, dance scholar Juliette Crump puts forth an interesting argument about Buddhist compassion and Butoh, clarifying her stance that many Buddhists regard their practice as a consciousness, not a religion, and that Japanese culture is Buddhist. (Crump 2006: 68). She argues that both Buddhism and Butoh have similar goals of transforming the world through changes of consciousness (Crump 2006: 62) and offers an alternative way of conceiving of the role of the Butoh performer. She conceives of the Butoh dancer as a modern-day Bodhisattva seeking to set others free from their suffering through a kinetic compassion (Crump 2006: 63). She cites how Hijikata 'did not acquiesce to the rural poverty that sent his sister into prostitution. By taking her into his 
body in performances-Hijikata writes of how his dead sister started living in his body (Hijikata 2000b: 58)—-he wanted to effect change' (Crump 2006: 64).

Crump's overall argument offers a reading of a Butoh performance that can be missed when the focus is on the dark and grotesque imagery of Butoh that often captivates the viewer. While I agree that her argument offers one way of conceptualising the role of the Butoh dancer, I think it is important to leave space for the spirituality that each Butoh dancer brings to his/her dance. For example, Kazuo Ohno was a devout Christian. However, as a Buddhist, I do place compassion at the centre of my dance, and as discussed in the preceding chapter on Nichiren Buddhism, the Buddhist concept of Bodhisattva of the Earth played a key role in He rawe/Becoming Dress.

Fraleigh and Nakamura find that the yin/yang polarity of Hijikata's and Ohno's aesthetics is what 'released the stunning energy that produced the original Ankoku Butoh [their italics]'(Fraleigh and Nakamura 2006: 31). Hijikata and Ohno first met in 1954 and collaborated until 1968 when 'they felt that there was no point in going any further' (Ohno and Ohno 2004: 137). In his writing about his father's dance, Yoshito Ohno, who not only danced with Hijikata, but spent his life collaborating and teaching with his father, describes Hijikata's and Ohno's different approaches to dance:

Tatsumi Hijikata, for instance, always stressed the importance of form in dance; he believed that once the structure and choreography had been established, the content would subsequently emerge itself. In his own words, 'Life catches up with form.' Kazuo, on the other hand, even to this very day, holds the diametrically opposite view: form comes of itself, only in so far as there is a spiritual content to begin with. (Ohno and Ohno 2004: 94)

This 'dramatic tension', as Yoshito called it, continues to exist among Butoh dancers.

Butoh dancer and theorist Paul Roquet finds that because Butoh was not well-accepted in Japan, Butoh performers began to travel to Europe and America as early as the 1970's (Roquet 2003: 45-46). The internationalisation of Butoh raised-and continues to raiseinteresting questions about Butoh and its relationship to its Japanese origins. There is no consensus on this point, as some argue for the 'Japaneseness' of Butoh, while others seek to make Butoh relevant to their own culture. Even the words of Hijikata and Ohno support both views and their development of Butoh was an interplay of western and 
Japanese influences. Roquet observes that, as the next generation of Butoh dancers learn Butoh from teachers in their home country, the 'Japaneseness' of Butoh becomes a nonissue (Roquet 2003: 48). Nonetheless, I agree with Butoh dancer Marie-Gabrielle Rotie's argument for a universal Butoh that is based on the individual body, allowing it to 'transcend any culturally specific reading', while, at the same time, calling for a greater understanding of Butoh's history and context (Roquet 2003: 20).

I learned Butoh not in Japan, but in Los Angeles and San Diego. Only one of my teachers is Japanese. None of my Butoh teachers, as far as I can recall, referenced the Japanese culture or aesthetics in their teaching of classes. Some talked about the history and development of Butoh, others did not. As a result, I had a smattering of knowledge about these things. I did not find that this hampered my skill as a Butoh performer, in part, because I felt that my teachers embodied this knowledge and were able to transmit the essence of Butoh to me through what I experienced with my body in their classes and workshops. Yet, having read much more extensively about Butoh for this thesis, I found that this textual knowledge has helped me become both a better Butoh dancer and teacher.

\section{THE DEVELOPMENT OF CRITICAL BUTOH}

As the discussion so far has suggested, there is a wide diversity among Butoh practitioners. Roquet observes that ' $[\mathrm{t}$ ] he genre stubbornly refuses to solidify into something solid, but it never quite breaks up completely either' (Roquet 2003: 9), and Crump sees that ' $[\mathrm{e}] \mathrm{ach}$ manifestation of butoh is different...Each group or performer connects with its Japanese butoh mentors but also sees increasing significance in individual and local concerns' (Crump 2006: 71). Of the earlier Japanese Butoh teachers, many urge their students to go out and establish their own schools and troupes (Cheng 2002: 209). As a result, Butoh dancers often study with a variety of teachers, picking and choosing what suits them - a state of affairs that makes sense given Butoh's grounding in body archaeology and arousal of movement from one's own psycho-social experience.

Furthermore, it is sometimes the case that Butoh performers, especially second generation American ones, come across Butoh after a result of their engagement in other performance and art forms and have a rich background and history grounded in these other practices that invariably influences their Butoh. Some intentionally utilise other practices with their Butoh work. For example, Shinichi Iova-Koga, whose background 
was in theatre and film, is well-known for using physical theatre and cinematic conventions in his Butoh work (Center for Cultural Innovation 2009).

So, it is not uncharacteristic in the dissemination of Butoh that my practice of Butoh is grounded in my life experience and that the development of what I have come to call Critical Butoh grew out of this praxis and is grounded in the specific circumstances and events of my shared artistic life with William Franco, my husband-a shared life that spans 26 years and that repeatedly crosses the borders between visual, media, dance and theatre arts. This is important to note because, as we have found, practitioners of these various arts don't necessarily conceive of their art practice the same way or speak the same language, and it is our artistic multi-linguality that gives us a somewhat unique creative positioning. Critical Butoh developed out of this positioning which, in turn, arose out of key events in our artistic practice. Additionally, remembering that Butoh demands the performer's own authentic expression, I, therefore, will present an abbreviated chronology of relevant key moments in our artistic lives, while foregrounding the elements that influenced the development of Critical Butoh and that will be discussed more extensively later in this chapter.

William and I met in 1984 in San Diego, CA. At that time, William was a still photographer, a master carpenter, a custom cabinetmaker and a Chicano activist. Frustrated that a photographer captured only one moment in time, he was looking to learn about video production. Having been a competitive gymnast and an aerialist in the circus, I was, at the time of our meeting, a feminist activist, a contemporary dancer and a mixed media artist. While I had not thought about video before, it seemed a natural progression in my development as an artist.

After having learned video production at San Diego City College and Cox Cable public access, we began our own production company, Speckled Gekko Productions, in 1987 and, until 2001, focused on producing our own experimental shorts, as well as doing industrial and corporate videos. Early on, we were fortunate to be asked to collaborate with established installation artists in San Diego to create the video components of their installations. In 1988, we worked on On a Mission for California Mission Daze (collaborators: James Asuna, David Avalos, James Luna, Deborah Small and William Weeks), which addressed the proposed sainthood of Father Junipero Serra (1713-1784), the founder of nine of the 22 California Catholic missions, from an indigenous standpoint. Then, in 1991, we worked again with Avalos and Small on the video, Ramona: 
birth of a mis-ce-ge-NATION, for Ramona's Bedroom which examined the issue of racial hierarchy and race-mixing in the US. Working on these projects served as our apprenticeship, learning the craft of art installation, observing the process of group collaboration and becoming aware of the power of activist art, as Avalos said about the collaborators of California Mission Daze, 'There's a belief in this group that art can affect people's consciousness in a way that has concrete benefits for society' (Leval 1992: 72).

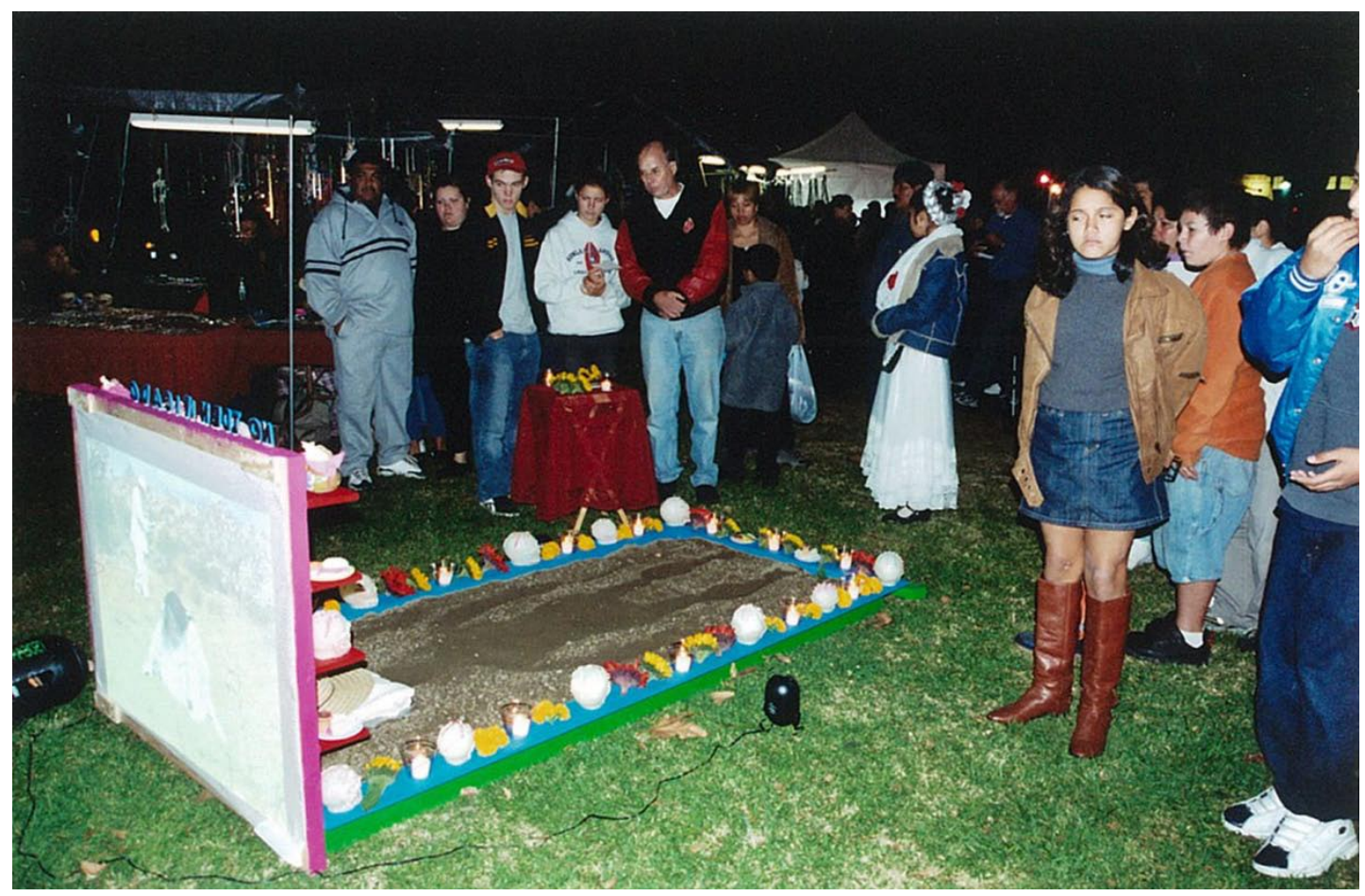

No Olvidado/Don't Forget Me, Highland Park, 200 1. (Photograph by William Franco)

In 2001, after a decade of working in video production, we began to create our own installations. For the first three years, we created offrendas (altars) as part of the public Dia de los Muertos (Day of the Dead) celebrations held by Art in the Park in the mixed race, working class neighbourhood of Highland Park, CA. Art in the Park sponsored these public celebrations of this Mexican holiday, where anyone could come and build an altar. It was art grounded in community, family, culture and history. It was also connected to the temporality of life and shunned the commercialisation of art; the altars were up for only one night and they weren't for sale. They were offerings.

While most altars were for family members or friends, our public Dia de los Muertos altars reconfigured the iconography of this tradition, inserting new media and addressing contemporary issues, e.g. the bombing of Afghanistan (Virtual Altar 2001), the war on 
terrorism (Quecholly - or how I learned to stop worrying and love weapons of mass destruction 2002), and (im)migration and the U.S.-Mexico border (No Olvidado/Don't Forget Me 2003). What we learned through these experiences was the importance-to us-of the context in which our work is presented. There had to be a dialogue between the location, the people who lived in the location, the people who came to see the art, the artwork and the artists. During these events, we did not merely present our altars. We talked with the people as they came and looked at the offrendas. We not only discussed the work, but more often than not, the conversations veered into other topics as well. A personal connection was made between us and our audience.

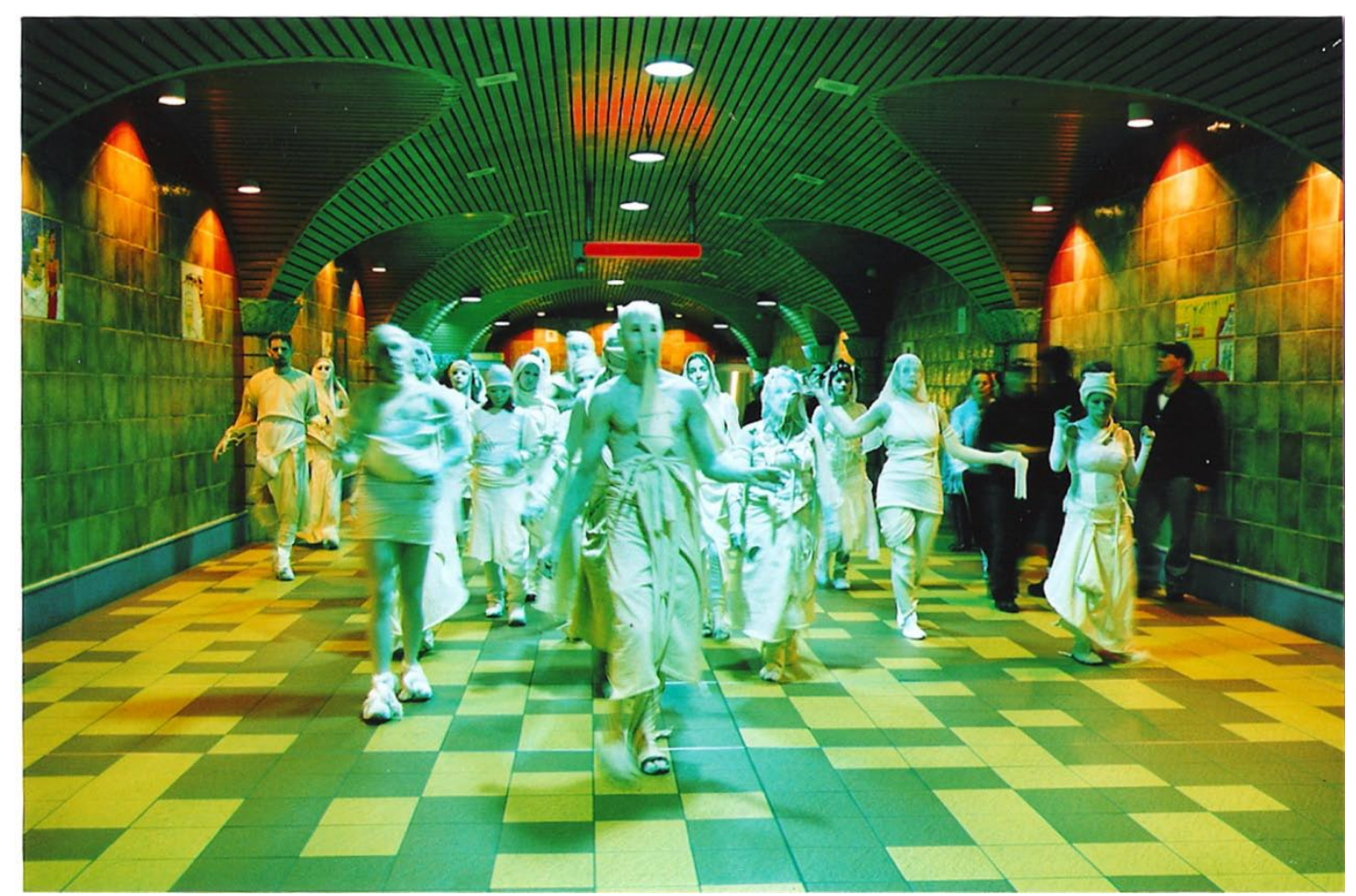

Corpus Delicti, Hollywood \& Vine subway station, 2003. (Photograph by William Franco)

In 1999, after a long absence due to chronic pain, I had begun dancing again. I took contact improvisation classes and workshops in making dances with Carmela Herman. As a result, in 2002, I presented work that combined improvisational dance and text at the Electric Lodge in Venice, CA and Angel's Gate in San Pedro, CA. Though William was not a dancer, we worked together on the production aspects of these performances.

So, by the time in 2002 when we met Joe Talkington, Corpus Delicti and Butoh, we already had developed a critical collaborative art practice. So, when Joe said he and Carla 
Melo were forming Corpus Delicti, an ad-hoc group of performers to do a Butohinspired procession at the upcoming 15 February 2003 anti-war protest in Hollywood, we were ready to join in.

On the day of the protest, we-about 25 of us—arrived just as a line of Los Angeles Police Department (LAPD) motorcycle cops came up to mark the end of the march, blocking the late-comers who wanted to join in. However, we were now moving Butohslow down the street and became a buffer between the police and the rest of the march, creating space for those late-comers to become part of the protest, foiling the LAPD's attempt to limit the size of the march. The empowerment I felt that day was extraordinary. First, a group of heretofore unacquainted individuals-afterwards, out of make-up, I couldn't identify the people with whom I had performed so intimatelytransformed into one 'being'. We moved as a whole, not as individuals. We were connected in Butoh Space. Second, we lived the power of art, the power of Butoh to literally intervene against the intentions and actions of an authoritarian power. Third, that intervention transformed the space where it took place. The street and the protest became more than what they were before we came. It became a site of transformation. As planned, we performed the stories of the protestors, the stories of the police, the stories of the Iraqi people yet to be invaded, and the stories of the millions of people who already had been.

After my introduction to Butoh through Joe Talkington and Corpus Delicti, I sought out other Butoh teachers, more firmly established in the Butoh idiom; the work of Corpus Delicti was considered to be Butoh-inspired. Since my purpose here is to provide the antecedents to the development of Critical Butoh, I will briefly discuss with whom I studied and how these training experiences shaped my understanding of Butoh.

It is important to note that, relative to other art forms, Butoh is rather under-researched and what research there is tends to focus on the development of Butoh within Japan. Very little has been written about non-Japanese practitioners. Of the teachers with whom I have studied, only Naoyuki Oguri and Diego Piñón have been the subjects of any academic writing. Meiling Cheng and Judith Hamera have written about Oguri, and, in 2009, Shakina Nayfack published his dissertation, Butoh Ritual Mexicano: An Ethnography of Dance, Transformation, and Community Redevelopment, on Piñón's Butoh Ritual Mexicano Dance Center that was established in Tlalpujahua, Michoacan, Mexico in 2002. 
Before discussing my training with Piñón, who had the greatest impact on my development as a Butoh practitioner, I will briefly mention my other teachers-Don McLeod, Oguri and Shinichi Iova-Koga. From McLeod, who studied with Butoh founder Kazuo Ohno among others, I learned how to base movement on images; how to transform and become other; how to release my body from my habitual gestures and preferred ways of moving; and how to use body distortions to awaken and release the mind and body. McLeod also thought it was important for his students to develop a better understanding of the development of Butoh. To that end, he showed rare videos of Japanese Butoh performances and interviews with key Butoh artists and engaged in discussions about the meaning and history of Butoh. Oguri, who had studied briefly with Butoh founder Tatsumi Hijikata, traces his lineage back to Min Tanaka and his school of kinetic training (Cheng 2002: 206). From Oguri, I learned a useful set of body conditioning and sensory exercises that I use as one of the foundations for my own workouts and classes. Koga had studied extensively with Hiroko and Koichi Tamano, who were members of Hijikata's company (Inkboat 2010). Therefore, Koga's workshops focused on the forms of Butoh, learning the body shapes that are distinctly Butoh. As a dancer, I enjoyed the discipline that was required to find these shapes and I also understood how finding these shapes liberated the body and erased its habits. Yet the most important thing that I took away from my workshops with Shinichi was that, as a performer, I clearly agree with Ohno that form follows spirit.

Piñón is the founder of Butoh Ritual Mexicano (BRM). In addition to his training in Butoh, with such teachers as Natsu Nakajima, Kazuo Ohno, Yoshito Ohno, Min Tanaka, Hisako Horikawa and Mitsuyo Uesugi, Piñón also draws upon his 25 years of research in Mexican energetic (indigenous) traditions, ritual dance, modern dance and contemporary theatre. In his thesis on BRM, Nayfack describes BRM as a 'fusion of Japanese aesthetic elements and Indigenous Mexican ritual structure, built upon Piñón's work in Japan and his years of training in Huichol traditions from central and western Mexico' (Nayfack 2009: 6). On his website, Piñón describes the mission of BRM as such:

As human beings used the energy of nature to survive, they created the first primitive forms of movement. In the Butoh dance we relive the sense of these primitive forms as a way to rescue all the lost parts of the human being. Butoh questions our habitual actions, expectations, and judgments. 
Butoh challenges us to awaken and explore all human qualities ranging from the subtle to the outrageous, both beautiful and ugly. Butoh seeks the emergence of the deeper self, to touch if only for a moment, the inexplicable matter of the human soul. Through this process of transforming our daily life by transforming our dance, we can offer more creative energy to our community. (Pinon 2011)

Learning Butoh from Piñón is like being led on a journey to an unknown destination by a knowledgeable guide. His preferred way of instruction is to hold workshops that last anywhere from two days to two weeks. I have attended three two-day workshops in 2003, 2004 and 2008. Additionally, I attended a public lecture and interviewed him in 2008. It is these experiences upon which I draw for the ensuing discussion on Piñón and BRM.

My other Butoh training focused on liberation through pushing physical limits, using the body as the impetus and site of internal transformation. There was no overt emotional or psychic content. There was a concentration on forms and physical presence. Shinichi used the metaphor of a painting. Before Butoh training, our bodies are completed paintings. In his view, in order for a new picture to be created, the already existing paint needs to be erased. This is the purpose of Butoh training. While Piñón also pushes the physical limits of the workshop participants, it is done with the intention of using this as a door to open their emotional and psychic spaces, and he works with overt emotional content in that he asks the participants to draw upon their own emotional world when engaging in the exercises. It is important to note that there is never a request or expectation of disclosure of what these emotional touch points might be; the training is not therapy. Piñón calls it 'anthropological research on ourselves'. In his April 2003 workshop, he explained that 'the basis of Butoh is to exchange energy from our collective spirits to resolve our personal shadows.' Piñón's Butoh training is designed to enable a dancer to confront his/her own darkness and not so much find the way to light, as to accept the totality of our complexity as human beings.

The relationship of the individual and the collective is important in Piñón's training. The task of confronting and cultivating oneself is the individual's responsibility, but its ultimate purpose is not for the individual, but in service for others. Furthermore, it is done within the presence of others to keep one honest, to have support for one's task and to support and witness the work of others. It creates a place of congruence between the individual and others. Such a perspective gives rise to a different understanding of 
performance, the relationship of the audience and the performers. Performances are not egocentric events where the performer asks the audience to look at him/her, but they become offerings, gifts the performer shares with the audience as gratitude for his/her life. Further, the dancer is seen as a vessel in service to others and his/her dance is to open the universal totality for the audience. Again, from his April 2003 workshop, Piñón, who has studied body-based energetic traditions around the world, said that the 'sacred meaning of dance is to use our bodies to communicate with the universe and other human beings to reach the universal, unconditional love.'

As a result of my training, I came to understand this about Butoh: Butoh awakens the energy of rebellion, to be against something which oppresses one's self, and seeks to use this energy as the force to propel a creative, transformative expression that breaks through the confines placed on one's body by one's self, family, education and society. Butoh seeks to liberate the mind from the way it habitually thinks, the body from the way it habitually moves and the self from how it habitually conceives of itself and its world.

\section{WHAT IS CRITICAL BUTOH?}

While William and I have been developing Critical Butoh through praxis over the last seven years, this is the first attempt to theorise about it. As such, my effort is tentative, searching to find its way and certainly not a final nor definitive offering. Following this, I will then discuss how Anahera and I used Critical Butoh to create He rawe/Becoming Dress.

Critical Butoh is a body-based methodology that draws upon Butoh, Butoh Ritual Mexicano, critical and indigenous theory, humanistic Buddhist philosophy and installation art. It is body-based in that the only way to learn Critical Butoh is through the bodily experience of finding Butoh Space. Critical Butoh is a method of inquiry that is committed to the following principles:

1. Critical Butoh is a body-based practice that is critical, decolonising and performative.

2. Critical Butoh is a body-based exploration of the Cultural Interface.

3. In Critical Butoh, process and product are inseparable.

4. Critical Butoh is strategic about what is created and where it is performed.

5. Critical Butoh is a collaborative, consensus-based practice. 
I will now discuss each of the principles of Critical Butoh and how they both draw upon and expand the already established ways of conceiving of Butoh.

\section{Critical Butoh is a body-based practice that is critical, decolonising and performative.}

Critical Butoh embodies criticality, decolonisation and performativity. Critical Butoh does (performativity) its critique, resistance and transformation (criticality) of the colonial matrix of power (decolonisation) through the use of the body-based aesthetic of Butoh. Environmental philosopher Ronnie Hawkins reviewed the recent research in neurology, biology, psychology and cognitive science to find that that linguistically-based rationality emerges out of the body and that 'our abstract concepts are largely derived from our experiences as embodied beings' (Hawkins 2009: 102). Such findings support the validity of this body-based practice.

\section{Critical Butoh is a body-based exploration of the Cultural Interface.}

The concept of the Cultural Interface was theorised by Torres Strait Islander and education researcher Martin Nakata in his book, Disciplining the Savages: Savaging the Disciplines. William and I had variously described our work as being cross-cultural, multicultural or intercultural; none of these terms satisfactorily described the work that we were undertaking. These terms not only did not accurately explain how we were working at the intersection of cultures, but they also felt to be too focused on cultural specificities rather than a broad understanding of the interaction of the cultural, historical, economic, social, political and personal. We also found that sometimes other artwork that was described by the terms cross-cultural, multicultural or intercultural was at odds with what we were seeking to achieve. In these cases, the artworks were by white artists who either appropriated concepts and iconography from other cultures and brought them into their own work without full understanding of the elements and their culture and without awareness of the implications of their appropriation, or who worked with artists of other cultures to serve their (the white artist's) vision of the world and thereby re-inscribing the historical relationship of Otherness. With regards to our own practice of Butoh, which did originate in another culture, as discussed earlier, it is a practice based on our own psycho-social experience within the context of our own culture. Whereas Nakata clarifies that the Cultural Interface is not limited to cultural specificities and that, in theorising about the Cultural Interface, he was seeking to rethink 
the space in which Torres Strait Islanders interact with others and understand 'the ways in which the specificities of the Islander experience are constituted in that space' (Nakata 2007: 196). Using the concept of the Cultural Interface in discussing our work signifies that we conceive of the broadest meaning of culture and that we seek to understand how we, individually and collectively, are constituted in that space.

Nakata describes the Cultural Interface as this:

The Cultural Interface is constituted by points of intersecting trajectories. It is a multi-layered and multi-dimensional space of dynamic relations constituted by the intersections of time, place, distance, different systems of thought, competing and contesting discourses within and between different knowledge traditions, and different systems of social, economic and political organisation. (Nakata 2007: 199)

He goes on to explain the connection between this theoretical space and the everyday:

All these elements cohere together at the Interface in the everyday to inform, constrain or enable what can be seen or not seen, what can be brought to the surface or sutured over, what can be said or not said, heard or not heard, understood or misunderstood, what knowledge can be accepted, rejected, legitimised or marginalised, or what actions can be taken or not taken on both individual and collective levels. (Nakata 2007: 199)

It is within this space that people make meaning of their lives and where they make decisions about their lives in the everyday on both personal and collective levels and how they do so is both 'constitutive and derivative of their position at the Interface' (Nakata 2007: 208).

By placing our Butoh work within the Cultural Interface, we provide a theoretical and lived context for our body archaeology. Our bodies are sites onto which these 'intersecting trajectories' are written. In her essay 'Performative Acts and Gender Constitution', gender theorist Judith Butler, drawing upon Beauvoir's and Ponty's understanding of the body as the embodiment of certain cultural and historical possibilities, argues that the body is a materiality that bears dramatic meaning; dramatic here means 'a continual and incessant materializing of possibilities' of available historical conventions (Butler 2002: 122). While acknowledging that the body is acted upon by 
historical social conventions, Butler also provides the body with agency and the ability to change through the use of the word 'dramatic'. (While it is near impossible to discuss such topics without giving the appearance of supporting the dualism of the mind-body split, it is important to remember that, within the context of the Butoh and Critical Butoh, this dualism does not exist.) Thus, Critical Butoh at the Cultural Interface not only seeks to mine how our bodies have been so written, but also through this recognition and understanding, seeks new ways of re-writing our bodies and by extension, the Cultural Interface.

How Critical Butoh works at the Cultural Interface is deeply influenced by William's and my years as Border Artists at the U.S.-Mexico Border. Gloria Anzaldúa, Chicana poet and cultural theorist, describes the Border as a place of nepantla, the Nahuatl word for 'an in-between state, that uncertain terrain one crosses when moving from one place to another, when changing from one class, race, or sexual position to another, when traveling from present identity to a new identity' (Anzaldua 1993: 110). Critical Butoh Space at the Cultural Interface is a space of remembering, acknowledging, accepting, encountering, contesting, shedding and transforming on both personal and collective levels.

The act of remembering is of particular significance. Rachel Buchanan, who has written about the 'forgotten' Māori history of her family, finds the appropriateness of a dementia wing being named for her grandmother, Rawinia Buchanan, and develops this event into an apt metaphor that is applicable beyond Aotearoa New Zealand: 'More than this, the dementia wing of our family history is a metaphor for the dementia wing of national history, for the way separate and intertwined Māori and Pākehā histories have been remembered and forgotten and reinvented, in complex cycles, since settlement of Aotearoa began' (Buchanan 2007: 174). Through our body archaeology at the Cultural Interface, as we (re)connect to our bodies, we reconnect to our personal histories and our family histories as we embody them and work to re-write them and the larger, grand narratives of which they are part and the cycle of remembering, forgetting, re-inventing and transforming. Others also recognise how Butoh can be used in such a context. Kate Parsons, who has worked with Kasai and Butoh Movement Therapy, is investigating the liberatory potential of Butoh with regards to the shared experiences of social groups (Kasai and Parsons 2003: 263). While Critical Butoh shares the liberatory capacity of Butoh, the goals of our artistic practice is primarily political rather than therapeutic. 
There is another aspect of Kasai's and Parsons' research that is relevant to this discussion of the Cultural Interface. Butoh uses what Kasai calls 'a diffused gaze' involving the passive perception of peripheral vision. It is a gaze that is well-known to the Japanese, but which is distinctly different than the focused gaze of westerners. The result of this passive perception is two-fold. First, the dancer 'by diffusing the extent to which s/he is "focusing" on the external world, s/he is better able to perceive the self, i.e. his/her own mind-body' and second, the diffused gaze 'invokes a perceptual pattern...in which the perceiver is inextricably part of the world around him/her'(Kasai and Parsons 2003: 260). Further, Kasai and Parsons suggest that there is a connection between the physical gaze and cultural/philosophical orientation (Kasai and Parsons 2003: 261).

\section{In Critical Butoh, process and product are inseparable.}

As our purpose is to transform ourselves and society, we need to use processes that support this goal, not ones that re-inscribe western dualisms and existing power relationships on us and our work. Thus, we use our critical positioning coupled with principles of Buddhist philosophy to provide the foundation for our aesthetic and organisational decisions. In the Introduction, I discussed this critical positioning and in Chapter Two, I discussed the principles of Nichiren Buddhism. It is important to note that Critical Butoh does not require its practitioners to be Buddhists. Rather Critical Butoh embraces a Buddhist compassionate cosmology, recognising the interconnectedness of all life, oneness of life and environment, and an ethical orientation as the basis of individual liberation. Such a cosmology overcomes western dualisms and values the individual qualities of wisdom, compassion and courage.

As a practical guide, Critical Butoh uses Tsunesaburo Makiguchi's concepts of 'beauty, good and gain'. As previously discussed, Makiguchi was a Japanese educator and founder of the Soka Gakkai, a lay Buddhist organisation. Makiguchi placed the creation of value at the centre of human life and defined a happy life as one in which the individual is able to discover and utilise his/her capacity for creating value (Gebert and Joffee 2007: 66). Critiquing Japan's neo-Kantian's conception of value, Makiguchi saw value as the 'relational power of the object measured by the quantitative response of the subject' (Gebert and Joffee 2007: 73-74):

'Beauty' (and its opposite) is a measure of partial, sensory response within an individual. 'Gain' is the measure of a relationship that extends and expands the 
total vital experience of the individual ('loss' is that which shrinks and limits this). 'Good' is to the life of social collective what gain is to the life of the individual ('evil' is the societal equivalent of individual loss). Grounded in these definitions, Makiguchi's reordering of 'beauty', 'gain', and 'good'—which, taken together, constitute his understanding of 'value'-represents concentric circles of expansion from within the life of the individual to the life of the community. (Gebert and Joffee 2007: 74)

Critical Butoh seeks to create beauty, good and gain not only in its artistic product, but also in the processes that bring the product into being.

\section{Critical Butoh is strategic about what is created and where it is performed.}

The topics that our work addresses, of course, arise out of our and our collaborators' interests, but there is reflection on the wider and deeper meanings and implications of undertaking such a project. Again, there is no separation or conflict between individual and community; both are privileged. Similarly, we carefully consider the location, as in country and city, and the venue within that location not just with regards to aesthetics, logistics and marketing, but with regards to its place in the world, its history, economics, politics, culture and people. There has to be a congruity between the place and the work; they have to listen and reflect back to each other. The place and the work have to support each other and become more than they would be alone.

Because we find the sense of place is stronger in 'lived' locations rather than the black box of the theatre, much of our work, both installations and performances, has been sitespecific. Further, by selecting these types of locations our work reaches non-art audiences. However, recently we have been exploring how to translate the qualities of these types of performances into theatrical settings. We came to this path after becoming aware that if we want to become part of the larger societal discourse, our work needs to be presented in theatrical settings as well. Not to discuss this extensively, but one example is that work presented in public places is not reviewed. Reviews function not only to give legitimacy to the work of art, but also to bring it into the media universe.

Our critical strategies also consider what happens to the work when it enters the public arena. Within the capitalist system, works of art are commodified, regardless of the wishes of their creators. As it is nearly impossible to work outside of the capitalist 
market, we have sought to understand this drive towards commodification and develop strategies to minimise the commodification of our work. This is a fraught position, especially with regards to the financing of our projects. Financing is sorted on a project by project basis, depending on its size and the availability of funding sources. To date, while a few projects have received grants, most of our work has been self-financed through working non-art day jobs.

\section{Critical Butoh is a collaborative, consensus-based practice.}

Western society and culture is steeped in individualism. Western democracy is based on the rights of individuals. There is nothing wrong with nurturing the individual; as a product of such a society and culture, I value my sense of individuality and my internal belief in my ability to act freely as an individual. Yet I am also disturbed by the social and personal cost of this heightened individuality. Further, when engaging in work to transform society, there needs to be a sense of community, a way of valuing a 'we', not just an 'I'. To that end, Critical Butoh seeks to build community through its process of Butoh training and performance creation.

While the values of community have been a hallmark of Butoh (Fraleigh and Nakamura 2006: 39), it is hard to separate this aspect of Butoh from its origins in Japanese society, where Nakamura observes that 'Butoh is communal only because it is in Japan' (Nakamura 2007: 7). Still, these values are present in Butoh and the challenge for western practitioners is how to hold on to them, how to support them in our practice, how to use our Butoh practice to overcome our conditioned tendency to privilege the individual over community, so that we may truly dance and heal what Kasai calls 'the community body' (Fraleigh and Nakamura 2006: 39).

To this end, Critical Butoh uses a collaborative, consensus-based approach. Collaborators are sought when only the merest idea of a project has formed, not once the creative vision has been seen and clarified. That is, collaborators are sought when the area of exploration has been broadly defined, when a vague question has arisen. Then, the task becomes finding people who are interested in such an investigation and, once found, the group explores the question and together shapes the direction of the exploration and develops the creative vision. 
To support this group process, Critical Butoh uses a consensus decision-making process. As an activist in San Diego and Los Angeles, I have had the benefit of receiving excellent training and practice in consensus decision-making; my first experience goes back to when I was part of the Womancare Collective in San Diego in 1981. Though it is beyond the scope and need of this thesis to discuss consensus decision-making in detail, a few key points need to be addressed. Consensus decision-making is a cooperative decisionmaking process where through a thorough collective exploration and examination of issues and questions with a problem-solving orientation, an integrated group will and decision emerges. Consensus decision-making is not voting nor is it compromise. It is a process that fosters the emergence of a group solution from individual positionings and desires. We have found that in a creative context, this process has enhanced creativity and vision, as well as empowerment and responsibility.

Our performances are devised and improvised, not choreographed. Not only does that bring an authenticity to the moment, but this approach supports and shifts the power dynamics of the performance. The power to decide the actualisation of the performance rests with all of the performers, not the choreographer or director. This form of improvised performance also enhances our desired relationship with our audiences. In an improvised performance, the audience is an active participant in the creation of the performance. We as performers respond to their presence and energy in the space at that moment in time. We do not come to the performance with an already fully crafted work to be presented to the audience; we create a space of meeting, a context in which we all come together and through our exchange, the performance comes into being.

In our experience of seeking out collaborators, we have found that we have always been in the position of training people to perform Butoh with us. This is partly due to the fact that there are not the number of Butoh dancers as there are ballet or contemporary dancers, but I think what speaks more directly to the point is that we don't always collaborate with dancers. For example, when we came to Aotearoa New Zealand to develop Nō Näianei, we were seeking Māori collaborators who were interested in a crosscultural exploration of the indigenous colonisation experience.

This situation of being teachers puts us in a position of power, which could undermine the collaborative and consensus-based nature of our work. There are two mechanisms we use to address this imbalance. First, we seek to impart whatever knowledge and skills we have to our collaborators in that we seek to make them equal to us as performers. 
Our function as teachers is to serve as guides to help the dancer learn to find Butoh Space, and once a dancer finds Butoh Space, the power of learning how to use that space and develop his/her capacity as a dancer and a performer rests with him/her, not us. Second, we recognise the differing knowledges and skill sets that our collaborators bring to the table and tailor the creative process to make use of all of our strengths and knowledge bases.

William and I developed Critical Butoh in Southern California. Coming to Aotearoa New Zealand gave us the opportunity to expand its context. As mentioned elsewhere, Nō Näianei, our first art project in Aotearoa New Zealand, used Critical Butoh. It was on this project that we introduced Anahera in Critical Butoh. On this, Anahera writes:

'Miki and William were my teachers of Butoh and were there to facilitate the emergence of [my] Māori Butoh, but this process was less like the imparting of knowledge from one vessel to another and more like an exchange of power between two parties...

...There is a basic exercise in Butoh called 'Slow Walk' which involves walking...in extreme slow motion. Apart from this being very difficult initially, I found each time I performed it I was beset with the feeling that my ancestors were walking with me; that I was shored up by a crowd of my Tipuna [ancestors], agreeing with the work I was doing and urging me on. I had the consistent sense that I was entering a ritualistic type of movement that resonated with me and found myself employing, almost without consciousness, both the wiri ${ }^{16}$ and the pukana $^{17}$ as I made my way across the room. It seems to me that through this movement I was able to issue a personal challenge, a baka of sorts, to both confront myself and to see if I intended any harm. This experience replayed itself multiple times until I felt myself stop resisting and accept that this would be how my practice of Butoh would begin. (personal communication, 25 February 2011)

Her experience of Butoh stood in contrast to her work in theatre: '... it had been a constant battle to find a place for me to stand, my turangawaewae. Theatre as I studied it at

\footnotetext{
${ }^{16}$ Wiri is a subtle side to side movement of the hand used in Māori kapa baka, which is a Māori customary performing art.

${ }^{17}$ Pukana is a widening of the eyes done when performing baka (Māori dance with rhymically shouted words) and waiata (songs) to emphasise certain words.
} 
university was heavily dominated by Europe and European thought—especially male European thought' (personal communication, 25 February 2011).

The collaborative relationship with Anahera continued with the development of $\mathrm{He}$ rawe/Becoming Dress.

\section{CRITICAL BUTOH AND HE RAWE/BECOMING DRESS}

While the DVD of He rawe/Becoming Dress can show Butoh as performance, it cannot convey the process that went into creating it. To provide some insight into the physical aspect of creating He rawe/Becoming Dress, I will discuss three Butoh exercises that Anahera and I did as part of our body archaeology to uncover our characters. The way Anahera and I practice Butoh and develop our performances is to devise Butoh exercises that are appropriate to what we are investigating; other practitioners may do it differently. I have studied with a variety of Butoh teachers, as well as having a long history in modern dance and contact improvisation; Anahera has an extensive theatrical background. We bring all these things into the mix, but ground them in the aesthetic of Butoh. Therefore, when I say, 'We did three Butoh exercises,' I mean we came up with these exercises as a way to further our investigation.

The first was done after we had decided what characters we wanted to be. We wanted to deepen our understanding of how they would move through space. To this end, we decided to experiment and find from which part of our bodies each character's movement originated.

The second was a three part exercise. To begin, we searched for a bird that represented the essence of each character. We then picked one character and her bird with which to work. For this second part of the exercise, we took twenty minutes to be this bird, from egg to death. In Butoh, we do not act out; we become. This exploration allowed us to impress the being and physicality of the bird on our own bodies. After this, we then returned to the character and explored her movements with the physical memory of the bird still held in our bodies.

Our third exercise involved using Butoh-fu. Butoh researchers Sondra Fraleigh and Tamah Nakamura describe Butoh-fu as 'visual/poetic images used as the basis for Butoh movement and gestures; they are sometimes referred to as notation used to guide the 
dancer or inspire dance movement and choreography' (Fraleigh and Nakamura 2006: 54). They do not illustrate a specific movement or gesture, but rather capture an essence to be discovered in the movement. Anahera and I decided to develop our own Butoh-fu for He rawe/Becoming Dress. To this end, we spent a day going through old Adbuster magazines and Dunbar \& Sloane auction catalogues. Our Butoh-fu can be divided into three types. The first set belong to each character pairing and suggest the shared space that they inhabit. The second capture a shared essence of one of Anahera's characters and one of mine, though they do not share the performance space at the same time. The third illustrate for us colonisation and being a woman. We also assigned a piece of text to each image. I then scanned the images, organised them accordingly and printed them out for us to use during our rehearsals. These Butoh-fu are in Appendix 1.

\section{CONCLUSION}

Our decision to utilise a body-based knowledge system to explore colonisation, gender and working across the hyphen acknowledges that our abstract thinking arises out of our experience as embodied beings. Anahera and I were able to use Butoh's body archaeology and explore our own unique trajectories within the Cultural Interface, as well as the intersection of those paths. Our use of Butoh as a tool of critical and decolonising analysis has expanded the application of this body-based aesthetic and led to the theorising of Critical Butoh for the first time.

While the purpose of this chapter was to discuss Butoh as a way of knowing, I would like to briefly mention something about the aesthetic aspect of a Butoh performance. Broadly speaking, a Butoh performance has the qualities of non-linearity, time-shifting, shapeshifting, beingness and nothingness. The Butoh performer's movements are suggestive of things coming into being, decaying and disappearing into nothingness. The Butoh performer's body tries to hold conflicting states of being in the same moment. When working with other Butoh performers, there are moments of connection, consonance and counterpoint.

The next chapter is an examination of Anahera's and my collaborative process, focusing on the dialogical process rather than the physicality of creating a Butoh piece. While Butoh is a body-based practice, both Ohno and Hijikata used words to develop their performances. Yoshito Ohno describes his father's creative process: '...Kazuo delves into his creative powers long before setting foot in the workshop studio to prepare the 
framework for a performance. He does so with pen and paper, by continually writing down his thoughts and reflections' (Ohno and Ohno 2004: 9). Through Kazuo Ohno's 'persistent jotting down, erasing and revising of notes', he is able to 'mine the body's many different strata: physical, emotional, and spiritual' (Ohno and Ohno 2004: 11). Yoshito Ohno goes on to observe that '[i]t is simply inconceivable that he [would] create a dance without initially "excavating" his body with the written word' (Ohno and Ohno 2004: 11). Kurihara Nanako, who translated many of Hijikata's writings into English, says of Hijikata, 'Despite being a man of the body, words were essential to Hijikata' (Nanako 2000: 14). She goes on to say that a 'tremendous number of words surround his dance' (Nanako 2000: 14). Drawing on this lineage, Anahera and I, too, used words to excavate our bodies. However, while we both did keep written journals, our use of words took the form of dialogue with each other. It is these words that are presented and discussed in the next chapter. 
CHAPTER FOUR

Collaborative Process

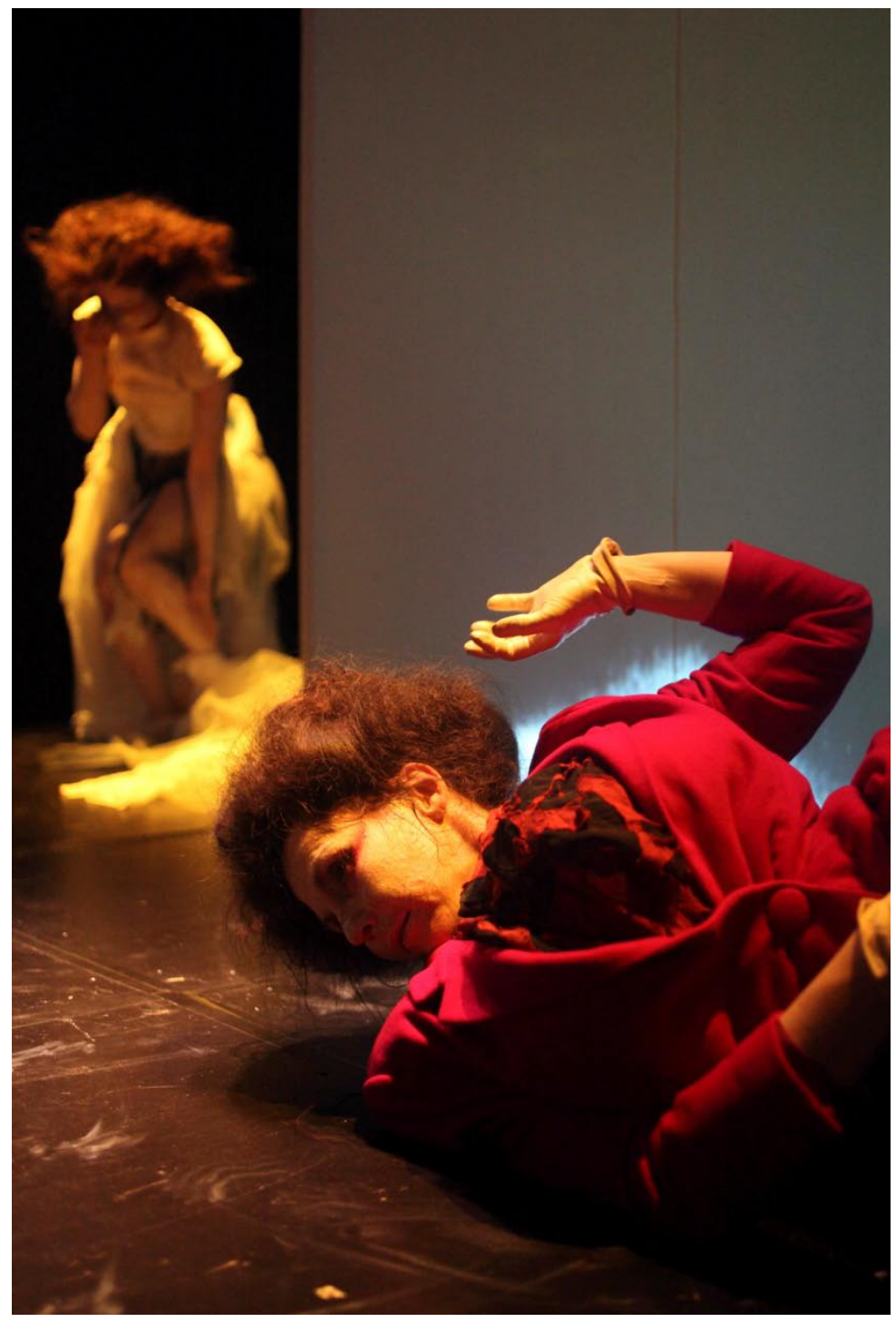


88 | P a g e 


\section{THE MAP AND THE STORY}

Conquergood uses Michel de Certeau's aphorism, 'what the map cuts up, the story cuts across', to describe the relationship between 'between two different domains of knowledge: one official, objective and abstract— "the map"; the other one practical, embodied, and popular—“the story."” (Conquergood 2002: 145) The map, which represents 'the dominant way of knowing in the academy', is 'that of empirical observation and critical analysis from a distanced perspective', 'a view from above the object of inquiry' (Conquergood 2002: 145). The story is 'another way of knowing that is grounded in active, intimate, hands-on participation and personal connection', 'a view from ground level' (Conquergood 2002: 145). Additionally, maps played an important role in colonisation. The opening sentence of this thesis is about how, according to Linda Tuhiwai Smith, indigenous space was colonised 'through the western construction of the concepts of line, centre and outside' (L. T. Smith 1999: 51-53). She goes on to find:

The 'line' is important because it is used to map territories, to survey land, to establish boundaries and to mark the limits of colonial space. The 'centre' is important because orientation to the centre was an orientation to the system of power. The 'outside' is important because it positioned territory and people in an oppositional relation to the colonial centre. (L. T. Smith 1999: 53)

In this way, the metaphor of map and story illustrates how the construction of the different domains of knowing and different expressions of that knowing are tied into colonisation and the colonial matrix of power.

The preceding chapters have been a 'map' that has located the positions of the key landmarks of the epistemological mix and perspectives that Anahera and I used in the creation and performance of He rawe/Becoming Dress. These chapters have focused on 'knowing about' (Conquergood 2002: 146). This chapter will tell 'the story', the 'knowing how' (Conquergood 2002: 146). Reclaiming the story as a way of sharing knowledge is very much part of the decolonisation of western knowledge (Swadener and Mutua 2008: 39). In her discussion of the tool of testimonio, the telling of stories of collective struggles, Linda Tuhiwai Smith finds that ' $[\mathrm{e}] \mathrm{mbedded}$ in these stories are the ways of knowing, deep metaphors, and motivational drivers that inspire transformative praxis' (L. T. Smith 2005: 89). This use of telling one's story as a way to 'inspire transformative praxis' is the underpinning of this chapter. For me, the telling of one's story has roots in my Buddhist 
practice in the SGI. As discussed in the chapter on Nichiren Buddhism, one of our primary activities is the sharing of members' experiences as a way of showing how the practice works and as a way of 'developing a shared sense of confidence and empowerment' in the practice (Ikeda 1999: 132).

At the core of Anahera's and my performative research project was the question, 'How do we as women decolonise ourselves?' To answer this question we employed a variety of knowledge systems: western knowledge, Critical Butoh, Nichiren Buddhism and Mātauranga Māori. In the preceding chapters, I discussed how their differing lenses provide a multi-dimensional look at colonisation and decolonisation. From a variety of scholars and researchers who have used the analytical tools of western knowledge to reflect back on itself came the concepts of criticality, colonial matrix of power, dualisms, performativity, working the hyphen, double-consciousness and the aesthetic. Critical Butoh's body archaeology at the Cultural Interface excavated the psycho-social aspects as embedded in the body. From Nichiren Buddhism came the Bodhisattvas of the Earth, who base their lives on the belief in the Buddhahood of all living beings and Nam-myohorenge-kyo, the true aspect of all phenomena. They perceive human suffering as arising from the three poisons of greed, anger and foolishness and strive to bring about inner and societal transformation. To express these knowledges in this way is to draw a map of them.

However useful a map may be, it is only one way of conveying knowledge about a place. A traveler generally will seek other information about their destination, including firstperson accounts by the inhabitants and travelers. The 'place' of He rawe/Becoming Dress is the place where decolonisation happened at the intersection of Anahera's and my lives, the intersection of the life of a Māori woman and the life of a white, American woman. This chapter is the first-person account of that place, the lived experience at ground level. As such, it will talk about the challenges we faced in navigating through this place and how we overcame them, while referencing landmarks on the map. It is the telling of our story to 'inspire transformative praxis'. The focus of this story is the performance of transformation, the doing of decolonisation. It is a weaving together of the doing of transforming on a personal level and the doing of creating a transformative public performance. The public performance could not be accomplished without the personal transformation; this is the inseparability of process and product in Critical Butoh. It also speaks of how decolonisation is a lived experience of transformation that must penetrate 
all aspects of being human—mind, body and spirit. Indeed, our epistemological mix included a mind-based knowledge system (western knowledge), a body-based one (Critical Butoh) and a spirit-based one (Nichiren Buddhism), as well as Mätauranga Mäori, indigenous knowledge. While these knowledges are not as separate and discreet as such a listing makes them to be, neither is how they came to bear on our performative project. These ways of knowing are deeply integrated into Anahera's and my lives; we perceive the world through all these lenses at once for our separate standpoints as a Māori woman and a white, American woman. Again, the difference between the map and the story.

For my discussion of our development process, I utilised transcriptions of our meetings and rehearsals. I recorded all our meetings and rehearsals, except for the all day intensives, on a digital audio recorder. After transferring the recordings to my computer, I transcribed them. In addition to these transcriptions, I also used material from the journals that both of us kept during the project. There were no guidelines about our personal journals - just that we both agreed to keep one and write down our thoughts and feelings as we went along. From 26 January to 10 April 2009, Anahera and I met three times a week for two-to-three hours. Our sessions were initially discussion meetings to work out our ideas, later becoming rehearsals as the ideas solidified and could be investigated physically. We had all day intensive rehearsals on 14 and 21 March, as well as a four-day intensive, 10-13 April, that was done in the theatre at Victoria University where the stage, lighting and projections were set up. The intensives were primarily physical investigations with little or no discussion. We also came together after the performance on 29 May 2009 to share and record our reflections on the project. Additionally, our Buddhist practice was an integral part of this whole process. We met once a week to chant together for an hour for the success of the project. We also used our own individual practice to support and facilitate our own human revolution which we needed to do in order to create a successful piece.

In our meetings and rehearsals, we not only talked with each other about our challenges, obstacles and breakthroughs and wrote about them in our journals, but we supported and inspired each other to keep moving forward. We both recognised that the success of our project hinged on both of us being able to achieve our individual transformation. Reading through the transcripts, I have identified three processes that allowed us to do this: 
1. Making an offer

2. Using non-directive dialogue

3. Creating strength from difference

Making an offer is used to develop devised and improvised performances. Anahera's and my backgrounds in performance gave us the facility to effectively use it in our meetings and rehearsals. In the making an offer process, the participants involved work together to co-create what happens and to do so, one person makes an offer, either verbal or physical, to which the other participants have to respond. Making an offer is based on respect for the other person and his/her ideas. There is no right or wrong. There is no one way of doing anything. The way forward is found through a shared doing.

Our meetings were rambling and unstructured, though we usually had specific tasks to do in each session. How we accomplished them was through non-directive dialogue and active listening. Anahera writes, "The kawa, or process, we created was to enable us to speak/perform/communicate from different perspectives yet not have them in opposition to each other'(personal communication, 25 February 2011). In addition to drawing upon our personal knowledge and experience-for Anahera, the bui (Māori meeting) and for me, consensus decision-making-we also drew upon our Nichiren Buddhist practice to create a shared discussion space: '...the practice of dialogue expresses a central tenet of Buddhism — faith in human beings, in their limitless dignity and potential as possessors and embodiments of universal truth' (SGI Quarterly Editorial Team 2007: para. 2). Shin Yatomi, who was a leader in the SGI-USA Study Department and frequently wrote for the SGI-USA publications, applies the 'three rules of preaching' that Shakyamuni expounded in Chapter Ten, 'The Teacher of the Law', of the Lotus Sutra, as guidelines for dialogue. The 'three rules of preaching' are: 'enter the Thus Come One's ${ }^{18}$ room, put on the Thus Come One's robe' and 'sit in the Thus Come One's seat' (Watson 1993: 166). Yatomi explains that 'to enter the Thus Come One's room' is 'to enter the "room" of compassion for all people'; that 'to put on Thus Come One's robe' is 'to put on the "robe" of gentleness and forbearance'; and that 'to sit in the Thus come One's seat' is 'to take the "seat" of emptiness of all phenomena' (Yatomi 2002: 5). 'To take the "seat" of emptiness of all phenomena' means 'to develop open-mindedness and wisdom' (Yatomi 2002: 6). Employing compassion, gentleness and forbearance, and open-mindedness and wisdom, Anahera and I truly strove to listen and understand the

${ }^{18}$ Thus Come One is another name for the Buddha. 
other, as well as to explain and clarify our reality for each other. Most importantly, however, no value judgments were made about the other, regardless of whatever she revealed about herself. We were committed to providing each other with a safe place in which to work.

Third, we created strength out of our differences. We chose to use our almost diametrically opposite ways of working to complement each other and to provide a counterbalance to our weaknesses, as discussed below. Similarly, our differing positions in relation to the hyphen were not a source of conflict, but a source of richness that yielded a multi-faceted, multi-layered outcome. Because working across the hyphen, in the broadest sense, means to learn to work with difference, this is not limited to only areas which clearly relate to the coloniser-indigene hyphen. Our ways of being and doing in the world are affected by our positions in relation to the hyphen in ways that are unknown and unseen.

As I look through the transcripts, I find it interesting that there was no explicit discussion about how we would negotiate the hyphen between us. We both approached our conversations from our own standpoints as women. It seems to me that we each chose to focus on explaining to the other what we wanted and needed to say about being women. The points of similarity and difference arose organically and were recognised, commented upon and integrated into He rawe/Becoming Dress. Because of the nature of Butoh performance, there was no need to construct one coherent, linear narrative. Because its depth and dimension is increased by counterpoint, Anahera and I could present our characters' differing realities simultaneously. Further, the performance of Butoh is not about finding definitive conclusions, but about being, unfolding, revealing, coming into being, dying away. The performance of Butoh is about being able to hold conflicting ideas and states of being at the same time. Because of this, we were free to listen and hear each other without the pressure to conform to one reality or another.

'Performative' describes our approach to the development of He rawe/Becoming Dress. As discussed in the Introduction, performativity uses the aesthetic not only to analyse what is, but to see and create transformation. Our performative approach employed the aesthetic to investigate how we each personally felt disempowered in our own lives as women, to search for ways to re-empower ourselves and to create a public presentation that expressed these things. Our performative approach informed the way we used criticality and decolonisation in our investigation. Both Anahera and I are university- 
educated and are knowledgeable about critical, feminist and decolonising theory. While we were able to utilise these theoretical tools, they were employed in an adaptive and improvisational way that was grounded in and responsive to our personal experience. Our personal experience was privileged; the theories were tools we chose to use- or not to use- - to assist us in digging out the relevant pieces of our lives for examination.

\section{THE STORY OF HE RAWE/BECOMING DRESS}

In this section, I support meeting summaries and commentary with excerpts from Anahera's and my journals and the transcripts of meetings and rehearsals to show how we came together not only to develop He rawe/Becoming Dress, but to support each other's 'performance' of decolonisation at the intersection of gender and the colonial matrix of power in the Cultural Interface. To assist with following the chronology of the development of He rawe/Becoming Dress and the character development, Appendix 2 is the Project Timeline and Appendix 3 is the Character Development Timeline.

\section{Meeting - 26 January 2009}

I was a bit nervous about our first project meeting. Even though Anahera and I had known each other since 2007 and had worked together on several collaborative art projects and various SGI Buddhist activities, I hadn't seen her for much of 2008. She had been busy writing her novel, and I was in my first year of my Ph.D. Also, working within the context of an academic research project added a level of formality to our collaboration that hadn't been there before. For example, it felt odd to present her with the consent form to sign. When engaging in research that involves people, Victoria University has an ethics approval process to protect the researcher, the participants and the university. Part of this protection is for participants to sign an informed consent before research begins. My ethics application, which includes my participant consent form is, in Appendix 4. Because I wanted to make sure all the formalities were covered, I had made a very simple agenda for this meeting. Anahera's response to this is illustrative of our working relationship:

Miki: As you can see, I wrote down little notes of what I thought we might cover...

Anahera: I would have expected nothing less. It's so well-organised. 
(Laughter)

Anahera: Let me write my own list on my blank sheet here. Wait. Maybe I'll draw a picture.

\section{(Laughter)}

As this suggests, Anahera and I have very different approaches to the creative process. She is non-directive, open, free-flowing. She just wants to get out all the ideas in whatever form or way they want to come. She welcomes chaos and happily finds her way from there into order. I, on the other hand, am very organised, linear, goal-oriented. I want to know the end point, then I can let the creative ideas flow in that direction. Our journals are a clear example this. While this could be a difficult working relationship, full of tension and conflict, Anahera and I actually work very well together because each of us respects the other one's process and sees how the other provides a needed counterweight to the other's deficiencies; so when we work together, we don't get bogged down in either chaos or organisation.

After covering off the 'boring bits' - the consent form, project deliverables and performance logistics - we roamed freely through the territory of women and gender, randomly pointing out interesting landmarks to one another. We explored how we might generate movement from written texts, including relevant academic and popular reading, poetry and literature, as well as the oral texts of our own personal and family histories. These last two generated topics and ideas that suggested fertile places to cultivate, as well as illuminating dialogue about ourselves and our families; this discussion already illustrating how we were looking at the same terrain but from different standpoints, suggesting how this 'dual vision' would inform the development of the project.

The two broad, yet intersecting topics that emerged were sexuality and body image; both came to be key drivers of the development of our characters for He rawe/Becoming Dress. The landmark, which anchored our exploration of sexuality, was a quotation by Daisaku Ikeda from his dialogue with British historian Arnold Toynbee that I had shared with Anahera. The underlying concept of Ikeda's and Toynbee's dialogue, a dialogue between an East Asian Buddhist scholar and western intellectual, a dialogue across cultures and disciplines, resonated with Anahera's and my project. The quotations provide a Buddhist frame to the issue of sexuality: 


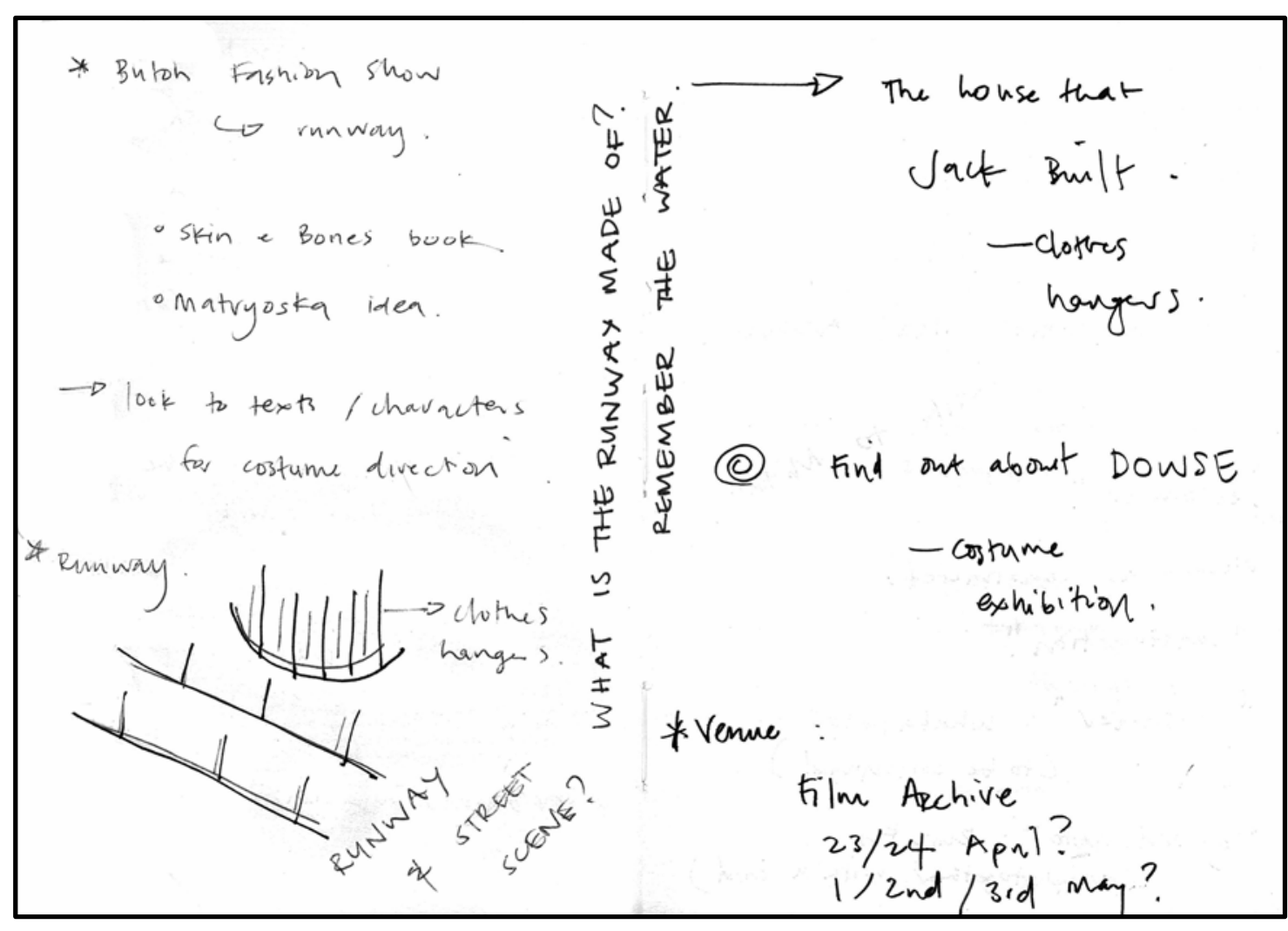

Scan of Anahera's Journal (above); scan of my journal (below)

26 Vomuang 09

Todon was our firt merting - Na \& 1.I wa pa nones - not so nunch about Na, but about tPa projict and briy able to conmunicate ufe drcivrbblar-makiy sur that the formal dataib - like ofe consunt form - were dakan care of Also, abont aper suf / otter refloufloiRno ste might farl sbont gez f ot ne a kno we midt do it - but it de wast so wall - I gaal so suppontad L this

96 | P a g e 
IKEDA: ...I suspect that the loss of sexual morality and the absence of love in sex is part of the trend to think of life in terms of material values only: sex is being converted into nothing but a means of pleasure completely divorced from spirituality. I am convinced that until we analyze this trend in the light of its fundamental causes, we will never arrive at a solution. (Toynbee et al. 1989: 18)

IKEDA: I see its true cause in a weakening of the inner life force of life. This weakening has been brought on by the oppressive influences of modern material civilization. The vibrant spirit of love required to establish sex in its proper place in human life cannot be born of enfeebled life force... The way to restore humanity to sexual behavior is either to eliminate exterior forces that oppress the spirit or to develop, activate, and strengthen the inner force that is the support and generating origin of life. (Toynbee et al. 1989: 20)

Below is an excerpt of Anahera's and my discussion around these quotations.

Anahera: The thing that Sensei [lkeda] says that it's a trend to think of things in terms of material values only... 'Sex is being converted into nothing but a means of pleasure completely divorced from spirituality. I am convinced that until we analyze this trend in the light of its fundamental causes, we will never arrive at a solution.' I love that. I really want to understand that. I think right now it is a fundamental question. I know so many people grappling with this exact issue actually. Women. Especially women 'cause they have come from a background where it's more socially unacceptable for them to consider sex as something outside of a marital situation or a relationship. Still.

Miki: Yet their bodies are constantly being objectified for sexual pleasure...

Anahera: Absolutely. And there's a huge discussion going on around people I know, especially women, about pornography... It's a really interesting discussion because it divorces people from any kind of spiritual aspect. It's entirely physical or animalistic.

This exchange points to how our Buddhist practice will influence not only our way of looking at and analysing the topics we raise, but also how we frame the questions we ask. It expresses our shared commitment to connecting the spiritual to the material in both our theory and praxis. In addition to being a central tenet of Buddhism, both Butoh and 
the indigenous worldview are premised on the indivisibility of the material and the spiritual, the body and the spirit. We thus begin to find articulation for what becomes one of our central questions: how do we as women integrate and express our lives as both sexual and spiritual beings while living in a world that isolates, objectifies and fetishises our bodies?

When we discuss body image, we mine the different ways in which we judge and objectify our own bodies and how we respond to those judgments. This exchange also shows how body image and sexuality are intimately connected.

Anahera: Body image is also interesting. And the lessons handed on via my mother about body image via her mother about body image via her...you know what I mean?

One of the key things for me when I think about my role as a woman is to do with childbirth and childbearing and your changed image and your changed body image, my body image prior to having a child and post having a child, and that's very current. When I think of women historically, I think about their childbearing selves because I'm the result of all of that childbearing self.

Miki: I agree. I think there's some things of interest in talking about fertility and infertility, and women's aging body, menopause and post menopause; as being an older, childless woman, what do these things mean for me.

There's also the ever-present dieting in women's lives and eating disorders.

Anahera: There's also what we learn about being sexual beings and our bodies. A real external objectification of our bodies. We learn that our bodies are being looked at constantly. I may live inside it, but I need to guard and be aware of what it is viewed as all the time.

Here, we map out four different angles of viewing body image that come to be incorporated into He rawe/Becoming Dress. Anahera's mother character grows directly out of her interest in women's childbearing selves. The question of older women becomes part of the subtext of the video of the 'bodyscapes' of real women that is projected on the centre screen. The distorted views of our bodies as expressed by obsessive dieting and eating disorders in the daily lives of women becomes embodied in our characters 
body distortions-Anahera's corseted, hourglass figure and my grotesque 'tits and ass', which simultaneously comment on the distorted way women view their bodies and the wave of plastic surgery to correct our 'deficits'. Finally, the concept of the performance as a fashion show reflects the constancy of the gaze, both male and female, on our female bodies.

What both these exchanges illustrate as well is how Anahera's position is constructed through her connection with other women. All her comments contain references to other women-her tipuna or ancestors, her mother, her women friends. As she said in another conversation, as a Māori woman, she is never alone. Such a sense of connectedness is something with which I struggle. Everything I believe in-Buddhism, feminism, decolonisation and anticapitalism-desires connectedness and community, yet deep down in the unlit corners of my being are deep etchings of a life raised in an individualist, competitive society. Everything starts with 'I'.

Further, these discussions began the excavation of our personal lives. Our process was not about reflecting and commenting on things 'out there', but rather our process revolved around our uncovering, analysing and resolving our own personal disempowerments. We both were personally involved and were committed to taking personal risks in this collaboration.

Neither of us individually claimed the ground that we were to explore, but through unrestricted, free-flowing dialogue, we came to see that our interests coalesced around three themes — the male gaze, body image and sexuality — which interact with each other and strongly influence how we feel about ourselves as women. For example, how we feel about ourselves sexually reflects how we feel about our bodies, but also how we feel about ourselves sexually is deeply connected to how those around us view our bodies and our sexuality.

However, the purpose of this first meeting wasn't to make any decisions but to explore and stir things up. That we succeeded shows in our journal entries following this meeting. I have included text from pages of our journals to also provide insight into how differently we both responded to these provocations. I want to note here that reproducing Anahera's journal content as typed text alters its flow and spatial relationship. 


\section{Excerpts from Anahera's journal - 26 January 2009}

First meeting. Went well.

Interesting subject matter...

exciting and intimidating at

the same time. This pen sucks.

The amount of time this

project will take seems

intimidating.

overwhelming amount of reading possible.

body image

a difficult $\&$ hugely personal subject.

$* * *$

violence

When I catch a glimpse of

my shin \& calf on my left leg

I am horrified. I want to

look away... to shut my

eyes...to make this not

my leg, not my shape, not my

scar, nothing up for scrutiny not

available to be objectified.

This is the reality of 
my reaction to myself. It cannot become a

source of shame to feel that

way or I will never

find my

way out of

it.

*****

dependent origination

gratitude

- On repaying debts of gratitude

- our victory as Disciples

is the greatest way to repay our debt of

gratitude.

4 kinds of gratitude:

All living beings

parents

sovereign

three treasures—Buddha, Dharma, Sangha (community)

Nam myoho renge kyo

$* * * * *$

MEDIA

I don't even want to 
look at my thighs.

I disassociate regularly

from my body. It is

the only way I

can survive it.

THIS PROJECT MUST ENABLE OTHERS TO

BECOME HAPPY

Through compassion

for others.

That's why we do this.

Body image affects everyone.

Men \& women alike.

It disempowers. It hurts.

$* * * * *$

(On reading Ngà Mòrehu: The Survivors; The Life Histories of Eight Māori Women by J. Binney and G. Chaplin.)

I have just read the introduction. I am angered already. Men in my life pop into my mind and make me not want to read on with their fingers outstretched toward my face - I am reprimanded. So much of this is familiar. It is thoughts \& feelings that I've had, formulated into university speak. "The Pike". I like that. And the truth of the interconnectedness of all things-that's Māori...and Buddhist. Colonisation. Again I visit you. You are ugly every time.

As her journal shows, Anahera jumped right in and began grappling with her personal feelings regarding body image. She then turned to principles of Buddhism—dependent 
origination, debts of gratitude and compassion — to help her find a positive way through her negativity.

\section{Excerpts from my journal - 26 January 2009}

I feel so supported in this project now - it's amazing - yesterday it was just me grappling w/this project - now it's the two of us - and she is so into it - it's great that the reflection part fits into what she does naturally as a writer and that figuring out how to represent our gaze at each other dovetails with work she wants to do with women in the Waiararapa - I feel pleased that this project, and all the accompanying research, feeds her goals, not just mine for my $\mathrm{PhD}-\mathrm{I}$ 'm very aware of not taking w/o giving - I want to make sure this project benefits my collaborator and Māoridom as a whole - today showed me w/Na that it's as good as it gets - this is work we both want to do - and how to do it and the research \& skills we both need to develop \& do helps each grow \& do other things we want to do.

It was such a compact? tight? meeting - I mean, we covered a lot of material in a short time - working together on Nō Näianei certainly helped - also just being her \& I, no Eugene \& Willie, has to factor in. I didn't notice until today's meeting how much we did struggle with gender in those meetings.

$* * * * *$

...the hard work that I've done not to be a racist. The risks I've been willing to take all these years to become part of Willie's family - example of Clifford [a white man who had married Willie's sister] \& I - how he was always seen as white $\&$ proud of it, while my whiteness was forgotten...

Unwillingness (however fleeting or long-lasting) to venture into that contested terrain... to be vulnerable to another's perspective \& risk everything - I hadn't realised what I had been doing all these years... I loved Willie. I loved his family. I wanted to be a part of it. So, there was nothing else to do, in my eyes. But, of course, it was a choice.

And it is this same work I am now doing here in Aotearoa and for my $\mathrm{PhD}$. These are some of the things I need to find space to talk about. It can't just be 
intercultural theory. It needs to be personal \& reflective. How do I do it? What did I do? What was required? (Skills, character traits, etc.) How to talk about it, talk about something I only was vaguely aware of doing, of what was required to do it.

Back to $\mathrm{Na}-$

When we talked about our families \& whakapapa, I realised I need to reflect on my family experience $\&$ them as people from a cultural perspective. My previous reflections have all been psychological.

I also need to figure out how to connect back to them, as women ( $\&$ men), as white people, as American white people.. What does this mean?

I know so little about the people who came before me. I've never seen a picture of Mammy [my grandmother] when she was young. I don't know what my greatgrandparents did. There's so much knowledge that is gone. What does my mother carry? What do [my cousins] Terry \& Pinky know about my dad's side they're the only ones left.

How do I do this kind of analysis? cultural? What questions to ask? What kind of lens to use?

If we can't let go of our personal privileges - race, class, etc. - how can we, as Americans in particular, let go of our collective privilege of nuclear weapons which continues to threaten the human race, of our collective privilege of economics/consumerism vis-à-vis global warming?

In contrast to Anahera's grappling with content, I reflected upon the context of our project, which takes place within the framework of my Ph.D. research, and I have situated myself as a white researcher in an indigenous community. I express my concerns about how I am to function within this space. However, as it happens with the creative process, things were percolating under the surface and the next day the concept of a Butoh fashion show for the performance came to me. 


\section{Meeting - 28 January 2009}

When I mention the idea of a Butoh fashion show to Anahera, we just take off. As this is a pivotal point in the development of He rawe/Becoming Dress, I have extracted rather long exchanges to illustrate the flavour of our creative process.

Miki: I know it's a bit early in our devising to talk about something specific, but this just happened to pop into my mind yesterday: the idea of having a section that is a Butoh fashion show.

Anahera: Mmhmm, I'm writing it down.

Miki: The fashion wouldn't be just about the clothes, but how would we walk and carry ourselves when we're in those clothes and could we change ourselves...

Anahera: According to the item of costume?

Miki: Yeah, also how do we transform that from one way of being to another within the same costume.

Anahera: We could apply text to a costume. Different costumes could have different elements of text applied to them.

Miki: Let's just say...for example—it's not Butoh-ish in the way of clothing — but let's just say, a very sexy half top, short skirt and boots, so you would normally think that you'd have a certain walk, a certain objectification...that your internal way of being in it...

Anahera: Like a mini-skirt, all butt focused, leg focused.

Miki: Yeah, but you would exaggerate that in a Butoh way. But also there'd be the various interior readings that would be possible...

Anahera: As in how you're really feeling...

Miki: How you're really feeling...

Anahera: Interesting... 
Miki: How that kind of reading of your body makes you feel and what would be the opposite of that. For example, maybe the thing is that you would think it's about being sexy and objectification and one way is that you're feeling really unempowered by wearing it. But on the other hand, you could feel really empowered. So, we look at the opposite ways that you could be interior.

Anahera: I think that's a great idea.

Miki: And that we could do it in such a way... we could do it very clearly that it is a fashion show...

Anahera: On a runway...

Miki: ... on a runway.

Anahera: I really like that idea. I think we should really start with that and see where it goes.

As a way of sparking ideas to further develop this concept, we looked through a catalogue from Skin + Bones: Parallel Practices in Fashion and Architecture, an exhibition on fashion and architecture that I had seen at the Museum of Contemporary Art (MOCA) in Los Angeles in 2006. One of the fashions in the catalogue was the Russian Doll by designers Viktor \& Rolf. In their Autumn/Winter 1999-2000 Haute Couture Collection, they had created the Russian Doll, a nine layer fashion based on the Russian nesting doll, or matryoshka. Upending the fashion runway standard of the model walking down the runway, the Russian Doll model, dressed in a form-fitting, short sleeve sheath dress, stood motionless while assistants dressed her, one layer at one time. Each layer engulfing her body more and more while, simultaneously, increasing the space that she took up until only her head poked, barely, out of this massive shell constructed from the most elegant fabric with a huge, but exquisitely made rose on the left shoulder, the stem of which wound its way up the front of the shell (Hodge et al. 2006: 232-39).

The following exchange is our first consideration of this fashion which became one of the fashions/characters of He rawe/Becoming Dress. 
Miki: That [the matryoshka] is an interesting idea.

Anahera: We should do that. No matter what our costume is, we could have an order in which we apply our costumes as well and add them on until, at the end, we're unable to move.

Miki: I like that.

Anahera: I know. So good, eh?

Miki: That's a metaphor for the whole...all the stuff that is piled on us. (Pause) Then, planning the costumes within that framework.

Anahera: So, at the end, can you image us trying to do Butoh in this? It'd be awesome, wouldn't it? It's alien-esque. We get to the point where we're almost non-human.

Miki: Exactly, how are we recognisable to ourselves and others. If we wanted to incorporate projection, we could project onto this. If this was the end, none of the projection would happen until the end.

Anahera: Maybe that's what we're left with. The male gaze? That very masculine medium, being video and the fact that the things that are projected are things that men want to look at. Heaps of ideas in there, eh? (Pause) We could both wear different things and still end up in the same mess, in that really stuck mess.

Miki: I think so.

Anahera: What I like is this uniformity at the end, in this awful...that we become androgynous, that we become the matryoshka, that idea of de-sexed, alien, uniform.

Miki: Because, regardless, as a white woman or a Māori woman, in one way, under the patriarchal male gaze, we're all the same.

Anahera: Correct. Especially living in New Zealand today, I have to encounter the same male gaze that everyone else has to encounter. 
Here, we begin to pick up various threads that are woven into He rawe/Becoming Dress. The costumes/fashions are seen as metaphors for the external roles and expectations that are placed on us as women — 'All the stuff piled on us' — and that we wearsometimes by choice, sometimes not-until we are so encased, 'de-sexed, alien, uniform', we wonder 'how are we recognisable to ourselves and others', as well as being 'unable to move'. Though what is underneath may be different, all women live under 'the male gaze', subject to both the watching and surveillance of the camera and the images it produces. Later, when Anahera expresses her desire to have a character who dances in her Pointe toe shoes, she sheds light on the power that items of clothing can have in women's lives and brings to the surface why Anahera and I find the concept of a fashion show such fertile ground for our exploration of gender.

Anahera: Every time I've thought of this, I think of my Pointe shoes, so somehow they have to be in a costume somewhere. They have such meaning for me, in terms of both love and hate. Absolute adoration and the strength and physicality that I feel when I'm dancing on them, 'cause it's incredibly difficult, but also, the total disempowerment. They're both of those things. I'm not even allowed my whole foot on the floor. It's really fascinating. [...] They were coveted. Are you on Pointe yet, was a question we were asking each other when we were growing up, you know, girls learning ballet.

There were additional ideas that came up at this time and became part of $\mathrm{He}$ rawe/Becoming Dress; some suggested by the fashions in Skin and Bones. Having discussed in our previous meeting the idea of body distortions, we are inspired by Body Meets Dress, Dress Meets Body in Spring/Summer 1997 collection of fashion designers, Comme Des Garcons. The dresses had gingham-cased tumours that enveloped and distorted the model's rail-thin body. We also took note of how, in some fashions, the designers had taken great effort to partially expose the 'muscle and bone' of the creation. Similarly, we decided to not only expose the foundation layers of the fashions, but also to expose the process of changing clothes.

As the above exchanges illustrate, our performance concept begins to take shape through our non-directive, interactive process, authorship belongs to both of us, as it arises out of our cooperative interaction. However, this does not mean that we didn't think and work out things independently of each other. Nor was our work on this project limited to just our meetings. Our journals show that we both continued to think about the project when 
away from each other. Our journals, in fact, were tools for moving the project forward, as this excerpt from Anahera's journal illustrates. The non-English words in italics are te reo (Māori language).

\title{
Excerpts from Anahera's journal - 28 January 2009
}

\author{
"Becoming" \\ women as constructed. \\ "construction" \\ "consumer": Whakapeto (to be consumed) \\ "co-ordinate": Ruruku (draw together with a cord) \\ "co-ordinates": taunga (resting place, anchorage) \\ "threadbare": pütaitai
}

Threads like whakapapa \& history \& clothing

"threads": 1. Miro - loose thread

2. Kaupapa

3. Karu(tia), tui(tia): needle

4. Ata haere, takawiri - car through traffic

\author{
"fabric": papanga \\ "construction": whakatūranga \\ "constriction": kukutitanga \\ "becoming": rawe
}

"She wore a becoming dress": He rawe tōna käkabu

Anahera's word play in her journal led to the title of our performance. By the end of two meetings, we had our performance concept and title. 


\section{Rehearsal - 30 January 2009}

We have some unplanned time together. Since our arrival in Aotearoa New Zealand in 2007, William and I had been running an open Butoh Lab. As it happens on this night, it is just Anahera and I, so we work on He rawe/Becoming Dress. Because it is unplanned, I am not prepared to record it. However, we both write in journals about it.

As we often would come to do, during our Butoh workout and rehearsal time, we chat a lot. It is our time to catch up on one another's lives and dreams and challenges, to reconnect as women friends who love and support one another, to sift through our feelings and random ideas about being women, about being Buddhists, about being Butoh performers, about being involved in this project.

In this session, we make an important decision about He rawe/Becoming Dress. We decide to reverse the order of the fashions and to go from Matryoshka to birth instead of the other way around; this is more of a creative, intuitive decision that just 'feels right'. The 'correctness' of this decision is borne out in our ensuing creative process. By starting in a place that expresses our inability to move, the performance then becomes about how do we find a way to move, how do we strip away the roles and ways of being that confine us, that alienate us from ourselves and each other. Through this decision, the performance is able to become a work about positive transformation, which is our deepest intention.

We also grapple with our collective realisation that the only way to end the piece is for us to be naked. Both of us have strong reactions to this, knowing that the work requires it of us, but to do it requires us to confront our own deeply embedded body image issues. Each of us has a different 'hated' body part that we keep hidden from others, that we constantly scrutinise and struggle with changing, but despite ongoing efforts, they remain unchangeable. How can we expose them to public scrutiny? Knowing that we are not alone in this internal battle — that is, most women experience it — we discuss a variety of creative options to work with it: to use duct tape to transform them (duct tape plastic surgery), write on our bodies what we think/feel about them, gather images that remind us or replicate the texture of our 'hated' body part, and photograph each other's 'hated' body part.

Below are excerpts from our journals that convey our personal responses to our rehearsal. 


\section{Excerpt from Anahera's journal - 30 January 2009}

Last night rehearsal with Miki - nakedness, photos. I carry my mother's body I carry my mother's body. It's not a matter of being looked at, not that simply observation by another's eyes. It's my own scrutiny I have to stand up with.

"Look me in the eye."

Huge challenge...makes me flail around looking for a way out - an intelligent way to change our project, to avoid this problem.

Is my body ok? My mother hated my body. And her own. We pass on to our daughters \& sons. How many generations back did they hate their bodies?

or is this a $20^{\text {th }}$ century phenomena

[At some unknown later date in another colour pen, Anahera added the words in bold.]

my body - being Māori Dusky Maiden

my post baby body Mother

my sexual body Bride ???

my non-media body Naked

my ideal body The Ballerina

$[\ldots]$

I wanted to be a boy

\section{Excerpts from my journal - 30 January 2009}

Very scary work - but exciting \& liberating at the same time - to confront my deepest secret body image distortions...

I find the duct taping part the scariest - it's ugly \& highlights the ugly in my body - it's hard to think of people not thinking I'm attractive 
Women want to be liked

Women want to be attractive

Otherwise, you're not a good person.

While, in the final piece, we do not utilise any of the ideas about our hated body parts and the use of duct tape, talking about how we feel about our bodies is a necessary step in our personal transformations. Being able to share with each other how we ourselves objectify our own bodies contributes to us being able to transform our self-hatred into self-love. It is the transformation that is important, not the specific devises, such as duct tape. It is the transformation that needs to be conveyed to the audience during our performance.

The impact that our sharing had on me is evident in my journal because, just a few days after this unscheduled rehearsal, I write for the first time about my own body image issues.

\section{Excerpts from my journal - 3 February 2009}

Never can be too thin

Cutting off parts of myself that are unacceptable - paring away of undesirable

Undesirable as defined by Adverts, consumerism, a societal/cultural norms - norms problem/ fault - buy a are required for functioning of product/service to fix it - not society, but ours is a sick society. internal process

Norms are to maintain power over/depower in order to make money, to maintain control

And for whose benefits?

The opposite is Sensei's humanism - a society built on the respect of all human beings. 


\section{Meeting - 11 February 2009}

Our next meeting is a key meeting where the backbone of the performance is developed. While at the end of our last meeting, we do not specifically task ourselves with developing a list of characters on which we want to work, we both arrive with nascent characters based on female images that were imprinted on us, images that shaped, for better or worse, how we define what it is to be a woman and how we feel about being a woman. They are aspects of being a woman that do not sit well with us, embodying what makes us feel discomfort, despair, dread, fear and even hatred at being a woman. They are the darkness of being a woman that we carry inside us, darkness that needs to be brought to light and transformed if we are going to affect change in society, to transform the relationships between women, especially those between white women and indigenous women.

When we begin to discuss these character-images, we use shorthand descriptive namesthe Mother, Bride, Black Widow, Puritan—-that conveys in broad, general strokes what they represent to us, which is the only way they exist in our minds at this moment. As Anahera says, 'I don't know what they mean or what characters they might be yet, but I know I have these dominant female images in my mind.'

While we each came with these nascent character-images already in progress, the process of drawing them out and finding their place in our performance world is a shared endeavour, where Anahera's germination and illumination spur mine and visa versa, where we both tug at their growing limbs to fit them into a logistically possible costume, where our characters bump into each other to find their proper place in their still evolving performance world. The following excerpt shows this process:

Miki: So, the other ones I have come up with. I really want to do a little girl.

Anahera: I haven't even thought about what I want to do, except I want to do a wedding.

Miki: Awesome! Perform for ourselves and perform for the male gaze is one of the ways I'm thinking of to do the shifting. So, for me, the Little Girl is both myself as a little girl, in passing referencing the sexual abuse, but also porn stars often do little girl things. 
Anahera: French maids. School girl dresses. Eoo!

Miki: Yeah. So, that was one of the ways I was thinking of working with that idea.

Anahera: I'm really interested in the wedding, the imagery that comes with wedding, what people do in a wedding, that costuming. There was something else. (Pause). The dressmaker's doll. The fact that we're just clothes hangers.

Miki: We're not planning on us having the same costumes, are we?

Anahera: No, but how do we interact, how does the Dressmaker's Doll interact with the Puritan. And the Ballerina. See, these are the things that I grew up with that were female imagery that said I had to behave in a certain way. So, I got these images. These three at least. I don't know what they mean or what characters they might be yet, but I know I have these dominant female images in my mind.

Miki: They're very clear to me what they are. You have Bride, Dressmaker's Doll, and Ballerina.

Anahera: Great!

Miki: Awesome!

Anahera: But I also have, in terms of women, the Māori woman, the piupiu (flax skirt), the thing I could never be. I'm not allowed it. Sort of. There's a whole lot of other things that go with that. The other thing that comes up is poi (ball attached to a string, used to develop strength and flexibility). It's more poi than skirts and things. My mum was so good at it. I was so bad at it. She'd laugh at me. I just couldn't get my wrists to do it and just wasn't good at it. I was better than 50 other people down the road, but she was like, 'No, that's terrible.' I just felt de-womanised in terms of my Māori womanhood.

Miki: So, I have Little Girl transforms to Porn Star, then I was thinking of Professional Woman 'cause I worked in corporate America for so long. [...] I also want to go with the idea of the tight skirt with the big bum. 
Anahera: That tumour looking thing.

Miki: Yeah. The thing I kept thinking about with that is the Professional Woman, like in Princesses \& Porn Stars, she talks about corporate America and what the costumes look like, the pencil skirt that you can't run away in, the high heels. So, I really want to work with that.

Anahera: Do you want high heels?

Miki: I don't know if I want to do the high heels or just pretend them. I was trying to think of names for them, so I started to put down 'Working Girl', but I was no, that's not it, but what if the Professional Woman transforms into Working Girl, the prostitute?

Anahera: I want to do prostitute as well.

For the first time, we both want to claim the same character, though we had already stated that we would do different characters. The following exchange shows how we work through this potential conflict by reflecting on our own feelings about prostitution and how they were shaped by our families.

Miki: So, we both could do it as different times.

Anahera: 'Cause I got that in my imagery. Slut is actually what I've got. I don't know what that actually means, but I got that idea of the female as slut, whatever that means. When I think of prostitute, I have a far better response than I do to slut.

Miki: Slut is very different. It's like you're doing it for free.

Anahera: That's right. Prostitute, I have quite a lot of respect for prostitute. Slut, I struggle. My father was worried I'd be a slut if I had makeup on and stuff like that. It's a different thing than prostitute.

Miki: We always used whore. In my family you were going to be a whore, which translates to prostitution which is illegal in the US.

Anahera: A whore for me is someone who gets paid. 
Miki: They're two very different things. In Princesses \& Porno Stars, she says that if you can't use the word 'slut', you can't denigrate women anymore.

Anahera: That's right. Slut is a really important thing. Women who like to have sex as sluts.

Miki: Maybe both of us work on that one as well.

Anahera: Yeah, yeah, yeah.

Miki: 'Cause I think that's such a key thing that she talked about.

Anahera: Same, same.

Through our discussion, we are able to show to each other why this character is important to both of us. So, we decide that we both can do the same character. Though, in the end, this character of Prostitute was not pursued by either of us, this decision of both of us doing the same character creates space for our Dressmaker's Doll duet.

By the end of this meeting, we arrive at our first character progression and pairing, which evolve and change as we continue to explore them and their relationship to each other. (See the Character Development Timeline in Appendix 3 for this evolution.) In this meeting, we also begin to dig deeper into what being naked means to us and what we see as our personal challenges to doing it on stage.

Miki: One idea that comes to me is that the Slut comes when we get to nude, that both of us go through that place until we transform that into 'us'. Fundamentally, when you get down to it...

Anahera: That's scary.

Miki: ...that's really the crux of the problem for women is how do we negotiate that slut, the male gaze, that's put onto our bodies, that's judgmental.

Anahera: Yeah, yeah, yeah.

Miki: And how do we not do that to ourselves. I'm doing the same things when I hate my thighs, hate my butt, I'm objectifying myself. And until I can change that and accept everything about me and who I am, that's not going to change, so I 
think the Slut is very important, that point of transformation. So, that can be not so much a costume as nakedness.

Anahera: Awesome. For me when I'm naked, I feel like a little girl. I don't feel like a slut.

Miki: Let us explore different meanings of nakedness for us 'cause there are times...

Anahera: I feel so vulnerable. Slutty to me is quite confident. I don't feel at all confident when I'm naked.

Miki: Well, maybe we do lingerie before we get naked.

Anahera: I think so.

Miki: Working Girl is much more about playing with the costuming, whereas Slut is getting down to underwear.

Anahera: Same. In underwear, I'm confident. Naked, I'm vulnerable as hell.

Miki: I think it's underwear that makes sluts.

Anahera: I agree.

Talking about the vulnerability that we both feel in being naked leads us to reflect on what the project so far has meant to us personally, how it is helping us to transform ourselves. In addition to our weekly hour of chanting to support our project, most Saturdays Anahera and I attended an SGI women's meeting held at a member's house. It is this meeting that we mention below.

Anahera: It's love story of/for women. I feel really empowered. Loving myself.

Acknowledging myself. Change is going on in me, but I'm liking myself more.

Miki: Cool.

Anahera: Don't get too excited, it's just more.

Miki: Any step in that direction is huge. I feel the same way. 
Anahera: It is huge.

Miki: Just the fact of being able to talk about my dark secrets around body image. Like with you and at Joce's place [at the Buddhist women's meeting]. It was something that had been bottled up and really getting in the way. My relationship with myself and what we draw out of people, what we're reflecting to them. Bringing it back to me.

Anahera: Yeah, right. That's such a good way of putting it. I want something different in this experience of performance this time round.

Miki: Talking to the [other Buddhist] women at Joce's about what I hate about my body, I've had a really good breakthrough with feeling more comfortable with my body and seeing it differently, working really hard to move past objectifying myself... and judging it 'cause that's really, truly the objectification of it.

Anahera: That's right.

Miki: That was so strong in me.

Anahera: The more I've been working out and dancing, the more I've been enjoying my body as a physical athlete, as an animal that can move and run. I'm loving it.

Miki: That's the interesting thing. I'm now trying to focus my workout on changing things that are hindering my movement rather than just doing things to make my legs look better. Working on things that don't function properly from a movement standpoint and looking at my body that way rather than how does it look.

We have now created a structure for our performance based on the order and pairings of our characters, though the characters and their pairings will undergo several more changes before they are finalised. Additionally, we both are beginning to feel shifts in ourselves as a result of working on this project. Through our process of developing characters for the performance, we are encountering those aspects of being a woman that we find uncomfortable and unresolved. Our personal progress is made through our commitment to doing this work as well as through talking about our secrets and fears 
with other women. This challenge of manifesting our personal transformation comes to the forefront in our next meeting.

\section{Meeting - 13 February 2009}

This meeting clearly shows the interconnectedness between our characters and ourselves. In conceiving these characters and bringing them to life, we are participating in an intricate interplay between gender commentary and personal transformation. While we each invest our characters with our own personal history and viewpoint, they also interrogate female roles and feminine stereotypes. We both chose to work with characters who embody what we do not like about being a woman, as based on the messages we received and experiences we had when we were girls growing up. For Anahera, having been raised Catholic, being a woman meant 'being controlled and closed and shut down and demure and squashed and tight'. It was de-sexualising; to be free and sexual was only available to men. Her characters represent the traditional roles of women: mother, bride, housewife, and ballerina. Her dressmaker's doll reflects back to Ibsen's A Doll House. Even her Dusky Maiden represents the traditional role of indigenous women within colonised society.

For me, having been sexually abused as a child, being a woman meant being sexually objectified. My characters flip around this axis, being either sexually available to men (Black Widow, Working Girl, Porn Star, Little Girl) or sexually inaccessible and nondesirable, either by situation or by choice (Puritan, Mother, Old Woman, Professional Woman, Little Girl).

In order for us to create authentic movement and express a genuine transformation when we reach nude, we each need to find a way through these personal quagmires. On the road to getting there, Anahera has been having days of crying because she hates herself, hates being a girl, feeling she was ripped off by being born one, not liking the roles that were offered to her as a girl. I was also struggling with self-hatred, only I was hating my body, fearing its sexuality.

At the start of this meeting, we share with each other the difficulty we each are having with connecting to our characters and our doubts about being able to succeed in doing so. 
Anahera: Ah, this is going to be so emotional for me 'cause the way I found my...I don't know what to call it...the way I feel most comfortable as me is so far outside of these characters. These are my most uncomfortable places to be as a woman but they are what comes to mind when I think about what I understood it meant to be a woman.

Miki: Me, too. None of these are places I feel...little girl is comfortable for me...

Anahera: None of these are comfortable.

Miki: But very emotional...

Anahera: Except maybe slut. Slut is probably my most comfortable place to be.

Miki: That just completely...

Anahera: I love it. I'd much rather be...

Miki: That's like for me...so unreachable and uncomfortable.

Anahera: Interesting, eh? We're going to have so much interesting stuff come up. I can already feel it.

Miki: It's already started.

Even though as the conversation unfolds, we find ourselves having the opposite problem from the other-that is, Anahera's difficulty stems from the unsexual nature of her characters, while my challenge comes from the sexual nature of mine-the tone is one of mutual support. We are free to express our fears and doubts, while honouring the difference that exist between what we each must confront and overcome. In this next section, the focus of our conversation shifts from the characters to ourselves, where we each offer revelations about ourselves.

Anahera: I hate being a girl. I never wanted to be one. I felt like I was ripped off by being born a girl... because boys don't have this, don't have to be closed-up ballerinas. They can go fuck anyone they like and they can just be free and do what they want. I didn't get that option. I was sent to ballet since four years old. Constricted...I got my Pointe shoes out. I've been on them since I thought I might use them. I thought I could exaggerate them if I used them. They're so 
constricting. You tie them right up your leg. I can wear them and when I deballerina-ise myself, I can take those stupid things off. So, for me, this is a journey from the hell to where I feel more comfortable, the nude and the sluttish.

Miki: Interesting. For me, it's really recognising how much I continue to objectify my own body, and so I've been moving to a place where I've been learning how to accept myself and realising that also...particularly for our personal nude part and our transformation, I have no idea what that means for me.

Anahera: I walk around the house nude all the time. It's my most comfortable place to be, but not in front of others.

Miki: But also thinking in terms of nudity and sexuality...

Anahera: That's harder.

Miki: For me, thinking what is my sexuality, what is me, how would I express this, how does it come into being, and that for me is the part that's really scary 'cause I've liked tucked it up, put it away and go, I don't do this anymore. (Laugh.)

Anahera: Whereas I've spent my whole life trying to shed those ideas of being female, from my inside, from my upbringing, from my beliefs, that females are demure and non-sexual. That's how I grew up, believing that the good female was non-sexual, so I grew up with a lot of self-loathing since I was certainly a sexual creature, not a non-sexual creature.

As this meeting ends, there is no resolution or conclusion, but having been through this creative process before, we both didn't expect one. It wasn't about finding a solution but about sharing and talking with each other what we are experiencing. Throughout this meeting, neither of us were judgmental about the other nor did we try to solve the other's problem. We both recognised that this is the process we each must go through and find our own way to resolution, but we also knew that the sharing and mutual support is essential.

Before moving to our next meeting where we further explore our characters' development, I have included the following entry from my journal because it reflects on our process of working together and a significant difference that came to light. 


\section{Excerpt from my journal - 2 March 2009}

At Friday's (27 Feb) rehearsal - I forgot the recorder! - we were doing some preliminary movement for our characters, exploring separately, but coming together - rather, talking or showing each other, from time to time. $\mathrm{Na}$ explores her characters from an emotional standpoint. I find mine intellectually/politically first. Given how differently we approach our creative process, it's amazing that we work so well together. Why is that? We give each other space to work however we need to - we trust the other's process: I believe/know that $\mathrm{Na}$ will devise something amazing - and visa versa. We don't try to control one another - I know I will file away Na's approach \& will work with it when it feels right for me.

That wasn't what I was planning to write about, but it was good. What I found of note on Friday was when we were talking about our characters. I was discussing how I was trying to find the Black Widow, how I was coming to realise that to be a woman dependent on a man, dependent on how well I could use my 'feminine wiles' in order to survive was very foreign to me. Na said that that was how she was raised - she was to marry \& have children. Her survival was supposed to depend on her having a man, particularly important was having children. She is seen, by her mother \& family, as an embarrassment, as selfish (she's not married, chosen to have 1 child, \& pursues her own interests) - Māori women are supposed to have children. Opposite of my upbringing - being told that children will ruin my life, not to get married $\&$ have children. I am seen as the successful one in my family. My family is very proud of me \& what I do. It's funny. I never thought that there could be another response to my choices, that my family wouldn't be proud of me - I always have been the shining star, the one with potential \& promise, the one they hoped \& supported to succeed. I never saw their support in this way. I had struggled with the negative side of being different...They don't have to change; neither do I. (Realisation moment.) All that matters is that we love \& support each other.

While I wouldn't draw any larger conclusions about the differences between how our families have reacted to our life choices, it does seem to me that this difference influenced our choice of characters to explore and provides a context to which we each 
were responding. It also allowed us to integrate into our piece as subtext on the differing expectations and reception to women's choices.

\section{Rehearsal - 9 March 2009}

In this rehearsal, we continue our Butoh exploration of our characters that we started at our 27 February rehearsal. Before embarking on the run through, we do a Butoh exercise where we pick one of our characters and find a bird that is representative of her. We then become that bird from egg until death. This exercise is discussed more fully in Chapter Three.

The focus of the run through is to explore how our characters would feel walking down the runway, how would they feel being publicly scrutinised about how they fit into the feminine ideal, how would they feel being looked at in that way, and how do they respond to that gaze because the runway is a place where none of our characters would find themselves:

Miki: Which is why, when I think of putting them in the context of the fashion show, it's about the gaze 'cause that is what we're reacting to.

Anahera: Mhhm, OK. But we want the reaction to the gaze. I'm still trying to get out of my head that I'm in a fashion show 'cause why wouldn't I just be the Mother trying to be (gesture), you know? It's their reaction to being looked at.

Miki: Exactly 'cause to me a fashion show is the epitome of the gaze on women and judgment of women and presentation of female icons.

Anahera: I get it! I think it is our best option. I think that makes more sense, eh? 'Cause that internal will be there because it's my internal response to being looked at.

Miki: Exactly.

As we go through the first go-round, we stop and talk as questions come up; in fact, this is the purpose of this exercise: to place our characters in the situation and see what questions arise. Out of this process, our characters begin to emerge from the darkness into the light, and we begin to understand more deeply why they had called to us. Anahera introduces the idea that they are our female whakapapa, our genealogy as 
women: what's been given to us, what's been left to us, what's been handed down to us. Intellectually, we know these genealogies are damaged and damaging, but in order to change them, we not only have to acknowledge them, but to embrace them; that is, we need to not only intellectually understand them, but we have to find compassion for them. We are dealing with, as Anahera aptly phrased it, 'two hugely different genealogies of women'. She also sums up why we are doing this piece: 'to change this genealogy for women'. Because Nichiren Buddhism believes in the interconnectedness of all life and emphasises that by each person doing her human revolution-that is, undertaking the challenge of personal transformation through chanting Nam-myoho-renge-kyo-society at large is positively affected. Therefore, here we both agree that the success of this piece hinges on our own success in winning over our personal female genealogies through our practice of Nichiren Buddhism and Critical Butoh. Creating this performance is a process of acknowledgement, acceptance and transformation:

Anahera: Which makes it so now, so Butoh, which I love. It's so present. I'm not going to be able to be not present. I won't be able to fake it 'cause it's my deepest terror. I hate it. I'm going to reveal my hideousness to all these people. It's scary, but I want to do it. I want to change this genealogy for women. That's why I want to do it. Intellectually, I understand that it's not appropriate that I have this genealogy. Why would I have it? But I do. That's the thing about this play. It's my female whakapapa, what's been given to me. I don't like it.

Miki: I like that way of thinking about it. We picked what resonated for us. We invented these characters for a reason.

\section{Anahera: Correct.}

Miki: We may not know the intellectual reasoning...

Anahera: It was like this female icon, I must deal with her. It's that simple. For me, when I was thinking about these characters, I want to deal with that one and that one and that one. (Pause) Yeah, it's a piece about truth, truth-telling.

While all characters represent 'two hugely different genealogies of women', they both have an external expression that is at odds with their internal sense of self. In fact, when Anahera observes, 'There is that sense, with all of our characters, a lack of 
comprehension of their own self, she reveals a theme that potentially connects all our characters:

Anahera: My characters, they all want to disappear. There's a lack of comprehension of their own core worth basically. They're busy trying to be - or not be - their external body. In some way. Mine are.

Miki: I'm not sure about mine. I don't think mine are all so connected. I think they had a bit more diversity. Or, I haven't found the similarity.

Anahera: In all of your characters, I see lots of similarities, except the Porn Star.

Miki: What sort of similarities do you see?

Anahera: They're all incredibly strong-willed. Each of those characters is all from the mind. Not from the body, even though their body is part of the picture. They got beaks, mate.

Miki: That's true. Then, the Porn Star. I think there is...

Anahera: There's an element of ruthlessness in all of your characters, including the Porn Star actually.

Miki: Yeah, if you get out of the idea of looking at the victim perspective, you look at the flip side...it's a ruthless business that you're in.

Anahera: Absolutely.

Miki: You have to be pretty...

Anahera: Ye-ah. So, in a way, your characters are trying very hard to be visible. They are working to be very visible 'cause that's what their lives rely on.

Miki: Yeah, you're right.

Anahera: Whereas mine are all trying very hard to be invisible and only be the external, so no one looks inside them.

Miki: Yeah. 
Anahera: In a way, my characters express the idea that the only thing valuable is the external.

Miki: And I think mine use the external to forward their own agenda.

Anahera: It's a totally different kind of woman.

Anahera's characters are about the external. Not only do they aspire to successfully embody the feminine ideal of bride, mother, maiden and ballerina, but for them, only their external self has value. They want their internal self to be invisible because they have a sense of shame about their perceived 'real' selves, which makes them fragile and leads them to be women as 'doormats'. Yet they are also what many young girls dream about being when they grow up. The fact that these female roles have their roots in white/Pākehā culture further problematises Anahera's relationship to them.

Mine, on the other hand, are what no girl dreams of becoming. They are various forms of the 'bitch'. They are incredibly strong-willed and determined. They are invulnerable and refuse to be fragile. Whereas Anahera's are from the female body, mine are from the mind. They use the external to further their own agendas. Still, at the core of both is fear, and this fear will have to be dealt with when we get to Costume-less, which is what we have come to call the section of the performance when we are nude. Anahera's characters fear that, without the external, people will see that she is rotten and awful and will be repulsed by her. Mine fear that, without their external protection, they will be taken advantage of, that her female attractiveness will be used to against her, to victimise her.

As a result of all these new understandings about our characters, Anahera and I see that the taking off our clothes is not about stripping but rather about the struggle to transform. The change from one costume to another is like breaking out of an egg and becoming the next incarnation. As we dig deeper into our characters, trying to understand them, why we are drawn to them and what they want to say and be in the performance, we both continue to use our journals as tools to facilitate this process, as the following entries from our journals show. 


\section{Excerpts from Anahera's journal - 14 March 2009}

I feel like such a failure in my characters... as a mother, bride, a Māori and a dancer, and as a woman. That sums up my whole life. It was expected that I would become each of these characters.

My characters' fear is about they had these potential moments - they missed them all. They never managed a single one of them. And now their chance has gone. Outside of these moments their only option is/was nothing=invisibility.

There was only a single given moment in which they could shine \& they (I) failed.

Each character is about not achieving these things .-. about holding on to the past - still trying to achieve that moment of VALUE when it's no longer possible - outside of my control.

Being a woman so far has meant NOT being able to CHOOSE MY OWN VALUE. My worth defined by others -

And my worth being external not internal. It being ordained from on high by the lineage of women spanning all the way back to the beginning of time.

\section{My whakapapa}

My womanly genealogy

As a woman I'm supposed to be desirable yet these images of desirability that I have are relics from colonisation. These are not the women my ancestors embodied. 'The Mother' character is enraged but GAGGED because she is Māori.

My labia are too big. And dark. I am Māori. We grew up aware of our vaginas and that men arrived via that channel. She is angry for having to be the castrated white vagina mother when she is clearly not. She is hips and thighs and buttocks.

We are emotion. Not that emotionless, childlike woman portrayed in the bride/Dusky Maiden/ballerina... waiting to be 'plucked'. And the Mother as the well plucked fruit. 
And it's so right that I am hairless as these characters. Colonialism overpowers but cannot hide the woman's labia.

the mother's

the adult's

the native's difference

When Anahera brought up this physical difference between white and Polynesian women, we decided to subtly incorporate this into the performance. It also opened up an opportunity to comment on the practice of shaving women's body hair. As a daughter of the second wave of feminism, I still carry Germaine Greer's apothem of women as hairless, sexless Barbie dolls and go back and forth about what to shave or not shave. As it happened at the time, Anahera was sporting a Brazilian and she was keen to keep it for the performance. So, we decided that she would be completely devoid of body hair, whereas I would just let it all grow.

\section{Excerpt from my journal - 15 March 2009}

for my characters, sex is not about sexuality, but about power relations - rape is not about sex - it's about power over.

anyone (male/female) can be raped

how to find security in a world of power-over is the question.

connection to other women, people

connection to my Buddha nature - the capacity to transform anything into value my characters answers are the anti-thesis to this - they found security in disconnection from themselves, from others - they continue the dominant power-over dichotomy.

They remain trapped in a power-over world/worldview.

End is about finding connection to

self / others 
Earth - material world/life

Buddha nature

In this entry, I have found my way through to understanding not only what my characters - and I-need to transform, but how to make that transformation possible. We, my characters and I, need to find our way out of a 'power-over world/worldview' through connecting to our Buddha nature. Reflecting back, I can see that through my struggle to transform myself and my characters, this is the moment when I am beginning to have an experiential understanding of how the colonial matrix of power, which is a 'power-over world/worldview', is embedded in my being and what I need to do to transform it.

What is interesting when looking at the juxtaposition of Anahera's and my journal entries is that for Anahera what she and her characters are fighting against is immediately and clearly connected to colonisation, while for me and my characters, we have to dig deeper to understand the connection between what is constraining our lives and colonisation. Because of the position I occupy on the coloniser-indigene hyphen, my view of how that positionality affects me, how the colonial matrix of power affects me, is obscured. The colonial matrix of power normalises hierarchy and domination. However because of her position on the hyphen, Anahera sees clearly how her life is constrained by the colonial matrix of power. As she wrote, her struggles with being woman come from her inability to 'choose my own value'; her images of being a woman are 'relics from colonisation' and 'not the women her ancestors embodied'. It seems to me that when Anahera says in our 9 March meeting that all her characters 'are all trying very hard to be invisible and only be the external, so no one looks inside them', it could be interpreted to mean that in order for her characters to appear to meet the coloniser's image of a being a woman, they have to make their Māoriness invisible. In the same discussion, she remarks, 'My female legacy was you will feel shit about yourself on the inside, but it's only what's on the outside that counts', and '...implicit in each of these characters is a sense of shame about their real self, their true self, 'cause it's only the external that matters.' She also says, 'When I get to the end and I'm naked, I'm terrified 'cause I'm afraid that they will see that I'm rotten, that I'm awful, that I'm not any of these lovely external things, that I'm just gross. That's my characters' and my genealogy.' Her characters' true selves are Māori, but in trying to meet the coloniser's expectations of being a woman, they have internalized the colonial 
matrix of power's view of being Māori. They fear that exposure of their true selves will cause others to perceive them as 'rotten', 'gross' and 'hideous'.

At this stage of our performative project, we both are digging inside our selves, doing our body archaeology at the Cultural Interface, doing our Buddhist human revolution, doing our decolonisation. At the same time, we are using the aesthetic to translate our lived transformation into a transformative public performance.

\section{Rehearsal - 16 March 2009}

In this rehearsal, I share with Anahera my insight into my characters and how that has led to my newfound understanding of the ending of the piece for my characters. What drives my characters' behaviour, underneath it all, is the fear of rape and how they are controlled by that. The question they need to resolve is how to find security in a world of power over. My characters' answer is to assume feminine power over roles, but to do so, they have to disconnect from themselves and from others. Therefore, at the end, the transformation becomes about reconnecting to self, to others, to the world and to our Buddha nature, the transformative power of being able to create value out of anything, of being able to change poison into medicine.

So, Dressmaker's Doll, which is when we truly 'see' each other, when we recognise our common humanity, is the transformative moment that leads to re-connecting with ourselves. It is through our connection with each other that we are able to start connecting to ourselves. For the first time, both our characters are able to be truly vulnerable, experiencing a vulnerability that comes from a deep acceptance of self. Anahera's characters are able to find strength to be who they are, while mine are able to give up control.

While Anahera agrees with this new understanding of the end point, she feels that she needs to follow her characters to where they lead her:

Anahera: ...I haven't found that place in my characters yet. So, I'm allowing them to find that place for themselves through this process rather than aim for it. Do you know what I mean in terms of the difference?

Miki: Which talks a lot about how you and I work.

Anahera: Yeah. 
Miki: 'Cause I need to know where my characters are going in order to get them there.

Anahera: And I need to follow mine. I need to follow them where they're going to take me, and then there might be place I can facilitate shift, but rather than say you are going here, make the path wherever you go. Does that make sense?

\section{Miki: Yeah.}

Anahera: So, I'm going yes I want that to be my ending, but if it isn't, I want to be true to my characters, but I don't think it's about victimhood necessarily. Yes, they are victim in some sense, but of themselves as well. It's not just of externals. And I want them to get to that...I imagine that they will get to that place of transformation 'cause that's what we're doing, so I imagine that that will be it, but I'm not exactly sure that it's the same as yours.

Miki: Yeah, sure. For my, that's my goal. I'm goal-oriented.

Anahera: You are!

Miki: They need to know where they are going, so what do I need to do to get there.

Anahera: My characters are terribly vulnerable. Yours are invulnerable. Mine are terribly vulnerable. I have to carry them along like this, 'Careful, we'll get there.'

Miki: And mine...their goal is to be invulnerable. If your deep-rooted fear is violation, you want to be invulnerable.

Anahera: So, my feeling at this point, the end point for my characters will be self achieved through true vulnerability, not through these external 'I'm so fragile' vulnerabilities, but through real vulnerability, acceptance of the self in that sense.

Miki: Yeah. I think that's true. I'm framing it differently 'cause mine are starting in a different starting point, but I think it's the same idea they need to shed their invulnerability... 
Anahera: I think that is what we're doing. It's axiomatic in terms of our performance in a sense. We are shedding and we will finish as ourselves in some sense, and...I'm interested to see what that might be.

Miki: I think of Shin Yatomi's essays on the difference between arrogance and confidence. It is really key for my characters 'cause mine continue to function in a power over world, and as long as you stay in power over, you have to maintain...

Anahera and I were both well-acquainted with these essays and had no need to discuss their meaning explicitly. The essay to which I refer is part of the book, Buddhism in a New Light: Eighteen Essays That Illuminate Our Buddhist Practice. The essay, 'Mistaking Arrogance for Confidence', makes the point that [a]rrogance makes us insecure, whereas confidence gives us peace of mind. The more arrogant we become, the more keenly we feel the dependence of our happiness upon the misfortune and weakness of others' (Yatomi 2006: 87-8). In the other essay, 'The Way We See Ourselves', Yatomi wrote,

...so long as we praise ourselves solely for who we are and for our innate Buddhahood, we will never become arrogant...the greatest way to praise ourselves is prayer that sincerely affirms our supreme potential. As Nichiren writes, "When you chant myoho and recite renge [meaning chanting Nam-myoho-rengekyo], you must summon up deep faith that Myoho-renge-kyo is your life itself (WND, 3). (Yatomi 2006: 32)

Continuing on, we build upon our shared understanding and move into an analysis of our characters using the Buddhist concept of the Ten Worlds, focusing on the worlds of Anger and Hunger.

Anahera: Yours are in the world of Anger 'cause anger is arrogance, not rage. It's competition.

Miki: Yeah, it took me a long time to get that.

Anahera: Others are less than me 'cause of what I've achieved.

Miki: And if I'm not more than you, I'm less than you. There's no equality that exists for them. 
Anahera: I think mine might be in the world of Hunger. I was trying to think about that. That need for others. The need for something external. That desperate need. Mine are needy. All of them.

Miki: Interesting.

Anahera: Pathetic, though. I have to like my characters. They're not in the world of Hell. They want so desperately validation from elsewhere.

Miki: I think that these are the two places women go to in trying to deal with domination.

Anahera: Yes, yes! Jealousy and hunger, that's all in the world of Hunger. The Bride having that sense of (gesture), you know?

Miki: And mine are competition with women, in a different way.

Anahera: The Buddha nature of Hunger is the incredible, strong desire for it to be different, for it to be better, the deep desire to have things change. And the Buddha nature of arrogance is to seek justice, to see justice done.

Miki: Let me write that one down.

\section{(Both laugh.)}

We end by considering the challenge we have set for ourselves and express our concerns about achieving it:

Miki: The challenge for my characters comes at the end, from Dressmaker's Doll to Nude, how to be vulnerable without being victims.

Anahera: And it's similar for me. Mine have to come into being, empowered in some sense. The Dressmaker's Doll is more empowered for my characters than any of them, so they have to step up into this character of the Dressmaker's Doll. They have to give up these images they want people to see them as.

Miki: I think that's true for both of us. So, there's a certain level of vulnerability when we get to Dressmaker's Doll. 
Anahera: That's a very hard transformation. That transformation's going to be...challenging. (Pause.) I want to deepen my sense of each character 'cause I'm going to have to go to places inside myself that I think are lost. (Laughs.)

Miki: I feel that way when I get down to the Stripper.

Anahera: This is why I keep coming away feeling churned up, which is Ok, but I'm like wow.

In this meeting, Anahera's and my dialogue revolves around the concept of vulnerability. In retrospect, I can see that our characters and their oppositional relationship to vulnerability could be interpreted in terms of their positions with regards to the indigenecoloniser hyphen and the colonial matrix of power. I think this is particularly apt if vulnerability is linked to Anahera's and my discussion of visibility during our 9 March meeting. For my characters, living on the coloniser's side of the hyphen, to be visible, to be visibly 'white' is to be safe. Being visible contributes to being invulnerable. However, for Anahera's characters it could be said that their vulnerability arises out of their need to be invisible. It's not just that their internal Māoriness needs to be invisible to meet the coloniser's image of being a woman, but that to be Māori and to be visible is to be unsafe. Here, I am reminded of bell hooks' remembrance of what it was like to be a black child walking through a white neighbourhood in the U.S.:

It was a movement away from the segregated blackness of our community into a poor white neighborhood, I remember the fear, being scared to walk to Baba's, our grandmother's house, because we would have to pass that terrifying whiteness those white faces on the porches staring us down with hate. Even when empty or vacant those porches seemed to say danger you do not belong here, you are not safe. (Cited in Taliaferro 1998: 95)

Similarly, Māori writer Patricia Grace remembers the consequences of being brownwhat she refers to here as being 'different'-when she was growing up: 'I found that being "different" meant that you could be blamed-for a toy gun being stolen then thrown into a drain, for neighborhood children swearing, for writing appearing on walls, for a grassy bank being set on fire (Grace 1998: 49-50).

On one hand, Anahera's and my characters are reacting to the question of visibility as women in relationship to the male gaze and how that affects how we see ourselves in the 
world. Anthropologist Ruth Behar writes, 'Woman...is always being looked at and looked over. A woman sees herself as being seen' (Behar 1995: 2). Yet viewed through the lens of colonisation, we have diametrically opposite experiences of being visible. With this insight, it is easy to see how Anahera's characters inhabit the world of Hunger, while mine are in the world of Anger. Her characters yearn for things to be different, while struggling to remain unseen. Mine are determined that things will be different. They refuse to adhere to the traditional roles for women and be doormats like Anahera's characters. Instead they puff out their chests so as not to be taken advantage of.

While Anahera and I may have concerns about our ability to transform our characters' worlds in time for the performance, we do not doubt the existence of the Buddha nature that is inherent in those worlds. Together we are working to make these transformations happen.

\section{Rehearsal - 30 March 2009}

While working the hyphen and the colonial matrix of power have been subtext in our meetings and rehearsals, in this session is our first overt conversation about colonisation and the relationship between Pākehā and Māori women. Our dialogue started with Anahera discussing a lecture she gave on the Treaty of Waitangi at an SGINZ Buddhist conference and how she really wanted to express the humanity of both sides of the argument:

Anahera: I can really imagine the culture shock for white women turning up in New Zealand and...having been tricked in a lot of ways into coming and having to go back to nothing, to starting with nothing, to starting with chopping down trees to build their house. To, perhaps, wanting to have friends, but they wouldn't have any 'cause other white women would be seen as competition for land, for resources, for whatever. And with Māori women, there's no way. So, there's combination of fear and just the need for human connection. A lot of the pioneering women were incredibly isolated, you know, just out in the wops with their asshole husband who went hunting and came back...I can envision scenarios in my mind where those pioneering women made forays towards a Māori community or a Māori woman, and they would have been so unable to communicate... 
There's such loneliness, the loneliness of a white woman, which a Māori woman doesn't have. I have ancestry. It never leaves me. I'm never alone. I never haveit's from my imagination-the same sense of isolation that I imagine white women to have. I just have it. When I die, I will be welcomed into the same spaces as all my ancestors have gone. I'm not alone...in the same way. Sometimes I can just get that sense of wanting to cry my heart out for the white women who are so fucking alone...fucking isolated.

And they may have tried to interact, to help, what they learn growing up to a good thing, and being rejected. They don't know how to function in that environment. So, for me, when I think about New Zealand history, I really have a sense of empathy for both European and Māori women, not just one. A really strong sense of empathy. I just think it's a horrible clash of human beings not knowing how to relate to each other. [...] I have such a wealth of compassion for white colonisers, which is interesting. I don't hate them. I just feel for people, not for the Empire.

Anahera's expressed compassion for Pākehā women leads me to bring up my own struggle as a white woman.

Miki: Right. What I struggle with is that I see that because I also think of presentday in terms of me as an American. I am part of a present-day Empire. And struggle with that on a daily basis of what does that mean to me. So, it's not that I don't have empathy for myself and for others, but the question for me becomes really is how to recognise that compassion for each person individually, yet also recognise that within each person, unless they challenge their white assumptions, they actually are part of the Empire on a daily basis.

Anahera: Yeah, I know what you're saying.

Miki: And that to me is sort of...

Anahera: But I don't think you can do that.

Miki:...sort of thinking about with my characters, working with that...and trying to think about how did I get to be who I am now, how did I...because I was fairly similar with my family...though I didn't accept racism the way my family accepted 
it for whatever reason. Clearly, as a child, it did not make sense to me and I kept that inside me. But what I had to work at changing was still those assumptions I had about people of colour and about the invisibility of my whiteness. And that to me, the question of how...maybe that's the thing to work with these characters as we go through the run through of how do they awaken in their process as they go down the runway, how do they awaken to these various things, of gender, of being women and responding to their colonisation as women, of being white, of being American.

Our conversation about colonisation problematises the intersection of the person as a human being and the person as part of Empire. As Buddhists, we both recognise the necessity of respecting all people and having compassion for them; yet how to do this, while still recognising how the colonial matrix of power has imbued one's way of being in the world. This discussion also highlights an important concern about the piece. We do not want to gloss over the differences and tensions that exist between white women and indigenous women, yet we also feel that there are issues that do connect us womanto-woman. In the same conversation, Anahera has aptly summarised our feelings about this tension:

You see, for me, I just see that, what I had envisioned, was that, yes, the cultural differences are visible, but the connection to do with being female is bigger and more important. I didn't-and don't-have the sense of that colonisation conversation that we're having as being bigger than the female-to-female conversation.

We decide to do a run through and get ready to do so, but as we begin to segue from discussion to rehearsal, Anahera starts to talk about what her characters brought up for her.

Anahera: All my characters are trying to transform from the world of Hunger, in one way or another. Over the last week or so, there has been a huge series of realisations for me and my practice.

I had guidance with Luk [a Buddhist leader in SGINZ] on Friday night... And she said you have to chant to appreciate the greatness of your life without 
adornment, as if you were naked. And I was omigod, that's the project. That's the naked moment.

I asked her what did that mean. She said without family, husband, money, clothing, with nothing, with just you. Then, she said to me-and it's importantyou must after that chant to appreciate your good fortune and the things that have come your way because it's not about not having adornments. To consider these things more important that the greatness of your naked life, is to look for happiness outside of your life, which is the world of Hunger.

$[\ldots]$

And I have to transform these characters. And to do that, I have to transform my own world of Hunger, which I wasn't prepared for.

\section{$[\ldots]$}

Miki: But you just gave me the commonality of our characters. They both exist in the world of competition, in the world of power over, and that's actually what we need to get out of. Mine manifests more from the world of Anger, that idea of arrogance, but yours comes from Hunger, but it's the same idea of power over.

This meeting has been a long and free-ranging conversation, responding variously to our individual creative needs, first mine, then Anahera's. Now we have come around to a moment where the commonality between our characters begins to emerge, and we return to a more mutually interactive dialogue, as we try to bring this glimmer into focus.

Anahera: I don't know what that [power over] means.

Miki: It means that my worth depends on how I rank with others. There has to be people better than me, and there are people less than me. And how I feel depends on how I fall in that ranking. I feel good if I'm at the higher end, if I'm over someone else. I feel worse if I see someone else over me. As opposed to seeing how do we exist that I'm awesome, you're awesome, she's awesome, and that's fine. We're all awesome together. It's not about a ranking, a hierarchy. And that's really what colonisation is about. Making people in competition with each other, of seeing ourselves in relationship to who's over and who's under. And 
what we carry in ourselves is that sense of competition, and it happens racially, culturally, gender-ly. So, we need to find our way out of that.

Anahera: Yeah. It'd be good if you could just tell me now.

Miki: [...] fundamentally, underneath for me, is figuring out how to see my worth without comparing myself to other people. So, that's the common struggle we both have.

Anahera: This is what I wanted other women to get from our performance. I want them to go away with a sense that there is a greatness to their life without adornment. That's what I realised that I wanted them to take away. That there is a greatness to their life without adornment is what I want every woman-and every man, but woman in that room—to part with that feeling. You know?

Miki: Yeah.

Anahera: 'Cause I want that feeling and I don't have it.

Miki: 'Cause I think when we get there, when we have that, we're no longer in competition with each other.

Anahera: I agree. (Pause) But I can't even fake it. I can't even find a way to pretend I have it. I don't have it. I don't even know what it feels like. So, for me, I have to transform this feeling internally in order to be able to do it on stage.

The above exchange so clearly demonstrates how our various ways of knowing-Critical Butoh, Nichiren Buddhism, critical and decolonising theory, Mätauranga Mäori-have come together and elicited a multi-faceted understanding of gender and colonisation that has illuminated for us a way to transformation. Here, for the first time, we both have a clear grasp of what the ending means and what we need to challenge in ourselves. As Anahera said, we can now see the problem, but we still need to 'break through the actual thing, transform the actual thing.' Our process does not stop with an intellectual understanding, but demands that we transform something in ourselves based on that new understanding. While we both have confirmed aloud that we haven't achieved it yet, there's an unspoken commitment to achieving it. The depth of this struggle for each of us is reflected in the following journal entries. 


\section{Excerpt from my journal - 10 April 2009}

Meanings of my dream:

to save my tooth I have to let go of my lesser self.

my characters represent facets of my lesser self/my delusional self - the difficulty of letting them go is they were survival strategies

Miss Texas - my little girl: everything is/should be beautiful/ life is a competition (gymnastics \& school)

Black Widow - living to fulfil my parents' expectations: mom - marry wealthy/ dad - athlete (riding outfit)

Executive - Puritan work ethic: mom's desire for money/success - actually, both parents desire for me to be successful

French Maid - working class girl in upper class school / Freddy's sex toy [Freddy was my oldest sister's husband who molested me from when I was ten to sixteen years old.]

Dressmaker's Doll - living for other people's expectations - external self/delusion self

These characters represent death - If I want to live, I must shed them. Yet, they feel like life \& to lose them feels like death - exchanging bag of rocks for bag of gold analogy - bag of rocks seem like gold - must let go before you receive the gold.

Exchanging gold for rocks is a reference to the idea in Nichiren Buddhism that by giving our lives to - in the sense of dedicating our lives to- the Mystic Law of the Lotus Sutra that it is like 'exchanging rocks for gold' (Daishonin 1999: 764).

\section{Excerpt from Anahera's journal - 13 April 2009}

Day four of four day intensive. So much has gone on and so much changed. I have not picked up a pen in all that time. This is my first moment. I know myself better. Dreams are evolved \& being realised. Kazuo Ohno’s book [Kazuo Ohno's 
World: From Without and Within] is incredible. Dance: "how then can we, as performers, become such an eternally beautiful flower." pg 223

It's interesting because women are often referred to as flowers and yet I feel so unflower like in this performance...or so I thought. But flowers are fragile, and strong, withstanding all weathers. They don't care what anyone thinks of their blooming or dying. They may have thorns, hundreds of thorns, and yet somehow, though I may think a particular flower to be ugly, by virtue of its incredibleness and its willingness to participate in the dance of 'life' it is incredibly, strongly, beautiful. And that much closer to how I feel as a woman. And what I wish all women would feel of themselves.

\section{The Costumes}

Have been incredible. They have allowed an opening to the rain for me, for my flower. I love working with them, in them, they're not separate from me now, from the meanings imbued in this piece. They are another layer of skin.

When I look at [my friend]...I think of how unutterably beautiful I think she is. Yet externally she might not seem that way, not to herself anyway. But she is extraordinary. She is stunning to me. Her inner self is so visible.

That's why children are beautiful - their externals are not interesting - not to them. Everything is how they feel \& respond to their world.

Somewhere in here I have discovered an interest in my inner self - facilitated by butoh, by this work. I want to continue to do work like this, with this making change and potential to change others.

\section{Miki’s Dream}

She doesn't want to let go of her layers - her selves.

I hate mine but am frightened to shed them. They are the expectations I wear. The expectations I have accumulated; chosen; embraced and allowed myself to use as excuses. 
So, on 10 April and 13 April, we both were still grappling with ourselves and our characters, yet our performances, scheduled for 17 and 18 April, were only days away. While we both had achieved greater clarity and understanding about the piece, our characters and ourselves through our development and rehearsal process, it was only through the actual performances that we were able to manifest our transformation and find resolution for our characters and ourselves.

\section{CONCLUSION}

What I hope I have achieved through this telling of Anahera's and my story was to provide a practice-based understanding of what it was like to undertake research using a decolonising epistemological pluralism that is critical and performative. As Anahera's and my interactions show, these concepts are intimately and inextricably interconnected. We moved effortlessly from one knowledge system to another to reach a deeper understanding of power relations as we experienced them as women and as coloniser and indigene. After reviewing the written artifacts of our process, I believe the results we were able to achieve were because we used a variety of shared and unshared ways of knowing, while simultaneously utilising the lenses of decolonisation, performance and criticality. It seems to me that to interrogate the hyphen these three lenses are like the base of a three-legged stool; take one away and it falls over.

As this is not the standard way of conducting research for many social science theses, I think it is worth speculating on the key factors that contributed to the success of our project. When we began, we had a broad goal to which we both were committed: a Butoh performance that looked at gender and colonisation. The open-endedness of our goal allowed us to come together and define it jointly. Neither of us had a greater say in establishing the terms of our research. Further, both the project and our relationship were based on reciprocity. The project provided equitable benefits to both of us; choosing to base the award of my Ph.D. on a written thesis rather than a combination of performance and thesis was a measure I took to ensure this equity. As the initiator of our collaborative endeavour, I made sure that the project would further the personal goals of Anahera as well as my own. As practitioners of socially engaged Buddhism, we both had a dedication that this project would create value not only for ourselves, but for our respective communities and society as a whole. Because of this mutual definition of the project and a relationship of reciprocity, we both were personally invested in the success 
of the project and were willing to engage deeply with each other. That is, we both agreed to take risks and allow ourselves to be vulnerable in this relationship. It must be acknowledged, though, that, due to the history of white researchers in indigenous communities, Anahera was inherently risking more than me. Ever aware of this gift of her trust, I was vigilant not to betray it. Such a foundation enabled us to effectively use the three processes I mentioned in the beginning of this chapter: making an offer, nondirective dialogue and valuing differences.

While this chapter has discussed the development process, the next chapter will describe and analyse the performance of He rawe/Becoming Dress. 


\section{CHAPTER FIVE}

He rawe tona kakahu/She Wore A Becoming

Dress

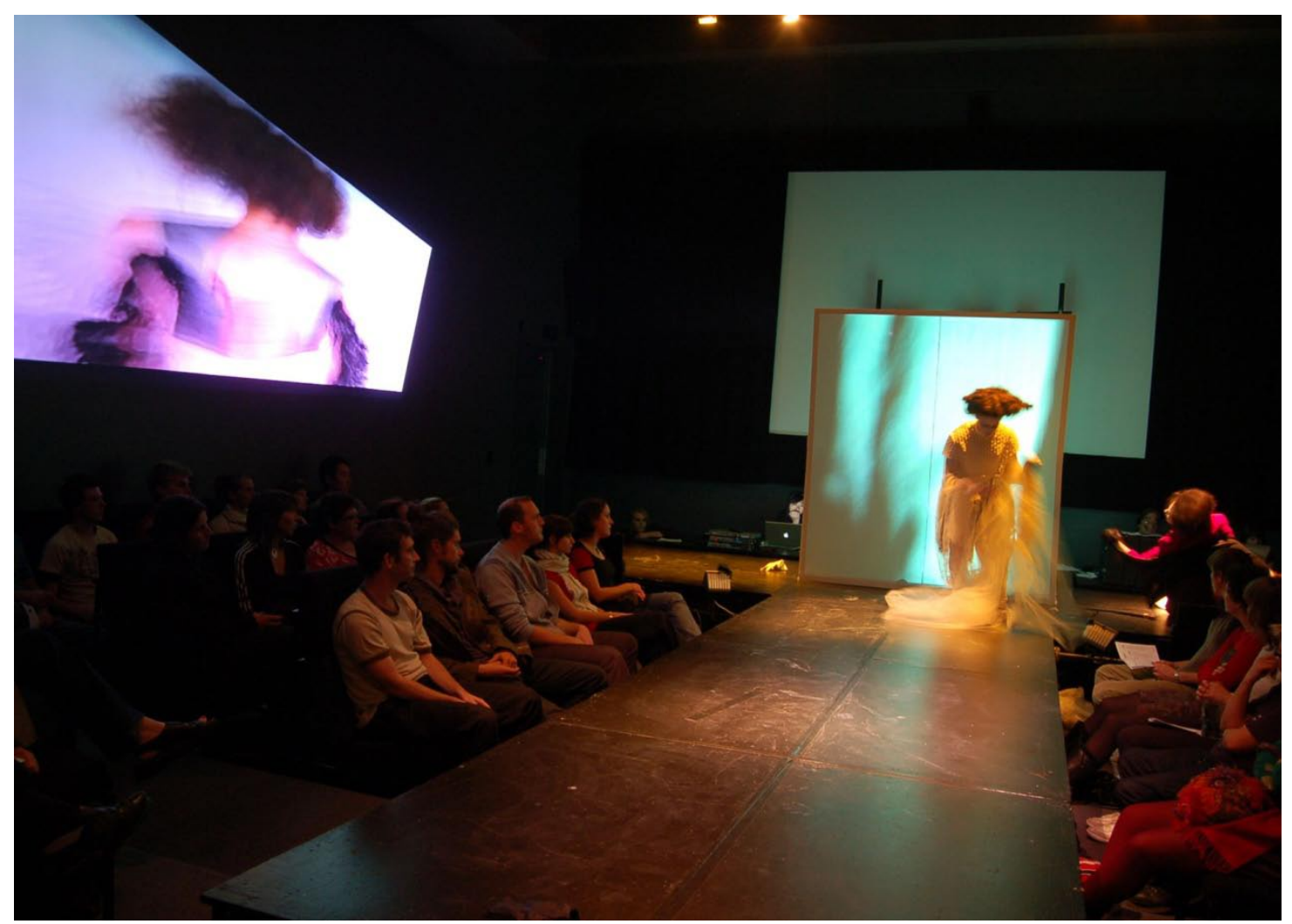




\section{HE RAWE TONA KAKAHU / SHE WORE A BECOMING DRESS}

While the previous chapter focused on the interaction between Anahera and I during the creation of He rawe/Becoming Dress, this chapter will discuss the outcome of that process. On 17 and 18 April 2009, He rawe/Becoming Dress was presented at the Film Archive in Wellington, New Zealand. The theatre was transformed into a high-end fashion catwalk with five video projections. It was a multi-layered event that interwove Butoh dance, grotesque fashions, video projections and a live DJ mix. It was an ineffable investigation where the Butoh idiom was expanded through its incubation in culturally diverse bodies and which delved into the complex relationship between women, fashion, contemporary ideals of beauty and women's self-image as played out on the real bodies of an American and a Māori woman. It was a performative investigation into gender as refracted through the lens of the colonial matrix of power.

He rawe/Becoming Dress was an hour-long Butoh performance created and performed by Anahera Gildea and me. William Franco was the Production Designer. Janet Dunn was the Costumier. Bex Weatherhead was the Lighting Designer.

He rawe/Becoming Dress was built around the ideas of a fashion show and the matryoshka, or Russian nesting dolls. Anahera and I were the models, going down the runway in different fashions; simultaneously, we were characters acting out their drama on the stage. We began the performance wearing all the fashions/costumes, layer upon layer. The removal of each layer of fashion/costume was done in full view of the audience and was not a seamless strip but rather a struggle and challenge to break free. Our fashions/characters were:

Miki

Matryoshka

Miss Texas

Black Widow

Executive

French Maid

Dressmaker's Doll

Costume-less

\section{Anahera}

Matryoshka

Mother

Bride

Dusky Maiden

Ballerina

Dressmaker's Doll

Costume-less 
We supported this structure by utilising Reading the Body, a poem by New Zealand poet Jenny Bornholdt. In the program, where we listed the fashions/characters, each fashion/character pairing was described by a verse of this poem, though the stanzas were presented in reverse order to the original. The program is reprinted in Appendix 5. Later in this chapter, before my analysis of each character pairing, I have included their assigned verse. Excerpts of this poem were also projected onto the Matryoshkas at the beginning of the performance. We felt that this poem spoke of the primacy of the body in this performance, as Anahera wrote in her journal on 4 April when she was playing around with ideas about using this poem as a structure:

The body dances

the body speaks

the body's own language \& song.

It was through our Butoh body archaeology that we created the performance. We also felt that each verse of the poem captured an essence about each character pairing and would help the audience find their way into the performance. As it turned out, the performance was clear enough for the audience to grasp without even any fashion/character names. On the first night of the performance, there was a glitch and the programs were never passed out; however, the after-show Q\&A showed that this did not diminish the audience's understanding and appreciation of the piece.

While the order of the fashions/characters was set in advance, the choreography was improvised. The physical expression of the characters was not generated from a physical space, but from finding the Butoh Space for that character in that moment in time in that specific environment. As discussed in Chapter Three, Butoh Space is the lived experience where boundaries are erased, where sense of time, place and self are altered, and from where authentic movement arises. So even though the movements were not exactly the same for the two performances, there was a shared space between them.

From the start, we knew we wanted to create the feel and atmosphere of a fashion show, so that led us to construct a catwalk, include video projections and have a live DJ as well as elaborate fashions/costumes. Each of these elements is discussed in turn below. 


\section{THE STAGE}

He rawe/Becoming Dress was performed in the Film Archive theatre that was usually used for cinema screenings and had no stage. The advantage of this setting was that the space was re-configurable. A T-shaped transverse stage was erected, and in the centre of the T was a large screen that was alternately used for video projection and shadow play. On the two long walls of the theatre were video projections. The audience was seated on three sides of the stage. There is a floor plan of the theatre layout in Appendix 6.

Unlike the proscenium theatrical experience, where the audience all face the same direction and the actors play to only one direction, there was no one definitive view of the performance; each audience member had their own unique position and perspective of the stage, performers and videos. Additionally, almost all the views included not only the performers and video(s), but also other members of the audience. These aspects of the configuration contributed to a theatrical experience where the audience was actively involved rather than passively watching.

When considering the venue for our performance, before we even knew what it was going to be, Anahera and I both wanted to perform in a theatre, but for different reasons. For Anahera, with her background in ballet, contemporary dance and acting, this was a familiar, comfortable place to perform. This project was to be only her second major Butoh performance, one where she would be only one of two performers. For me, on the other hand, most of my Butoh performances had been either in the street or sitespecific locations. However, I wanted to see if I could create work in a theatrical setting that still involved the audience in the way that street and site-specific work does. As I discussed in Chapter Three, Critical Butoh is strategic about where it is performed, and I had concluded that, in order for my work to become part of the larger societal discourse, it was necessary to be able to successfully present work in a theatrical setting. One of the reasons was that, as a rule, street performances are not reviewed, but theatrical ones are. The validity of this line of thinking was borne out; He rawe/Becoming Dress was my first performance to be reviewed. The review is in Appendix 7 and is discussed in Chapter Six.

Once we decided that it was to be a theatrical performance, we looked at locations that could fulfil our logistical requirements. We needed a re-configurable space that was available within our project's timeframe. Additionally, since we had a very small budget, 
we were hoping to have a venue at no cost and that would handle the publicity for the event. It was for these reasons that we came to perform at the Film Archive. The Film Archive, as the name indicates, houses 'predominantly New Zealand film, video and television dating from 1895 to the present day' (The Film Archive/Ngā Kaitiaki O Ngā Taonga Whitiāhua 2011). Interestingly, when William, Anahera and I first began collaborating on Nō Näianei, it was here that Anahera brought us to show us documentaries on Bastion Point, the Land March and other key moments in recent Māori history.

\section{THE VIDEOS}

There were a total of five video projections in He rawe/Becoming Dress.

Two were raked on the long walls of the theatre in order to distort the image and were exactly the same video, though played 30 second out of sync, so identical images were not displayed at the same time. These were running when the audience entered the theatre and ran continuously throughout the performance, going to black when Anahera and I became Costume-less. The video was divided into seven sections that corresponded to the seven fashion/character pairings. They were constructed from a mixture of found footage from fashion shows, both historical and contemporary; newsreels showing the manufacturing of thread and fabrics; 1950s promotion for Simplicity patterns; a model selection process; and a time lapse showing the process of going from 'real' woman to model (hair and makeup application) to photograph to photoshopping the photograph to billboard. These projections functioned to (1) bring images of 'real' fashion shows into the space; (2) act as counterpoints to the 'liveness' and flawed bodies of the performers on stage; and (3) offer brief reminders of the business behind the manufacturing of these images. William Franco found the footage and was the supervising editor, while Fern Karun was the editor. (See the accompanying DVD to view this video.)

The centre stage video was a black-and-white video of extreme close ups of the bodies of women of a variety of ages, colours and shapes. The purpose of this video was to provide an alternative mediated image of women's bodies to the mediated images of the fashion show models. Further, it was hoped that women would have a response to seeing these imperfect bodies on the screen in that they would not only judge those bodies on the screen but would be comparing themselves to them as well, willingly or not, 
consciously or not. Again, this video was running when the audience entered the theatre and ran continuously throughout the performance, except when the performers went behind the screen to do shadow play and the last few minutes of the show. The video was shot and edited by William Franco. (See the accompanying DVD to view this video.)

As mentioned earlier in this chapter, the remaining video was scrolling excerpts from Jenny Bornholdt's Reading the Body poem that was projected onto the shells of the two Matryoshkas. It read:

\section{THE BODY AS ANT}

The body lives underground

in a nest

and collects food.

\section{THE BODY AS INCIDENT}

The body

happens to itself

by itself.

\section{THE BODY AS INTENTION}

It means so well

that it falls backwards over itself.

THE BODY AS MASTERPIECE

The body

is still

life.

\section{THE BODY AS DESIRE}

The body

desires

a body

any body

just not its

own body.

The text was selected by Anahera and me. The video was created by William Franco.

\section{THE SOUNDTRACK}

Originally, we envisioned a woman DJ with her gear, scratch table and all, as another performer in the theatre, though not on the stage with us. However, given the small 
stipend we could offer in relation to the amount of work required to construct the soundtrack-DJ's specialise in certain kinds of music and we wanted the soundtrack to encompass all genres, including those not normally associated with DJ'ing-we could not find someone to work with us on this project. This turned out to be a benefit. Out of necessity, William stepped in and created our live, improvised soundtrack. The three of us-Anahera, William and I-collected and contributed music, while William, using an iPod, an audio mixer, a computer and a CD player, created the mix as we performed on stage. I say this outcome was a benefit because it turned out that the DJ needed to be able to 'dance' with us on stage — that is, to understand the nature of our Butoh performance and respond to, as well as inspire, what we were creating on stage. Because William had performed Butoh with us, he was able to accomplish this with great success.

\section{THE FASHION/COSTUMES}

Because He rawe/Becoming Dress was based on the premise of a Butoh fashion show, the fashion/costumes were an integral element of the performance. We were fortunate to be able to work with Janet Dunn, who had participated in many fashion shows throughout her career as a fashion designer. The relationship between the three of us was very collaborative. Once Anahera and I discussed with Janet the concept of the work, what we were hoping to accomplish and an in-depth analysis of each of our characters, Janet quickly became a partner in bringing the fashions/costumes to life, as well as resolving the not-small logistical challenges of nesting one fashion/costume over another.

Given the intersection of fashion and costume in this piece, it was important for us to understand this terrain in regards to our purposes. During our 23 February 2009 meeting, we concluded that costume works in service of the performer, whereas in fashion, the model is in service to the fashion. We mapped out the details as follows:

- Clothing is material and tangible, but fashion is image. Fashion could be seen as a form of costume in that, as Janet wisely stated, 'people present a particular face to the world or a particular persona.'

- There is an indefinable intersection between performance and fashion. The catwalk is a performance arena and theatricality is often invoked in its presentation. Janet mentioned how the fashion designers, Comme les Garcon, are 'working in fashion, but injecting it with a lot of social commentary.' 
- In some fashion shows, there is the idea that these garments are designed to be worn in certain contexts, like eveningwear and sportswear. However, in the avant-garde shows, there is no such pretext. By its nature, fashion is defining and restrictive, and there is a tension between fashion on the runway and fashion in daily life.

- Costumes are about creating an impression and they are often made with—as in our case-tight timeframes and budgets. The pragmatic takes precedence over the aesthetic. In fashion, especially haute couture, it is all about the aesthetics with practically no restriction of time or money, and the end product shows that - they are exquisite pieces of material and craftsmanship that bears up under scrutiny.

After the costumes were completed, we were all pleased with the outcome. In our 11 March 2009 meeting with her, Janet remarked, 'When I put them all together, I go, wow, there is a kind of fashion feel about them, as a set of garments. 'Cause if you think back to the Victor \& Rolf layers, where we got the idea for the outer covering from, that's what's brilliant about them. It's such a brilliant fashion statement in itself. Every item, every layer has got that fashion feel to it...'

In our initial stages of conceptualising the characters and their costumes, Anahera and I wondered about the effect the big, fantastical costumes that we were envisioning could have on the audience, questioning whether they would come to dominate the performance and shift the audience's focus away from us and the meaning of the piece. However, once we realised that only the first costumes would be big because we would be stripping them off and getting smaller and more intimate as the piece went on, we recognised that this sequencing would serve to engage the audience in the hype and excitement of a fashion show by giving them some really big visual 'eye candy' while they adjusted to Butoh reality and time, knowing that it often takes a while for an audience to settle into a Butoh performance.

\section{INTRODUCTION TO CHARACTER ANALYSIS}

In our lived lives, Anahera and I absorbed the experiences of real women we knew, the images and stories of women in the media universe, the social constructs of gender as conveyed by them and, as women deeply concerned with women's lives and issues, 
feminist theories that came our way through written texts and other non-tangible means. We absorbed them through our own idiosyncratic filters that allowed contradictory ideas and beliefs to come in and live comfortably side by side with each other. As beings that exist across time - that is, we age and the world around us changes over time - the new is absorbed without necessarily discarding the old or examining the old vis-à-vis the new.

In creating He rawe/Becoming Dress, as the previous chapter illustrated, we strove to bring out and examine these 'absorptions' that continue to influence our lives, in particular, those that were hindering our ability to live happy and fulfilling lives as women and as coloniser-indigene. Because of our Buddhist belief that personal transformation can affect change in society, we viewed this process not merely as a personal journey, but a societal one as well.

Butoh, because of its fluid, transitory nature, its coming-into-being, going-out-ofexistence quality, its ability to hold contradictory spaces at the same time, was the perfect medium for this exploration. However, it is these very same qualities that make it a very challenging task to render the meaning of a Butoh performance into written words. Words are black and white solid shapes captured on paper, while Butoh is multi-colored, multi-layered shape shifting, passing and fading away. Further, in the case of this chapter, these written words are within the context of a doctoral thesis that demands academic rigour and consistency. Therefore, my following analysis of the characters will try to hold this tension between 'lived' and 'written' and 'academic'.

Before explaining how I constructed the following analysis, I want to state very clearly that this is only one possible interpretation of this performance. He rawe/Becoming Dress does not have a single, monolithic narrative nor does it offer one definitive interpretation. I have based my analysis on the transcripts of Anahera's and my meetings, our journals, personal communications with Anahera, my experience of performing it and watching the video of the Saturday night performance. ${ }^{19}$

${ }^{19}$ Due to technical difficulties, the recordings for the Friday night performance were unusable. 


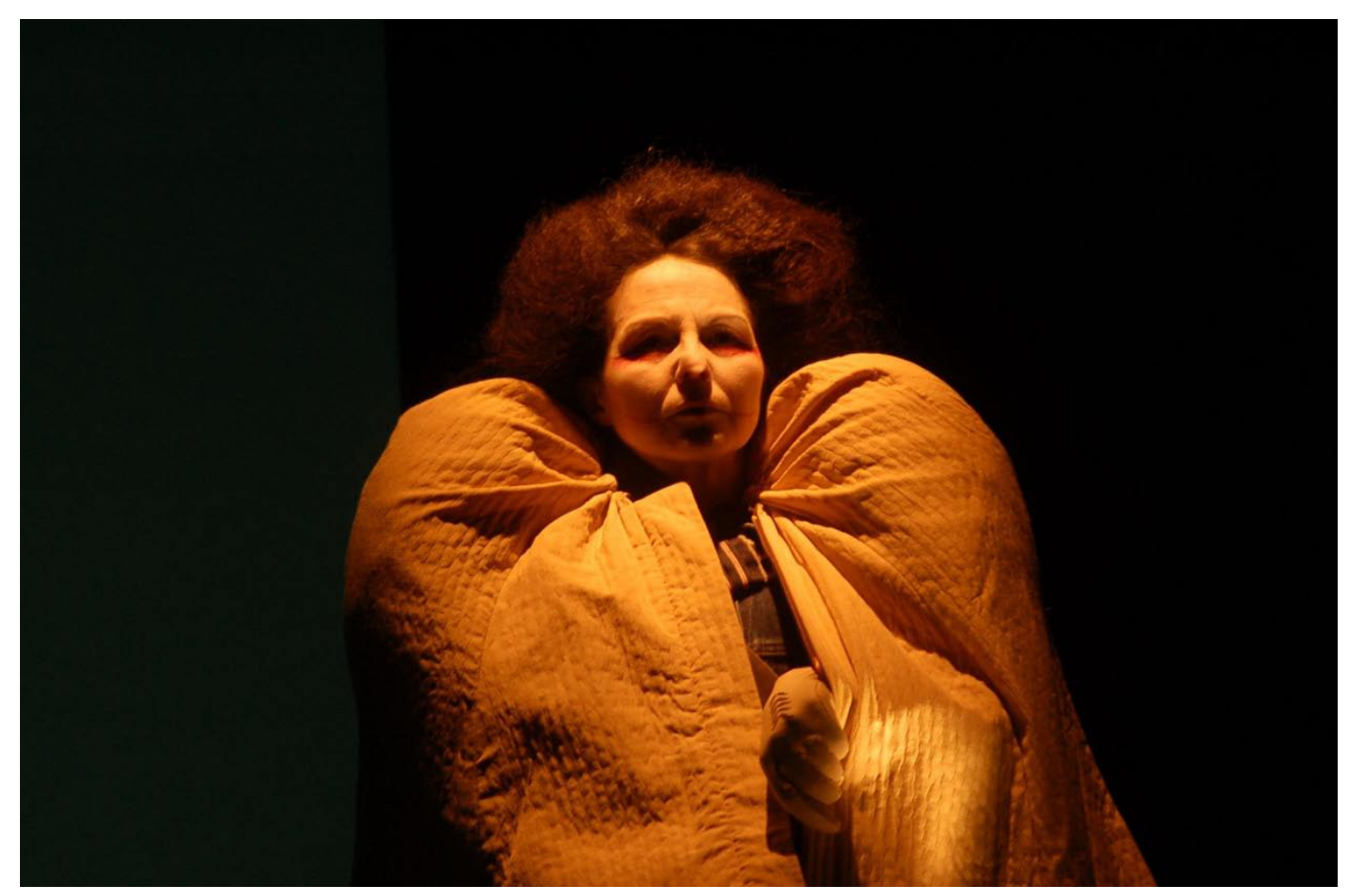

Miki Seifert as the Matryoshka. (Photograph by Chris Murphy)

\section{THE MATRYOSHKA}

THE BODY AS DESIRE

The body

desires

a body

any body

just not its

own body.

-Excerpt from Reading the Body by Jenny Bornholdt as presented in the program for $\mathrm{He}$ rawe tona kakahu/She Wore A Becoming Dress 


\section{The Description}

The Matryoshka literally set the stage: welcoming the audience, defining the context of the performance and suggesting what is to come. When the audience entered the theatre, the performance was already underway. They entered into an alien universe that enveloped them, drawing them into its yet-to-be-known, yet-oddly-familiar reality. When attending a performance, a 21 st century audience expects to be entertained, to experience spectacle, to have sensory stimulation, perhaps even overload. The presentation of the Matryoshka responded to those expectations with five video projections contained not just on box-like screens, but bouncing off the walls and snaking up the performers. This visual spectacle was accompanied by the repetitive, pulsating calls from the first minute of Emerson, Lake \& Palmer's Karn Evil 9: 1st Impression, Pt. 1:

Welcome back my friends to the show that never ends

We're so glad you could attend

Come inside! Come inside!

There behind a glass is a real blade of grass

Be careful as you pass

Move along! Move along!

Come inside, the show's about to start

Guaranteed to blow your head apart

Rest assured you'll get your money's worth

The greatest show in Heaven, Hell or Earth

You've got to see the show, it's a dynamo

You've got to see the show, it's rock and roll

Right before your eyes we pull laughter from the skies

And he laughs until he cries then he dies then he dies

Come inside the shows about to start

Guaranteed to blow your head apart

You gotta see the show

It's a dynamo 
You gotta see the show

It's rock and roll

Dominating the space, however, were two silent and motionless alien creatures.

Impressive and commanding through the strength of their presence, they beckoned the audience to 'come inside', bidding them to question what lies beneath, 'guaranteed to blow your head apart'. This 'beneath' was to be excavated, stripped away, exhumed. There were hints of what was to come: the words scrolling up the bodies of the aliensthe body as ant, as incident, as intention, as masterpiece, as desire; the unsettling video images of women on catwalks and of female body parts; the physical construction of an actual catwalk; and the lyrics of Karn Evil 9-'he laughs until he cries then he dies then he dies'—all suggested a darker, existential spectacle to unfold.

It was a most definitely female body universe, though the usual ways of displaying women's bodies, either clothed in extravagant feminine costumes or nude, were appropriated for purposes other than the titillation of the male gaze. The raked projections of the fashion models on the catwalk distorted their rail-thin bodies, while the non-eroticised, non-airbrushed black-and-white nudes of 'real' women's bodies displayed textured landscapes of flaws and imperfections, of lives lived and memories embodied. In contrast to these exposed bodies, the bodies of the performers remained silently cloaked in heavy fabric. Even the usual signs of being female, hair and make up, were appropriated to express the desires of the ones wearing the hair and the make up rather than to instill pleasure and desire in the viewer. Our faces and bodies were covered in white make up, as is generally the custom for Butoh performers. To this, we added red make up above and below our eyes, as well as used red lip liner to colour our lips and draw a thin line from our lips to halfway through each cheek.

After ten minutes of stillness, one alien began moving down the catwalk. She clearly tried, despite the inappropriateness of her size and shape, to perform the signs of the female human as she was projected on the walls of the theatre. Meanwhile, the second alien began to crack through her shell, gradually and grotesquely emerging, relishing the exposure of her darkness. Despite their similar outer appearance, their bearing and intentions were quite different. One embodied the desire to conform to the external images, while the other determinedly remained alien, embracing her darkness and otherness. 


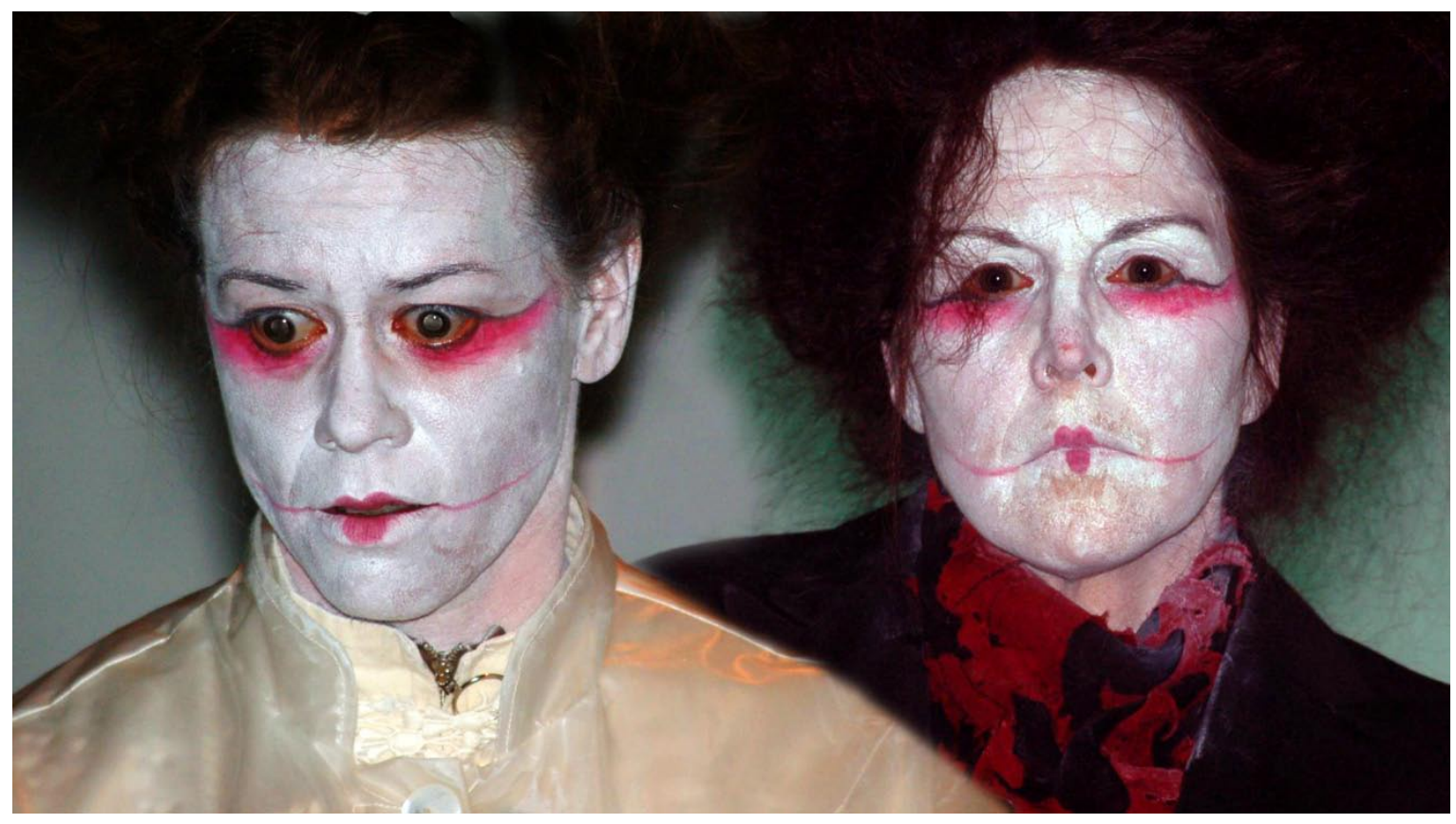

Close up of make up - Anahera Gildea (left) as the Mother; Miki Seifert as the Black Widow. (Composite by William Franco; original photographs by Chris Murphy)

\section{The Themes}

The Matryoshka embodied the various meanings that could be ascribed to 'alien' and 'alienation'. Drawing from both feminist and postcolonial theorists, the Matryoshka's alien-ness was that of being the Other (Said 1995).

In her presentation of both recognisable and unrecognisable human features, one possible reading of her encounter with the audience was that of a re-creation of the colonial encounter. The audience members were the colonists arriving for the first time in this new territory, which has yet to be explored and understood in their terms. Having purchased their tickets, they arrived with the expectation of ownership, of being able to claim a piece of the territory as their own. However, the environment was unfamiliar and unknown. The usual signs of a traditional performance were not present. There were no assigned seats nor ushers to show them the way. To even those who had attended other events at the Film Archive, the space would have been unfamiliar. We had unbolted many of the rows of seats and changed their orientation, re-configuring the space and adding a raised transverse stage and full theatrical lighting. This was the first time such a performance was held in this venue; the Film Archive had even had three-phase power installed for us, so we could use professional theatrical lighting. 
Unlike more traditional theatrical performances, where the audience enters, then the performance begins, our performance was already underway when they entered. They entered into a disorienting environment that was dimly lit, with large images flashing on two walls, loud rock and roll music playing, and a transverse stage that interrupted the seating configuration.

Then, there was the presence of the Matryoshkas on the stage. They dominated the space through their size and stillness. We intentionally played with their scale. I, who am a mere 1.55 metres, stood on a $30 \mathrm{~cm}$ high box. Our hair was large and added to our height. In the initial colonial encounter, before the mass influx of settlers tipped the power relations in their favour, the indigenous peoples of North America and Aotearoa New Zealand were seen as fierce and savage. Stephen Turner explains that the worldview of the colonial Europeans was shaped by Hobbes and Locke and, therefore, they believed that a 'society without a sovereign was by definition primitive, and most likely violent' (Turner 1995: 42). Having such a perspective, Captain Cook, upon seeing the Māori $p \bar{a}$ (fortified villages), commented 'that this people must have long and frequent wars, and must have been long accustom'd to it...' (Turner 1995: 60) and Joseph Banks, an amateur scientist aboard the Endeavour, upon acquiring a preserved head, observed that the Māori 'give no quarter [in battle]' (Turner 1995: 60).

This 're-enactment' was not merely historical referencing, but provided one of the key underpinnings of the whole performance: that as citizens, we participate on a daily basis in the re-creation of our nations and, therefore, we, as performers, in both the private and public sense, are not only responsible for its continuation, but are empowered to change it. For the theoretical basis of this, I am indebted to E. J. Westlake's essay on a Nicaraguan women's theatrical collective: national identity is based not only on a shared culture that is transmitted through institutions, but also an imagined shared culture that is transmitted through media, which 'shapes the idea of the nation within the imagination of the citizen', therefore, Westlake concludes that ' $[\mathrm{t}]$ he drive is to create a seamless sense of one nation, but the performances are inconsistent and fragmentary, leaving openings for the formerly disenfranchised to enter the debate' (Westlake 2005: 22).

While Westlake's discussion describes the instability of national identity with regards to Latin American nations, there is no reason to think that the social construction of nationhood in First World nations, like the U.S., is any different. The mechanism is merely more firmly entrenched, providing the illusion of epluribus unum and eternal 
nationhood. In He rawe/Becoming Dress, Anahera and I offered an alternative experiential construction of the dualistic relationships that form the foundation of national identity in settler countries, such as the U.S. and Aotearoa New Zealand: indigene and settler, female and male, other and self. He rawe/Becoming Dress used Kester's concept of the aesthetic, as first explored in my Introduction, 'to identify and describe the operations of the political, social, cultural, and economic power, while at the same time allowing it to think beyond the horizons established by these forms of power' (Kester 1998: 8).

Though their world was vibrant and disorienting, our imposing Matryoshkas sought neither confrontation nor conquest with the audience but grounded in their hidden identities as Bodhisattvas of the Earth, they wished to embrace the audience with compassion and together embark on a non-verbal dialogue to transform these dualistic relationships. As discussed in Chapter Two, for the purposes of this performance, the Bodhisattvas of the Earth represented a revolution in consciousness, connectedness, groundedness, empowerment and transformation. As modern-day Bodhisattvas of the Earth, our Matryoshkas willingly took on and sought to transform the trials of their lives into order to encourage others 'to seek out their own inherent brilliance' (Ikeda et al. 2001: 208). Through their behaviour on stage, the stripping away of layers of costumes, which, in this instance, can be read as delusions, our Matryoshkas revealed not only their true identities but that of the audience as well. As Ikeda finds, 'The appearance of countless Bodhisattvas of the Earth in the 'Emerging from the Earth' Chapter points all people to the greatness of their lives' (Ikeda et al. 2001: 208).

Another, simultaneous reading of the Matryoshka was as female responding to the gaze, which was discussed above. While she was still subjected to the implications and consequences of the male gaze, she has absorbed the gaze and its values and judgments and turned it so ruthlessly on herself that she has become alien to herself. This will be further explored in the following discussions of the remaining characters. 


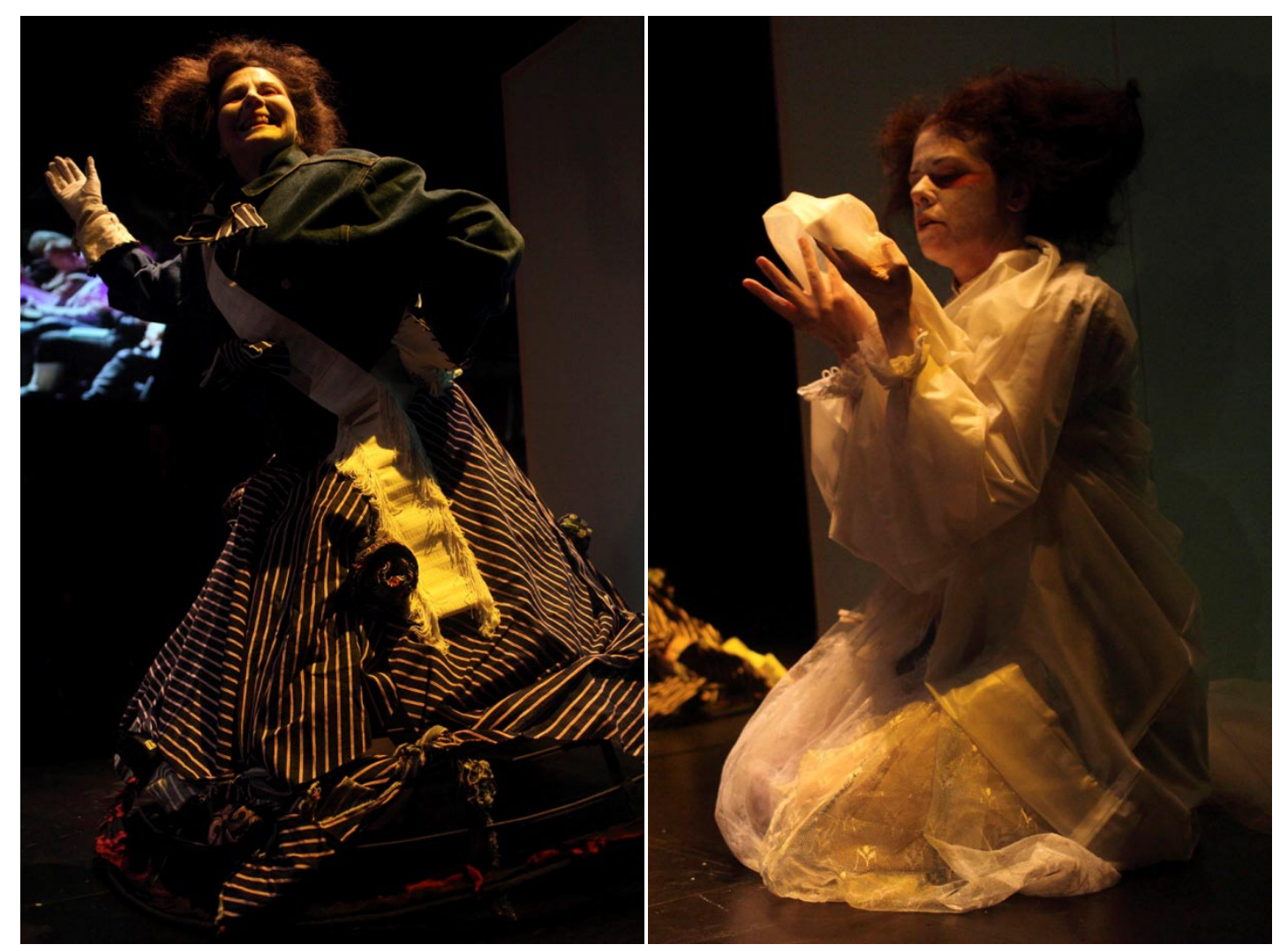

Miki Seifert (left) as Miss Texas; Anahera Gildea as the Mother. (Photographs by Craig Thomson)

\section{MISS TEXAS / THE MOTHER}

THE BODY AS MASTERPIECE

The body

is a big body

is a work

of Art.

The body

is still

life.

-Excerpt from Reading the Body by Jenny Bornholdt as presented in the program for $\mathrm{He}$ rawe tona kakabu/She Wore A Becoming Dress 


\section{The Description}

The larger than life, aging beauty queen Miss Texas triumphantly emerged from her Matryoshka shell into the pulsating, competitive world of beauty and fashion. Dressed in a cowboy blue jean jacket, pioneer-inspired red, white and blue jean skirt that only partially covers the black crinoline beneath, thoughtfully accessorised with white cowgirl gloves, she confidently strutted down the runway, accepting imaginary applause and kudos, oblivious to her grotesqueness and misshapen body, unperturbed by her uneven gait caused by a missing white boot. She was the mistress of her world.

Yet when she almost finished her return upstage, the Mother, dressed in a sheer plastic muumuu-housecoat with lacy cuffs poking out from the plastic sleeves, was beginning to emerge from her shell. Within the Other (the Matryoshka), there was now a new Other. The Mother tentatively found her way out of her Matryoshka shell, carefully taking her first step into Miss Texas' world. Unsure of herself and her place in this world, she hung back, almost willing herself to remain unseen. She hesitatingly echoed the gestures made by Miss Texas who was now on her way back downstage. This time, as she moved down the runway, Miss Texas' demeanour began to subtly shift from unassailable confidence to uncertain questioning. A foot dangling in mid-air asked where it should be placed, and soon she found herself face down in a crumpled heap at the end of the runway, the same foot raised behind, again questioning its place. Still, she steadfastly strove to remain in control, as she slowly returned upstage, walking on the very edge of the runaway like a tightrope performer, passing the Mother like ships on the night sea.

As the Mother moved from the background into the limelight, a quiet air of domesticity blanketed the stage. Her hands alternatively carried the imprint of mundane daily household chores, the loving touch of a mother comforting her baby and the loss of something of great value. She moved with purpose but tried not to draw attention to herself. After she had made her pass down the runway and returned upstage, she turned and, as if she suddenly remembered she's a woman being looked at, her hand selfconsciously reached to check to see if her hair was in order. As if this remembrance of womanliness had prompted a memory, she began to remove her plastic muumuuhousecoat. 


\section{The Themes}

The earlier examination of the Matryoshka was from an assumed outsider position, as if I was separate from this character, as if I were not her creator-performer, as if I did not embody her, and she, me. This approach worked for the Matryoshka because of her function as the theatrical construct of setting the stage and her embodiment of alienation and separation. However in order to discuss Miss Texas and the Mother, as well as the other remaining characters, it is necessary to delve into the shared space that exists between the characters and Anahera and I as creator-performers.

The characters of He rawe/Becoming Dress came about as devices or constructs through which Anahera and I could examine our own distress in response to being women and to being coloniser-indigene, and as such, our relationship to our characters is similar to the relationship of our actual faces and the reflection of our faces in a mirror. Further, just as a mirror allows us to see aspects of ourselves that we would not otherwise be able to see, our characters allow us to examine aspects of ourselves that we cannot easily see. In this case, the word 'reflection' works on multiple levels.

Finally, in order for my reflection to appear, my presence is required. So, too, with my characters. However, in Butoh, presence goes beyond mere physicality. It encompasses the presence of the whole being. Because we are present in the performance of our characters, our internal experience is expressed to the audience. Therefore, it is entirely appropriate-necessary even—-to discuss Anahera's and my thoughts, feelings and intentions about these characters, in addition to the assumed outsider position.

Even without her moniker, Miss Texas was clearly a white, American woman, who, through her possession of the signature American traits of (over)confidence, competitiveness and bigness, inhabited a world of her own invention. She believed this was the best of all possible worlds, despite potential evidence, like her missing shoe, to the contrary. However, she was not as secure in her delusion as her initial performance suggested. Did her uncertainty arise from some unknown internal memory that bubbled to the surface, or was it a reaction to her unacknowledged encounter with her Other, the Mother, or some combination of the two? In any case, she was not quite capable of examining her assumptions, but she wavered slightly. A chink, however small, in her armour had appeared. 
Miss Texas developed after I saw the photos of myself in costume as the Puritan/Victorian. Immediately I saw that, as presented in the photo, she was too historical. Through this character I wanted to convey colonisation as a contemporary act, that the continuation of the U.S.A. is an ongoing expression of the colonisation of the indigenous people of the Americas, that I, as a white, American woman, participate in its re-constitution every day. Her costume/fashion gave no sense of her being American. In this performance, I needed to be identified as an American, as my characters and their issues grew out of that continental, Empire-making soil. Further, in the Introduction, I argued for the use of a transnational lens to locate my position in the coloniser-indigene relationship finding it both valid and valuable in such a research endeavour, as well as discussed how Buchanan found that the history of settler states and one's own family history implicate one another. As the previous chapter showed, Anahera and I did indeed excavate our own individual and family histories to comment on gender and colonisation in He rawe/Becoming Dress. This process required us to trust the other enough to allow ourselves to be vulnerable, as well as to be able to offer nonjudgmental support to the other. One of the reasons we were able to do this within this project's timeframe was because we were not from the same indigene-coloniser pairing, which mitigated the possibility of potential conflicts arising from a shared history and its emotional baggage.

I discussed my realisations about the Puritan/Victorian with our costumier Janet. Together we concluded that we should contemporise the costume/fashion and include distinctly American markers. With regards to contemporisation, we drew from a skirt from Vivienne Westwood's Anglomania Collection, Autumn/Winter 1993-94 and a dress from her Wild Beauty Collection, Autumn/Winter 2001-02, both of which engage with street fashion, history of costume and antiquated elements of dress (Hodge et al. 2006: 244-5). As for American markers, we came up with blue jeans, cowboys, beauty pageants and red, white, and blue, though we determined to use the latter subtly. Out of this process, Miss Texas was born.

The Mother's sheer plastic muumuu-housecoat spoke volumes about her life. The muumuu itself referenced the history of colonisation in the South Pacific. The muumuu was just one of the varieties of Pacific Island dress that developed from the Mother Hubbard dresses that the missionaries brought to the Pacific Islands (Kuchler and Were 2005: xxiii). Fashion historian Chloe Colchester states that Protestant missionaries placed an emphasis 'on defining ordinary everyday activity, a pursuit in which the imposition of 
foreign practices of domesticity, home-making, dress and deportment were regarded as being as central to conversion as translating the Holy Book' (Colchester 2003: 2). The elegant craftsmanship of this hideous, baby vomit-proofed frock, lacy cuffs defiantly poking out from the plastic sleeves, suggested that something more lay beneath, something that remained obscured from view by the necessities and practicalities of family life, much like the plastic slipcovers that women use to preserve the sofa in the family living room. The Mother was a real woman, full of exhaustion, tension and resentment from endless nights of interrupted sleep followed by never-ending days of mopping, washing, cooking, sewing, bathing, dressing, feeding, and tending, encased in the mythic matriarch who maintains the perfect household, never raises a word and joyfully sacrifices her greater life for the fulfillment of motherhood.

In our debriefing meeting after the performance on 29 April 2009, Anahera explained that she conceived of the Mother as a way to reconcile-and find compassion for-her own experience as a mother with the experiences of her mother and all the mothers who came before her, with her experience of those women as mothers, with all of their, expressed or unexpressed, desires for independence, sexuality, fulfillment of their personal dreams — in short, a life of their own — with the myth of motherhood:

They created this myth of the mother, which means we have no compassion for her as a woman. What were her dreams as a woman? How does she be a wife when she's mother to nine children? How does she be a sexual woman when she's mother to nine children that she's up all night dealing with? The stories, the myth of the mother who sat up all night rocking her sick child - who is she as a woman in that moment? How is she defined other than the mother? (29 April 2009)

Despite her plastic muumuu-housecoat, the Mother carried herself with dignity and purpose. She was solemn and focused. She carried the gift and burden of life. Somewhere inside her, she knew that, despite its mundaneness, her daily life was also the enactment of the great drama of life and death. Daily she faced death: her children, whom she has birthed, will inevitably die. Yet she continued on.

The Mother emerged into a world different than who she is. While the differences between Miss Texas and the Mother were obvious, there was another level to this difference. The Mother was Māori, though the audience may not yet have perceived her 
Māori-ness since the Mother-and all of Anahera's characters with the exception of the Dusky Maiden—foiled the typically held racialised stereotypes of Māori. Further, Anahera was intentionally seeking to create a portrayal of Māori women who reflected her experience, something she has had difficulty finding. As she related in our meeting on 26 January 2009:

We're still in the stage in Māori literature of having very customary traditionaltype figures or having contemporary urban Māori figures, but we haven't got that many. Obviously, I haven't read everything that's been written, but the prevalent ones that we got aren't literary Māori women. They're just not. They're trapped Māori women in urban society. They're not university-schooled, which is my background. It's really interesting when you say culturally representative I'm going to have to work very hard to find that. I may find emotionally culturally representative women, but not in terms of so many aspects of how culture works for me.

Her characters embodied a Māori perspective: the way they see themselves in the world and the way they conceive of the world. What did this mean concretely? When Anahera and I were in the early stages of developing this project, Anahera's viewpoint was always constructed through her connection with other women. Her comments usually contained references to other women-her tipuna, her mother, her women friends. As she said in our 30 March 2009 meeting, as a Māori woman, she is never alone: 'I have ancestry. It never leaves me. I'm never alone... When I die, I will be welcomed into the same spaces as all my ancestors have gone.'

When the Mother emerged, it was into the world of Miss Texas, a place of whiteness, individualism and competition, a place very different than her own which values whakapapa (genealogy), whanaungatanga (focus on relationships)and manaakitanga (looking after people). Whereas in western culture the focal point is the individual, in Māori culture it is relationships. Whakapapa, according to Māori scholar Hirini Moko Mead, is 'a fundamental attribute and gift of birth...A child is born into a kinship system which is already in place and has been for many generations' (Mead 2003: 42). It is through whakapapa that an individual claims his/her 'right to a place for the feet to stand, that is, türangawaewae' (Mead 2003: 43); it is the one place on Earth that s/he can claim 'I belong here.' Educator James Graham expresses an expanded view that 'recognises that whakapapa can be seen as a shared illumination of the interconnections between people 
and their spiritual and physical connections to the land and not just collective biological connections' (Graham 2009: 2). Whanaungatanga both embraces whakapapa and reaches beyond it to include non-kin people (Mead 2003: 28). Whanaungatanga expresses the responsibilities and obligations of the individual to the collective and the collective to the individual. Manaakitanga is 'nurturing relationships, looking after people, and being very careful about how others are treated' (Mead 2003: 29). Manaakitanga is the value that underpins all Māori customs (Mead 2003: 29).

For the Mother then there was an immediate dilemma: according to whose values should she raise her children? In our 30 March 2009 rehearsal, Anahera articulated the Mother's position this way:

Mother is all about...I want to meet the needs of my ancestors, but I'm encountering white, middle class judgments here and I have to meet them to be a good mother, but I have to meet my ancestors' to be a good mother, but I'm not meeting either of them.

Elsewhere, Anahera elaborated:

As mother, I was trapped in plastic (capitalist, materialist, white person's) housecoat that was transparent...As I performed my role as Mother, I battled internally with how to perform this (WHITE) role while at the same time having 'mother' unalterably connected to Papatūanuku [the land] and all my 'genealogical mothers'-I reach down into the earth to find them and myself and I cannot connect with them but/yet I have produced offspring that I am letting into this world. (personal communication, 25 February 2011).

The Matryoshka positioned herself as Other to the audience, but then the pairing of Miss Texas and the Mother raised the notion that there can be Others within Others, that the positionality of a white, American woman is not the same as that of a Māori woman. These characters have added another layer to the performance's exploration into the intersection of gender and colonisation. They have raised questions and issues, but offered no answers. They have grappled with their own inner conflicts but reached no resolution. They are in progress, in transition, but to what? 


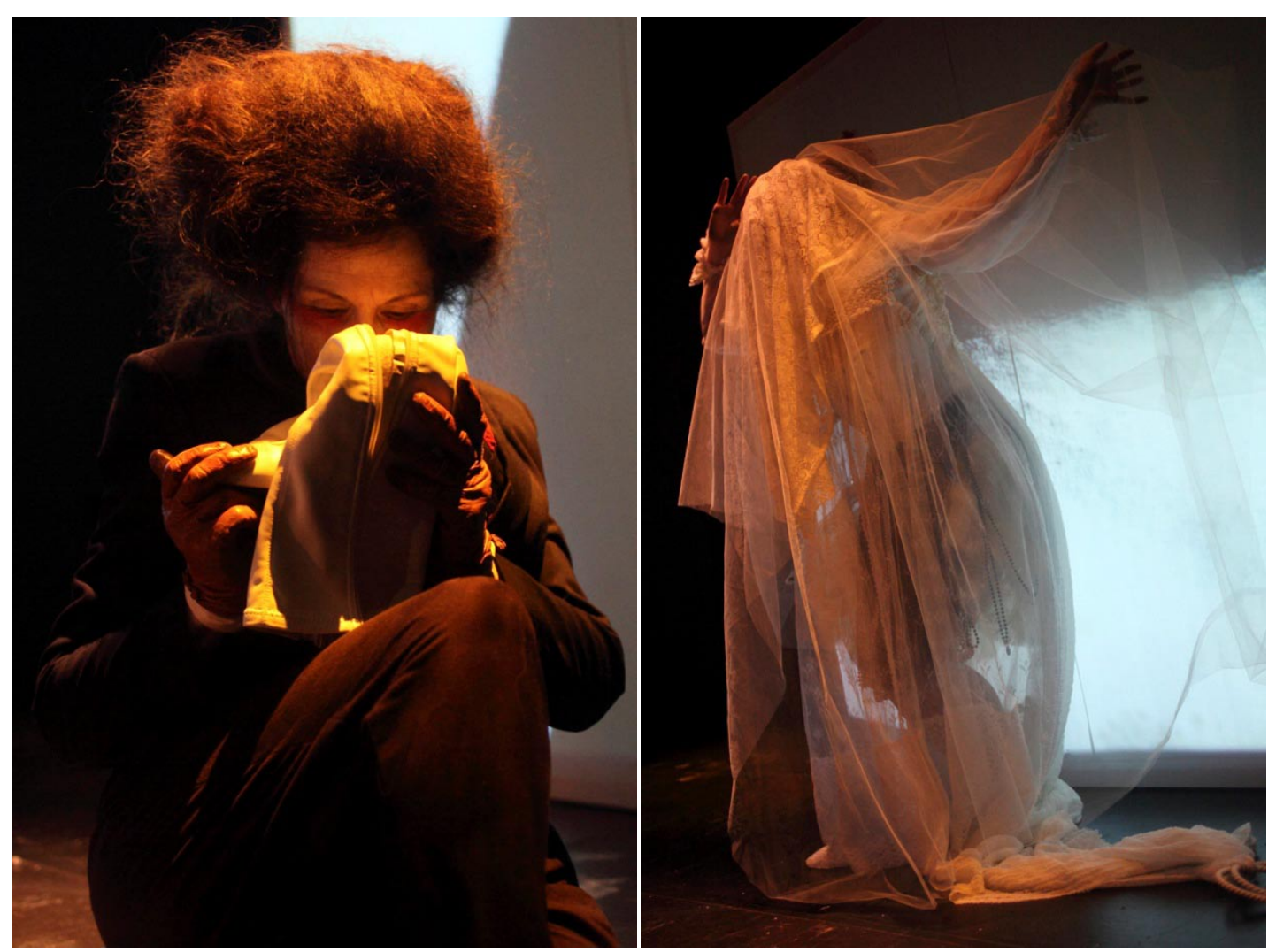

Miki Seifert (left) as the Black Widow; Anahera Gildea as the Bride. (Photographs by Craig Thomson)

\section{THE BLACK WIDOW / BRIDE}

THE BODY AS INTENTION

The body

means well.

It means so well

that it falls

backwards

over itself.

The body

is full

of good

intent.

-Excerpt from Reading the Body by Jenny Bornholdt as presented in the program for $\mathrm{He}$ rawe tona kakabu/She Wore A Becoming Dress 


\section{The Description}

The Bride was dressed in a gossamer white, Empire-waisted wedding gown, fashioned from sheer lacy curtains. She, centre stage, was kneeling, preening and primping, fawning over her gown and placing her veil on her head; performing the ritual of being a bride. As the Black Widow, dressed in a short-waisted black riding coat, black jodhpurs, brown leather riding gloves and one white boot, stepped behind the centre stage screen that had become a shadowbox, she transmogrified into a giant predatory insect. Her shadow loomed menacingly over the angelic Bride. Stepping from behind the screen, the Black Widow regained her misshapen human form. Her carriage bespoke of good breeding, refined manners and well-learned lessons in the art of proper living. Yet as she walked down the runway, a weariness enveloped her and her head bobbled, as her body wavered. Still, she flashed her Queen Elizabeth smile as she reached the end of the runway.

On the Black Widow's return trip, as she furiously rode her horse, which was she, her left hand hitting her buttock to spur on her steed, the Bride began her walk down the aisle, basking in her moment of glory, royalty for a day. The Black Widow collapsed onto the floor and swept into the Bride's story, picked up the tassel drapery tieback at the end of the Bride's train and placed it on her head. Together they formed a bizarre bridal procession, more akin to crawling and squatting than to marching down the aisle, but in the end, the Bride rose to the moment, only to discover the absence of a groom.

The procession receded. The Bride, bereft, wound herself into a cocoon of veils, as the Black Widow rolled and scooted on the floor, discarding her beloved boot in the process. Worlds have fallen apart.

\section{The Themes}

The Black Widow and Bride were the first characters to directly define themselves in relation to men - though the Mother hinted at this relationship, she is defined more in relation to her children than to her husband-and, perhaps, as a result of this, they also introduced the dualism of good girl/bad girl. Women who follow the appropriate forms of female sexual behaviour are deemed to be good girls, while those who don't are bad girls, often called sluts, whores and bitches.

Despite being from different generations, both Anahera and I found negotiating our way around this line a defining experience of being a woman. Our discussion on 11 February 
2009, which is recounted in the previous chapter, regarding the differences — and the different responses we had to them-between prostitute, whore and slut highlighted two key elements that make up the good girl/bad girl construct. First, it is a form of social control of women's sexuality that is passed to us through our families. Second, that while it is 'bad' to accept money in exchange for sex, it is worse to have sex for free. Both of us grew up with the understanding that, as women, our sexuality is not for us to enjoy but a commodity to exchange.

As the piece developed, the good girl/bad girl dualism became a subtext rather an explicit examination. As discussed in the previous chapter, while we did not plan it to be this way- that is, each of us suggested characters that we were drawn to exploreAnahera's characters, with the exception of the Dusky Maiden, represent the traditional roles of women; they are what many young girls dream about being when they grow up. My characters, on the other hand, are what no girl dreams of becoming. They are various forms of the 'bitch', incredibly strong willed and determined. They are invulnerable and refuse to be fragile. Whereas Anahera's are from the female body, mine are from the mind. They use their bodies to further their own agendas.

The Bride was 'a knowing sacrifice... [who] knew what she was doing but felt trapped as though she had no other options' (personal communication, 25 February 2011). She had subsumed herself and existed only in relation to others, as Anahera wrote in her 16 March 2009 journal entry: 'She wants to be magnificent. As she goes down the runway she is increasingly aware of those looking at her with envy, dislike and adoration. She is a receptor of others' opinions.' Hers was only a momentary existence. Once she completed her walk down the aisle and the marriage ceremony was conducted, she would no longer be the Bride. She has become a wife with the expectation of soon becoming a mother. What becomes of her when there's no groom? Anahera's journal entry continues:

She is transparent. Now the audience can see her...can see into her. Can see through her...She cannot let go of her image but she is now in DOUBT...Colonial influence - is one Maori? What does she think of herself at the end of the runway. Validity as a female bound up in being a bride. At the end of the runway she is no longer a bride. She is nothing. She disappears. TRUSSED CHICKEN. 
The Black Widow, a species of spider where the female is known to eat the male after mating, is a term used for seductive women who use their feminine charms to lure men into marriage and then kill them for their money. She is a form of the femme fatale who appears throughout literature, art and films. She hoped to be a bride or has been a bride or both, but without the romantic notions of the bride. Was her silhouette behind the Bride and her participation in the bridal procession acts of mockery? And of whom?

What is clear, when the grotesque procession retreats in disarray, is that both of their worlds have been shaken. Neither remained who she was when she first appeared. 


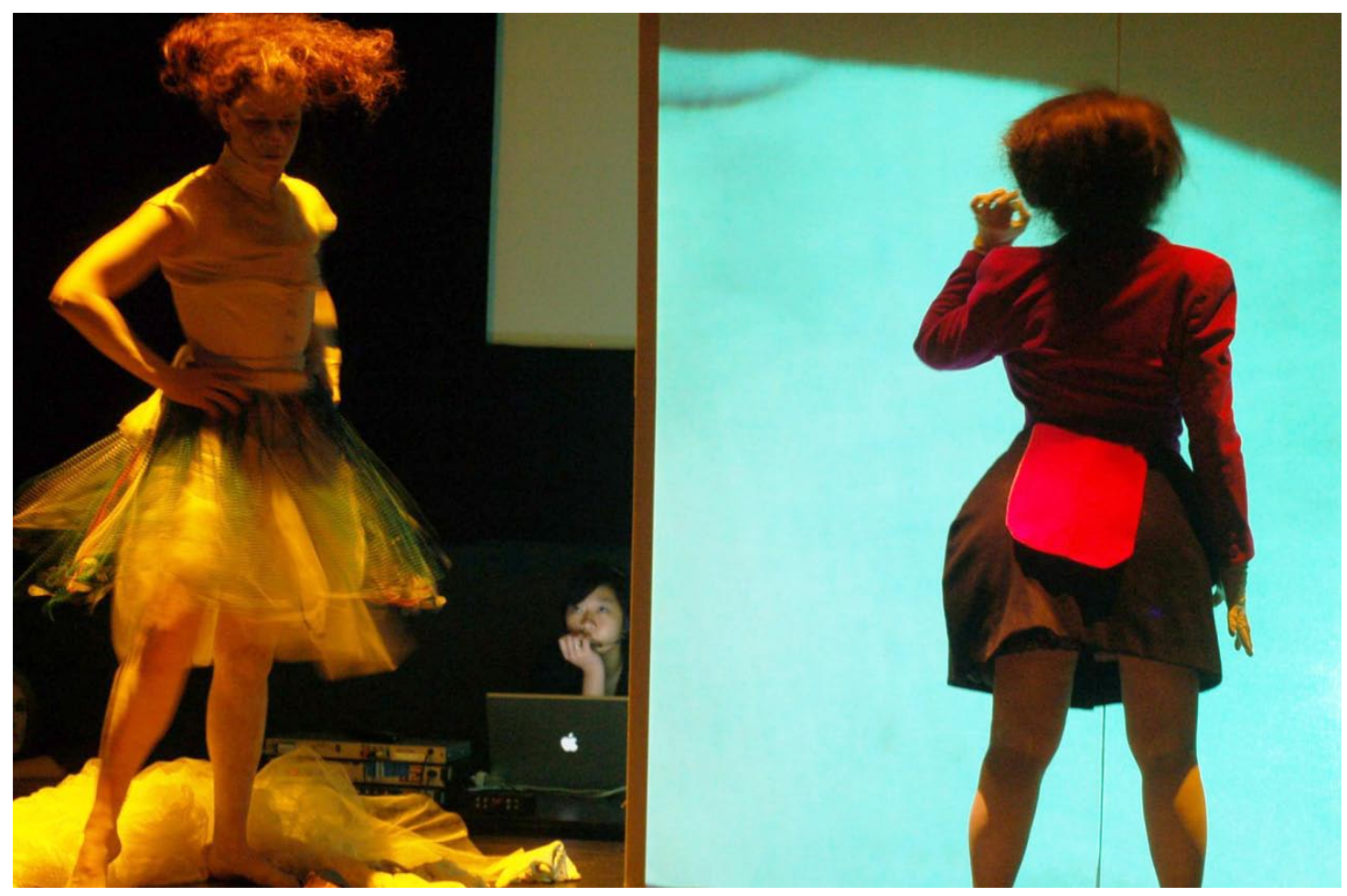

Anahera Gildea (left) as the Dusky Maiden; Miki Seifert as the Executive. (Photograph by Chris Murphy)

\section{THE EXECUTIVE / DUSKY MAIDEN}

THE BODY AS INCIDENT

The body

happens to itself

by itself.

-Excerpt from Reading the Body by Jenny Bornholdt as presented in the program for $\mathrm{He}$ rawe tona kakahu/She Wore A Becoming Dress 


\section{The Description}

The Executive's kid-gloved hands tucked, adjusted and smoothed her fuchsia pink power jacket—complete with padded shoulders and cinched waist—and her classic navy blue wool skirt, tailored with a special panel to accommodate her extra buttock. She used the centre stage screen as her mirror to apply her makeup and finishing touches to her hairdo. On the left side, the Dusky Maiden, dressed in a white corset with lace and blue ribbon trim over a modest cotton undergarment and a piupiu made from blue and orange bead strands over a tulle skirt, shook her hips, stopped, observed the Executive, strutted behind her, shook her hips and made her way behind the screen.

The Executive was already on her way down the runway-to a board meeting, perhaps? — when the Dusky Maiden's distorted, disjointed silhouette swished and gyrated behind the screen. Between her power gestures of tapping on her PDA and silently assigning tasks to her invisible minions, the Executive seemed on the verge of collapse. She bobbled and waverd, willing herself back into composure. She then began her 'presentation'- to stockholders? - standing in front of the screen with the Dusky Maiden's sitting silhouette, who was solemnly putting on stockings and Pointe shoes. The Executive traced the outline of the Dusky Maiden's outstretched leg as if it were a line of her graph of profits. Her gloved finger, in spite of itself, continued upward, pulling her until she was standing, body stretching, straining, hands and arms upraised, pressed against the screen. It was a moment when she seemed to sense the humanity behind the screen and gave into the desire for contact. She sunk down, melting almost, until she was face-to-silhouette face with the Dusky Maiden, who was gently dangling a poi from her hand. The Executive mirrored this gesture, then slowly retreated to the left side of the stage.

The Dusky Maiden, moving slowly from sitting to kneeling to standing, twirled the poi in her hands, slow, fast, slow, fast, punctuated by a hip swish. Standing, poi silenced in her cupped hands, she did a second position grand plié. Then, her hands made their way towards her mouth, as if she was going to eat her poi, but instead, she rolled them down her body until they fell onto the floor.

\section{The Themes}

With the Executive and Dusky Maiden, our characters fully entered the world of commerce and capitalism, to which aspects of the previous characters alluded. Miss 
Texas' empire is based on capitalism and exists to create new markets and control resources. The lack of value attached to the role of Mother can be seen to arise from her position as unpaid labour, which contributes nothing to the gross national product. The Black Widow brought class consciousness into the mix, as well as her English riding attire, standing in contrast to Miss Texas' western riding style, similarly referencing Empire, though British Empire. Both she and the Bride raised the issue of sex as a commodity.

The Executive is the epitome of Second Wave liberal feminism, a woman who has broken through the glass ceiling and risen to the top of the managerial class, working vigorously for her company's targets, market shares and $\mathrm{P} / \mathrm{E}$ ratios. On one level, her moments of near collapse could be read as a result of personal angst about her life, what she has had to sacrifice to get to where she is. On another level, read in relation to the Dusky Maiden, they could reference the inadequacies of Second Wave feminism to recognise and address the different standpoints of indigenous women. Summing up an indigenous critique of this feminist movement, Native American educator Sandy Grande writes: '... women of First-World nations have fought for "women's" equal pay and equal status without stopping to consider how that pay and status continue to be based on a consumption model that not only deeply compromises the lives of indigenous women but also violates the rights, lands, and resources of their respective nations' (Grande 2004: 151). Could the Executive's simulated Powerpoint presentation in front of the screen, using the Dusky Maiden's body outline as lines on her profits graph, be her unconscious acknowledgement of Grande's statement?

From paintings to photographs to adverts, the Dusky Maiden, as a marketing tool to 'sell' the Pacific to western 'consumers', has a long history, going back to the colonial period when governments funded artists 'to help popularise the 'colonies' and a colonising ideology' (Taouma 1998: 2). These images portrayed 'Polynesian women as shy alluring creatures who are sexually knowledgeable but fundamentally naïve' (Taouma 1998: xii). Art historian Lisa Taouma describes how the Dusky Maiden, who is 'not dark, not white' (Taouma 1998: $\mathrm{x}$ ) and who 'could be manifested as being a 'spiced up' version of the white woman, close enough to be made familiar but distanced enough to be sexualised as an available exotic' (Taouma 1998: 10), fulfilled the pornographic fantasies of white, Christian males, while simultaneously fulfilling the urge for the expansion of empire and civilisation by 'showing the Pacific region to be a pleasure filled paradise awaiting western 
occupation' (Taouma 1998: 2) and offering 'a vision of these lands and people inviting the possession of the viewer/coloniser' (Taouma 1998: 1). These stereotypic images have become part and parcel of how the Pacific is represented, continuing to be used in western travel and tourism industries (Taouma 1998: 17).

As Anahera wrote in her journal, her Dusky Maiden grappled with being a 'prostitute on a card', while mourning the 'death of a nation'. Taouma's following interpretation of the Dusky Maiden makes clear to that which Anahera eluded: 'The image of the dusky maiden is also in this way an image of domestication, of the tamed 'noble savage' and the accommodating belle. The image can be read as a reassuring metaphor of change from an old order to the new one accomplished by western dominance of Polynesian culture' (Taouma 1998: 15).

The pairing of the Executive and the Dusky Maiden brought to the forefront what laid hidden beneath all the characters that came before them. They were the clearest articulations of the colonial matrix of power. This pair referenced the intersection of capitalism and colonisation, the interrelatedness of the control of land and labour, authority, sexuality and gender, and knowledge and subjectivity. The Executive challenged the limitations that circumscribe her existence as a white woman in a patriarchal society, while simultaneously serving the capitalist and colonising agenda. The Dusky Maiden, the only role available to indigenous women within this agenda, was caught in the web of the colonial matrix power. Her being, her sexuality and her culture were not defined by her, but by the matrix's control of land, authority and knowledge. The differing experiences of the Executive and the Dusky Maiden within their shared space of the stage not only highlighted the racism that underpins the colonial matrix of power but illustrated how gender refracts differently through the lens of colonisation. The struggle of Anahera's characters with the gender roles of the Mother, the Bride, the Dusky Maiden and the yet-to-come Ballerina involved not only how they defined themselves as women, but they have had the added burden of responding to ideals that not only come from outside of their culture but conflict with the values of their culture, as discussed in the earlier analysis of the Mother.

All the preceding characters performed within their own insular worlds, oblivious to their other; even the interplay between the Black Widow and the Bride was a fulfilment their own scripts, e.g. the Black Widow was the Bride's absent groom. The Executive and the Dusky Maiden were the first to acknowledge the other's existence. The Dusky Maiden 
watched the Executive put on her makeup, while the Executive momentarily showed her longing to make contact with the woman behind the screen. The question then at this point midway through the performance is: can contact be made? 


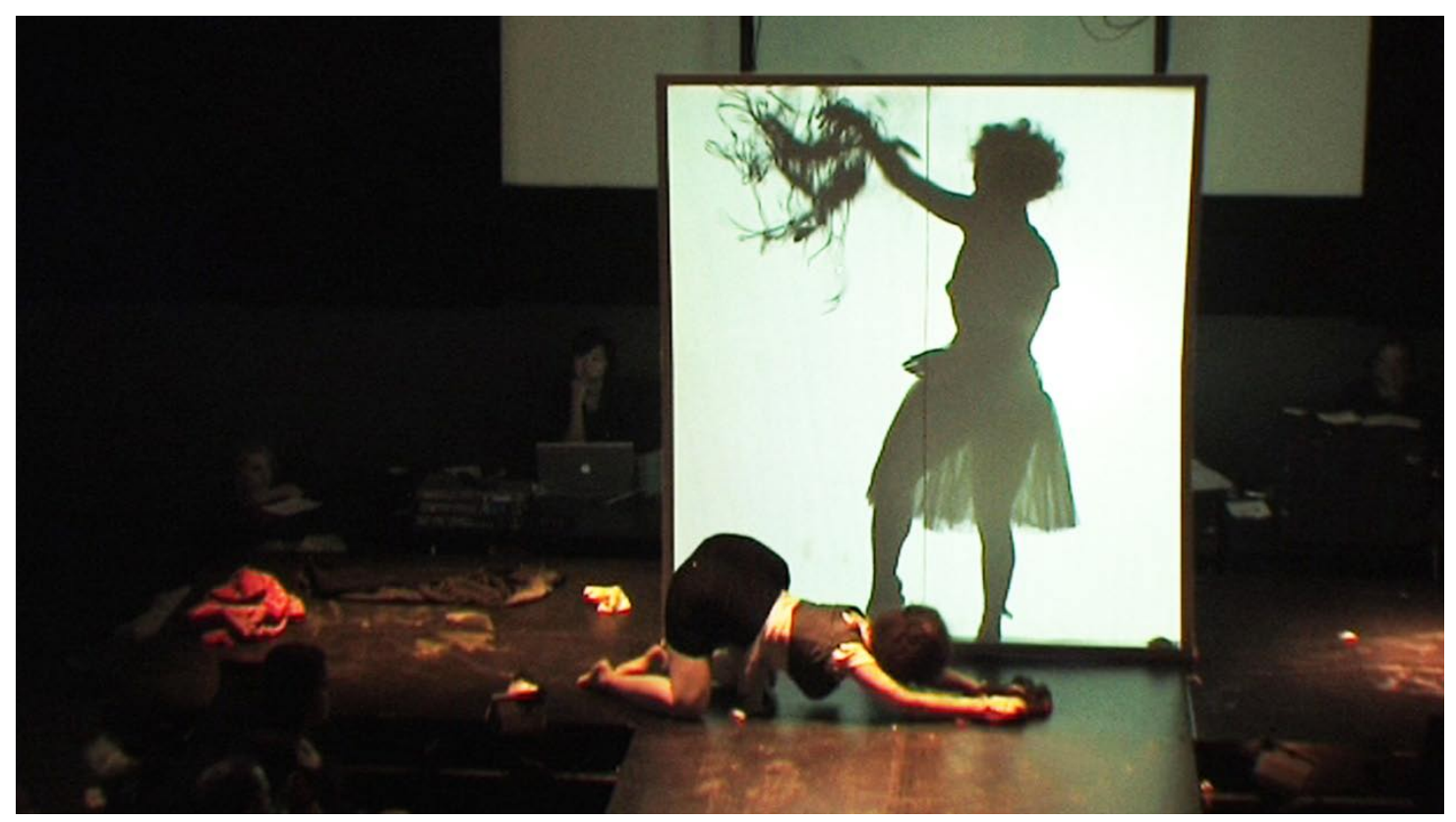

Miki Seifert (in front) as the French Maid; Anahera Gildea as the Ballerina. (Video still by William Franco)

\section{THE BALLERINA / FRENCH MAID}

\section{THE BODY AS ANT}

The body

is small

and crawls

fast.

The body has

lots of

legs.

The body

lives underground

in a nest

and collects food.

-Excerpt from Reading the Body by Jenny Borlandt as presented in the program for He rawe tona kakahu/She Wore A Becoming Dress 


\section{The Description}

The Dusky Maiden, still behind the screen, carefully removed her pimpiu, and the Ballerina bunched it into a ball and threw it on the floor. She coyly played with her tutu before performing a series of bourée turns. Meanwhile, the French Maid scrubbed the stage right floor with the blouse of the Executive. Having finished her work, she stood, checked and smoothed her uniform, offered one gloved hand in service and wearily shuffled down the runway. Halfway down she, half-suggestingly, began to remove her right hand glove. Another step or two, and she transformed from servant to stripper. Teasingly, she finished taking off her right glove with a swish of her hips and a toss of her head. Having returned upstage, she removed her left glove and casted them both aside. Seamlessly, if somewhat uninspiredly, she stripped her apron, dragging it behind her as she walked to stage left and continued her lackluster performance, as the Ballerina on Pointe made her entrance. She skillfully performed her grotesque ballet on the runway, while the Stripper continued her slow striptease behind the screen, turning into a wild go-go girl, shaking it madly. The Ballerina finished her performance, bowed and went behind her imaginary curtain. As the Ballerina removed her stockings and shoes, massaging aching feet and bathing in afterglow and exhaustion, the Stripper stepped out from behind the screen, stage right, and posed in her one-piece foundation garment of two different size orange wool breast enhancers and one orange wool butt enhancer. Then, the Ballerina undid her tutu, stepped out of it and walked upstage in her undergarment and corset.

\section{The Themes}

While the Ballerina and the French Maid reprised the dualism of the good girl/bad girl, they also brought to the fore women's bodies under the gaze. They represented two ends of the spectrum, the ideation of anorexic, you-can-never-be-too-thin body and the it'sall-about- tits-and-ass body. As ethnologist Marianne Thesander observes, 'Even if the female body has today been liberated from tight and confining corsetry, it has by no means been liberated from idealization and alteration to conform with contemporary perceptions' (Thesander 1997: 14-15). These body ideals, presented by Anahera's corseted figure and my uneven, grotesquely large bosoms and 'half-butt', have been a subtext throughout the piece. Interestingly, as mentioned earlier, while Anahera's characters were from the body and mine were from the mind, mine presented the bodily signs of womanliness. Yet rather than making them objects of sexual desire, my 
characters seemed to use these attributes as armour against the world rather than enticements to it. Anahera's characters with their sheer, filmy, gossamer costumes/fashions further attested to their need to take up as little space as possible, their desire to be as close to invisible as possible. Anahera explained an unexpected outcome of their obsession with thinness:

The anorexia of the Ballerina (and the other characters), their desire to disappear is made even more obvious here. This character of all of them has the strongest desire to be thin...to simply be really thin. The irony being that the closer my characters get to their bones, the closer they get to their land (their whenua, the place where the bones will be returned and from whence they've come). It seems that no matter how my characters try and hide their true selves, they are Māori. (personal communication, 25 February 2011)

During our rehearsal on 20 March 2009, Anahera observed how this need to be skinny is a very colonial, very western ideal. The desire to be skinny and not eat is not appropriate in Māori culture. She felt she was a failure as a ballerina because she could not not eat since it conflicted with her mother's Māori values, while the mothers of the white ballerinas would actually support them in not eating.

As discussed in Chapter Four, creating this work was a confrontation with our own body image issues, especially when we collectively realised that the only way to end the piece was for us to be naked. Both of us had strong reactions to this, knowing that the work required it of us, but also knowing how deeply embedded these issues were. Tellingly, this was the first time I honestly revealed to another person the extent of my body image distortions and obsessions. Having been a feminist almost all of my life, it did not feel appropriate that I would worry about my weight and how I looked. Similarly, Anahera related the story of her friend, who does research in women's studies and is really a strong woman, yet who disclosed to Anahera that she thinks constantly about her weight, in spite of what she tells herself.

One aspect of body image for us was our own inability to accurately see our own bodies. Anahera realised that she did not have an accurate sense of her body, that she would not be able to walk down the street and point to another woman who has her same body shape. Only through this project, was I able to start gaining a better sense of my body size, that is, when looking in the mirror, being able to see how small and thin I really am; 
I had truly thought I was bigger and fatter. Such body image distortions are said to be the basis for eating disorders, yet neither of us have full-blown disorders. This led us to wonder how common such body image distortions are for other women.

Anahera and I talked about how it is perfection or nothing and how it does not matter what others tell us because that is not the criteria we are using to judge ourselves-it is the rail-thin model to whom we compare ourselves. Looking in the mirror is not an act of admiration but an act of self-criticism. Each of us had a different 'hated' body part that we kept hidden from others, that we constantly scrutinised and struggled with changing, but despite ongoing efforts, they remained unchangeable. How could we expose them to public scrutiny? In our 30 March 2009 rehearsal, we had discussed a variety of creative options to work with it: to use duct to transform them (duct tape plastic surgery), write on our bodies what we think/feel about them, gather images that remind us or replicate the texture of our 'hated' body part, and photograph each other's 'hated' body part. Our final resolution to this quandary will be discussed in the next two sections, as they are about achieving resolution. 


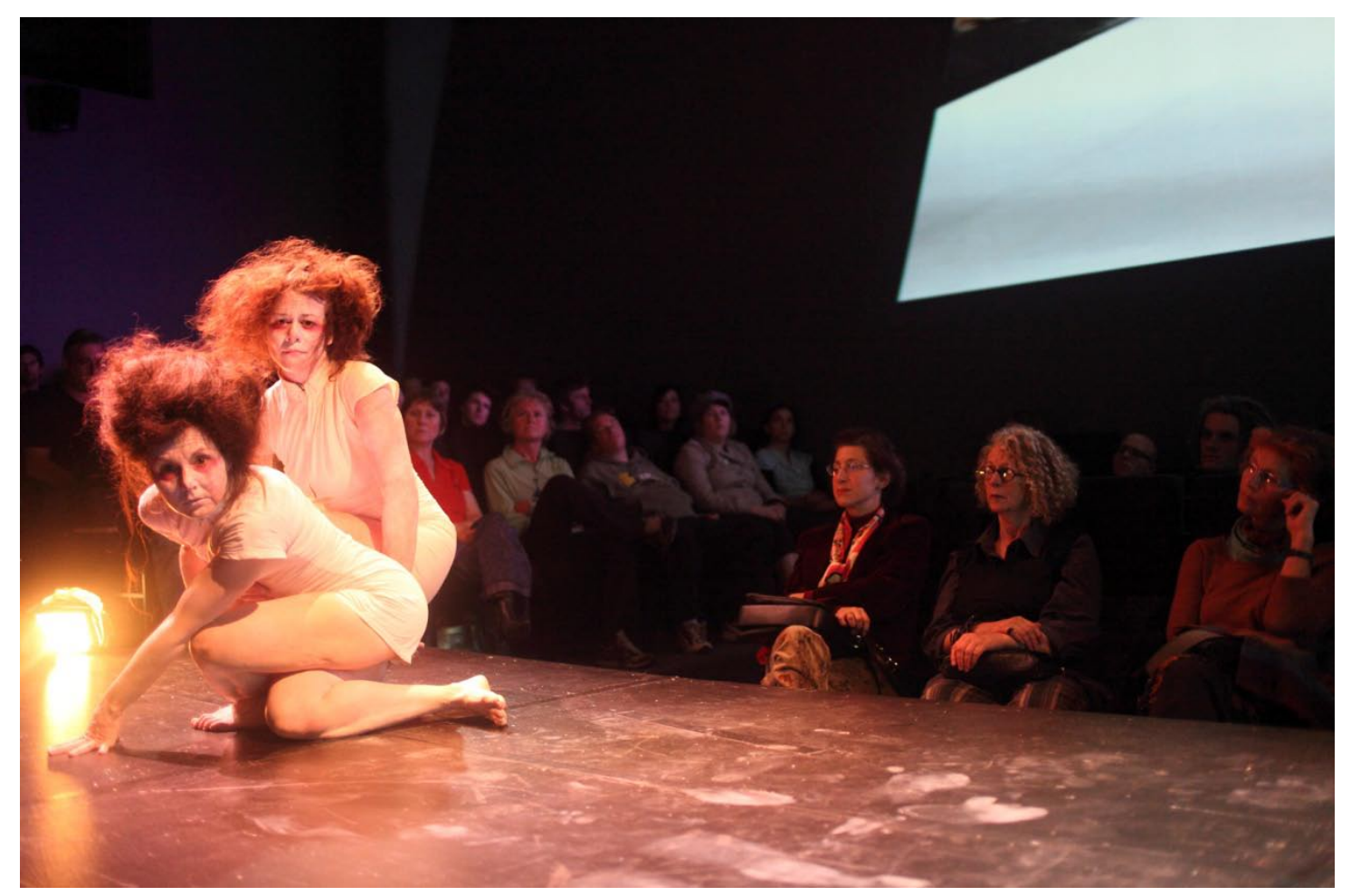

Miki Seifert (front) and Anahera Gildea as Dressmaker's Dolls. (Photograph by Craig Thomson)

\section{DRESSMAKER'S DOLL}

II

Here are some pictures

See the way

of the body.

spine tails down

to a fine twitch

These are the bones

of my beginning.

the way the ribs

They have stayed

are arms curved

with me like

in welcome

true friends. They

have given

the way the hip bones

very fine

lie like an open book.

support.

-Excerpt from Reading the Body by Jenny Borlandt as presented in the program for He rawe tona kakabu/She Wore A Becoming Dress 


\section{The Description}

I walked down the runaway, modeling my one piece foundation garment. Anahera walked down and modeled her corset. We both stoppe mid-way and began removing them; Anahera frantically, I slowly, but both experiencing a bit of sadness, uncertainty and trepidation. Having extricated ourselves from them, we both were wearing our final layer: a one-piece, off-white, short-sleeve, short-leg, one piece jumpsuit, styled to suggest the fabric that covers the mannequin on which dressmaker's use to construct garments. We offered our 'distortion' to the other, which we each accepted with care and awe, and explored the 'reality' of the Other. I then placed Anahera's corset on the stage in front of the centre stage screen. Anahera then wrapped my garment in it. For the first time in the whole performance, we touched and our bodies came together. We danced the Dressmaker's Doll duet mentioned previously and became one, creating shapes and pairing, only to pass away and form anew until we separated to claim our spot side by side on the runway.

\section{The Themes}

The Collaborative Process Chapter showed how Anahera and I used many different lenses to view our characters. The above examinations of themes have brought most of them to light. One that has not yet been discussed is how Anahera and I used the Buddhist concept of the Ten Worlds to explain our characters and their resolution at the end of the performance, which we discussed extensively in our rehearsal on 30 March 2009. As presented in the chapter on Nichiren Buddhism, the Ten Worlds are not actual, separate worlds but are the various life-states human beings can experience.

Anahera's characters were in the world of Hunger. They were in desperate need of something external and so desirous of outside validation. As a result, they also lived in a world of competition, competing to win approval. The Mother felt the judgment of others regarding how well she has been raising her child and has been in competition with other mothers to be the best mother. The Bride wanted 'the best man, the best dress, the best wedding, the best everything, the best, best, best' in order to authenticate herself as a desirable woman. The Dusky Maiden sold herself and her culture in her quest for acceptance, while the Ballerina has been literally starving herself for approval.

Mine were in the world of Anger, which is arrogance and competition. Because their selfworth depended on how they compared to others, they were constantly ranking 
themselves in relation to others: if I am not more than you, I am less than you. The question they needed to resolve was how to find security in a world of power over, and they answered it through continuing the dualism of power over by assuming power over roles, but to do so, they had to disconnect from themselves, disconnect from others. Miss Texas continued on as if her glory days had not passed her by years ago. The Black Widow used her sexuality and class to maintain superiority over men (and women). The Executive reveled in her power over labour, capital and markets. The French Maid, as servant and stripper, enjoyed her control over her respective domains, the mistress's house and the lust-filled audience.

Still, at the core of both sets of characters is fear. Anahera's characters feared that, without the external, people would see that she is rotten and awful and would be repulsed by her; she feared exposure of her Māoriness. Mine feared that, without their external protection, they would be taken advantage of, that their female attractiveness would be used against them to victimise them. Looking at their fear through the lens of colonisation, it could be argued that, for both, the underlying source of their fear is the colonial matrix of power which utilises racial and gender hierarchies to create differentials of power.

In order for us to create authentic movement and express a genuine transformation when we reached Costume-less, we each needed to find a way through these personal quagmires. On the road to getting there, we both struggled with our self-hatred: Anahera hating being a girl, feeling ripped off by being born one, and I hating my body, fearing its sexuality. At the end, therefore, the transformation becomes about reconnecting to self, to others, to the world through revealing our Buddha nature, the transformative power of being able to create value out of anything, of being able to change poison into medicine. Based on the mutual possession of the Ten Worlds, Buddha nature can be expressed in each of the Ten Worlds. Thus, the Buddha nature of Hunger is the incredible, strong desire for it to be different, for it to be better, the deep desire to have things change. The Buddha nature of Anger is to seek justice, to be determined to see justice done. My characters' journey was to go from being arrogant and basing their lives on power over others to recognising that their happiness and security can only come from living in a just world.

The Dressmaker's Doll, which was when we truly 'saw' each other, when we recognised our common humanity, was the transformative moment that led to re-connecting with 
ourselves. It was through our connection with each other that we were able to start connecting to ourselves. For the first time, both our characters were able to be truly vulnerable, experiencing a vulnerability that came from a deep acceptance of self. Anahera's characters were able to find strength to be who they are, while mine were able to give up control. Perhaps they are suggesting that this is the way across the indigenecoloniser hyphen? 


\section{COSTUME-LESS}

I

Back lit

clipped

on the board

light goes

through you

shows you up in

black and white for

what you are - a

gather of bones

a curled frond

of a spine

lightly embraced by

that scooped-out

smoothness of hip

cavity whose bones

like open palms

seem to

offer themselves out

in a kind of

blessing.

-Excerpt from Reading the Body by Jenny Borlandt as presented in the program for He rawe tona kakabu/She Wore A Becoming Dress 


\section{The Description}

Anahera and I, standing mid-way on the runway, facing upstage, were shedding our last remaining layer, as if crawling out of an alien skin and being re-born. Naked, we walked in unison to the end of the runway and back. By the time we reached the centre stage screen, all videos had stopped, and there only remained the two of us, side by side.

\section{The Themes}

This performance was a journey into the intersection between gender and colonisation. Our goal was to transform our experience of being women and of being woman on different sides of the colonising relationship. Costume-less was not the culmination of the stripping away of layers of distortions and delusions; Costume-less was present the entire piece. As previously discussed in Chapter Four, we came to the understanding that if Anahera and I each had our own colonising experience on the runway, we would not be able to transcend the colonial dualism. If we shared the same experience beneath our differences, then we had moved past the entrapment of the colonial matrix of power. Rather than dancing to our characters and their costumes/fashions/delusions, we danced to our greater selves. So the transformation that was revealed in Costume-less had been there throughout the entire piece. This is another way of stating that the true hidden identities of the Matryoshkas as Bodhisattvas of the Earth, which had always been present, was revealed in Costume-less. Costume-less was the physical expression of what we wanted to impart to every woman in the audience: that there is a greatness to their lives without adornment.

\section{CONCLUSION}

He rawe/Becoming Dress grew out of Anahera's and my standpoints as a Māori woman and a white, American woman investigating the intersection of gender and colonisation. Using Critical Butoh, we were able to interrogate our personal worldviews as they interacted in the Cultural Interface. Though He rawe/Becoming Dress was personal and idiosyncratic, it was, through the power of the aesthetic, suggestive of something larger. It was a public performance where we invited the audience into a universe where questions were raised and ideas contested. It was a lived, shared experience that sought to transform the experience of being women and of being women on different sides of the colonising relationship. 


\section{CHAPTER SIX}

\section{Conclusion}

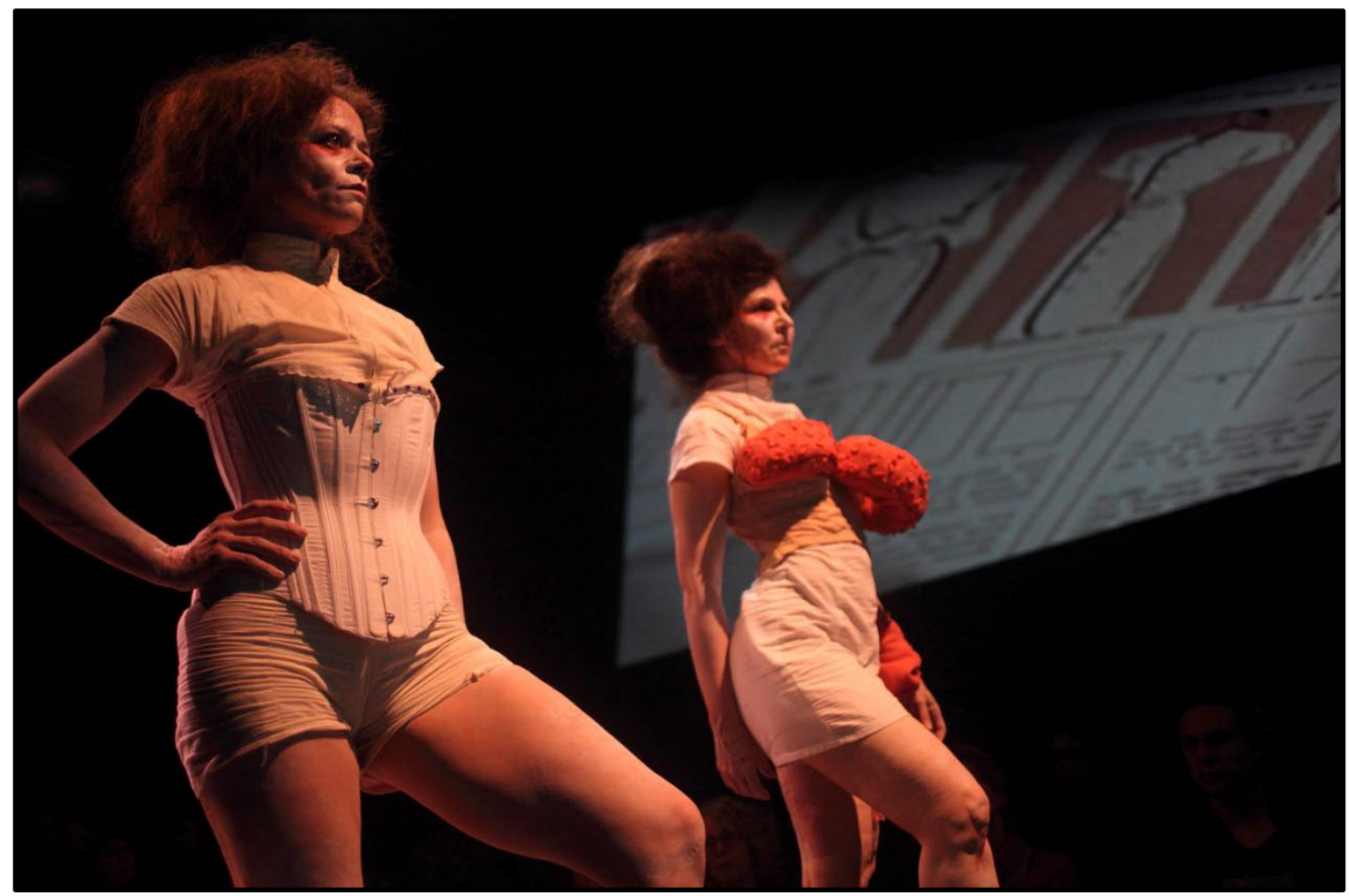


Anahera Gildea and I, a Māori woman and a white American woman, performed He rawe tona kakahu/She Wore A Becoming Dress at the Film Archive in Wellington on 17 and 18 April 2009 with approximately 160 people in attendance in total; about 50 more had been turned away because there were no more available seats. Throughout my writing about the collaborative process and the performance itself, I spoke about the necessity of Anahera and I succeeding in our own personal transformations in order to communicate the essence of the piece to the audience. What indeed had we managed to impart to our audiences? What was the audiences' reactions to the performance? While it is problematic to answer these questions, below I present a sampling of responses, both verbal and written, as a general indication of the feedback that we received regarding $H e$ rawe/Becoming Dress.

He rawe/Becoming Dress was reviewed by the Victoria University student magazine, Salient. Fiona McNamara begins her review with:

Attending theatre should be an experience; and the best kind is when every single thing around the audience creates that. Rarely do I have the joy of fully experiencing this, but upon entering She Wore a Becoming Dress I stepped into a large-scale world fashion show, where the thrust stage was a catwalk, the audience became the audience at a fashion show, the two dancers, dresser and AV operator were all a part of the fashion show I had been transported into. (McNamara 2009: para 1)

She concludes by writing that 'She Wore a Becoming Dress is a compelling, visually stunning and thought-provoking performance of feeling and intellect' (McNamara 2009: para 6). The full review is in Appendix 7.

When women came up and spoke with Anahera and I after the performances, they spoke of how they had been so moved that they cried, of how liberating it was to see 'real' women's naked bodies and of how, by the end, they felt transformed and reborn. These women were young, middle age and old; Māori, Pākehā and other; professionals, students and stay-at-home moms; friends, acquaintances and strangers. In addition to these private conversations, we had a question and answer session immediately following each performance. Below are the comments from the audience members who chose to remain after the Saturday night performance; as I had mentioned in Chapter Five, the footage from Friday night was unusable. I have presented these comments in the order that they 
arose, though I have left out questions presented to Anahera and I, as well as our responses. I chose to do this because the questions were more of an informational nature, e.g. where did Butoh originate, which came first—-the costumes or the choreography, etc., whereas the comments seem to reflect the audience's personal responses to the performance. I have indicated only whether it was a man or a woman speaking.

Woman: Incredible. Such a brave courageous performance.

Woman: Fantastic performance. Thought-provoking. Very inspiring. You guys are very beautiful.

Woman: I was really struck by the backdrop of this stale, sterile product that women's bodies have become and your performance seemed to be a reaction to that. Almost a ripping away of that and it actually evoked really...I felt really sad during some of it 'cause I just really felt this kind of horror at this sort of consumerism of women's bodies.

Woman: Thank you very much. It was a beautiful and very compelling performance. I just wanted to make a comment about the images on the screen and you as performers and how to start with, they were competing to some extent and I was interested in the competition that was going on between them. As the performance went on, the sort of fakeness of the images that we were seeing on the screen in that kind of world had a sense of emptying out. There was a huge emptying out of the images on the screen. They almost sort of disappeared and almost became invisible. And there was almost like there was an energy that was being sucked out of those images on the screen and drawn into you. And you were becoming bigger and bigger, and more and more defined as they emptied out. It was very strong. Extraordinarily full of what you were trying to define and work with intellectually and as artists.

Man: Towards the end there, even though you were unclothing yourself, I felt that you were still clothed.

Woman: Thank you very much. It was spellbinding. I had difficulty closing my mouth. Thank you. It was a wonderful work. 
Man: I'm still trying to figure out how to put this into words. I find the whole thing to be a remarkable foundation in terms of impact on both on the cognitive and the affective sides. So, there's stuff working around in my head that I'm still having a visual and auditory reaction to everything that you did. It's an incredible combination of hitting both the emotional, the physiological arousal impact as well as the cognitive- you know, what is the message and of course, it differs for everyone here, as to what they take out of it, depending on their background. I'm white American. It's one of those things where I go, OK I'm still decompressing...I find surrealism in terms of visual artforms tend be directed towards the cognitive whereas the surrealism of this really hits the affective, and when you describe it as getting the internal states, the embodied emotions out, I guess that's what it really hits the audience with. You were very, very successful in that.

Man: I admire tremendously your courage. The nudity doesn't worry these days, but it's the fear of actually showing bodies that are not perfect 'cause when we see fashion and that on TV, we're all expected to look like that. So I just wanted to say that I acknowledge your wonderful courage and showing your bodies and not worrying too much about the fashion TV.

Woman: It's interesting to know that it is all improv because visually as well-it wasn't just the amazing forms you were doing with your bodies, but the negative spaces between you two was actually beautiful and this was highlighted by the silhouette going on behind the screen.

Woman: When you touched each other, that was such a moment. Finally. Some connection. Human interaction. Humanity. Love. The touch was tremendous.

Woman: I just want to say that it struck a real cord with me. I continually talk to people about how the perception of beauty and how we are so fundamentally judged by each other on what is perceived as beauty, especially as a Māori woman, having to try and fit in to the stereotypical beauty that we're bombarded with. It's continual. Especially with the young people and how they're...it's in a sense getting worse. That's what I found extremely useful in your performance, showing younger people what the actual reality is, and I think it would be really important if someone was able to fund you and you could go out into the schools 
and be able to influence some of the younger people to understand the illusion, the perception of beauty...It's losing sight of what is true inner beauty and people don't see that...I'm the person inside, but they don't see that. They see what's on the outside, they see my ta moko—I really appreciated the Māori components within the piece-it's amazing how still strong it is, even though it's like 2009, and it's just incredible by how influenced we are by what we see. Thank you very much for that performance.

What had Anahera and I done in these performances to evoke such responses? What factors had contributed to this outcome?

What had we done? In the setting of a fashion show catwalk, we 'modeled' the fashions that embodied what made us feel discomfort, despair, dread, fear and even hatred at being a woman. Under the lights of the catwalk, we illuminated the darkness of being a woman that we carried inside us. We interrogated the messages about female roles and feminine stereotypes that we had received as girls growing up on different sides of the hyphen in different countries. In the presence of our audience, we traced our differing female whakapapa, our differing genealogies as women-what had been given to us, what had been left to us, what had been handed down to us - that shaped how we responded to the male gaze, felt about our bodies, and expressed and repressed our sexuality. We piled them on our bodies all at once and then stripped them away, broke free from them and emerged naked, transformed, reborn. At its most basic level, He rawe/Becoming Dress was a public performance of decolonisation. During this hour-long Butoh performance, Anahera and I peeled away the layers that encased us as women on different sides of the indigene-coloniser hyphen. To create this performance, we employed shared and unshared ways of knowing that arose out of our lives—Nichiren Buddhism, Critical Butoh, decolonising and critical theory, and Mätauranga Mãori-and used these lenses to create a multi-faceted performance of gender as refracted through the colonial matrix of power. In other words, He rawe/Becoming Dress was about the transformation of the mind, body and spirit.

Nichiren Buddhism gave us a practice to fuel our inner transformation, a practice to affect a change in our hearts and spirit. Nichiren Buddhism, based on Shakyamuni's Lotus Sutra, teaches that the way for all human beings to reveal their innate Buddhahood - that is, the compassion and wisdom that lies in the depth of all life-is through the practice of chanting Nam-myoho-renge-kyo, the name of the Mystic Law of the 
universe. This practice is not seen as separate from everyday life but is used to transform life's problems and sufferings into causes for happiness. Bodhisattvas of the Earth, who emerged from the space beneath the Earth in Chapter Fifteen, 'Emerging from the Earth', of the Lotus Sutra, embody this idea of transformation. Further, through their own transformation, they serve to point the way and inspire others. As modern-day Bodhisattvas of the Earth, Anahera and I used our Buddhist practice to effect a revolution in our own consciousness to see the interconnectedness and interdependency of all life, to connect to our greater selves and to each other, to empower ourselves to live the greatness of our lives without adornment and to have our personal transformation ripple out to our audience, to our communities and to the world. Through our performance on stage, through the stripping away of our layers of fashions/costumes, we revealed not only what we felt to be our true identities as Bodhisattvas of the Earth but that of the audience as well. We were able to do this through the aesthetic of Butoh.

Critical Butoh provided us with a physical practice and process to enact this transformation in our bodies as well as a means to communicate this transformation through performance. The power of the Butoh aesthetic arises out of its quest for authentic movement. Authentic movement arises out of Butoh Space, which is the lived experience where the boundaries between mind/body, self/others and self/environment are erased and from which it is possible to create authentic movement, where the quotidian experience of self, time and space is altered. Bodies are sites onto which the intersecting trajectories - the historical, material, social, political, cultural time and place_ of the Cultural Interface are written. Through using Butoh's body archaeology, Anahera and I sought to mine how our bodies had been written. Our tools of excavation were body-based Butoh exercises, journaling, non-directive dialogue, making an offer and valuing differences. Then, through our performance, we enacted a re-writing of our bodies and made it our offering to our audience.

Decolonising and critical theory supplied us with the analytical tools to frame this transformation within a theoretical construction that made power relations visible. Through our Buddhist and Butoh practices, Anahera and I uncovered unacknowledged aspects of our lives as a Māori woman and a white, American woman. Through the use of decolonising and critical theories, Anahera and I were able to understand these 
idiosyncratic aspects of ourselves in relation to the wider societal power relations and issues of social justice.

As discussed in Chapter One, Mãtauranga Māori provided us with an alternative perspective on the nature of knowledge that influenced and supported our use of different knowledge systems. There was a parallel between Charles Royal's articulation of the three levels of knowing — externalised, internalised and consciousness-in Mätauranga Mãori (Royal 2005: 6) and the knowledges that we chose to use: critical and decolonising theory (externalised), Critical Butoh (internalised) and Nichiren Buddhism (consciousness). Further, mätauranga is used to refer to knowledge that is shared and passed between people. The creation of He rawe/Becoming Dress was an exchange between the Anahera and I, while the performance was an exchange between the audience, Anahera and I. Additionally, I used my knowledge and understanding about Kaupapa Māori, Māori culture, history and political thought to align my research with Māori values, ethics and aspirations and conducted my research under the auspices of Te Kawa a Māui/School of Māori Studies. ${ }^{20}$ It is in these ways that I find that Mãtauranga Mãori was an integral part of the creation of He rawe/Becoming Dress.

As I wrote earlier, He rawe/Becoming Dress was about the transformation of the mind, body and spirit, but how to articulate Anahera's and my transformation? When trying to convey the outcomes of Anahera's and my decolonisation in regards to He rawe/Becoming Dress, I found that words were a poor subsitute for the lived experience. Words were not able to bring presence and being into the discussion, and for me, this is the realm of decolonisation in which Anahera and I acted. The work that we did happened on a level beyond words. Here, I am reminded of my experience of the psychotherapy of sand play, which is often used with children and adults survivors of abuse. Rather than trying to get the clients to find words to explore their trauma, the clients engage with archetypal figures and create scenes within a sandbox. After completing the scene, there is no expectation of discussion. The healing does not take place through words but through the scene creation. Even now, I could not articulate what and how I was transformed as a result of these sessions, but I can say that, without a doubt, subterranean plates did shift, and my experience of my self and the world took on new hues, and my external behaviour changed. Similarly, it seemed that it was almost beyond Anahera's and my

${ }^{20}$ To support the performance aspect of my research, I had co-supervision from the School of English, Film, Theatre and Media Studies. 
ability to articulate exactly what we each transformed, but we both recognised the transformations within our selves.

I did, however, find in the transcript of our debriefing session on 29 May 2009, an exchange between Anahera and I where we shared with each other something that we could say about what was transformed:

Miki: ...but there was something connected to being able to be light and humourous about my position as a white person because, for me, I really felt like exploring Miss Texas, the Black Widow, the Corporate Executive, those were very powerful positions for me and thinking about how do I fit into that, how do I deal with that privilege that I carry that I don't necessarily want, but there it is...But it was great 'cause I feel like it opened the door to figure out how to start looking at it. I don't quite have words yet to articulate what it meant. I think, in some ways, it may never get to a conscious level. I think the idea that how I inhabited those characters in Butoh in that space and did it, sort of transformed for me that relationship of...I guess some of it is self-hatred, of wanting to be something other than what I am.

Anahera: I think that's equally the same for me. Like in terms of culture, through this performance, what I discovered was that every time, no matter what, being Māori is underneath, is fundamental and underlies everything. With each character, the ones that were clearly with that intention, the ones that weren't...There's nothing more important than being Māori for me...So, for me, being Māori underpins everything. I couldn't remove it, even if I tried. There's no way and that was really important, in a similar way, that really was crystalised for me through this performance: no matter how I've lived this life...I didn't grow up on the marae, didn't grow up on my kuikui's knee.

And maybe, at the end of the day, this is what decolonisation is about. It is about acceptance of self, acceptance of one's history, and the acceptance of difference.

He rawe/Becoming Dress was more than a performance. It was a performative research project. The making and the performance was just the first step in the research process. The next step was for me to reflect back and write about what we did. To think of $H e$ rawe/Becoming Dress in this way is to go back to the map and the story. Anahera and I 
began with the map of gender across the indigene-coloniser hyphen as drawn by the colonial matrix of power. This map contained the landmarks that gave rise to our characters. In creating and performing He rawe/Becoming Dress, Anahera and I inhabited the terrain that the map denoted. By inhabiting this terrain with the intention of decolonisation and transformation, we changed the terrain. This thesis then is the new map, which references the old one while noting what has changed, how it changed and why it needed to change. The chapter on the performance itself describes the change. The chapters on Buddhism, Butoh and our collaborative process discuss the how the change was done. The introduction expresses why such a change was necessary.

This thesis posits, then, that one way to change the map that has colonised indigenous space and has placed the settler at the centre is through a multi-level exploration of the terrain that the map has claimed. Based on the findings of Anahera's and my performative research project, such an exploration needs to:

1. reconnect the story and the map

2. include knowledges that were not used to draw the colonising map

3. employ a mix of knowledges to change mind, body and spirit

It has been my intention in both the creation of He rawe/Becoming Dress and the writing about the creative process and performance to show that reconnecting the story and the map aids in dismantling the dualistic thinking that underpins the colonial matrix of power and its hierarchies of knowledges. Whereas the colonial matrix of power seeks to create dualisms and hierarchies, reconnecting the story and the map emphasises the interconnectedness and interdependency of life and knowledge. Further, the story makes space for the aesthetic, for the imagination, as well as the lived and the doing.

Reconnecting the story and the map is another way of stating that to decolonise western knowledge and research, knowledge production needs to be performative and transformative, as well as critical and analytical. Building on previous work and confirmed in this project, I believe that performativity and transformation, criticality and analysis all need to be present. Performativity simply means something must be done, some action beyond theorising must take place. Transformation requires that something has to shift, change, be different than it was at the beginning. Criticality and analysis ensure that there is an understanding of the wider context of colonisation and its power relations. Together they form a holistic approach to decolonisation. 
Our use of Nichiren Buddhism, Butoh and Mätauranga Mãori show how using previously excluded knowledges — that is, knowledge systems outside of the western tradition, including indigenous knowledges — can bring into view that which was occluded by the employment of only one lens or knowledge system. Based on my experience in the development of He rawe/Becoming Dress, I find that this approach facilitates the uncovering of the hidden ways in which the colonial matrix of power and white privilege have permeated my being and my being-in-the-world. However, to uncover and see is not enough. I believe the success of our performative research project for us and for our audience hinged on our use of knowledge systems that affected changes in our minds, bodies and spirits. As Anahera and I found in our exploration of gender across the hyphen, the colonial matrix of power did not just exist in Anahera's and my minds but was expressed through how we moved our bodies, how we felt about our bodies, how we felt about ourselves and how we conceived of ourselves in the relation to the universe. Therefore, to decolonise ourselves we needed to transform our minds, bodies and spirits. Further, once the spiritual, as in connectedness and making connections, is acknowledged, it becomes clearer how the transformation of the individual can reverberate out into the wider community.

In this performative research project, I chose to work in collaboration with an indigenous person; indeed all of my decolonisation work has been undertaken in conjunction with indigenous people. This begs the question of whether or not white people can do decolonisation without the physical inclusion of indigenous people. While I do not presume to have a definitive answer to this question, I will offer a few thoughts. By working with indigenous people directly, I find that I am positively challenged to seek out the unrecognised ways in which I continue to carry the colonial matrix of power within me. The more I participate in their world, the more I develop my doubleconsciousness and the more comfortable I become in non-white situations.

This thesis is written after I had already been working in the area of decolonisation for over twenty years, and my response to being in non-white situations is completely different than when I first started this engagement. I no longer have to grapple with coming to terms with the struggle and tensions involved in the initial experience of decentring my own whiteness. I am now comfortable being in contexts where whiteness is de-centred, such as working on $N \bar{o}$ Näianei where being Māori and Chicano were privileged. 
By saying this, I don't mean that decolonisation and decentring is a once and done thing. It is an on-going process, but the experience is different depending on where one is in this process. The insights I gained as a result of doing He rawe/Becoming Dress and writing this thesis reflect where I am now. For example, my biggest new awareness is a greater understanding of how knowledge functions differently within a Māori context than in a western academic setting. I can appreciate that for Māori knowledge arises out of the intricate web of relationships, both between people and between people and the land, and that this interaction gives rise to a particular set of responsibilities, expectations and values about the use of that knowledge that is distinctly different than those of western knowledge. On a personal level, my own view of knowledge has expanded from seeing it as something that belongs to the individual to recognising that it can also be something that belongs to a community, and that it is important to respect the ramifications of both of these understandings of knowledge.

Further, the legacy of colonisation is a loss of trust between white/coloniser/settler and indigenous peoples. Action and interaction is needed to rebuild that trust. Relationships need to be established and nurtured. I have found that my engagement in projects with indigenous people is the soil which allows the seeds of friendship to grow. However, building relationships and establishing trust requires time. In the context of academic research, what this means is that a long lead-in time needs to be built into the research schedule and, perhaps, a stepping stone approach—starting with a small project and building upon its success_ c could be useful. For example, I see my research with Anahera as a stepping stone to my returning to the U.S. to undertake research with Native Americans. The premise of working with Anahera was that being from different indigene-coloniser pairings would allow us to hone our skills in working across the hyphen without the added burden of a shared history and its emotional component.

In writing about He rawe/Becoming Dress and the decolonising epistemological pluralism that gave rise to it, I am making an offer. I believe that the principles, ideas, concepts and tools that we used and that have been detailed in this thesis have the capacity and flexibility to be used in many different settings, including those far removed from creative endeavours, and can be applied to many different epistemological mixes. While I intend to conduct additional research to continue the development of this methodology, I hope that others who have vastly different knowledge sets than I will see the value of this methodological approach and adopt and adapt it to their research projects as well. 


\section{Appendices}

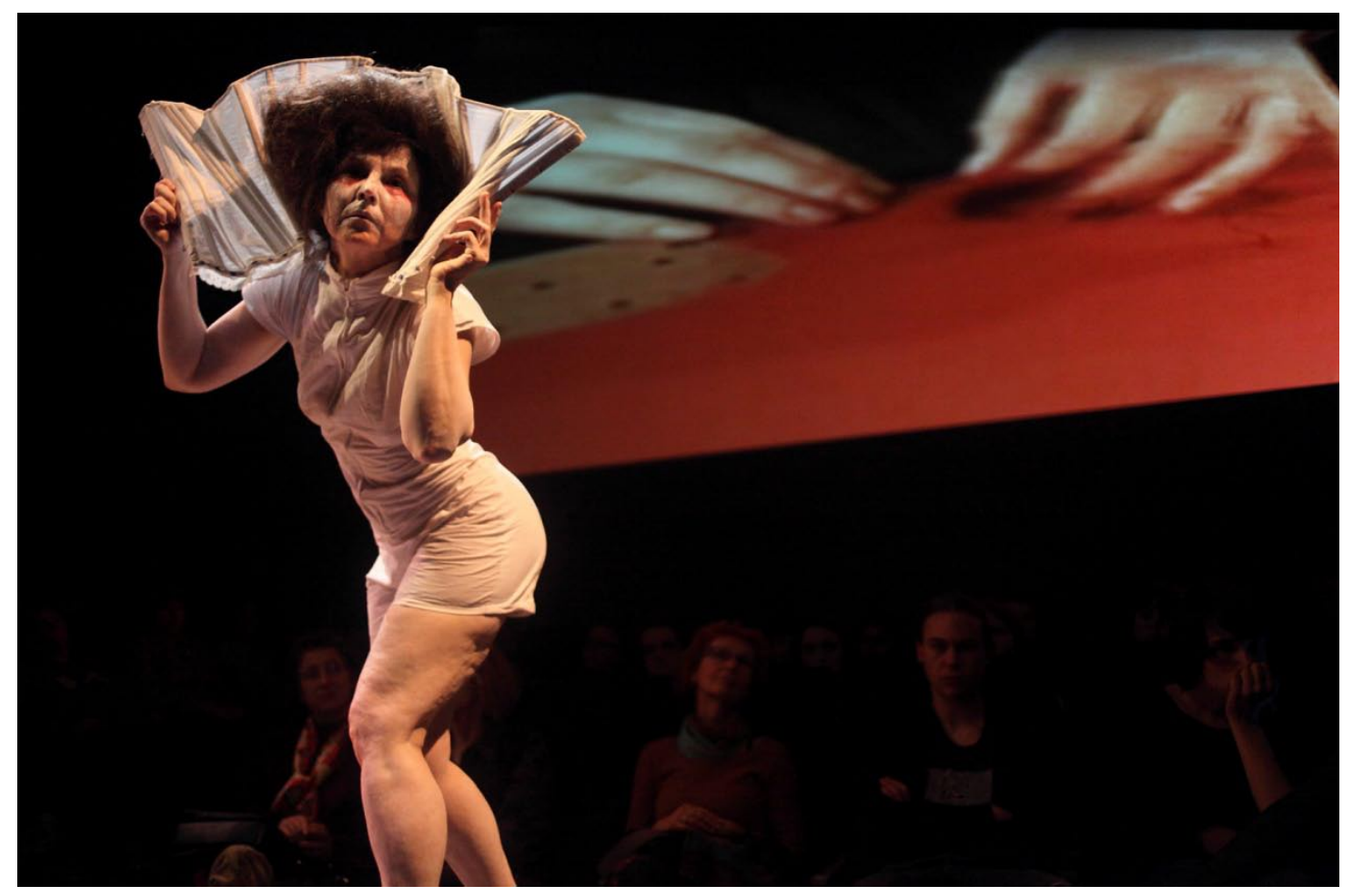


APPENDIX 1 - HE RAWE/BECOMING DRESS BUTOH-FU

Images have been removed due to Copyright restrictions. 


\section{APPENDIX 2 - HE RAWE/BECOMING DRESS PROJECT TIMELINE}

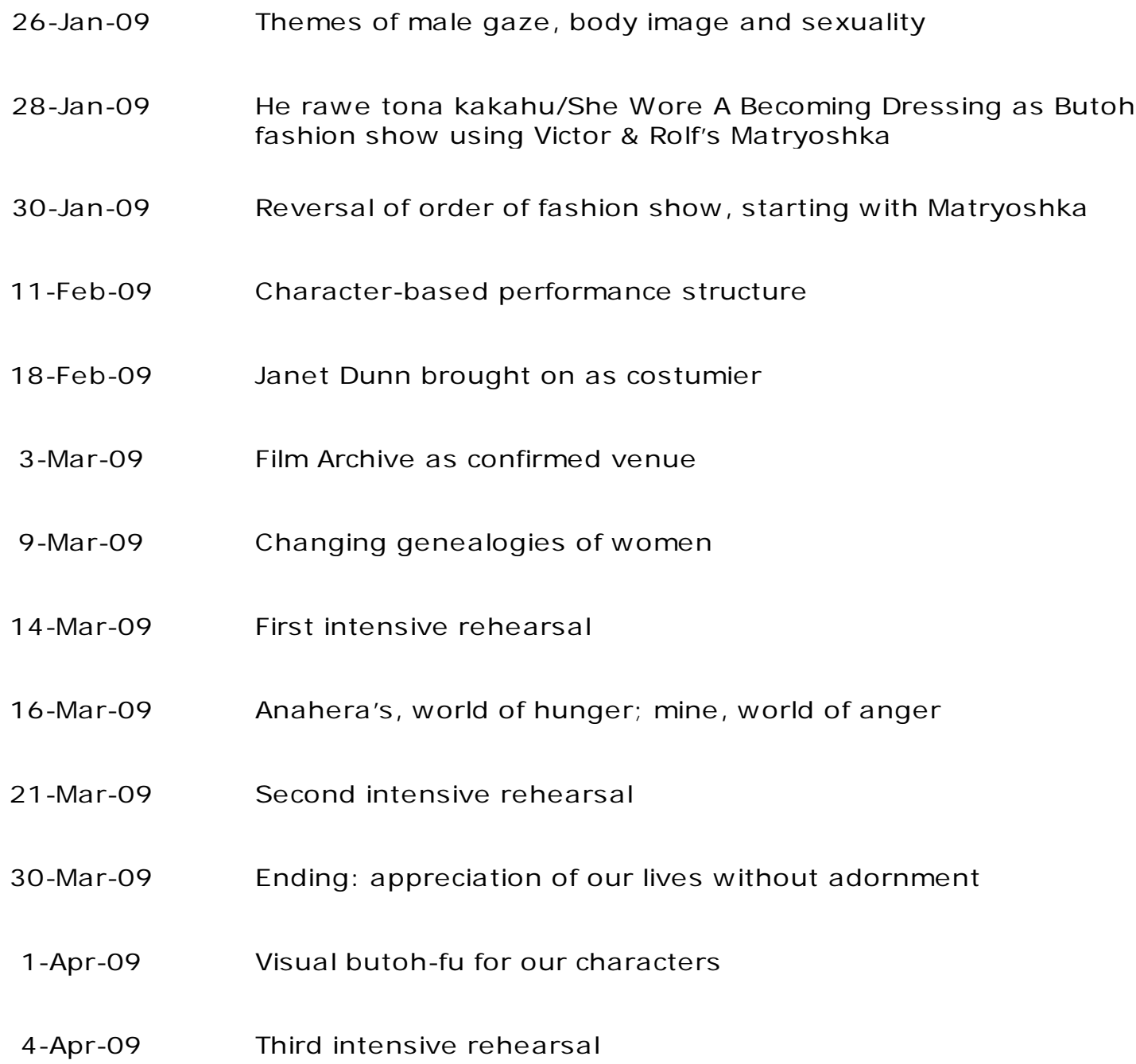


APPENDIX 3 - HE RAWE/BECOMING DRESS CHARACTER TIMELINE

11 February 2009

\begin{tabular}{|l|l|}
\hline \multicolumn{1}{|c|}{ Miki } & \multicolumn{1}{c|}{ Anahera } \\
\hline Matryoshka & Matryoshka \\
\hline Black Widow/Puritan & Giant Mother-hood/babies/pregnancy \\
\hline Mother/ Old Woman & Bride/1950s Housewife \\
\hline Professional Woman/Working Girl & Dusky Maiden/Poi Woman \\
\hline Little Girl/Porn Star & Ballerina/Dressmaker's Doll \\
\hline Slut & Slut \\
\hline Taped & Taped \\
\hline Nude & Nude \\
\hline
\end{tabular}

13 February 2009

\begin{tabular}{|l|l|}
\hline \multicolumn{1}{|c|}{ Miki } & \multicolumn{1}{c|}{ Anahera } \\
\hline Matryoshka & Matryoshka \\
\hline Black Widow & Mother \\
\hline Puritan Old Woman & Bride $>$ 1950s Housewife \\
\hline Corporate Executive & Dusky Maiden \\
\hline Porn Star/French Maid > Little Girl & Ballerina $>$ Dressmaker's Doll \\
\hline Slut & Slut \\
\hline Taped & Taped \\
\hline Nude & Nude \\
\hline
\end{tabular}


16 February 2009

\begin{tabular}{|l|l|}
\hline \multicolumn{1}{|c|}{ Miki } & \multicolumn{1}{c|}{ Anahera } \\
\hline Matryoshka & Matryoshka \\
\hline Black Widow & Mother \\
\hline Puritan Old Woman & Bride \\
\hline Corporate Executive & Dusky Maiden \\
\hline Porn Star > French Maid & Ballerina > Dressmaker's Doll \\
\hline Costume-less & Costume-less \\
\hline
\end{tabular}

23 February 2009

\begin{tabular}{|l|l|}
\hline \multicolumn{1}{|c|}{ Miki } & \multicolumn{1}{c|}{ Anahera } \\
\hline Matryoshka & Matryoshka \\
\hline Black Widow & Mother \\
\hline Old Victorian & Bride \\
\hline Corporate Executive & Dusky Maiden \\
\hline French Maid Stripper & Ballerina \\
\hline Dressmaker's Doll & Dressmaker's Doll \\
\hline Costume-less & Costume-less \\
\hline
\end{tabular}

30 March 2009

\begin{tabular}{|l|l|}
\hline \multicolumn{1}{|c|}{ Miki } & \multicolumn{1}{c|}{ Anahera } \\
\hline Matryoshka & Matryoshka \\
\hline Miss Texas & Mother \\
\hline Black Widow & Bride \\
\hline Corporate Executive & Dusky Maiden \\
\hline French Maid Stripper & Ballerina \\
\hline Dressmaker's Doll & Dressmaker's Doll \\
\hline Costume-less & Costume-less \\
\hline
\end{tabular}




\section{APPENDIX 4 - VUW ETHICS APPROVAL AND APPLICATION}

Originally, my research was called The Lotus and the Koru: seeds for a dialogical art and was going to be a series of three projects.

$$
\begin{array}{ll}
\text { Phone } & 0-4-4635676 \\
\text { Fax } & 0-4-4635209
\end{array}
$$

\begin{tabular}{l|l}
\hline TO & Miki Seifert \\
\hline COPY TO & Dr Maria Bargh, Supervisor \\
\hline FROM & Dr Allison Kirkman, Convener, Human Ethics Committee \\
\hline
\end{tabular}

\begin{tabular}{l|l}
\hline DATE & October 14,2008 \\
\hline PAGES & 1 \\
\hline
\end{tabular}

\begin{tabular}{l|l} 
SUBJECT & Ethics Approval: No 16001, The Lotus and the Koru: seeds for
\end{tabular} a dialogical art.

Thank you for your application for ethical approval, which has now been considered by the Standing Committee of the Human Ethics Committee.

Your application has been approved from the above date and this approval continues until 31 December 2010. If your data collection is not completed by this date you should apply to the Human Ethics Committee for an extension to this approval.

Best wishes with the research.

Allison Kirkman

Convener 


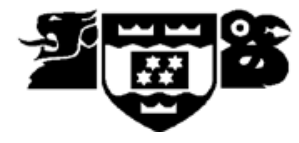

HUMAN ETHICS COMMITTEE

Application for Approval of Research Projects

Please write legibly or type if possible. Applications must be signed by supervisor (for student projects) and Head of School

Note: The Human Ethics Committee attempts to have all applications approved within three weeks but a longer period may be necessary if applications require substantial revision.

1 NATURE OF PROPOSED RESEARCH:
(a) Staff Research
Student Research $\bigotimes$
(tick one)
(b) If Student Research
Degree $\mathrm{PhD}$
Course Code
(c) Project Title: The Lotus and the Koru: Seeds for a dialogical art

\section{INVESTIGATORS:}

(a) Principal Investigator

\begin{tabular}{|l|l|}
\hline Name & Miki Seifert \\
\hline e-mail address & miki.seifert@vuw.ac.nz \\
\hline School/Dept/Group & Te Kawa a Maui \\
\hline
\end{tabular}

(b) Other Researchers Name

Position

(c) Supervisor (in the case of student research projects)
Maria Bargh
Pukenga

\section{DURATION OF RESEARCH}

(a) Proposed starting date for data collection 1-11-2008

(Note: that NO part of the research requiring ethical approval may commence prior to approval being given)

(b) Proposed date of completion of project as a whole 31-12-2010

\section{PROPOSED SOURCE/S OF FUNDING AND OTHER ETHICAL CONSIDERATIONS}

(a) Sources of funding for the project

Please indicate any ethical issues or conflicts of interest that may arise because of sources of funding e.g. restrictions on publication of results

New Zealand International Doctoral Research Scholarship and personal funds. 
(b) Is any professional code of ethics to be followed If yes, name

(c) Is ethical approval required from any other body If yes, name and indicate when/if approval will be given

\section{DETAILS OF PROJECT}

Briefly Outline:

(a) The objectives of the project

In the globalised, colonised world that we presently live in - and have lived in for the past 500 years - the dominion of the Euro-American scientific, capitalist paradigm has controlled how we conceive of our selves and our relationship to the external world - the defining act for human beings, individually and collectively, determining how we exist in the world. These existential issues precede questions of control, right, and power in matters economic and political. (Jackson 1998:21) My research questions is: How can I - as a woman, a Buddhist, and a Euro-American interrupt the hegemony of this dominant discourse through an intercultural collaborative art practice with Maori artists and scholars?

b) Method of data collection

This research will encompass two types of activities. One will be collaborative art projects with Maori artists and scholars. This activity will include the creation of art

installations/performances, planning and development meetings that will be recorded (stills, video and audio), as well as interviews where these participants' life stories and world views will be recorded (stills, video and audio). The second type of activity will be interviews of subject matter experts, which will be recorded (stills, video and audio).

(c) The benefits and scientific value of the project

To further the development of intercultural, collaborative art practice.

This is not a scientific research project.

(d) Characteristics of the participants

Adult professional artists and scholars.

(e) Method of recruitment

Previous personal contacts and referrals from colleagues, fellow artists, friends, and others.

(f) Payments that are to be made/expenses to be reimbursed to participants

Out of respect for their time and participation, a koha of at least $\$ 20$ will be made to each 
participant.

(g) Other assistance (e.g. meals, transport) that is to be given to participants

If visiting a participant at their home or hosting them at mine, light food will be provided.

(h) Any special hazards and/or inconvenience (including deception) that participants will encounter

None

(i) State whether consent is for:

(i) the collection of data

(ii) attribution of opinions or information

(iii) release of data to others

(iv) use for a conference report or a publication

\section{$\mathbf{Y} \otimes \mathbf{N}$}

(v) use for some particular purpose (specify)

$\begin{array}{cc}\mathbf{Y} \bigotimes & \mathbf{N} \square \\ \mathbf{Y} \bigotimes & \mathbf{N} \square \\ \mathbf{Y} \bigotimes & \mathbf{N} \square\end{array}$

$\mathbf{Y} \square \mathbf{N} \bigotimes$

(iii) Besides myself, my supervisors will have access to the raw audio/video recordings and interview notes. Additionally, the video editor and other necessary post-production technicians will have access to raw audio/video recordings on an as-needed basis.

Attach a copy of any questionnaire or interview schedule to the application

(j) How is informed consent to be obtained (see sections 4.1, 4.5(d) and 4.8(g) of the Human Ethics Policy)

(i) the research is strictly anonymous, an information sheet is supplied and informed consent is implied by voluntary participation in filling out a questionnaire for example (include a copy of the information sheet)

\section{$\mathbf{Y} \mathbf{N} \bigotimes$}

(ii) the research is not anonymous but is confidential and informed consent will be obtained through a signed consent form (include a copy of the consent form and information sheet)

\section{$\mathbf{Y} \square \mathbf{N} \otimes$}

(iii) the research is neither anonymous or confidential and informed consent will be obtained through a signed consent form (include a copy of the consent form and information sheet)

\section{$\mathbf{Y} \otimes \mathbf{N} \square$}

(iv) informed consent will be obtained by some other method (please specify and provide details)

$\mathbf{Y} \square \mathbf{N} \otimes$

$\mathrm{N} / \mathrm{A}$ 
With the exception of anonymous research as in (i), if it is proposed that written consent will not be obtained, please explain why. $\mathrm{N} / \mathrm{A}$

(k) If the research will not be conducted on a strictly anonymous basis state how issues of confidentiality of participants are to be ensured if this is intended. (See section 4..1(e) of the Human Ethics Policy). (e.g. who will listen to tapes, see questionnaires or have access to data). Please ensure that you distinguish clearly between anonymity and confidentiality. Indicate which of these are applicable.

(i) access to the research data will be restricted to the investigator

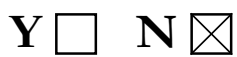

(ii) access to the research data will be restricted to the investigator and their supervisor (student research)

\section{$\mathbf{Y} \square \mathbf{N} \bigotimes$}

(iii) all opinions and data will be reported in aggregated form in such a way that individual persons or organisations are not identifiable

(iv) Other (please specify)

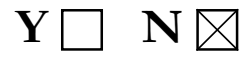

Research is neither anonymous nor confidential The consent form will be used to gain approval. Besides the researcher and her supervisors, the video editor and any other necessary postproduction technicians will have access to the recorded data on an as-needed basis.

(l) Procedure for the storage of, access to and disposal of data, both during and at the conclusion of the research. (see section 4.12 of the Human Ethics Policy). Indicate which are applicable:

(i) all written material (questionnaires, interview notes, etc) will be kept in a locked file and access is restricted to the investigator $\mathbf{Y} \bigotimes \mathbf{N}$

(ii) all electronic information will be kept in a password-protected file and access will be restricted to the investigator $\quad \mathbf{Y} \square \quad \begin{aligned} & \mathbf{N} \\ & \square\end{aligned}$

(iii) all questionnaires, interview notes and similar materials will be destroyed:

(a) at the conclusion of the research $\mathbf{Y} \square \mathbf{N} \bigotimes$

or (b) 2 years after the conclusion of the research $\quad \mathbf{Y} \square \mathbf{N} \square$

(iv) any audio or video recordings will be returned to participants and/or electronically wiped $\quad \mathbf{Y} \square \mathbf{N} \bigotimes$

(v) other procedures (please specify): 
Research is neither anonymous nor confidential. Interview notes and raw video and audio footage will be retained by the researcher, then destroyed two years after completion of the project.

If data and material are not to be destroyed please indicate why and the procedures envisaged for ongoing storage and security

(m) Feedback procedures (See section 7 of Appendix 1 of the Human Ethics Policy). You should indicate whether feedback will be provided to participants and in what form. If feedback will not be given, indicate the reasons why.

Feedback in the form of a summary results and/or copy of resulting article or conference paper will be provided to subjects who so request by ticking appropriate box on consent form. In addition, for the collaborating artists/scholars, they will be able to request the final documentary video and stills of the art projects.

(n) Reporting and publication of results. Please indicate which of the following are appropriate. The proposed form of publications should be indicated on the information sheet and/or consent form.

(i) publication in academic or professional journals $\quad \mathbf{Y} \bigotimes \quad \mathbf{N} \square$

(ii) dissemination at academic or professional conferences $\mathbf{Y} \bigotimes \mathbf{N}$

(iii) deposit of the research paper or thesis in the University Library (student research) $\quad \mathbf{D} \mathbf{N} \square$

(iv) other (please specify)

Documentary video and stills.

Signature of investigators as listed on page 1 (including supervisors) and Head of School.

NB: All investigators and the Head of School must sign before an application is submitted for approval
Date
Date
Date

\section{Head of School:}

Date 


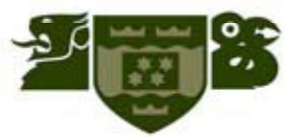

\section{Consent to Participation in Research \\ Project: The Lotus and The Koru: Seeds for a dialogical art Researcher: Miki Seifert, Te Kawa a Māui}

I consent to information or opinions that I have given during this research being attributed to me by name in any reports on this research.

I consent to the use and reproduction of images and voice recordings of me created during this research for multimedia research reports.

I understand that I will be given the opportunity to check, make corrections to, and/or withdraw any quotations or discussions attributed to me or images of me before they are used by the researcher.

I understand that the information I provide will not be published for any other purpose or released to others without my written consent.

I have been provided with sufficient information about this project.

I would like the raw video/audio recordings of my interview returned to me at the conclusion of the project. $\quad \square$ Yes $\quad \square$ No

I would like to receive a copy of any publication or conference paper from this research, which may be sent to the mailing address below. $\square$ Yes $\square$ No

Signed: Date:

Printed Name:

Email:

Phone(s):

Mailing address: 


\section{VICTORIA UNIVERSITY OF WELLINGTON \\ Te Whare Wānanga o te Ūpoko o te Ika a Māui}

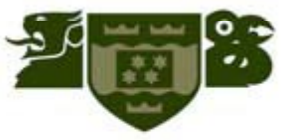

\section{Participant Information Sheet \\ Project: The Lotus and The Koru: Seeds for a dialogical art Researcher: Miki Seifert, Te Kawa a Māui}

I am a PhD candidate at Victoria University. For over twenty years, I have created unique intercultural art work that fuses Butoh, video, installation art, and political science into a unified whole. My art and performances have been seen in variety of venues around the world. I have a Bachelor of Arts in French and Political Science from Moravian College, Bethlehem, PA.

I am currently investigating the use of intercultural collaborative art practice with Maori artists and scholars as a means to interrupt the hegemonic discourse generated by the dominant Euro-American, scientific, capitalist paradigm.

Victoria University requires that ethics approval be obtained for research projects involving human participants. Since I intend to use quotations and images from interviews and meetings conducted as part of this project, and to attribute those quotations and images by name to the participants, I am required to obtain your written permission before proceeding with the interviews and meetings. Should you feel the need to withdraw from the project, you may do so without question at any time before the data is analysed. Just let me know at the time.

You will have the opportunity to check, make corrections to and/or withdraw quotations or other discussions in which I refer to these interviews and meetings before I submit any paper for publication or conference presentation. You will have the opportunity to check, make corrections to and/or withdraw images and video/audio recordings before I submit any multimedia report for publication or conference presentation.

Interview notes and video/audio recordings will be kept in a locked cabinet and destroyed two years after the completion of the project unless you indicate on the consent form that you would like the video/audio tapes returned to you. Besides myself, my supervisors will have access to the raw audio/video recordings and interview notes. Additionally, the video editor and other necessary post-production technicians will have access to raw audio/video recordings on an as-needed basis.

If you have any questions or would like to receive further information about the project, please do not hesitate to contact me. Additionally, you can contact my supervisor, Dr Maria Bargh at maria.bargh@vuw.ac.nz or +64-04-463-5465.

Sincerely, Miki Seifert

Email: miki.seifert@vuw.ac.nz

Phone: +64-021-100-5813

Address: 36A Adams Terrace, Aro Valley, Wellington, New Zealand 

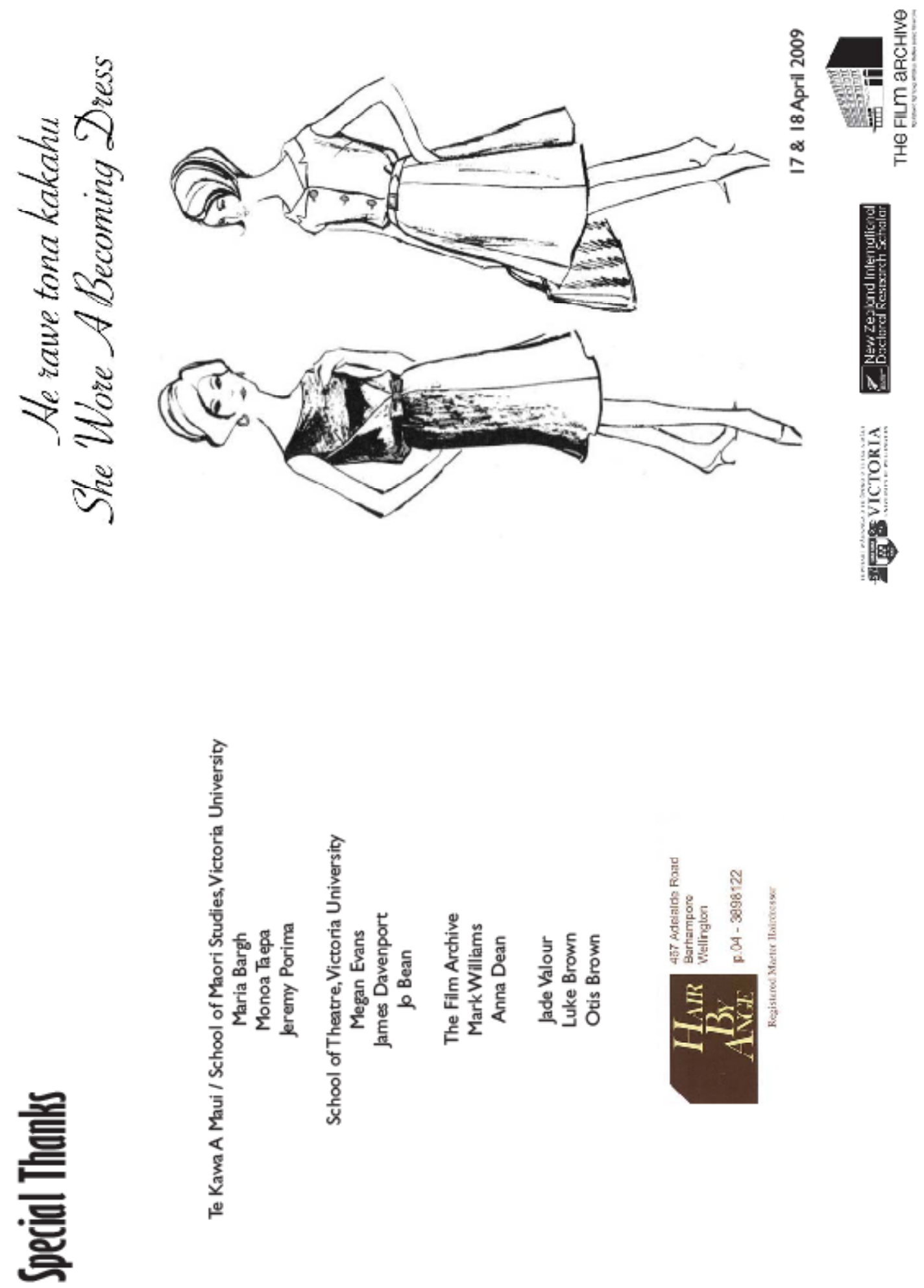

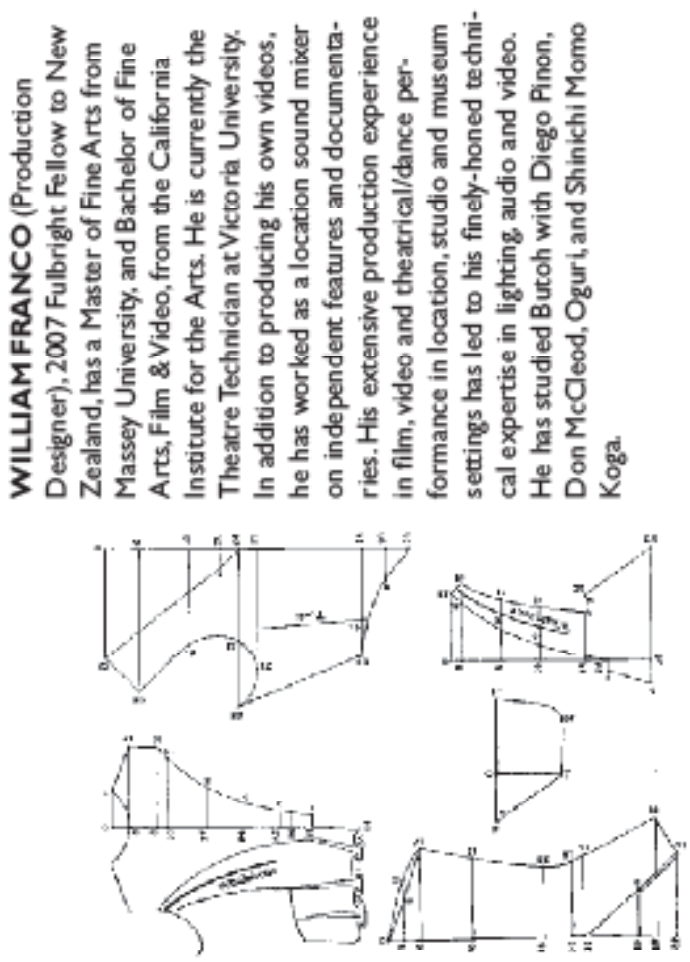
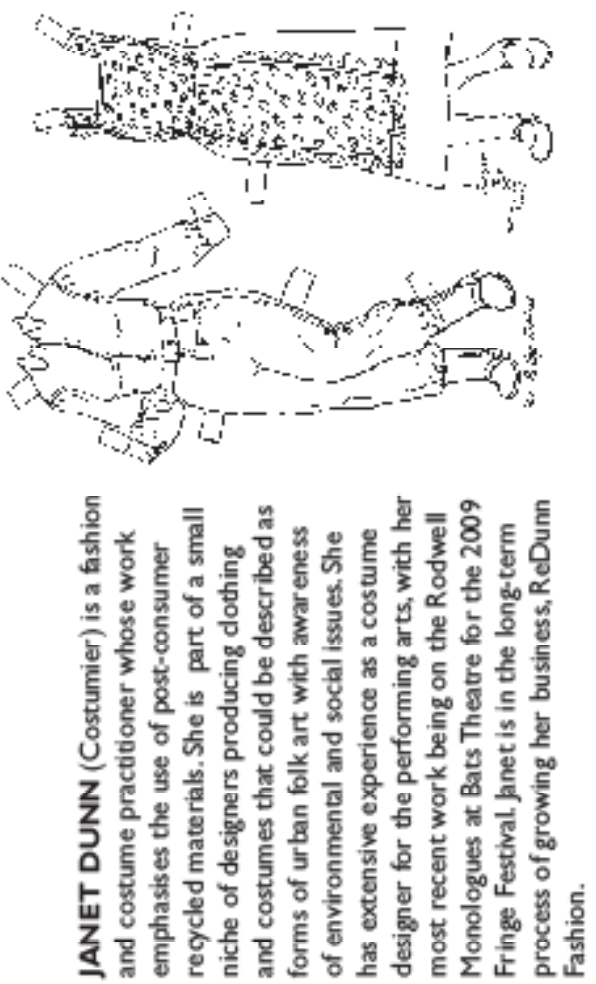

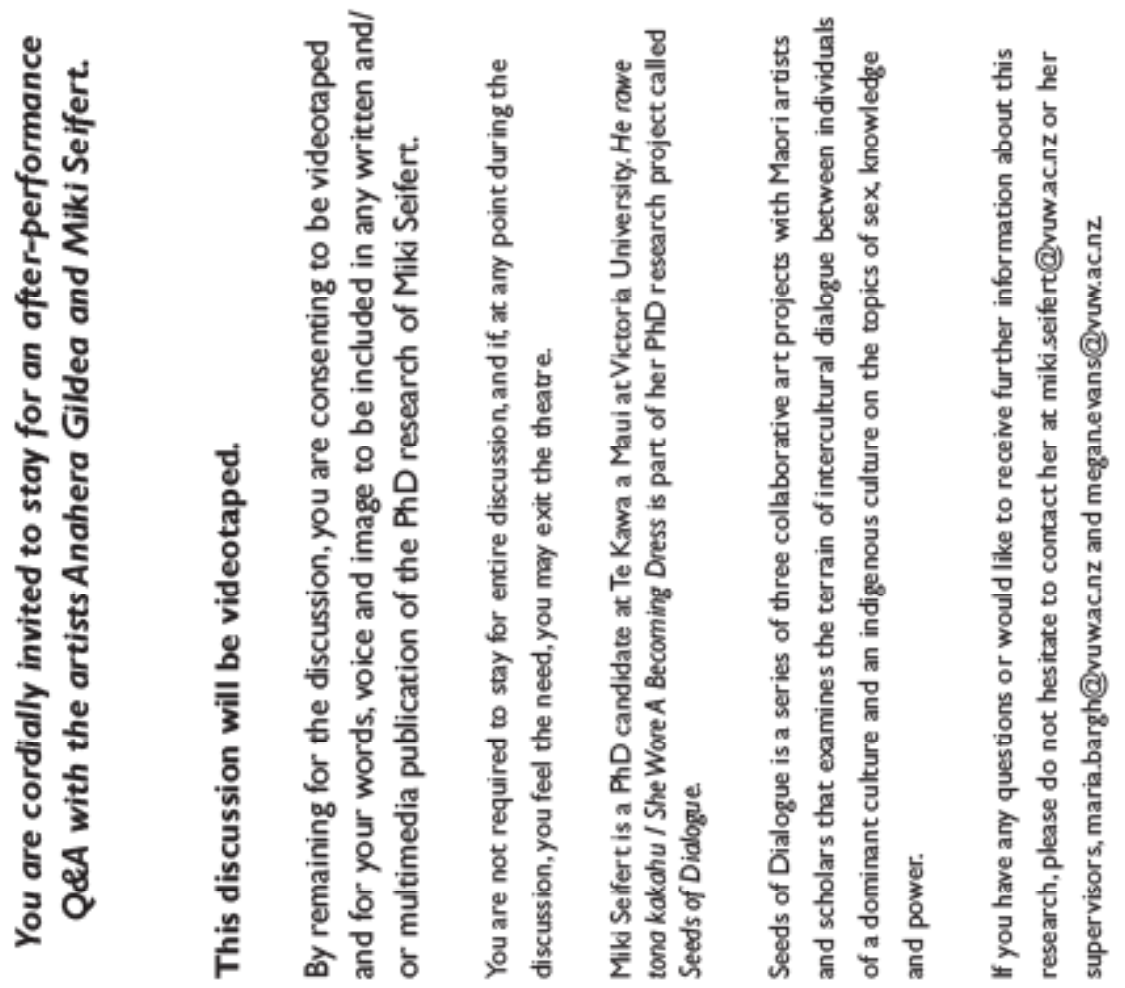



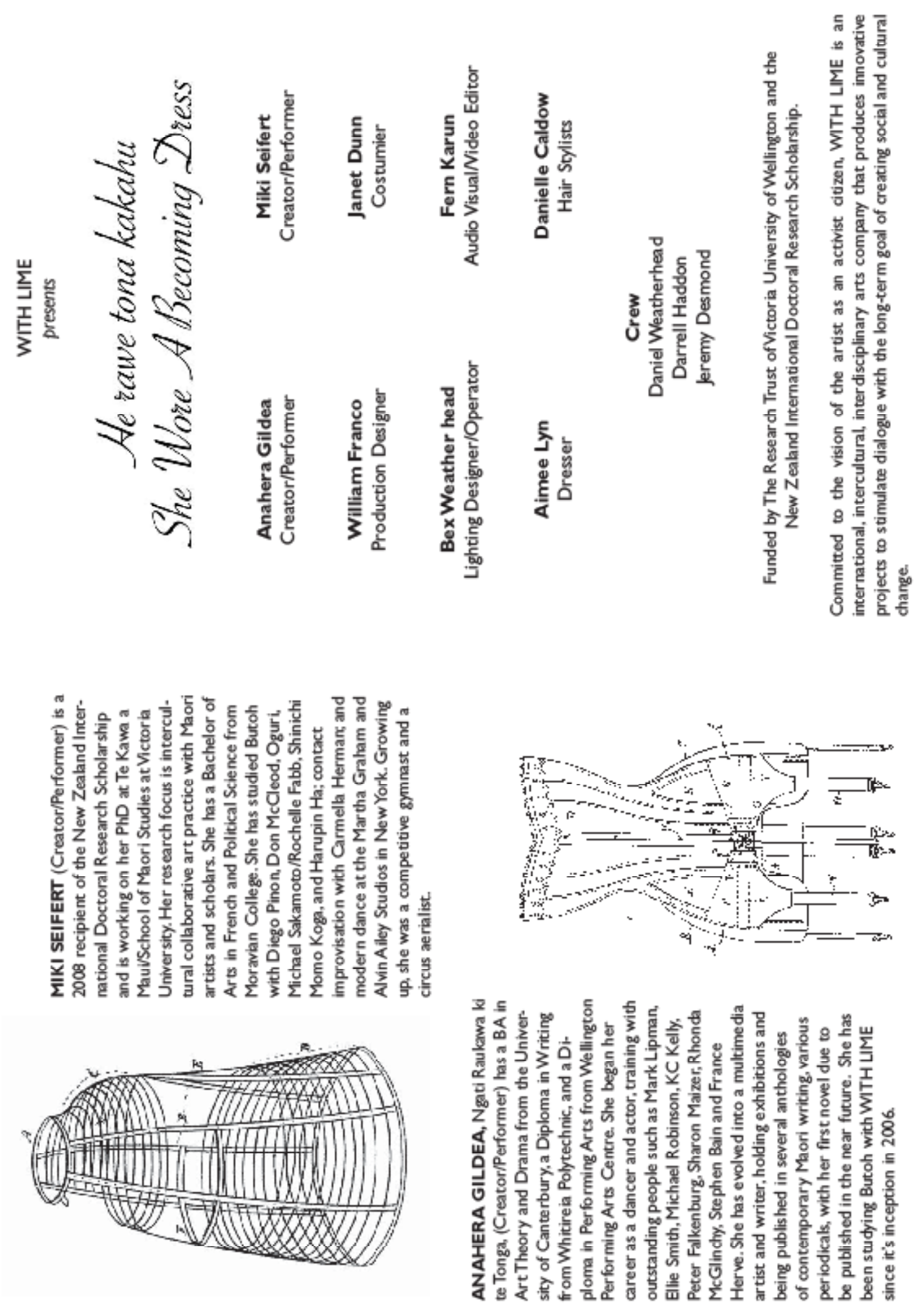


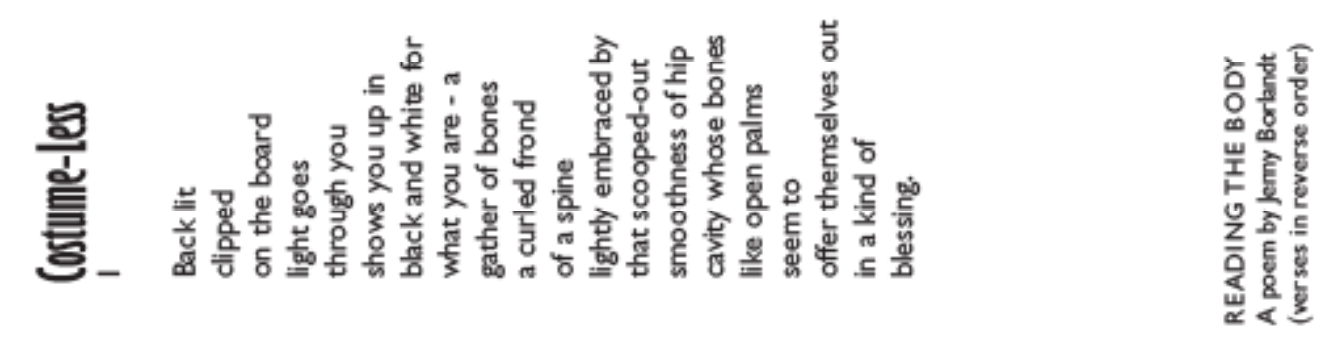

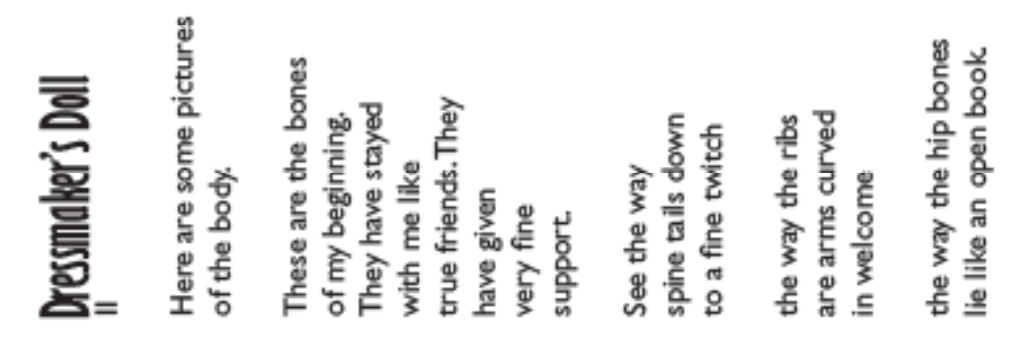
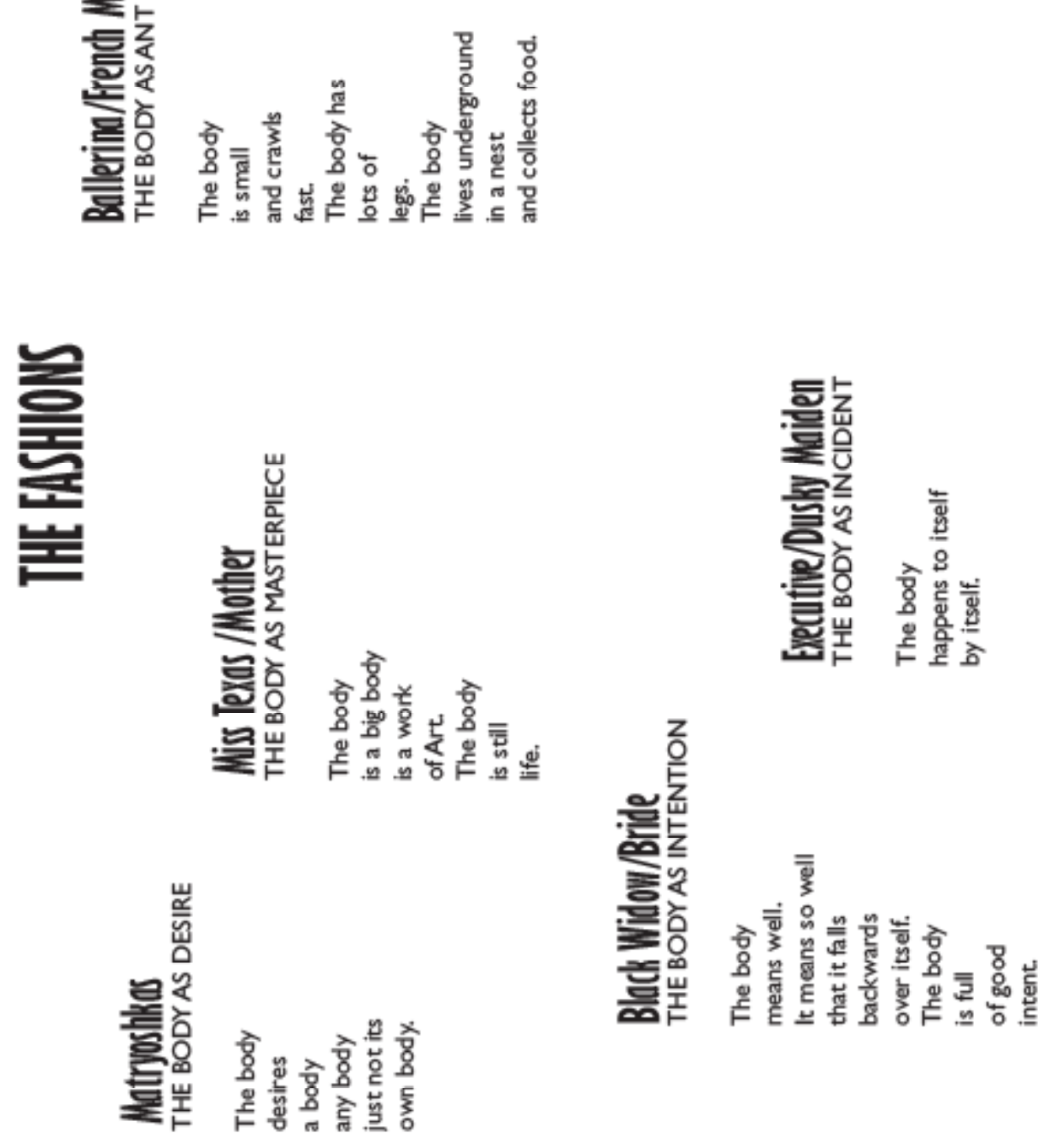
APPENDIX 6 - HE RAWE/BECOMING DRESS FLOOR PLAN

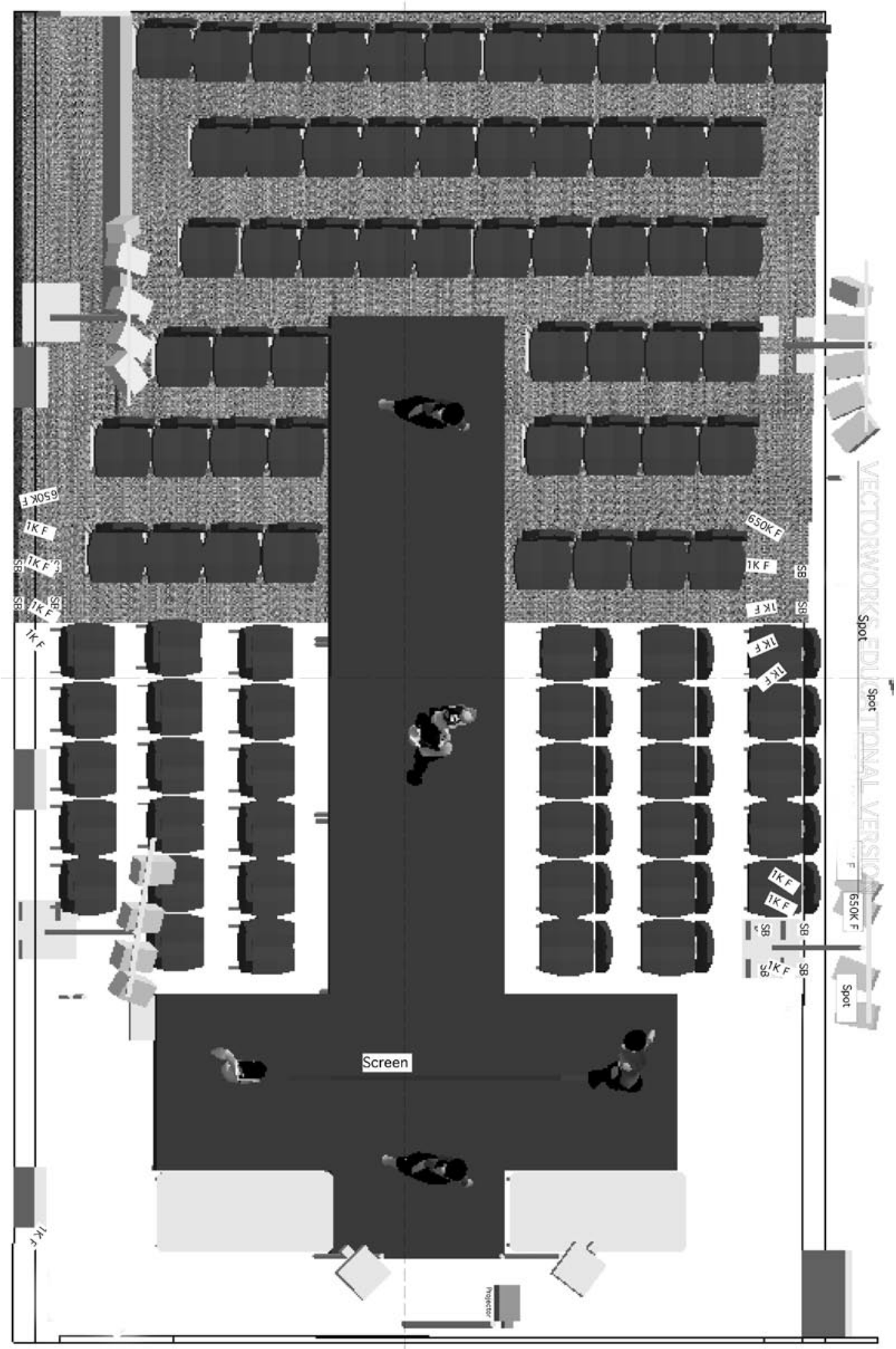




\title{
APPENDIX 7 - SALIENT REVIEW OF HE RAWE/BECOMING DRESS
}

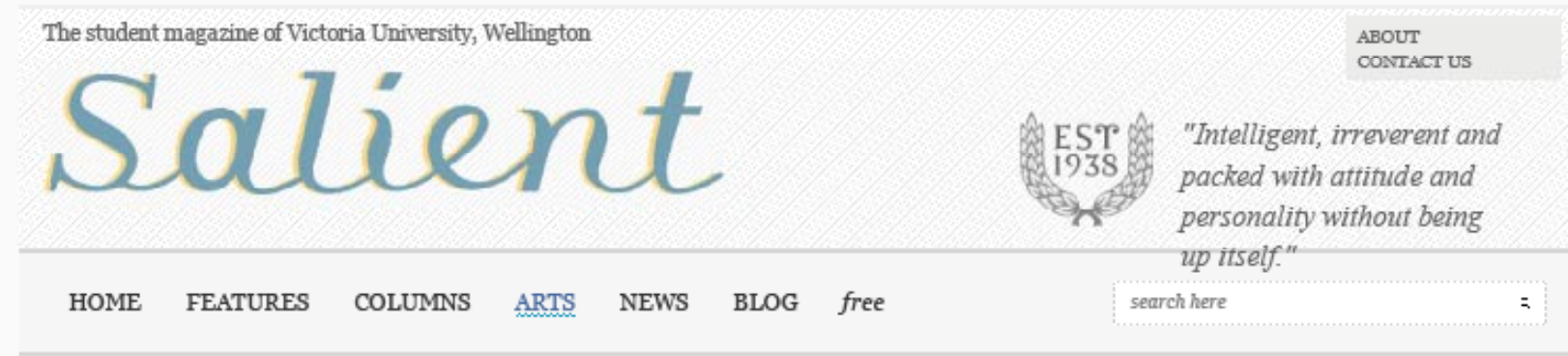

Fou are here $>\underline{\text { Home }} / \underline{\text { Arts }} / \underline{\text { Theatre }} /$ She Wore a Beconing Dress

\section{She Wore a Becoming Dress}

by Piona MeNamara, Mon, 4 May 2009. 190

Skip to comments

\begin{abstract}
A TTENDING THEATRE SHOULD BE AN EXPERIENCE; AND THE BEST KIND IS WHEN EVERY single thing around the audience creates that. Rarely do I have the joy of fully experiencing this, but upon entering She Wore a Becoming Dress I stepped into a large-scale world fashion show, where the thrust stage was a catwalk, the audience became the audience at a fashion show, the two dancers, dresser and AV operator were all a part of the fashion show I had been transported into.
\end{abstract}

She Wore a Becoming Dress is a butoh dance performance exploring gender constructions and the effects of the fashion industry on women today, created by the Wellington-based arts company With Lime, who describe themselves as "an international, intercultural, interdisciplinary arts company ... with the long-term goal of social and cultural change".

Miki Seifert and Anahera Gildea 's controlled trance-like movement is mesmerising to watch. Butoh is a free form of dance that originated in Japan, but both performers said that they did not feel that they were presenting a Japanese art form, rather something very personal to themselves and their own situations, Seifert as an American woman and Gildea as a Maori woman.

Janet Dunn's costume design is effective and complex in meaning. As Seifert dances, she slowly and sensually strips off layers of clothing, eventually revealing grotesquely shaped cushions that distort, falsely shape and sexualise her body.

Fern Xarun and william France's Audio Visual design is an excellent extension of the live performance adding layers of meaning. Film is projected onto the bodies of the performers and images of high profile fashion shows are projected onto two walls, giving each of the three sides of the audience different experiences.

She Wore a Becoming Dress is a compelling, visually stunning and thought-provoking performance of feeling and intellect.

Miki Seifert is a PhD candidate at Te Kawa a Maui at Victoria University. He rawetona kakahu. She WoreA Becoming Dress is part of her PhD research project called Seeds of Dialogue. She Wore a Becoming Dress was funded by New zealand International Doctoral Research Scholarship and The Research Trust of Victoria University of Wellington.

Created and performed by Miki Seifert and Anahera Gildea

Production designer william Franco

Wellington Film Archive, 17 and 18 April

Comments are closed

CONTACT

Student Union Building, Victoria University of Wellington PO Box 600, Wellington DDI: 6444636766 , FAX: 6444636990
The student magazine of Victoria University $\vec{i}$. Salient is available on campus free each Monday during term

Site-help | Site-map | Legal | E-mail contact form

\section{AUTHOR INFO}

Fiona McNamara

Piona was named "Recessionista" in the ASPA Fashion Awards 2009 for her Takaka op-shop frock and spray painted shoes. She coedits the arts section and also likes to write about women and other stuff.

Other articles by Fiona McNamara

Related articles

Huia Short Stories 5

by Tmira New Zealand. 90

It Makes You Think - Victoria Placed Amoung Top 500 Universities

by Chris Leggett. 90

Sex and the City

by Jemina Powell. 9

Bouncers

by Jackson coe. $=0$

Bud

by Hannah Smith. 90

ADVERTISEMENT

WHO'S YOUR FAVCURITE LECTURER? TO NOMINATE TXT O27 CUSTARD OR EMANL EOITOFGS.AUENT ORG N

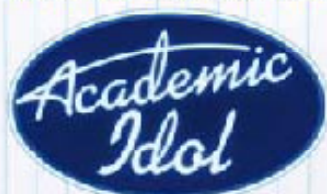

KEEF AN EYE OUT IN SALIENT FOR MORE JETAILS

Advertioe wath is

RSS FEEDS

All articles, Features, Columns, Arts, News, Blog Copyright 102010 Salient Ltd, website by Catch a- 


\section{Works Cited}

Adas, Michael (2001), 'From Settler Colony to Global Hegemon: Integrating the Exceptionalist Narrative of the American Experience into World History', The American Historical Review, 106 (5), 1692-720.

Alexie, Sherman (2000), The Toughest Indian in the World (New York: Grove Press). Allen, Chadwick (2002), Blood Narrative: Indigenous Identity in American Indian and Maori Literary and Activist Texts (Durham and London: Duke University Press).

Anderson, Benedict $(1983,1991)$, Imagined Communities: Reflections on the Origin and Spread of Nationalism (London and New York: Verso).

Anderson, Kay (2000), 'Thinking "Postnationally": Dialogue Across Multicultural, Indigenous, and Settler Spaces', Annals of the Association of American Geographers, 90 (2), 381-91.

Anzaldua, Gloria (1993), 'Border Arte: Nepantla, El Lugar de la Frontera', in Kathryn Kanjo (ed.), La Frontera/The Border: Art about the Mexico/United States Border Experience (San Diego: Centro Cultural de la Raza and Museum of Contemporary Art, San Diego), 107-23.

Behar, Ruth (1995), 'Introduction: Out of Exile', in Ruth Behar and Deborah A. Gordon (eds.), Women Writing Cutlure (Berkeley, CA: University of California Press), 1-29.

Bell, Avril (2006), 'Bifurcation or Entanglement? Settler Identity and Biculturalism in Aotearoa New Zealand', Continuum: Journal of Media \& Cultural Studies, 20 (2), 25368.

--- (2008), 'Recognition or Ethics?', Cultural Studies, 22 (6), 850-69.

Bishop, Russell (2005), 'Freeing Ourselves From Neocolonial Domination in Research: A Kaupapa Maori Approach to Creating Knowledge', in Norman K. Denzin and Yvonna S. Lincoln (eds.), The SAGE Handbook of Qualitative Research (3rd edn.; Thousand Oaks: Sage Publications), 109-38.

Buchanan, Rachel (2007), 'The Dementia Wing of History', Cultural Studies Review, 13 (1), 173-86.

Butler, Judith (2002), 'Performative Acts and Gender Constitution', in Michael Huxley and Noel Witts (eds.), The Twentieth-Century Performance Reader (2nd edn.; New York: Routledge), 120-34.

Castro-Gomez, Santiago (2006), 'The Social Sciences, Epistemic Violence, and the Problem of the "Invention of the Other"', in Saurabh Dube and Ishita BanerjeeDube (eds.), Unbecoming Modern: Colonialism, Modernity, Colonial Modernities (New Delhi: Esha Beteille, Social Science Press), 211-27.

--- (2007), 'The Missing Chapter of Empire: Postmodern Reorganization of Coloniality and Post-Fordist Capitalism', Cultural Studies, 21 (2-3), 428-48.

Center for Cultural Innovation (2011), 'CCI "Investing in Artists" Grantee Profiles, Round III', [website], (updated 5 December 2009) $<$ http://www.cciarts.org/ia profiles 03.htm>, accessed 18 Feburary 2011.

Cheng, Meiling (2002), 'Haiku in the Flesh: Oguri's Theatre of Transmutation', in Rebecca Schneider and Gabrielle Cody (eds.), Re: Direction - A Theoretical and Practical Guide (London: Routledge), 206-14.

Colchester, Chloe (ed.), (2003), Clothing the Pacific (Oxford and New York: Berg).

Conquergood, Dwight (1995), 'Of Caravans and Carnivals: Performance Studies in Motion', The Drama Review, 39 (4), 137-41.

--- (2002), 'Performance Studies: Interventions and Radical Research', The Drama Review, 46 (2), 145-56.

Cram, Fiona (1997), 'Developing Partnerships in Research: Pakeha Researchers and Maori Research', SITES, 35. 
--- (2001a), 'Rangahau Maori: Tona Tika, Tona Pono', in Martin Tolich (ed.), Research Ethics in Aotearoa New Zealand: Concepts, Practice, Critique (Auckland, N.Z.: Longman), $194 \mathrm{p}$.

--- (2001b), 'Ma Te Wa e Whakaatu Mai: Time Will Tell', Feminism \& Psychology, 11 (3), 401-06.

Crump, Juliette T (2006), "'One Who Hears Their Cries": The Buddhist Ethic of Compassion in Japanese Butoh', Dance Research Journal, 38 (1 \& 2), 61-73.

Daishonin, Nichiren (1999), The Writings of Nichiren Daishonin, i, ed. The Gosho Translation Committee, trans. The Gosho Translation Committee (Tokyo: Soka Gakkai).

Denzin, Norman K. (2003a), Performance Ethnography: Critical Pedagogy and the Politics of Culture (Thousand Oaks: Sage Publications).

--- (2003b), 'The Call to Performance', Symbolic Interaction, 26 (1), 187-207.

--- (2005), 'Emancipatory Discourses and the Ethics and Politics of Interpretation', in Norman K. Denzin and Yvonna S. Lincoln (eds.), The SAGE Handbook of Qualitative Research (3rd edn.; Thousand Oaks, CA: Sage Publications), 933-58.

Denzin, Norman K. and Lincoln, Yvonna S. (2003), 'Introduction: The Discipline and Practice of Qualitative Research', in Norman K. Denzin and Yvonna S. Lincoln (eds.), Strategies of Qualitative Inquiry (Thousand Oaks, CA: Sage Publications), 145.

--- (2008), 'Introduction: Critical Methodologies and Indigenous Inquiry', in Norman K. Denzin, Yvonna S. Lincoln, and Linda Tuhiwai Smith (eds.), Handbook of Critical and Indigenous Methodologies (Los Angeles: Sage), 1-20.

Durie, Mason (2004), 'Understanding Health and Illness: Research at the Interface Between Science and Indigenous Knowledge', International Journal of Epidemiology, 33, 1138-43.

--- (2005), 'Indigenous Knowledge Within a Global Knowledge System', Higher Education Policy, 18, 301-12.

Escobar, Arturo (2007), 'Worlds and Knowledges Otherwise', Cultural Studies, 21 (2), 179210.

Fine, Michelle (1994), 'Working the Hyphens: Reinventing Self and Other in Qualitative Research', in Norman K. Denzin and Yvonna S. Lincoln (eds.), Handbook of Qualitative Research (2nd edn.; Thousand Oaks, CA: Sage Publications, Inc.), 70-82.

Finley, Susan (2005), 'Arts-Based Inquiry: Performing Revolutionary Pedagogy', in Norman K. Denzin and Yvonna S. Lincoln (eds.), The SAGE Handbook of Qualitative Research (3rd edn.; Thousand Oaks, CA: Sage Publications), 681-94.

Fraleigh, Sondra Horton and Nakamura, Tamah (2006), Hijikata Tatsumi and Ohno Kazuo (1st edn., Routledge Performance Practitioners; New York: Routledge).

Gebert, Andrew and Joffee, Monte (2007), 'Value Creation as the Aim of Education: Tsunesaburo Makiguchi and Soka Education', in David T. Hansen (ed.), Ethical Visions of Education: Philosophies in Practice (New York: Teachers College Press), 120.

Grace, Patricia (1998), 'Two Worlds', in Witi Ihimeara (ed.), Growing Up Maori (Auckland, NZ: Tandem Press), 47-57.

Graham, James (2009), 'Na Rangi taua, na Tuanuku e takoto nei: Research Methodology Framed by Whakapapa', MAI Review, (1).

Grande, Sandy (2004), Red Pedagogy: Native American Social and Political Thought (Lanham, MD: The Rowman \& Littlefield Publishing Group, Inc.).

Grosfugel, Ramon (2009), 'A Decolonial Approach to Political-Economy:

Transmodernity, Border Thinking and Global Coloniality', Kult 6(Special Issue), 10-38. 
Hamera, Judith (1990), 'Silence That Reflects: Butoh, $M a$, and a Crosscultural Gaze', Text and Performance Quarterly, 10, 53-60.

Hawkins, R. (2009), 'Extending Plumwood's Critique of Rationalism Through Imagery and Metaphor', Ethics and the Environment, 14 (2), 99-113.

Healy, Stephen (2003), 'Epistemological Pluralism and the 'Politics of Choice", Futures, 35, 689-701.

Henry, Ella and Pene, Hone (2001), 'Kaupapa Maori: Locating Indigenous Ontology, Epistemology and Methodology in the Academy', Organization, 8 (2), 234-42.

Hickey, Wakoh Shannon (2010), 'Two Buddhisms, Three Buddhisms, and Racism', Journal of Global Buddhism, 11, 1-25.

Hijikata, Tatsumi (2000a), 'Inner Material/Material', The Drama Review, 44 (1), 36-42.

--- (2000b), 'From Being Jealous of a Dog's Vein', The Drama Review, 44 (1), 56-59.

--- (2002), 'Man, Once Dead, Crawls Back!', in Michael Huxley and Noel Witts (eds.), The Twentieth-Century Performance Reader (2nd edn.; London and New York: Routledge), 225-28.

Hodge, Brooks, Mears, Patricia, and Sidlauskas, Susan (2006), Skin + Bones: Parallel Practices in Fashion and Architecture (New York: Thames \& Hudson).

Hoffman, Ethan and Holborn, Mark (1987), Butob: Dance of the Dark Soul (New York: Aperture).

Hurst, Jane (2000), 'A Buddhist Reformation in the Twentieth Century: Causes and Implications of the Conflict between the Soka Gakkai and the Nichiren Shoshu Priesthood', in David Machacek and Bryan Wilson (eds.), Global Citizens: The Soka Gakekai Buddhist Movement in the World (Oxford: Oxford University Press), 67-96.

Ikeda, Daisaku (1995), Peace and Human Security: A Buddhist Perspective for the Twenty-first Century - A lecture delivered at the East-West Center, Hawaii, January 26, 1995, trans. SGI Public Relations Bureau (Tokyo: Soka Gakkai International).

--- (1996), Thoughts on Education for Global Citizenship - Delivered at Teachers College, Columbia University, June 13, 1996 (Tokyo: Soka Gakkai).

--- (1999), 'The SGI's Peace Movement', in David W. Chappell (ed.), Buddhist Peacework: Creating Cultures of Peace (Somerville, MA: Wisdom Publications), 129-38.

--- (2000), A Youthful Diary: One Man's Journey of Faith to Worldwide Leadership for Peace (Santa Monica, CA: World Tribune Press).

--- (2001), 2001 Peace Proposal: Creating and Sustaining a Century of Life - Challenges for a New Era (Tokyo: Soka Gakkai).

--- (2004), The Human Revolution, $i$ (Santa Monica, CA: World Tribune Press).

--- (2005), 'Message to A Vision of 21st Century Oriental Thought From the Symposium Co-sponsored by the Daisaku Ikeda Research Society of Beijing University', Journal of Oriental Studies, 15, 43-47.

--- (2008), Study Lecture Series: On Attaining Buddhabood in This Lifetime (Wellington, NZ: Soka Gakkai International of New Zealand).

--- (2009), Study Lecture Series: The Heritage of the Ultimate Law of Life (Wellington, NZ: Soka Gakkai International of New Zealand).

Ikeda, Daisaku and Unger, Felix (2005), 'The Humanist Principle-Compassion and Tolerance (1)', Journal of Oriental Studies, 15, 3-41.

--- (2006), 'The Humanist Principle-Compassion and Tolerance (2)', Journal of Oriental Studies, 16, 3-39.

Ikeda, Daisaku, et al. (2000), The Wisdom of the Lotus Sutra, $i$ (Santa Monica, CA: World Tribune Press).

--- (2001), The Wisdom of the Lotus Sutra, iii (Santa Monica, CA: World Tribune Press).

Inkboat (2011), 'Biography Shinichi Iova-Koga', [website], (updated 23 March 2010) <http://inkboat.com/inkbio/biomomo.html>, accessed 7 February 2011. 
Jones, Alison (1999), 'The Limits of Cross-Cultural Dialogue: Pedagogy, Desire, and Absolution in the Classroom', Educational Theory, 49 (2), 299-316.

Jones, Alison and Jenkins, Kuni (2008), 'Rethinking Collaboration: Working the Indigene-Colonizer Hyphen', in Norman K. Denzin, Yvonna S. Lincoln, and Linda Tuhiwai Smith (eds.), Handbook of Critical and Indigenous Methodologies (Los Angeles: Sage), 471-86.

Josei Toda Website Committee (2011), 'Human Revolution', Josei Toda: Reviving Buddhism in Today's World [website], (updated 7 February 2011) $<$ http://www.joseitoda.org/religious/hr>, accessed 7 February 2011.

--- (2011), 'Soka Gakkai Second President', Josei Toda: Reviving Buddhism in Today's World [website], (updated 7 February 2011)

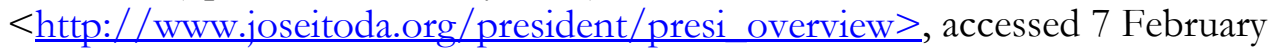
2011.

Kanno, Hiroshi (2007), 'The Bodhisattva Way and Valuing the Real World in the Lotus Sutra', Journal of Oriental Studies, 17, 180-97.

Kasai, Toshiharu (1999), 'A Butoh Dance Method for Psychosomatic Exploration', Memoirs of the Hokkeaido Institute of Technology, 27, 309-16.

Kasai, Toshiharu and Parsons, Kate (2003), 'Perceptions in Butoh Dance', Memoirs of the Hokkaido Institute of Technology, 31, 257-64.

Kawada, Yoichi (2009), 'The SGI within the Historical Context of Buddhism and its Philosophical Basis', Journal of Oriental Studies, 19, 103-23.

Kester, Grant H. (1998), 'Ongoing Negotiations: Afterimage and the Analysis of Activist Art', in Grant H. Kester (ed.), Art, Activism, and Oppositionality: Essays from Afterimage (Durham, NC: Duke University Press Books), 1-19.

Kincheloe, Joe. L. and McLaren, Peter (2005), 'Rethinking Critical Theory and Qualitative Research', in Norman K. Denzin and Yvonna S. Lincoln (eds.), The $S A G E$ Handbook of Qualitative Research (3rd edn.; Thousand Oaks, CA: Sage Publications), 303-43.

Kobayashi, Masahiro (2008), 'Nichiren's Philosophy of Peace', Journal of Oriental Studies, $18,149-54$.

Kuchler, Susanne and Were, Graeme (eds.) (2005), The Art of Clothing: A Pacific Experience (London: UCL Press).

Lawson, Alan (2004), 'Postcolonial Theory and the 'Settler' Subject', in Cynthia Sugars (ed.), Unhomely States: Theorizing English-Canadian Postcolonialism (Ontario, Canada: Broadview Press Ltd.), 151-64.

Leval, Susana Torruella (1992), 'Recapturing History: The (Un)Official Story in Contemporary Latin American Art', Art Journal, 51 (4), 69-80.

Marsden, Maori (2003), The Woven Universe: Selected Writing of Rev. Maori Marsden, ed. Te Ahukaramu Charles Royal (Otaki, New Zealand: The Estate of Rev. Maori Marsden).

Matsuoka, Mikio (2005), 'The Buddhist Concept of the Human Being: From the Viewpoint of the Philosophy of the Soka Gakkai', Journal of Oriental Studies, 15, 5065.

McNamara, Fiona (2011), 'Review: She Wore a Becoming Dress', [website], (updated 2 March 2011) < http://www.salient.org.nz/arts/theatre/she-wore-a-becomingdress $>$, accessed 2 March 2011.

Mead, Hirini Moko (2003), Tikanga Maori: Living by Maori Values (Wellington: Huia Publishers).

Memmi, Albert (1965), The Colonizer and the Colonized (Boston: Beacon Press by arrangement with The Orion Press, Inc.). 
Mignolo, Walter D. (2007), 'Delinking: The Rhetoric of Modernity, the Logic of Coloniality and the Grammar of De-Coloniality', Cultural Studies, 21 (2-3), 449514.

Mignolo, Walter D. and Tlostanova, Madina (2008), 'The Logic of Coloniality and the Limits of Postcoloniality', in Revathi Krishnaswamy and John Charles Hawley (eds.), The Postcolonial and the Global (Minneapolis University of Minnesota Press), 109-23.

Miller, Thaddeus R., et al. (2008), 'Epistemological Pluralism: Reorganizing Interdisciplinary Research', Ecology and Science, 13 (2), 46 [online]. $<$ http://www.ecologyandsociety.org/vol13/iss2/art46/>, accessed 31 October 2010

Miyata, Koichi (2000), 'The Lotus Sutra and Tsunesaburo Makiguchi and Josei Toda', Journal of Oriental Studies, 10, 56-71.

Mody, Bhavana (2002), 'Lost in Indophile Translation: A Validation of My Experience', in Daisy Hernandez and Bushra Rehman (eds.), Colonize This!: Young Women of Color on Today's Feminism (Emeryville, CA: Seal Press), 268-78.

Nakamura, Tamah L. (2007), 'Beyond Performance in Japanese Butoh Dance: Embodying Re-Creation of Self and Social Identities', Ph.D. (Fielding Graduate University).

Nakata, Martin N. (2007), Disciplining the Savages : Savaging the Disciplines (Canberra: Aboriginal Studies Press) viii, 247 p.

Nanako, Kurihara (2000), 'Hijikata Tatsumi: The Words of Butoh: [Introduction]', The Drama Review, 44 (1), 12-28.

Nayfack, Shakina (2009), 'Butoh Ritual Mexicano: An Ethnography of Dance, Transformation, and Community Redevelopment', Ph.D. thesis (University of California, Riverside).

Nichiren Shoshu International Center (1993), Fundamentals of Buddhism, Third Edition (Tokyo: Nichiren Shoshu International Center).

Ohno, Kazuo and Ohno, Yoshito (2004), Kazuo Ohno's World from Without and Within, trans. John Barrett (Middletown, CT: Wesleyan University Press) xviii, 323.

Pelias, Ronald J. (2007), 'Performance Ethnography', in George Ritzer (ed.), Blackwell Encyclopedia of Sociology (Malden, MA: Blackwell Publishing Ltd.).

Pérez, Laura Elisa (2007), Chicana Art: the Politics of Spiritual and Aesthetic Altarities (Durham: Duke University Press).

Pihama, Leonie (2001), 'Tihei Maori Ora: Honouring Our Voices - Mana Wahine as a Kaupapa Maori Theoretical Framework', Ph.D thesis (University of Auckland).

Pinon, Diego (2011), 'Mission', [website], (updated 7 February 2011) $<$ http://butohritualmexicano.com/Mission.html $>$, accessed 7 February 2011.

Plumwood, Val (1993), 'The Politics of Reason: Towards a Feminist Logic', Australasian Journal of Philosophy, 71 (4), 436-62.

Roquet, Paul (2003) Towards The Bowels of the Earth: Butoh Writhing in Perspective [online text], <http://www.bodyweather.net/rouquet.pdf $>$

Rouse, Joseph (1996), Engaging Science: How to Understand its Practices Philosophically (Ithaca, NY: Cornell University Press).

Royal, Te Ahukaramu Charles (2005), 'Exploring Indigenous Knowledge', The Indigenous Knowledges Conference - Reconciling Academic Priorities with Indigenous Realities (Victoria University of Wellington), 1-19.

Said, Edward (1995), Orientalism: Western Conceptions of the Orient (London: Penguin Books). 
SGI Quarterly Editorial Team (2007), 'Buddhism in Daily Life: Dialogue in Buddhism', SGI Quarterly, January. < http://www.sgiquarterly.org/buddhism2007Jan1.html>, accessed 5 February 2011.

Shahjahan, Riyad Ahmed (2005a), 'Mapping the Field of Anti-Colonial Discourse to Understand Issues of Indigenous Knowledges: Decolonizing Praxis', McGill Journal of Education, 40 (2), 213-40.

--- (2005b), 'Spirituality in the Academy: Reclaiming From the Margins and Evoking a Transformative Way of Knowing the World', International Journal of Qualitative Studies in Education, 18 (6), 685-711.

Smith, Graham Hingangaroa (1992), 'Tane-Niu-A-Rangi's Legacy...Propping Up the Sky (Kaupapa Maori as Resistance and Intervention)', NZARE/AARE Joint Conference (Deakin University, Melbourne Australia).

--- (1997), 'The Development of Kaupapa Maori: Theory and Praxis', Ph.D. thesis (University of Auckland).

Smith, Linda Tuhiwai (1999), Decolonizing Methodologies : Research and Indigenous Peoples (London and Dunedin, N.Z.: Zed Books and University of Otago Press).

--- (2005), 'On Tricky Ground: Researching the Native in the Age of Uncertainty', in Norman K. Denzin and Yvonna S. Lincoln (eds.), The SAGE Handbook of Qualitative Research (3rd edn.; Thousand Oaks, CA: Sage Publications), 85-107.

Smith, Sharon Elizabeth (2008), 'Buddhism, Diversity and Race: Multiculturalism and Western Convert Buddhist Movements in East London', Ph.D. thesis (University of London).

Soka Gakkai (2002), The Soka Gakkai Dictionary of Buddhism (Tokyo: Soka Gakkai). --- (2006), 'Soka Gakkai International: An Introduction', (Tokyo: Soka Gakkai).

Soka Gakkai International - USA (2011), 'The Precept of Adapting to Local Customs', [website], (updated 25 February 2011) <http://www.sgiusa.org/memberresources/resources/buddhist concepts/bc34 adapting to loc al customs.php $>$, accessed 25 February 2011.

Soka Gakkai International (2011), 'Soka Gakkai International', [website], (updated 25 February 2011) < http://www.sgi.org/about-us/what-is-sgi.html $>$, accessed 25 February 2011.

Strand, Clark (2008), 'Faith in Revolution', Tricycle: The Buddhist Review, 18 (2). $<$ http://www.tricycle.com/interview/faith-revolution>, accessed 22 January 2011.

Swadener, Beth Blue and Mutua, Kagendo (2008), 'Decolonizing Performances: Deconstructing the Global Postcolonial', in Norman K. Denzin, Yvonna S. Lincoln, and Linda Tuhiwai Smith (eds.), Handbook of Critical and Indigenous Methodologies (Los Angeles: Sage), 31-43.

Taliaferro, Denise M. (1998), 'Signifying Self: Re-Presentations of the DoubleConsciousness in the Work of Maxine Greene', in William Pinar (ed.), The Passionate Mind of Maxine Greene (Bristol, PA: Falmer Press), 89-98.

Taouma, Lisa (1998), 'Re-Picturing Paradise: Myths of the Dusky Maiden', Masters thesis (University of Auckland).

The Film Archive/Ngā Kaitiaki O Ngā Taonga Whitiāhua (2011), 'About the Archive', [website], (updated 22 February 2011) $<\underline{\text { http://www.filmarchive.org.nz/index.php?option=com content\&task=view\&i }}$ $\underline{\mathrm{d}=3>}$, accessed 22 February 2011.

Thesander, Marianne (1997), The Feminine Ideal, trans. Nicholas Hills (London: Reaktion Books Ltd).

Thorpe, Jocelyn (2005), 'Indigeniety and Transnationality?', Women \& Environments International Magazine, 68/69, 6-8. 
Toynbee, Arnold Joseph, Ikeda, Daisaku, and Gage, Richard L. (1989), Choose Life : A Dialogue (Oxford: Oxford University Press).

Tribunal, Waitangi (2011), 'Waitangi Tribunal Introduction', [website], (updated 28 February 2011) < http://www.waitangi-tribunal.govt.nz/about/intro.asp $>$, accessed 28 February 2011.

Turner, Stephen (1995), 'Cultural Encounter, Aesthetics, and the Limits of Anthropology: Captain Cook and the Maori', Ph.D. thesis (Cornell University).

Walker, Ranginui (1990), Ka Whawhai Tona Matau: Struggle Without End (Auckland, N.Z.: Penguin).

Walsh, Catherine (2007), 'Shifting the Geopolitics of Critical Knowledge', Cultural Studies, 21 (2-3), 224-39.

Watson, Burton (1993), The Lotus Sutra (New York: Columbia University Press).

Westlake, E. J. (2005), 'Theoretical Foundations and Intercultural Performance:

(Re)writing Nations on the Margins', in Laura B. Lengel and John T. Warren (eds.), Casting Gender: Women and Performance in Intercultural Contexts (New York: Peter Lang), 19-34.

Yatomi, Shin (2002), 'The Buddha's "Three Rules" for Improving Dialogue', Living Buddhism, July, 5-6, 33.

--- (2006), Buddhism in a New Light: Eighteen Essays That Illuminate Our Buddhist Practice (Santa, Monica, CA: World Tribune Press). 


\section{Photographic Acknowledgments}

\section{Craig Thomson}

French Maid \& Dusky Maiden, p. 8; Dressmaker's Dolls, p. 34; Bride \& Black Widow, p. 54; Executive \& Dusky Maiden, p. 77; Miss Texas \& Mother, p. 148; Black Widow \& Bride, p. 155; Dressmaker's Dolls, p. 168; Foundation Garments, p. 174; Dressmaker's Doll (Miki Seifert), p. 183.

\section{Chris Murphy}

He rawe/Becoming Dress Performance, p. 133; Matryoshka (Miki Seifert), p. 142;

Mother \& Black Widow, p. 145; Dusky Maiden \& Executive, p. 159.

\section{William Franco}

No Olvidado/Don't Forget Me, p. 60; Corpus Delicti at Hollywood \& Vine, p. 61; French Maid \& Ballerina (video still), p. 164. 